\title{
Migration and networks in transit
}

Citation for published version (APA):

Wissink, M. J. (2019). Migration and networks in transit: The co-evolution of migration trajectories and social networks of sub-Saharan African migrants in Turkey and Greece. [Doctoral Thesis, Maastricht University]. ProefschriftMaken Maastricht. https://doi.org/10.26481/dis.20191004mw

\section{Document status and date:}

Published: 01/01/2019

DOI:

10.26481/dis.20191004mw

Document Version:

Publisher's PDF, also known as Version of record

\section{Please check the document version of this publication:}

- A submitted manuscript is the version of the article upon submission and before peer-review. There can be important differences between the submitted version and the official published version of record.

People interested in the research are advised to contact the author for the final version of the publication, or visit the DOI to the publisher's website.

- The final author version and the galley proof are versions of the publication after peer review.

- The final published version features the final layout of the paper including the volume, issue and page numbers.

Link to publication

\footnotetext{
General rights Owners
rights.

- You may freely distribute the URL identifying the publication in the public portal. please follow below link for the End User Agreement:

www.umlib.nl/taverne-license

Take down policy

If you believe that this document breaches copyright please contact us at:

repository@maastrichtuniversity.nl

providing details and we will investigate your claim.
}

Copyright and moral rights for the publications made accessible in the public portal are retained by the authors and/or other copyright owners and it is a condition of accessing publications that users recognise and abide by the legal requirements associated with these

- Users may download and print one copy of any publication from the public portal for the purpose of private study or research.

- You may not further distribute the material or use it for any profit-making activity or commercial gain

If the publication is distributed under the terms of Article $25 \mathrm{fa}$ of the Dutch Copyright Act, indicated by the "Taverne" license above, 


\section{1}

20010

\section{Marieke Wissink}

\section{Migration and Networks in Transit}

\section{The co-evolution of migration trajectories and social networks of sub-Saharan African migrants in Turkey and Greece} 000000000 nononocose 1001111 110 1000 กी

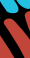
100<smiles>C=C1C=CC(C2CC3C=CC2C3)=C1</smiles>
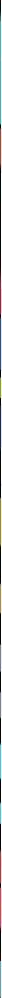
Migration and Networks in Transit

The co-evolution of migration trajectories and social networks of sub-Saharan African migrants in Turkey and Greece 
ISBN: 978-94-6380-506-3

Layout and printed by: ProefschriftMaken - www.proefschriftmaken.nl 
Migration and Networks in Transit

The co-evolution of migration trajectories and social networks of sub-Saharan African migrants in Turkey and Greece

\author{
Dissertation
}

to obtain the degree of Doctor at Maastricht University,

on the authority of the Rector Magnificus Prof.dr. Rianne M. Letschert in accordance with the decision of the Board of Deans, to be defended in public on Friday, 4 October 2019 at 10:00 hours.

by

Maria Johanna Wissink 


\section{Supervisor}

Prof. dr. V. Mazzucato, Maastricht University

\section{Co-supervisor}

Dr. F. Düvell, Deutsche Zentrum für Integrations- und Migrationsforschung (DeZIM)

\section{Assessment Committee}

Prof. dr. M. P. Vink (Chair), Maastricht University

Dr. J.L. Molina González, Universitat Autònoma de Barcelona

Dr. J. Schapendonk, Radboud University

Prof. dr. R. Skeldon, Maastricht University

This research was funded by the Faculty of Arts and Social Sciences of Maastricht University 


\section{Acknowledgements}

I am highly grateful and indebted to the people who allowed me to travel and reside along their sides for a while. This was one of the most precious experience I have ever had, not as a researcher but as a human being. I will cherish this long beyond my time as a researcher.

In Turkey and Greece, numerous people helped me to get settled and move along. Piril, Taner, Ela, Pinar, Cavidan, Selen, Kirsten, Salinia, Mariana, Katerina, Christina, Natassa, Efi, Mustafa, and all dear other friends at Mülteci-Der and Kayiki: you made many things so much easier. It was wonderful to be surrounded by so many friendly, knowledgeable and passionate people.

My supervisors, Valentina and Franck, I am incredibly thankful that you have been there for me throughout this PhD project. Valentina, I will never forget your constant reminders to celebrate each achievement. A piece of advice I will carry with me beyond the PhD, no matter how challenging the circumstances. Thank you as well for helping to constantly regain my focus and to "de-complexify". Franck, you were the one who advised me to go to Izmir for my Master thesis, when I was actually preparing to do my fieldwork elsewhere. Izmir, a city I had never heard of until then, now feels as my second home town, not least because it is home to my in-laws! Thank you for enlarging my knowledge on transit migration, particularly in Turkey. Thank you both for bearing with me and for continuing to believe in me, beyond my time at Maastricht University.

In Maastricht I was surrounded by many colleagues and friends who provided for both interesting academic discussions as well as the necessary relaxation, in particular Kim, Tom, Sonja, Rik, Özge, Koen, Karlijn, Miranda, Joan, Lotte and everyone taking part in the TMG and GTD -groups. I also appreciated your continued support and friendship when I moved to The Hague (as some of you did, too, luckily!)

Many other friends, some who had long graduated and left academia, witnessed me working on my PhD for quite a while. Marieke, Welmoed, Karen, Ciska, Elissa, Maik, Mariëtte, Ghislaine, Yrrah, Lidewey, Ilse, Sara, Olga, Jo-Anne, Hester, Annelies, Paula: while to the surprise of some of you, I kept going and would never have been able to do so without your continued interest, support and encouragement. You mean a lot to me.

My former colleagues at the Dutch Council for Refugees: thank you for your support, interest and for providing me with the best possible environment to put my findings into practice. My new colleagues at Perspektief: it is great being part of your organisation. After completion of this work I can handle any extra team!

Special thanks to my paranymphs. Rik, you encouraged me to do a PhD and I appreciate you help me finishing it. Thank you for continuing to remind me that there is light at the end of the tunnel. Kim, without your never-ending support and encouragement, way beyond this $\mathrm{PhD}$, this book would not be there. Sengs mate, for our friendship and for always being there. Also, a special word of thanks to Sonja, especially in recent years your support has lift me up, thank you for that. 
My dear parents, Jan and Willijanne, sisters and their partners Ellen and Jeroen, Brechtje and Minette, and Anne and Amilanda: my "werkstuk" is completed. How amazing it was to grow up and be part of a family with such great interest in cultures, countries and social justice. And with a great sense of humour. Thank you for your stimulation, encouragement, jokes, positivity and understanding. How blessed I am that you are my family. A big thank you as well to my aunts, uncles and cousins for your continued interest at family events. In loving memory of my dear grandmother who has recently passed away, of whom I know she was very proud.

Orçun, you were more than a partner, more than a very essential source of support and information, more than a mirror: you were my rock. Thank you for the space you gave me to complete this work and for believing in me and for helping me to do the same. Amar, my dearest son and inspirator to live the moment: I love you so much. 




\section{Table of contents}

Chapter 1: Introduction $\quad 13$

1.1 Migration flows versus migration trajectories $\quad 15$

$\begin{array}{ll}1.2 \text { The impact of migration policy } & 17\end{array}$

1.3 The role of transnational social networks $\quad 20$

1.4 Research design $\quad 21$

1.5 Overview of the thesis $\quad 23$

Chapter 2: Theoretical Framework $\quad 27$

2.1 Introduction $\quad 29$

2.2. Theoretical perspectives on migration $\quad 30$

2.3 The role of social networks 38

2.4 The analytical framework $\quad 45$

Chapter 3: Research methodology 49

3.1 Research design: capturing processes of change $\quad 51$

3.2 Case selection and fieldwork setting 54

3.3 The research sample $\quad 64$

3.4 Data collection tools $\quad 69$

$\begin{array}{ll}3.5 \text { Analysis techniques } & 74\end{array}$

3.6 Ethical and methodological considerations 78

$\begin{array}{ll}3.7 \text { Limitations } & 82\end{array}$

Chapter 4: Navigating the Aegean: Trajectories of sub-Saharan African migrants in Turkey and Greece 85

4.1 Introduction $\quad 87$

4.2 Sub-Saharan African Migration in Turkey and Greece 89

4.3 A diversification of migration trajectories 90

4.4 Societal developments and the creation of a volatile migration environment 93

4.5 The creation of a volatile migration environment 99

4.6 Navigating the societal developments in the Aegean Region 100

$\begin{array}{ll}4.7 \text { Conclusion } & 102\end{array}$

Chapter 5: In Transit: Changing Social Networks of sub-Saharan African migrants in Turkey and Greece 105

$\begin{array}{ll}5.1 \text { Introduction } & 107\end{array}$

5.2 Transit migration in Turkey and Greece 108

5.3 A dynamic perspective on migrants' social networks 109

$\begin{array}{ll}5.4 \text { Critical events and network changes } & 110\end{array}$ 
5.6 The changing networks of sub-Saharan migrants in Istanbul and Athens

5.7 Individual opportunity structures

Chapter 6: The evolution of migration trajectories of sub-Saharan African migrants in Turkey and Greece: The role of changing social networks and critical events

6.1 Introduction

6.2 Theoretical framework

6.3 Methodology

6.4 The evolution of trajectories and networks

6.5 Case studies

Chapter 7: The co-evolution of migration trajectories and social networks

8.2 Main findings and implications for research

8.3 Implications for policy

References

Nederlandse samenvatting 


Chapter 1 Introduction 



\section{Chapter 1: Introduction}

\subsection{Migration flows versus migration trajectories}

In 2009, I had just lost my credit card when I was about to buy a ticket for a boat trip from Turkey to Greece. It took one phone call to my Dutch bank and the presentation of my Dutch passport in order to collect money from a Turkish bank. I knew that that very same night, Senait, an Eritrean woman whom I had met in Izmir, was also about to make a boat trip from Turkey to Greece. She had no credit card, nor a passport. She did not embark on a ferry, but on a small fisherman's boat. It took two months before I heard from her. She had nearly drowned in the waves and was rescued by the Turkish coastal guards. She was then taken into detention and released weeks later, when we met again in Izmir. Our paths crossed several times in the following years, including during fieldwork for the present study. We first met in Istanbul, where she was working as a babysitter. A year later, she moved to a rural Turkish town, where she was obliged to reside after she had applied for asylum. Recognised as a refugee by the UNHCR, she waited to be resettled to a third country. Yet, she clandestinely travelled to Athens in 2011, where we met again in 2012 and in 2013. Finally, in 2015, we met again in the Netherlands, where she had meanwhile applied for asylum and received a refugee status.

Clearly, Senait's journey was not a linear move from Eritrea to the Netherlands. During the six years she had spent in Turkey and Greece, she did not always aspire to continue her journey to Western Europe. During this period, she had adopted various migration strategies: she resided irregularly, attempted to cross borders, applied for asylum and worked irregularly. In this thesis, the sequence of applied migration strategies is defined as a 'migration trajectory'. Senait's migration trajectory shows that while en route, migratory intentions and strategies are subject to change. Senait's trajectory is not unique; the trajectories of irregular migrants commonly evolve in non-linear ways, meaning that trajectories do not necessarily consist of migration strategies by which a linear move is anticipated or realised (Collyer, 2007; Schapendonk, 2011; Wissink, Düvell, \& van Eerdewijk, 2013). 'Irregular' implies that parts of a migration trajectory, such as entry, residence, labour, and exit are irregular (Jordan \& Düvell, 2002). The aim of this thesis is to investigate the mechanisms that underlie this non-linear evolution of migration trajectories of irregular migrants.

The evolution of migration trajectories has only recently attracted scholarly interest (Pathirage \& Collyer, 2011; Schapendonk, 2011; Schapendonk \& Steel, 2014). Typically, migration studies focus on explaining causes of migration from countries of origin and the consequences of migration for countries of origin and destination, as well as for the linkages between them. Migration trajectories that form the actual course of migration are typically only assessed in terms of migration flows between origin and destination 
countries (Schapendonk, 2011). In this way, migrants who are en route and reside in socalled transit countries, such as Turkey and Greece, are expected to continue attempting to migrate onward.

This thesis argues that it is inadequate to analyse the evolution of migration trajectories merely through the lens of migration flows. First, analyses of migration flows focus primarily on causes for their emergence. Studying the evolution of migration trajectories from this perspective would presume that decision-making processes predominantly take place at the start of the trajectory, and that migration is supposed to follow in an almost linear fashion (cf. Wissink et al., 2013). While Senait intended to migrate to Europe when she left Eritrea, we cannot describe her six years in Turkey and Greece as time simply spent waiting to cross the border and move onward. It would be equally reductive to assume that her decision to move from Turkey to Greece in 2011 was taken under the same circumstances and motivated by the same reasons as she had in 2009. In order to understand the overall evolution of her migration trajectory, we need to see how new decisions are taken en route.

Second, adopting the perspective of a migration flow to show how trajectories evolve would presume there is a (more or less) clear intended final destination. However, ideas about the intended destination may change over time. Moreover, migrants may not even have an intended destination in mind, or they may not think of their migration trajectory as a process with a definite ending. Centralising an (intended) destination in explanations of the evolution of migration trajectories is not helpful when destinations are changing, when there is no destination foreseen, or when the trajectory is continuously evolving without a clear final intended or actual ending (Crawley, Düvell, Jones, McMahon, \& Sigona, 2017; Schapendonk, 2011).

Third, explaining the evolution of trajectories against the background of migration flows would presume that trajectories comprise similar stepwise stages that are typically distinguished in migration flows, such as emigration, transit, immigration, settlement or return. However, research has shown that migrant individual trajectories do not necessarily follow a stepwise path: integration and settlement can be rapidly followed by a new journey and return, before moving elsewhere (Collyer, 2007; Schapendonk \& Steel, 2014; van Geel \& Mazzucato, 2017). This incites the question of what mechanisms underlie the evolution of migration trajectories, as this thesis will address.

Fourth, studies on migration flows commonly distinguish between flows of different types of migrants, such as refugees and economic migrants (Bivand Erdal \& Oeppen, 2018; Crawley \& Skleparis, 2018). The observation that trajectories may involve multiple and successive strategies implies different statuses, for example, when people apply for asylum, reside irregularly later on, and subsequently obtain a business visa, reveals that migrants may have different migration statuses and may fall in different migrant categories along the way. Senait, for example, could have been an "irregular" or "transit" migrant in 2009 and in 2011 when she attempted to clandestinely cross the border between Turkey and Greece, but an "asylum-seeker" and "refugee" in 2010 in Turkey and in 2015 in the 
Netherlands, respectively. While it is common practice in both research and policy designs to treat refugees and irregular migrants as distinct groups, trajectories such as that of Senait illustrate that various legal statuses and migration strategies can be unified in the trajectory of one person. Therefore, whether or not someone applies for asylum or enters a boat, and qualifies as a refugee or as an irregular migrant, is possibly rather a reflection of how personal circumstances were at that specific moment in the migration trajectory than indicative of migratory intentions (Wissink et al., 2013). Rather than explaining differences in trajectories of refugees and irregular migrants, this research aims to investigate the mechanisms by which the strategies throughout a migration trajectory change.

Thus, while typical origin and destination countries migration flows can be observed on a macro level, individual migration trajectories do not necessarily follow a similar linear pattern on a micro level. Therefore, by starting from the macro level perspective of a migration flow to analyse the evolution of migrant individual trajectories, dynamics in the evolution of individual trajectories remain invisible. This thesis adopts a micro level perspective by analysing individual migrant trajectories. In this way it aims to answer the main research question: By what mechanisms do the migration trajectories of irregular SubSaharan African migrants in Turkey and Greece evolve? This evolution concerns both the geographical direction and the migration strategies applied in situ.

In order to grasp these mechanisms, the thesis first considers two factors widely associated with irregular migration flows: migration policies and social networks. Restrictive migration policies in the European Union have, for example, been associated with the rise of irregular migration flows between Africa and Europe when people no longer had any regular alternative (Jordan \& Düvell, 2002). The literature further stipulates that social networks in both origin and destination countries play an important role in facilitating, as well as hampering, migration (Collyer, 2007; Faist, 1997; Fawcett, 1989; Massey, 1987; Pries, 2004). While the role of policies and social networks have been predominantly discussed on a macro level to explain migration flows, this thesis will assess how these factors play a role in the evolution of individual migration trajectories. The subsequent sections elaborate on how this is done.

\subsection{The impact of migration policy}

The impact of migration policies for migration flows has been widely examined by both policy makers and migration scholars. There is a general academic consensus that there has been a discursive shift towards a securitisation of migration in the European Union (EU), meaning that migration is a security issue (Buonfino, 2004; Huysmans, 2006; Léonard, 2010; van Munster, 2009). This explains the rather restrictive and suppressive policy approach towards irregular migration by the EU. Examples include readmission agreements with countries of transit and origin, where resources are exchanged in return for these countries' 
efforts to prevent emigration and irregular onward migration (Ulusoy \& Battjes, 2017). Another notable policy development is that of strengthened border controls, supported through the establishment of FRONTEX and EUROSUR ${ }^{1}$. The EU has further aimed to combat smuggling as a way of reducing incentives for irregular migration (European Commission, 2015). Within the EU, irregular migration is combatted through the deportation of migrants. At the same time, the EU claims to uphold options to grant (temporary) residence permits to people meeting the eligibility criteria as laid out in the 1951 Geneva Refugee Convention. The establishment of a Common European Asylum System needs to guarantee these rights are the same in each Member State (Thielemann, 2010). Yet, because of the non-binding status of the CEAS convention, scholars have argued that it is effectively a race to the bottom where most members states do not meet the minimum protection standards (Langford, 2013; Thielemann, 2010).

Academic studies have shown that restrictive migration policies do not deter migration flows, but in fact lead migrants to embark on other, irregular, often more dangerous journeys (Baldwin-Edwards, 2006; Carling, 2007; Düvell, 2006; Jordan \& Düvell, 2002; Kiza, 2008; Spijkerboer, 2007). In this vein, the increase in numbers of migrants clandestinely crossing Europe's borders that has grown since the 1990s has been associated with a rise in more restrictive migration policies that the EU put into effect around that time (Düvell, 2011). When visa policies make it harder for people to travel from Africa to the European Union, people from African countries engage in alternative migration strategies such as travelling by small fishing boats or by hiding in trucks (Carling, 2007; De Haas, 2008; Düvell \& Vollmer, 2009; İçduygu, 2000; Joly, 1998). As a consequence, journeys evolve in a rather fragmented fashion, where time is spent in transit locations, and people take detours or alternative routes to arrive at a certain destination (Collyer, 2007; Schans, Mazzucato, Schoumaker, \& Flahaux, 2018; Schapendonk, 2011; Schwarz, 2018). It is not surprising that when restrictive migration policies are in place, trajectories like that of Senait do not evolve as linear moves from one country to another.

Explaining that irregular migrants' non-linear evolution of trajectories is primarily a result of policy interventions is insufficient, however, for four reasons. First, it assumes that migration was intended to evolve linearly, and that policies cause migrants to either succeed or fail to realise their objectives. As stated, migrants do not always leave with a certain destination in mind, or their ideas about the destination can change (Crawley et al., 2017; De Clerck, 2015; Van Hear, 2006). In an earlier study, I found that most Ethiopian and Eritrean women in Turkey and Greece had initially migrated to the Middle East to work as domestic workers, and never planned to continue their journeys to Europe; some only moved to Turkey after political turmoil in Lebanon in 2008 (Wissink et al., 2013). More recently, after the outbreak of the Syrian civil war in 2011, it is plausible that many Eritrean and Ethiopian women who had been migrant workers have fled Syria, too. This questions the extent to

\footnotetext{
1 FRONTEX is the European Border and Coast Guard Agency; EUROSUR is the European Border Surveillance System.
} 
which policy interventions "interrupt" a migration plan that has existed since departure from countries of origin, and raises the question of what other factors shape migration trajectories besides policies.

Second, by focusing on constraints produced by policy interventions, we are likely to overlook opportunities that may emerge while travelling, which may equally incite alternative migration intentions and strategies. Third, while restrictive migration policies will discourage some people to migrate onward, others have continued to cross borders. Little is known about the variation in individual circumstances, which could explain how people respond to or act upon similar policy constraints and opportunities, and how this variation emerges.

Fourth, there is a large emphasis in policy analysis on how policies effect specific key events and stages in migrants' trajectories, such as the crossing of a border. Singling out certain stages and key events in policy analysis comes with the risk that less attention is attributed to how stages and events that passed at other moments are related. This results in a rather narrow view of migration as something that can "be turned on and off like a tap through laws and policies" (Castles, 2003, p. 12). People do not just 'appear' at borders or at admission centres; these acts are informed by earlier experiences and, as will be argued later, are embedded in a changing social context. In order to better understand why migrants pursue certain migration strategies, such as crossing a border or not, and to understand how these strategies are affected by policies, it is crucial to view the circumstances through which migrants have taken the decision to pursue them and how these circumstances came into being.

This research contributes to the understanding of irregular migration by investigating how migration strategies en route are embedded in migrants' trajectories. In other words, in order to understand a single migration strategy, it needs to be viewed in the context of a sequence of migration strategies, i.e. a migration trajectory. It investigates the evolution for these trajectories by contextualising them within the changing social context in which they are shaped. Thus, while policy analyses often focus on explaining certain key events (e.g. border-crossings), or the effect of specific policy instruments (e.g. border controls), this thesis adopts a processual approach towards understanding the relation between, among others, policy-induced events and the evolution of non-linear irregular migration trajectories. This processual approach focuses on the analysis of trajectories that emerge as a sequences of successive migration strategies, rather than centralising the impact of one specific, pre-defined event. This is done by analysing how policy-incurred events concur with other events, and how these are embedded in a changing social context (Langley, Smallman, Tsoukas, \& Van de Ven, 2013). The thesis further adopts a subject-oriented approach to analyse how individual migrants deal with manifestations of policies in their daily lives, rather than how policy interventions impact flows. It thus aims to scrutinise the mechanisms by which migrants negotiate the effects of migration policies in their daily lives, to advance our understanding how migration trajectories evolve. This thesis 
does not provide analysis on the effectiveness of certain migration policies. Yet, by better understanding how migrants deal with policy implementations in their daily lives, their effectiveness could be better understood.

\subsection{The role of transnational social networks}

Aside from policy, transnational social networks also affect the evolution of migration flows, and this thesis assesses their role for the evolution of migration trajectories. Studies have demonstrated that the networks which migrants maintain across the boundaries of the nation states where migrants reside, play a vital role in the formation of migration intentions and the facilitation of migration strategies (Chelpi-den Hamer \& Mazzucato, 2010; Collyer, 2007; Devillanova, 2008; Faist, 1997; Fawcett, 1989; Haug, 2008; Koser Akcapar, 2010; Massey, 1987; Pries, 2004; Schapendonk, 2015; Suter, 2012a; van Wijk, 2010). This is the case, for example, when people migrate with the aim of supporting their families: inspired by watching others who have migrated and who send remittances back home, they migrate with the hope of doing the same (Åkesson, 2011). In the same vein, studies have illuminated that when migrants do not reach the intended country of destination or are unable to send remittances, feelings of guilt and shame lead to social withdrawal and prevent them from going back (Åkesson, 2011; Hernandez, 2002; Schmalzbauer, 2004). The literature has further discussed the role of network members in destination countries: while earlier studies highlighted their facilitating function (Faist, 1997; Fawcett, 1989; Massey, 1987; Pries, 2004), other studies have shown that earlier migrants no longer support the journeys of newcomers, for instance because of labour market competition (Collyer, 2005; De Haas, 2010). The phenomenon where migrants "strand" at the borders of Europe and cannot move forward nor back home, has been explained in relation to social network dynamics, where people either fail to provide support, or do not receive anticipated support (Collyer, 2010).

This thesis takes a different approach to the study of the role of social networks in migration trajectories. Common interpretations of the role of networks as described above are rooted in a narrow conceptualisation of the nature and functioning of migrants' networks. This conceptualisation entails that networks are the collection of (potential) linkages between people in countries of origin and destination. This reveals an understanding of the migration trajectory as evolving between a fixed starting and foreseen destination point, with (potential) network members in each end of the flow. Yet, this is problematic because these points are not necessarily fixed, therefore the locality of influential network members cannot be assumed to be fixed either. Such an origin-destination conceptualisation of networks obscures any other possible relationships elsewhere in the world that may affect the evolution of migration trajectories. Furthermore, the emphasis on networks in destination countries typically imply a focus on migrants' strong relationships with family 
and close friends (all migrants) overlooking the potential role of weaker ties and chance encounters and non-migrants in destination countries (Gladkova \& Mazzucato, 2017; Suter, 2012a).

Analyses of social networks in the context of international migration have also commonly dealt with static networks, i.e. networks in a particular moment in time. This study builds on recent work recognising that migrants' networks are changeable entities, both in terms of members of the network and the relationships that are maintained (Lubbers et al., 2010; Ryan, Sales, Tilki, \& Siara, 2008; Schapendonk, 2015). As relationships (of which networks are composed) change over time, the role networks play during migration is expected to change as well. The scenario where migrants experience feelings of shame and guilt and do not return as a consequence, is, however, too often presented as a permanent situation. By following the evolution of network composition and use throughout migrants' trajectories, this thesis aims to illuminate a variety in the characteristics and functioning of migrants' social networks, as well as the mechanisms by which they change. For readability, in the remainder of this thesis, I predominately use the term 'social network', but these are understood as transnational social networks.

\subsection{Research design}

The transit migration hubs of Istanbul (Turkey) and Athens (Greece) were chosen as the locations for empirical fieldwork. Transit migration hubs are suitable locations to study the evolution of trajectories, because of their highly volatile migration environment. While migration trajectories can evolve non-linearly from any migration context, for example from traditional places of settlement, changes in trajectories are more likely to take place in highly volatile migration environments, such as in transit migration contexts. A highly volatile migration environment implies that social and institutional structures are causing fluctuations in opportunities and constraints to pursue migration strategies. A volatile social structure entails that local social networks are changing at a rapid pace, due to constant arrivals and departures of people. And a volatile institutional structure entails that the rules of the game pertaining to migration and asylum policies are frequently changing, due to weak asylum and migration legislation, a seemingly arbitrary implementation of policies, and the widespread presence of a migration broker industry, whose modus operandi regularly changes. These volatile structures incite migrants to often change or develop new strategies, making it a suitable place for the analysis of the evolution of migration trajectories.

I followed 40 Sub-Saharan African informants residing in either Athens or Istanbul during 2 fieldwork periods within 17 months between early 2012 and late 2013. The total period of contact I maintained with informants ranges between 3 and 90 months: 8 informants were involved in previous projects I conducted, and I maintained contact beyond periods of fieldwork with 23 informants, while in 12 cases the contact lasted less than 17 months. By 
means of participant observation, in-depth interviews and social networks analysis (SNA), I gathered information of their migration trajectories and networks in retrospect, as well as in actual time by regularly visiting informants and keeping in touch via telephone and social media between and beyond the periods of fieldwork. Triangulation between these methods reduced interpretation errors, and complemented each other in reconstructing the evolution of trajectories and changes in networks (Bernard, 2002).

The study builds on and contributes to methodologies used in migration studies in three ways. First, this research builds on insights generated by transnational migration studies. Whereas migration studies in the 1970s and 1980s mostly focused on either migration decision-making in countries of origin, or integration processes in countries of destination (De Jong, Root, Gardner, Fawcett, \& Abad, 1985; Gardner, De Jong, Arnold, \& Cariño, 1985), transnational migration scholars in the 1990 s recognised that migrant lives are lived between the origin and destination context (Dahinden, 2009; Faist, 2000; Glick Schiller, Basch, \& Blanc, 1995; Mazzucato, 2004). This entails that practices across the borders of nation states, such as the maintenance of social relationships and the exchange of goods, money and other resources, shape migrant livelihoods, including migration strategies. To understand the evolution of migrants' trajectories, it is therefore crucial to see how these are embedded in transnational practices. Most empirical studies within transnational migration studies, however, include transnational connections only between specific countries of origin and destination. In migration from Africa to Europe, this typically concerns migration between specific sets of typical origin and destination countries in Africa and Europe. Transit migration contexts, such as Turkey and Greece, only recently have been included in studies on transnational migration between Africa and Europe (Collyer, 2007; Schans et al., 2018; Schapendonk, 2011). This study adds not only a third context to the study of transnational migration between Africa and Europe, but also empirically studies transnational connections that African migrants in Turkey and Greece may have with other parts of the world.

Second, transit migration itself has become an established subfield within migration studies over the past decade. However, the phenomenon of transit migration is often approached from a legal/policy perspective, focusing on policy-making processes in the field of asylum, border and migration management. While there is an increasing body of ethnographic studies on transit migration that has been conducted in West Africa, Spain and Italy (Carling, 2007; De Haas, 2010; Hamood, 2006), ethnographic studies in Turkey and Greece have, at the time of this study, mostly covered migration from their neighbouring countries. This thesis contributes to these ethnographic studies on African transit migration in and through Turkey and Greece (See also: De Clerck, 2015; Schapendonk, 2015; Suter, 2012b; Wissink et al., 2013; Yükseker \& Brewer, 2011).

Third, this thesis contributes to migration studies by combining social network analysis with ethnographic fieldwork. While the idea of incorporating social network studies into the field of migration has been raised by various scholars (Boyd, 1989; Gurak \& Caces, 
1992; Krissman, 2006; Ryan et al., 2008; Vertovec, 2004), this study is among the first to apply social network analysis (SNA) in (transnational) migration studies (Bilecen, Gamper, \& Lubbers, 2018; Lubbers et al., 2010; Mazzucato, 2009).

\subsection{Overview of the thesis}

This thesis is based on articles, some of which have been published as journal articles or as a book chapter. When this is the case, the precise publication is referenced on the title page. Each of the published chapters can be read as a stand-alone chapter, hence there is some repetition in the explanations of the conceptual and methodological approach. This introduction is followed by Chapter Two, presenting the theoretical framework of the study. It elaborates on why mainstream migration theories are generally ill-suited to analyse how the evolution of migration trajectories takes place, given that they generally start from the perspective of an existing migration flow between certain origin and destination countries. It further discusses recent literature that conceptualises migration as constantly evolving, nonlinear process. Chapter Two also presents how social networks have been commonly conceptualised in migration studies, elaborating on how this study builds on new approaches viewing networks as changeable entities. It further elaborates on the analytical subject of 'critical events', which entail manifestations of the volatile social and institutional structure, including policy-induced events, in the personal lives of migrants, as well as life events. Critical events are in turn associated with changes in social networks and migration trajectories.

The methodology used for data collection and analysis is presented in Chapter Three. Chapter Three explains how the methods of social network analysis and ethnographic fieldwork were synthesised in the research design.

Whereas it is often assumed that Sub-Saharan African migrants in Turkey and Greece have emigrated with the intention to move on to Europe and that they will ultimately try to do so, Chapter Four describes the variations that can be observed in how trajectories of Sub-Saharan migrants in Turkey and Greece may evolve. It explains how this variation is associated with three societal developments in this region, causing a volatile migration environment: 1) a securitisation of migration policies, 2) a rise in xenophobic sentiments in Greece, and 3) reverse economic developments in Turkey and Greece. However, in order to understand how migration trajectories of individuals evolve in relation to a volatile migration environment, it is necessary to analyse how this environment manifests itself in migrants' daily lives. This is done in Chapter Five, introducing the concept of critical events which are produced by a volatile migration environment. It analyses how these critical events are associated with changes in migrants' social networks. It presents mechanisms that advance our understanding of how changing relationship preferences, resources and 
communication infrastructures help explain why and how migrants' social networks change along the migration trajectory.

How changes in social networks are associated with the evolution of migration trajectories is central in Chapter Six. It considers to what extent and in what circumstances support exchanges can enable or constrain the migration strategies migrants intend to pursue. Chapter Seven is a brief, synthesising chapter bringing the findings of the preceding chapters together. It explains how all findings combined lead to a model showing how migrants' social networks and trajectories co-evolve through the ongoing experience of critical events. Chapter Eight, the concluding chapter, presents the implications for the study of irregular migration processes, as well as avenues for future research. 

Chapter 2

Theoretical Framework 



\section{Chapter 2: Theoretical Framework}

\subsection{Introduction}

International migration and the role of social networks has long held scholars' attention. A large part of the literature engages with understanding the root causes of migration, answering questions such as why it is that people decide to leave their countries of origin, and what explains the existence of migration flows. Another substantial body of literature examines the effects of international migration, for example on the well-being of immigrants, development of origin countries and the linkages between origin and destination countries. Both bodies of literature have contributed to the understanding of migration. Yet, they mostly engage with pre- and post- migration questions, that is, the situation in origin and destination countries. Recently, scholars began paying attention to the actual process of migration, which entails the process of being en route: when a person has emigrated from his or her countries of origin, but whose migration process has not (yet) concluded in longterm settlement.

As explained in the introduction of this thesis, migration processes of irregular migrants are typically characterised by frequent changes of intentions, migration strategies and places of temporary settlement. I refer to this sequence of changes as the migration trajectory. This thesis contributes to an emerging body of literature examining how migration trajectories evolve. In this way, this thesis aims to contribute to a better understanding of the migration process itself.

In this chapter, I argue that mainstream migration theories are generally ill-suited to analyse how this evolution takes place. This is because these theories generally depart from the perspective of an existing migration flow between certain origin and destination countries. For the analysis of trajectories, this entails that they are analysed against the background of such flows. Trajectories that do not evolve along the route that is constituted by these flows are then interpreted as being deviant. Such interpretations depict an underlying supposed linear evolution of the migration trajectory. I argue that while this interpretation is not necessarily wrong, it does restrict the interpretation and explanation of how trajectories evolve. Section 2.2 elaborates on this point.

In the literature, specific attention has been paid to the role of social networks in migration processes. This role is increasingly a subject of debate: while its potential vital role for initiating and facilitating migration has been demonstrated, studies have pointed to other factors that are more explanatory for the migration process than social networks are. The debate revolves around the question of whether or not networks can explain why migration occurs. This thesis does not aim to move beyond this network approach, but beyond the question of whether networks for migration matter or not. Instead, it assesses how and when social networks help show how individual migration trajectories evolve, and how this 
role itself is subject to change. Section 2.3 elaborates on how this thesis conceptualises social networks and their role in the migration process.

The central premise of this thesis is that migration trajectories and social networks co-evolve. To study this, I adopt a processual and subject-oriented approach towards trajectories and networks. Section 2.4 explains what this entails and introduces the building blocks of the analytical framework of this study.

\subsection{Theoretical perspectives on migration}

Explanations of migration flows and the evolution of trajectories have been initiated by a wide range of academic disciplines, resulting in many theoretical models. This section argues that most theories depart from a binary origin-destination perspective to explain the characteristics of migration flows, or initial decision-making in countries of origin. Mechanisms by which migration trajectories evolve over time remain theoretically underaddressed. This section concludes with a reflection on the relevance of the literature on forced migration for the present study.

\subsubsection{Origin-destination versus processual conceptualisations of migration}

Migration has been theorised on a micro level, scrutinising individual decision-making processes, and on a macro level, theorising the existence of migration flows. Both macro and micro theories often take a binary origin-destination perspective: they either aim to explain migration at one end of a migration flow (e.g. the origin or destination county), or the movement between the two. This thesis complexifies this binary approach, as the migration trajectories of irregular migrants do not necessarily develop linearly between two predefined ends. I argue that a processual conceptualisation of migration trajectories is more helpful in understanding how they evolve, instead of centralising the beginning and anticipated ending. First, I discuss how commonly applied migration theories conceptualise migration to illustrate the binary origin-destination perspective.

World-systems theory (Wallerstein, 1974) is a macro level theory that explains migration in global economic and political forces. Here, the unequal distribution of power among nations is regarded as a driver of international migration from poorer countries to richer ones. Macro level theories have been criticised for undermining the individual decision-making process: not everyone migrants in similar macro level circumstances (De Haas, 2010). Micro theories of migration, instead, focus on the individual decision-making process. One of the earliest micro theoretical models of migration is rooted in neoclassical economics, and stipulates that people make cost-benefit calculations and migrate to maximise their economic gains (Harris \& Todaro, 1970; Ravenstein, 1889; Todaro, 1969). This theoretical model assumes that pull factors, such as labour demand and better living circumstances, and push factors such as relative deprivation, act as drivers of migration. 
Such theories have been criticised for overemphasising rational considerations in individual decision-making processes. Furthermore, they have been criticised for failing to explain why some people migrate and others do not, and to where people migrate (Castles \& Miller, 2009). They focus on the start of the migration process, disregarding the evolution of migration trajectories that may follow.

The New Economics of Labour Migration (NELM) theory assigns more value to the role of households rather than individuals, considering migration a household strategy to mitigate risks (Stark, 1991). NELM contributed to migration studies by recognising that migratory decisions are not based on considerations by individuals only. That said, NELM has been criticised because of its focus on economic cost-benefit calculations, while aspirations other than economic ones may inform the decision to migrate (De Haas, 2010). Moreover, this thesis stipulates that while en route, migrants constantly adjust their migratory objectives and strategies, while NELM centralises the initial decision taken based on cost-benefit calculations prior to migration.

The notion that migrant decision-making does not take place in a social vacuum is centralised in migrant network theory. This theory embeds the individual behaviour of migrants in larger meso structures. According to migrant network theory, migration is more likely to occur when social networks are prevalent between people in origin and destination counties (Massey, 1987). It stipulates that through networks, migration becomes a selfsustaining process where earlier migrants facilitate the migration of newcomers. Social networks are thus often conventionally considered as channels through which resources such as information, goods, ideas and money can be exchanged across the borders of nation states (Faist, 1997; Fawcett, 1989; Massey, 1987; Pries, 2004). Social networks have been mostly associated with the initial decision to migrate and with integration and settlement processes. Less attention has been paid to the role social networks may play en route (but see: Pathirage \& Collyer, 2011; Schapendonk, 2015; Suter, 2012a). In section 2.3, I elaborate further on the role of social networks in different phases of the migration process.

In the early 1990s, transnational migration studies emerged. These studies build on migrant networks, but went further by arguing that migration is inherently a transnational process, which has been defined as "the process by which immigrants forge and sustain simultaneous multi-stranded relations that link together their societies of origin and settlement" (Glick Schiller et al., 1995, p. 48). This entails that not only the migration process can be understood by transnational networks linking sending and origin countries, but also that migrant lives continue to be shaped by these transnational linkages (Dahinden, 2009; Faist, 2000; Glick Schiller et al., 1995; Mazzucato, 2004; Portes, Guarnizo, \& Landolt, 1999). This approach furthered migration studies by moving beyond what has been termed "methodological nationalism", the implicit assumption that only networks in a receiving context shape processes of immigration (Wimmer \& Glick Schiller, 2002). The relationships migrants maintain with people in origin countries are crucial for understanding how migrant lives are lived. Empirical approaches in transnational migration studies, however, continue 
to focus predominantly on the rather dichotomous linkages between origin and destination countries, and adopt a transnational perspective to study the consequences of migration for these linkages. As Schapendonk (2011) has argued, transnational migration studies could be further developed by equally addressing the evolution of migration trajectories itself.

Migration system theory similarly recognises that, in order to understand migration, both ends of the flow should be taken into the analysis of migration processes. A migration system is defined as two or more countries who exchange migrants with each other, as well as goods, capital, ideas and information (Castles et al., 2014; Fawcett 1989; Gurak \& Caces, 1992 ). Migration system theory stipulates that existing historical links between origin and destination countries provide a context for migration to occur. Migration flows between countries are explained through the interaction of macro structures, such as the political context, and micro structures, such as migrants' informal social networks. These two levels are connected through meso structures, composed of the 'migration industry'; the collection of brokers, agencies, smugglers and intermediaries linking individuals with political and economic institutions. Migration system theory has contributed to the understanding of migration processes by connecting various levels of analysis. Yet, the explicit articulation of two ends of a migration flow reinforces the dominant binary origindestination perspective in migration studies, leaving less attention for the evolution of nonlinear migration trajectories.

The migration theories briefly described here have been helpful in identifying various factors that lead to migration. Above all, they have illuminated the fact that migration is a complex phenomenon, intrinsically linked to various macro, meso and micro structures. In general, they are used in explanations of why people leave their country of origin and how the integration process progresses, or why migration flows emerge, continue or cease to exist. An additional body of migration literature not described here examines the effects of migration, for example for development in countries of origin. They do not address how individual migration trajectories evolve, which has been less theorised in studies of migration.

Migration theories are usually based on the analysis of particular migration flows, with a known origin and destination context. Incorporating such an origin-destination perspective in the analytical framework by which the evolution of individual migration trajectories is analysed, leads to a possibly false assumption that the migration trajectory was supposed to evolve along the lines of a migration flow, and that the destination context factors are vital in understanding this evolution. This assumption is useful when for instance, given the existence of a migration flow between West Africa and Europe via the Mediterranean, a study aims to analyse why West African migrants aspire to reach Europe, why some are "stranded" in the Mediterranean region, and how their networks in Europe have played a role in migratory aspirations and strategies. Yet, it is questionable to what extent the European context is the major defining factor in the evolution of the individual migration trajectory. Studies have shown, for example, that for some migrants, 
neither Europe, nor any other country is hoped for as a final destination (De Clerck, 2015; Şaul, 2014). By adopting mainstream migration theories, the migration trajectory of WestAfricans in the Mediterranean is automatically framed against the background of a flow with a known destination context. This is inadequate when the destination is unknown, or plans and ideas about destinations evolve en route. Abandoning the dominant origin-destination approach towards explanations of migration trajectories is likely to reveal more insights on the constant reshaping of the migration process.

\subsubsection{Understanding the evolution of migration trajectories}

This thesis understands migration trajectories as composed of a sequence of migration strategies. Migration strategies refer to the mode of migration by which migrants enact their migratory aspirations at a specific moment in time (Carling, 2002). Examples of a migration strategy are applying for asylum, starting a business, overstaying visa, and crossing borders. These strategies may concern modes of travelling (i.e. attempting to cross a border) as well as strategies in situ to realise or secure residency (i.e. applying for asylum or starting a business). To a certain degree, strategies may be imposed by the state, for example when migrants have no option other than to travel or reside irregularly. While such strategies may only emerge due to imposed restrictions and opportunities, there is a diversity of choices that migrants can make in such circumstances.

Strategies, as well as a change of a strategy, are not necessarily a "purposive and preplanned pursuit of calculated goals [but] the active deployment of objectively oriented lines of action that obey regularities and form coherent and socially intelligible patterns" (Bourdieu \& Wacquant, 1992, p. 25). This study asserts that migration strategies do not evolve from only migrants' individual deliberations, but are embedded in social and institutional contexts which are deemed highly volatile in the case of this study (Carling, 2002; Faist, 2000).

The fact that migration does not necessarily evolve linearly following the decision to migrate has been widely acknowledged. De Jong et al. (1985) and Wimmer (1985) demonstrated the importance of place utility to indicate that local conditions may change and affect the decision to migrate. Similarly, Gardner et al. (1985) highlight that financial and legal barriers can explain why migrants behave differently than aspired. Yet, these studies focus on the initial migratory decision, while conditions may continue to change en route. This is particularly the case for migrants whose trajectories are (in part) irregular, where migrants are not eligible for legal ways of immigrating, travelling and settling (Düvell, 2011; Jordan \& Düvell, 2002).

The migration literature recognises various phases of the migration process. For example, King and Skeldon (2010) point to the increasing complex journeys of migrants, and how they consist of multiple and sequenced pathways, which include both national and international moves. Commonly recognised phases are that of decision-making in the country of origin, emigration, the journey, transit migration, immigration, settlement, 
integration and possibly return or migration elsewhere. Each phase presents a new context in which new rounds of decision-making processes take place. While these phases show that migration is not a straightforward matter of emigration and subsequent settlement, they still mark a linear evolution between origin and destination countries, albeit stepwise. With some migrants, however, trajectories do not follow this stepwise evolution: immigration and settlement can be rapidly followed by a new journey onward, return to the country of origin, before moving elsewhere later on. Immigration and settlement processes may involve multiple strategies, for example when people apply for asylum, reside irregularly, and obtain a business visa later on. Little is known about the mechanisms by which these trajectories evolve, both in terms of the geographical direction as well as in terms of the sequence of applied migration strategies.

The fact that migration does not evolve linearly from one place to another has been recognised in studies of circular migration. Already in the 1940s, scholars of the Manchester School studying migration in southern Africa conceptualised migration as a circular and temporary movement, rather than as a uni-directional and linear movement (Gluckman 1941; Wilson 1941, 1942). While the concept of circular migration at the time was mainly used to study internal migration, it has helped to understand that people can move temporarily, in multiple directions, back and forth between new and old destinations, without resulting in long-term permanent settlement elsewhere (Chapman \& Mansell Prothero, 1985; Skeldon, 2015). The notion of 'circular' does justice to the dynamics involved in the shaping of migration trajectories. It also reveals an underlying assumption that trajectories of circular migration end where they begin, which may be true for some, but not all trajectories that continue meandering.

Another concept that helped to address the non-linearity of migration trajectories following the decision to migrate is that of transit migration, which gained popularity in the mid-2000s. While there is no clear scientific agreement on its definition, the concept indicates situations where migrants spend considerable time in a certain country before moving on to another. This indicates a stepwise and a continuing migratory decision-making process following initial emigration. Transit migration has as such been termed the "missing link" between emigration and settlement (Papadopoulou-Kourkoula, 2008).

Despite the valuable contribution of the concept of transit migration to migration studies by recognising the process between emigration and settlement, there are two related potential conceptual fallacies when used to analyse the evolution of individual migration trajectories. First, it presumes that residence in a transit migration context is a stop-over in an (intended) linear migration process. It continues to reinforce migration trajectories as a predictable, stepwise development. Yet, sometimes, an intended transit country eventually becomes the country of destination or vice versa (Düvell, 2012; Papadopoulou-Kourkoula, 2008). Studies have shown that migrants may return to countries of origin from the transit context, or return to what previously has been a transit context. A transit context is rather 
a crossing-point for people travelling in multiple directions, rather than a stop-over for any individual that finds him- or herself in such a context.

Second, because not everybody in a transit context eventually moves elsewhere, the distinction between transit and de facto immigration is blurred. This lack of a clear distinction has sparked criticism regarding the heuristic value of transit migration (Collyer, Düvell, \& de Haas, 2012). Elsewhere, I have argued this value remains intact when the concept of transit migration is a feature of global migration flows, where spaces of transit can be identified because of the many people who temporarily reside there before moving onward (Wissink et al., 2013). Yet, when studying the evolution of migration trajectories, it is not migration flows but rather individual migrants that become the key units of analysis. It is a conceptual fallacy to disaggregate the concept of transit migration to individual migrants and speak of transit migrants, as is commonly done in (transit) migration studies, because this can only be observed in retrospect.

Transit contexts are characterised by the emergence of a particular version of the migration industry to facilitate onward migration, as demonstrated by an abundance of temporary cheap housing solutions and the presence of brokers and smugglers. This is typically combined with policy interventions aiming to curb irregular onward migration and residence, while options to apply for asylum or regularise are limited. The combination of frequent changes in the social composition of transit contexts and in the frequent and rather ad hoc policy interventions constitute a volatile migration environment. This volatility is reflected in rapid and continuous changes in the institutional structures brought forward by (migration) policy implementations. Volatility is also reflected in changing social structures, notable due to continuous and sudden arrivals of other migrants and fluctuating opportunities to form and maintain social networks.

The volatile social and institutional environments manifest themselves in the daily lives of individual migrants through critical events. Critical events are potential turning points during the migration trajectory or in the formation and maintenance of social networks. Critical events are pivotal moments that can foster a change in or secure a continuation of an ongoing process due to new opportunities or constraints they bring forward. A change can entail a change of plans, but also a new direction when there was no prior plan. Examples of critical events include arrest at the border, outcomes of the asylum procedure, changes in relationships such as the type and frequency of interactions and, last but not least, life events are examples of potential critical events.

The concept of critical events is in particular meaningful for assessing the impact of migration policies in migrants' daily lives. The effect of policies is only critical when it brings forward benefits or constraints with respect to pursuing a migration strategy. This thesis investigates how migrants' embeddedness in social networks helps explain whether policyinduced events are critical where benefits can be capitalised and constraints be dealt with.

The volatile migration environment makes the transit context different from migration contexts from where people typically depart (origin countries) or arrive and settle (destination 
countries). Thus, rather than a phase, a transit context can be best regarded as a space in the migration process, which characterises the environment in which trajectories are being shaped, but not the directions or outcomes of these trajectories (see also: Hess, 2012).

The non-linearity of (irregular) migration trajectories has been further addressed by studies on the impact of restrictive migration policies. Examples of such policies are strict border controls and visa policies, leading to the arrest, detention and/or expulsion of migrants. This may lead to interruptions of journeys or incite alternative and often riskier ways of travelling (Carling, 2008; De Haas, 2010; Mainwaring \& Brigden, 2016; Schapendonk, 2011). The problem with explaining deviations from potentially linear trajectories as stemming primarily from policy interventions that aim to stop migrants is that doing so cultivates the notion that migration is linear, that migrants have to be "stopped" and can either "manage" or "fail" to move onward. This is further enhanced by common academic and policy discourse employed to describe migrants residing in transit contexts and who do not move forward: while transit countries serve as a "stepping stone" for some, others are described as being "stuck" or "stranded". While this may be true for some, it is not for all.

Nevertheless, a relation between migration policies and migration flows has been established in the literature. Several studies have demonstrated that restrictive measures, such as strengthened border controls, lead to alternative routes and to precarious situations of migrants who cannot migrate further, but they are departing from their countries of origin (Baldwin-Edwards, 2006; Carling, 2007; Kiza, 2008; Pugh, 2004; Spijkerboer, 2007). However, the impact of policy differs across individual migrants: while some engage in more dangerous routes, the trajectories of others evolve in other directions. Policy interventions alone can therefore not explain how people's trajectories evolve in relation to policy interventions. This raises the question of by what mechanisms do opportunities and constraints offered by policy interventions (or the lack thereof) influence the trajectories of individual migrants.

To conclude, this thesis questions the value of an origin-transit-destination perspective to understand the evolution of migration trajectories, where trajectories are understood against the background of a dominant flow between origin and destination countries, and deviations are explained as result of policy interventions, or, as argued in the next section, of very specific social network dynamics. By incorporating a specific or expected migration flow in the analytical framework by which individual migrant trajectories are studied, we likely fail to witness other mechanisms, strategies and routes that constitute their evolution. In other words, an origin-transit-destination perspective is too deterministic to understand the evolution of individual migration trajectories. Existing theoretical frameworks are helpful for analysing how migration flows, why people depart and how they settle, but those frameworks are insufficient when analysing the evolution of individual migration trajectories. 


\subsubsection{Forced migration}

Mainstream migration theories have been criticised for assuming that the choice to migrate is voluntary, disregarding forced migration. Forced migration studies have theorised forms of involuntary migration, notably concerning people who fled their home countries in fear of persecution. While it has been recognised that the distinction between forced and voluntary migration is blurred and that migration motives are often mixed, to date it is still common in migration research and policy to distinguish between types of migrants based on their level of voluntariness of migration, with 'refugees' on one end of the spectrum and 'economic migrants' on the other, or as Bivand Erdal and Oeppen (2018) note: "the distinction between forced and voluntary [migration] [...] has a tendency to stick around in academic work and policy" (p.981).

An often-made argument in favour of this distinction - be it in research samples or NGO beneficiaries - is the difference in institutional opportunities and constraints between people meeting the criteria of the 1951 Geneva Convention on Refugees and who are hence eligible to receive a recognised refugee status, and those who do not meet these criteria. Furthermore, the character of the diaspora, and people's transnational social networks, has said to be been different for refugee populations than for economic migrants, who typically migrate because of historical (post-colonial) linkages with their countries of origin (Van Hear, 1998).

Considering these differences, the trajectories of refugees are arguably different for those who migrated for economic reasons. Yet, there is increasing empirical evidence and theoretical arguments questioning the relevance of this distinction. It has been argued that the distinction between refugees and economic migrants is not doing justice to the continuum that voluntary and forced migration constitute in reality (Bivand Erdal \& Oeppen, 2018). While critical perspectives on the dichotomy started with the acknowledgement of 'mixed migration', this notion seems to suggest that people seek protection for fully or only partially rightful reasons, and that only the right mix of motivations make people eligible for protection (Bakewell, 2011; Bivand Erdal \& Oeppen, 2018). A true continuum implies there are different degrees of coercion involved in migratory decisions, and this degree may change over time.

Empirical studies indicate that while the original motives to migrate may differ, the contexts in which migration trajectories evolve is not necessarily different. In Greece, for example, opportunities to apply for asylum and recognition rates are low $(<1 \%$ in 2012), implying there is de facto no difference between institutional opportunities and constraints between those meeting the 1951 Geneva Convention criteria and those who do not (Pratsinakis, Hatziprokopiou, \& King, 2017). Pratsinakis et al. (2017) argue, accordingly, that while the distinction between refugees and other migrants may be useful for analytical purposes, its value for understanding patterns and forms of mobility is very limited.

A focus on original migration motives also undermines the comparable if not identical challenges that both refugees and other migrants experience en route. During the fieldwork 
of this study, I encountered many Eritrean and Ethiopian women working as domestic workers in the Middle East before coming to Turkey and Greece. While Eritreans are more likely to meet the 1951 Geneva Refugee Convention criteria based on the conditions in their home country than Ethiopians, their experiences in the Middle East and motivations to move onward to Turkey and Greece, and their experiences in these latter countries, are very similar.

For these reasons, this thesis does not empirically nor analytically distinguish between different categories of migrants. Whether a person can be classified as a 'refugee', 'economic migrant' or any other category is rather a reflection of the access to institutional opportunities at a specific moment time and it indicates little about a person's objectives, needs, intentions and future evolution of the trajectory. Instead of wanting to explain the trajectories of refugees or other types of migrants, this study is engaged with understanding how the trajectories evolve, during which the same person may be assigned different categorical labels or and experience varying degrees of volition. This thesis investigates the evolution of this process and does not seek to explain differences in the outcomes thereof for different groups of migrants.

\subsection{The role of social networks}

Using the concept of social networks in migration theory has followed a remarkable trajectory throughout the past decades. In the 1960s, the formation of social networks across borders was a 'side effect' of migration (Castles et al., 2014). It was, however, key in explanations of migration in the 1980s and 1990s. Today, a lot of explanatory power continues to be attributed to social networks in understandings of migration, albeit sometimes implicitly. At the same time, a growing body of literature questions the importance of social networks for migration. In this section, I briefly discuss various perspectives regarding the value of social networks in understanding migration, and how I build on this in the present thesis.

\subsubsection{Social network approaches to migration}

Research on chain migration in the 1960s recognised that newcomers were assisted by earlier migrants, and that family members reunited with people who had migrated (MacDonald \& MacDonald, 1964). Throughout the 1980s, the formation of networks between people in sending and receiving countries was not merely considered a consequence of migration, but as a crucial driver instead. Structural migration theories, as discussed in the previous section, were found inadequate for the purpose of explain the behaviour of individuals, while micro theories overemphasised individual decision-making (Boyd, 1989). Social networks represented the ultimate meso level, embodying the structural linkages between receiving and sending countries. Social networks allowed for embedding the behaviour of individual migrants into larger macro structures (Boyd \& Nowak, 2012; Gurak \& Caces, 1992). 
Empirical studies supported the thesis that migration continues to occur precisely because of social networks. Notably, the Mexican Migration Project, initiated by Durand and Massey in the 1982, collecting data on migration between Mexico and the US, has demonstrated that migration is more likely to occur when social networks are prevalent between people in the sending and receiving countries (Durand, Massey, \& Parrado, 1999; Massey, 1987). The core assumption of the migrant network theory is the cumulative causation effect of networks; migration becomes a self-sustaining process where earlier migrants continue to facilitate the migration of newcomers.

An important contribution of migrant network theory is the recognition that social networks constitute channels through which resources, such as information, goods, ideas and money, can be exchanged across the borders of nation states (Faist, 1997; Fawcett, 1989; Massey, 1987; Pries, 2004). Not only does this foster the formation of migration plans and foreseen destinations (Faist, 1997; Fawcett, 1989; Massey, 1987), but social networks can also facilitate several phases of the subsequent migration process. Social networks have as such been associated with reducing the risks and costs of migration (Faist, 1997; Pries, 2004), enabling the crossing of borders (Böcker, 1994), and assisting with finding employment and accommodation in the receiving country (Boyd, 1989). In particular for migrants for whom legal channels to migrate are inaccessible, social networks have been demonstrated to provide crucial assistance with realising migration strategies (Broeders \& Engbersen, 2007; Collyer, 2007; Devillanova, 2008; Koser Akcapar, 2010; Suter, 2012a; van Wijk, 2010).

More recently, social networks have also been associated with a decline of migration flows. Because of negative feedback that migrants send to people in countries of origin, migratory aspirations decline. Engbersen (2013) termed this effect 'diminutive causation', where the prevalence of social networks inhibits migration. Reasons for this negative feedback include fears for labour market competition (De Haas, 2010), changing beliefs and norms of people who have migrated.

In sum, the literature has discussed cases where social networks are associated with both the rise and the decline of migration. At the same time, critical perspectives have emerged questioning the importance of examining social networks in order to understand migration.

\subsubsection{Critical perspectives}

Scholars have warned for a network bias (Schapendonk, 2015); a tendency to explain migration predominantly through the lens of networks, while negative feedback-loops within networks (Bakewell, Kubal, \& Pereira, 2016; De Haas, 2010) or other factors, such as labour market outcomes, remain neglected (Boyd \& Nowak, 2012; Carling, 2008; Snel, Engbersen, \& Leerkes, 2006). In this vein, several scholars question the explanatory power social networks have for understanding migration processes (Broeders \& Engbersen, 2007; Collyer, 2005; Kalir, 2005; Krissman, 2006). For example, the mere existence of transnational 
social networks does not automatically lead to migration, nor can it explain to where people migrate. Collyer (2005) showed, for example, that Algerians preferred to move to the UK instead of to France to be away from their families. Similarly, Kalir (2005) demonstrated in his study of Ecuadorians in Israel that migrants move to countries where they maintain no strong relationships.

Additionally, the facilitating role of social networks can be hampered through migration policies that hinder the transfer of resources and of communication and visits, such as strict family reunification procedures or the presence of a fence (Broeders \& Engbersen, 2007; Grillo \& Mazzucato, 2008). Moreover, as stated, network members sometimes deliberately choose not to help newcomers, for example due to labour market competition (Broeders \& Engbersen, 2007; De Haas, 2010). Another type of criticism entails that networks often remain loosely conceptualised and it is not clear why some people are considered part of networks while others are not (Bakewell et al., 2016; Krissman, 2006). It is therefore not clear how networks play a variable role in migration.

Bakewell et al. (2016) question the importance given to networks in explaining the rise of what they term migration systems, and explore the avenue to move "beyond the network" in explaining migration systems. They argue, for instance, that when someone gains assistance from a network only after moving, the network itself cannot explain the cause of migration. This argument illustrates the difference between their endeavour and mine: this thesis does not aim to investigate the cause of migration, but rather its course. The role of social networks for the evolution of individual migrant trajectories is still unclear.

While critical perspectives on the role of networks have helped to recognise that networks are not self-evident factors in migration processes, it does not mean that social network approaches to migration studies should be dismissed. The question of what role social networks play in initial decision-making and the rise of migration systems or flows seems to underlie a rather fixed notion of what networks are - as if they were independent, moderating factors which could affect migration. However, as I elaborate below, networks are dynamic entities comprised of relationships which need creation and maintenance and which can dissolve (Mazzucato, 2011; Mazzucato, Kabki, \& Smith, 2006; Mollenhorst, Völker, \& Flap, 2014). Similarly, the mobilisation of resources through networks that can facilitate migration requires a relational effort (Pathirage \& Collyer, 2011). Both the processes of relationship management and resource mobilisation can be challenged during migration. It is thus necessary to conceptualise networks as changeable entities in order to assess their link with migration processes (Schulz \& Tompkins (1990) made a similar argument for research on the relation between social networks and health).

\subsubsection{Towards a re-conceptualisation of social networks in migration studies}

As with migration trajectories, migrants' networks are commonly conceptualised against the background of existing migration flows. This entails that networks are the linkages between people in particular origin and destination countries. Trajectories do not necessarily evolve 
like dominant migration flows, and they may evolve in unanticipated and unknown directions instead. Defining network members by a destination context is therefore not helpful when this destination is unknown.

Further problematising an origin-destination country perspective on networks is that this perspective does not allow for the inclusion of influential network members residing elsewhere in the world, in the places people transit, but also in other parts of the world. Especially when people make use of information and communication technologies, it is not required for a network member to live in a particular (foreseen) destination country in order to influence the evolution of the migration trajectory, for example through the exchange of resources (Dekker \& Engbersen, 2014; Hiller \& Franz, 2004).

Another problem regarding the conventional reading of networks in the context of migration is that specific roles are typically attributed to specific components of the network. For example, network members in a (foreseen) destination country are regarded as potential facilitators of migration, and local (e.g. network members in the destination county) as facilitators of integration. Instead, network members in any part of the world could facilitate (or hamper) any part of the migration process.

What is more, in line with conceptualisations of networks as the linkages between origin and destination countries, most studies on networks focus on the role of strong ties between family and friends in either of the locations (Haug, 2008; Ryan et al., 2008). Recent studies have addressed the role of weaker ties in migration processes (Gladkova \& Mazzucato, 2017; Ryan et al., 2008; Suter, 2012a). Suter (2012) found, for example, that fellow migrants in transit contexts are crucial providers of instrumental support. Also, Gladkova and Mazzucato (2017) illustrate the effect chance (coincidental) encounters can have on the turn migrants' trajectories take.

By predefining the geographical locations of network members and relationship strength, we not only risk missing out on other influential network members, but we also fail to notice the dynamics in networks, which migration studies have only recently begun to recognise and analyse (Lubbers et al., 2010; Ryan et al., 2008; Schapendonk, 2015; Somerville, 2015; Wissink \& Mazzucato, 2018). Studies have demonstrated that networks are both shaping and shaped by migration, suggesting that the relation between the two is interdependent (Krissman, 2006; Pathirage \& Collyer, 2011; Ryan, 2011; Schapendonk, 2015). This implies that networks change as the migration process evolves. Thus, in order to understand the relation between networks and migration, it is essential to analyse the inherently changeable nature of networks (Lubbers et al., 2010; Ryan et al., 2008; Schapendonk, 2015).

Thus far, the changeable nature of social networks has mainly been demonstrated by cross-sectionally comparing the networks of migrants in different migration phases, such as emigration, transit, immigration, settlement, integration and possible return (Chelpi-den Hamer \& Mazzucato, 2010; Haug, 2008; Hiller \& Franz, 2004; Massey, 1987; Muanamoha, Maharaj, \& Preston-Whyte, 2010; van Meeteren, Engbersen, \& van San, 2009). These 
studies show that relationships are formed in accordance with opportunities and needs associated with the particular phase of the migration process. While these studies suggest that networks change over time, most do not yet explain how and why networks change. Moreover, as stated in the previous section, migration trajectories do not always develop according to clearly distinguishable phases, nor in this particular sequence. It is therefore inadequate to assume that networks follow a similar stepwise development.

Several scholars have conceptualised and investigated networks in the context of migration as changeable entities. Pathirage \& Collyer (2011), for example, speak of "social network work" to refer to the constant actions people take to foster relationships for their own benefit. Similarly, Schapendonk (2015), argues that 'networking' is a more fruitful concept than 'networks' to counter the image that networks are a "social given" to which migrants only have to "plug in" in order to retrieve resources. In his qualitative study of African migrants heading to Europe, he found that that timing and opportunities to connect with others contribute to the dynamics of networks during migration. Lubbers et al. (2010) point out that by recognising the dynamic character of networks, new research questions arise instead of whether they impact or not, such as the question this thesis aims to address. This thesis extends these lines of research on how and why networks change by conceptualising migrants' networks as inherently dynamic, by moving away from an origin-destination country perspective and by lifting all time and strength restrictions when qualifying network members.

\subsubsection{Social network analysis}

In order to re-conceptualise migrants' networks, I build on social network analysis (SNA). This field of study is, as the name already suggests, entirely focused on understanding and analysing the formation and characteristics of people's social networks. The idea of incorporating social network analysis in migration has been put forward by various scholars (Boyd, 1989; Gurak \& Caces, 1992; Krissman, 2006; Ryan et al., 2008; Vertovec, 2004). Krissman (2006) argued that the concept of networks is used rather metaphorical in migration studies, referring to a type of social interaction without specifying with whom exactly, how, why and when. He stated that SNA scholars have developed many methods that would enable the in-depth analysis of networks. However, he concluded that Boyd's initial call to incorporate SNA literature in migration studies has gone unheeded. Chapter Four of this thesis is part of a special issue published in 2018, which, according to the editors Bilecen et al. (2018), is among the first to discuss research where SNA has been finally applied in (transnational) migration studies (but see: Lubbers et al., 2010; Mazzucato, 2009; Mazzucato et al., 2006).

Traditionally, SNA is based on cross-sectional data to explain variety in social network compositions and structures of different individuals. Network compositions entail the prevalence of people with certain characteristics in networks, such as gender, the geographical location, relationship types (e.g. kin and non-kin) and relationship qualities 
(e.g. emotionally close and distant ties). Network structures reveal information about the connections and interrelatedness of members of a network. As such, networks can be dense, scattered and consist of isolates and sub-groups (Wasserman, 1994). Certain types of network compositions and structures are associated with specific benefits and constraints. Granovetter (1973) showed for instance that networks that include members not densely connected (i.e. weak ties) are beneficial for mobilising new resources beyond the inner circle of strong ties. Similarly, when network members have varying characteristics, they can provide access to various sets of resources (McPherson, Smith-Lovin, \& Cook, 2001).

Social network scholars have recognised that both the structure and composition of network can change, due to changes in the presence and characteristics of relationships of which networks are composed (Feld, Suitor, \& Hoegh, 2007; Suitor, Wellman, \& Morgan, 1997). In the late 1990s, social network scholars began conducting longitudinal analyses to explain why these changes occur over time. These changes have been associated with transformations in the personal lives and institutional environment of individuals (Bidart \& Lavenu, 2005; Hollstein, 2003; Lubbers et al., 2010). Such transformations create new social contexts which allow for the creation and dissolution of social relationships (Bidart \& Lavenu, 2005; Mollenhorst et al., 2014). In the context of irregular and transit migration, changes in the personal and institutional environment of migrants are the matter of the day, for example because of the constant arrival and departure of people and policy interventions.

SNA distinguishes between personal and whole social networks. Whole social networks concern all possible linkages between people that form an entity based on social or geographical boundaries, for example a school. Not all children in the school will know each other, but through mutual connections they are connected to the other children. Migrant networks (that are only composed of migrants), or migrants' overall networks (composed of both migrants and non-migrants) can both be considered as whole networks: they are composed of the linkages between people in the geographically bounded set of countries of origin and destination. Not everyone in the network knows each other, but they are connected through the linkages between others. The embeddedness in such networks has been associated with the probability of migration and the nature of integration processes (e.g. the embeddedness of someone in a network with the native population is commonly used as a proxy for integration) (Lubbers et al., 2010; Snel et al., 2006).

A personal social network, on the other hand, concerns all personal ties of an individual (known as "ego" in social network analysis). Here, all personal connections of a child in and beyond the school constitute a child's network. A personal network is not defined by a geographical or social boundary, but by all personal relationships of an individual (the definition of what qualifies as a relationship, however, is bounded by predefined criteria). Thus, in a personal network, the individual knows all members of the network. The difference between the two network conceptualisations is presented in Figure 2.1. 
Figure 2.1 Whole versus personal networks
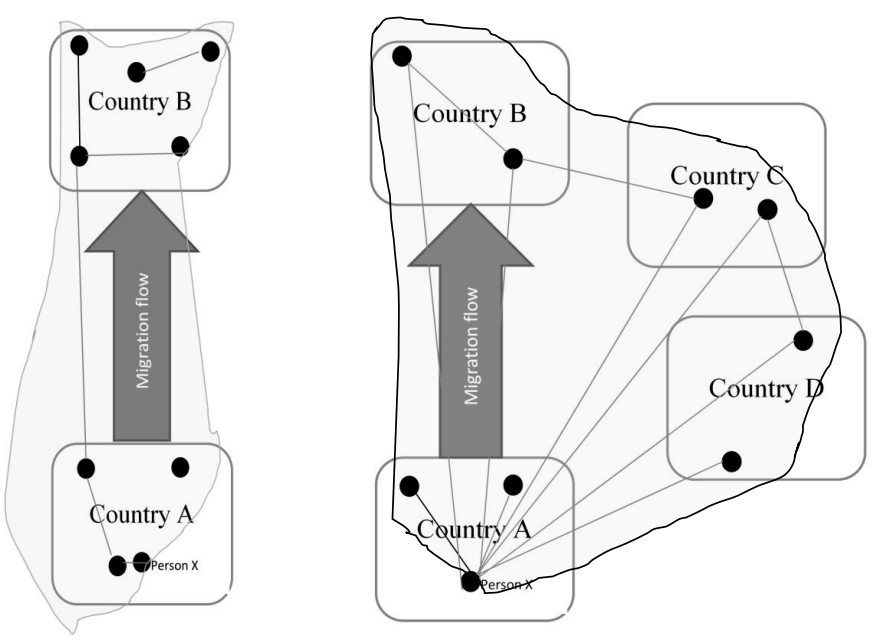

The figure on the left represents a whole network, which is bounded by the geographical restriction of an existing migration flow between two countries. The network is thus defined as the collection of linkages between people in these two countries. Person $\mathrm{X}$ is not personally connected to everyone in the network, just as the child of the example above is not connected to all children in the school. He is, however, connected via others. The figure on the right represents the personal network of person $\mathrm{X}$ : it illustrates the personal (transnational) linkages this person has in and beyond the country of origin, and it shows how his or her network members are mutually connected.

In the migration literature, migrant (or migrants') networks are typically discussed as whole networks, and used to explain migration between the geographical components of the network. In this thesis, I regard migrants' networks as personal networks, and study how this relates to the evolution of a personal migration trajectory. There are several studies that have investigated migrants' personal social networks. Mazzucato et al. (2006), for example, have assessed how migrants' personal social networks explain how resources circulate between networks. Lubbers et al. (2010) have analysed the changes in the personal social networks of Argentinean migrants in Spain. I build on these studies by analysing personal social networks of migrants, changes therein, mechanisms that constitute these changes and how this relates the evolution of migration trajectories.

In this personal network approach, relationships are identified based on the interaction that has taken, is taking, or can take place between the migrant and anyone else. Following SNA studies, interaction is defined as an exchange of contact or of a type of support, where a distinction is made between instrumental, financial, informational and affectional/ emotional support (Bilecen, 2016; House, 1981). I thus understand social networks as the changeable collection of all people with whom migrants do, can or have exchanged 
instrumental, financial, informational or affectional/emotional support. I further recognise that the presence of people in a network may change, as well as the type and intensity of interaction that takes place between them.

In sum, this thesis understands social networks as the collection of an individual's personal relationships with whom support exchanges are maintained, lacking, stopped, or potentially activated. Four types of support exchanges are discussed: instrumental, financial, informational and affectional support (House, 1981). Characteristics of social networks included in the analysis were the geographical composition (e.g. where network members are located), the relationship (kin versus non-kin) and the frequency and intensity of interaction and exchange.

\subsection{The analytical framework}

This thesis contributes to a growing body of literature stressing the need to move beyond pre- and post-migration questions and to better understand the evolution of migrants' trajectories instead (Schapendonk, 2011). I move beyond the rather dichotomous question of whether people will migrate or not, and whether social networks impact on migration or not, instead to assess the inherent dynamic character of both migration and networks. In the previous sections, I argue that in order to analyse how these processes occur, we need to move away from an origin-destination perspective in analyses of the evolution of migration trajectories and of the role of migrants' social networks. Instead, we need to investigate the mechanisms underlying the non-linear evolution of both. To this end, the analytical framework of this thesis is based on a processual, subject-oriented and iterative approach.

A processual approach is rooted in process metaphysics, and entails that the phenomena under study, networks and trajectories with this research, are constantly evolving (Langley et al., 2013). With this study, this means that the evolution of both migration trajectories and networks are not regarded to follow a predefined path between fixed points or configurations. This contrasts approaches rooted in substantive metaphysics, where the evolution of migration trajectories is analysed by addressing various predefined stages (e.g. emigration - transit - immigration - and possible return), along with changes in networks at each stage. This latter approach is suitable for finding answers to research questions on certain outcomes, for example the differences in networks between migrants in different stages of migration, or differences in the outcomes of their trajectories (e.g. who migrates to Europe, and who gets "stuck" in transit countries). A processual approach is better suited to find answers to different questions on the evolution of networks and trajectories (e.g. how are relationships being maintained, by what mechanisms do trajectories evolve).

The subject-oriented approach entails that the individual migrants serve as the starting point for investigating his or her network and trajectory. This thesis therefore does not focus on a specific phase in the migration process, nor on a specific type of migrant, 
nor does it aim to explain a specific outcome (those who move to Europe and those who do not). Instead, it recognises that throughout the migration trajectory, migrants may obtain new legal statuses, develop new migratory aspirations and travel back and forth between places. Similarly, networks may become dense, scattered, local or transnational over time, and will likely facilitate at certain times and hamper migration at others. I therefore generally speak of "people", "informants" or "migrants" in this thesis, even though some may have applied for asylum and could be hence termed asylum-seekers, and others who fled their countries of origin could be termed "refugees", and those residing irregularly termed "undocumented" or "irregular" migrants. In the same vein, a personal network approach is adopted where the personal connections of individual migrants are the starting point for analysing networks, rather than vice versa where migrants' networks would be identified apart from the individual migrant, whose embeddedness in these networks follows next. In other words, networks are defined as the collection of personal relationships based on potential, actual or provided support exchange, that are maintained by the individual migrant.

The analysis follows an iterative approach, meaning that data collection and data analysis form a cyclic process. I depart from analytical constructs derived from the literature while I remain sensitive to theoretical constructs that arose from the empirical work. This counterbalances the risk in processual approaches and lifting of analytical fixed categories where all processes in the social world could be regarded as one "mutually influencing flux" (Langley et al., 2013 p. 5), which challenges any form of analytical induction and deduction. What matters is an adequate choice for the analytical subject derived from theory. In a process ontology, the world is not composed of substantial matters, but of events and experiences. Each event and experience arises out of, and is constituted through, its relations to other events (Langley et al. 2013). By studying sequences of events and the mechanisms that lead to the experience of events, it becomes possible to grasp the way processes evolve. Three themes are central in this thesis: migration trajectories, social networks and the volatile social and institutional environment in transit migration hubs.

Figure 2.2 presents how the analytical concepts form the building blocks guiding the analysis, along with which chapters deal with specific concepts and the interlinkages between them. Chapter Four investigates the linkages between the volatile transit migration environment in Turkey and Greece and a variety of migration trajectories among Sub-Saharan migrants that evolve in and from these countries. Chapter Five discusses the associations between this volatile migration environment and migrants' transnational social networks. Chapter Six builds on these findings by assessing how changes in migrants' transnational social networks are associated with the evolution of migration trajectories. Chapter seven, finally, is a short chapter synthesising the findings of the preceding chapters and explaining the mechanisms underlying the evolution of migration trajectories. 
Figure 2.2 Graphical representation of the analytical building blocks.

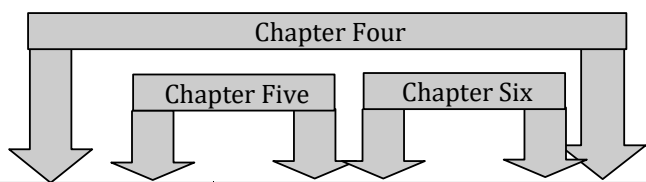

\begin{tabular}{|l|l|l|}
$\begin{array}{l}\text { Volatile transit } \\
\text { migration } \\
\text { environment }\end{array}$ & $\begin{array}{l}\text { Transnational } \\
\text { social networks }\end{array}$ & $\begin{array}{l}\text { Migration } \\
\text { trajectory }\end{array}$ \\
\hline $\begin{array}{l}\text { Institutional } \\
\text { constraints and } \\
\text { opportunities / } \\
\text { Critical events: } \\
\text { Policy interventions } \\
\text { Social network } \\
\text { changes }\end{array}$ & $\begin{array}{l}\text { Personal social } \\
\text { events: } \\
\text { Characteristics of } \\
\text { relationships } \\
\text { (lacking) Support } \\
\text { exchanges }\end{array}$ & $\begin{array}{l}\text { Changes in } \\
\text { migration } \\
\text { strategies } \\
\text { Modes by which } \\
\text { migrants reside and }\end{array}$ \\
\hline \multicolumn{1}{|l|}{ travel. } \\
\hline
\end{tabular}



Chapter 3

Research methodology 



\section{Chapter 3: Research methodology}

\subsection{Research design: capturing processes of change}

A lot of migration research is based on cross-sectional data, which cannot account for the variable nature of certain characteristics, such as legal status. Such approach enables the comparison of certain outcomes across individuals. This present study, instead, is about people whose intentions, migration strategies, and legal statuses change across time and space. The study aims to understand how trajectories unfold, rather than to explain and compare specific outcomes. In the previous chapter, I argued for the need to move beyond analytical dichotomies dominant in migration studies, and I called for a processual and subject-oriented approach towards migration and networks. In this section, I outline the implications this had for the design of the research according to four characteristics: 1) a longitudinal research design, 2) a multi-sited and mobile approach, 3) mixed methods, 4) data collection and analysis form a cyclic process.

\subsubsection{A longitudinal research design}

A longitudinal research design allows for incorporating a temporal dimension of the subjects under study into the methodological approach (Axinn \& Pearce, 2006). It is therefore wellsuited for the analysis of how and why processes take shape. Retrospective data was gathered during interviews were people were asked to reflect on their past migration strategies. Since this research focuses on the formation of ideas, adaptations of migration intentions and strategies, and transformations in social networks, the collection of retrospective data was complemented by a prospective longitudinal approach. This approach, rather than a mostly retrospective one, allows for the collection of data as they emerge. It enables the identification of associations between conditions at one moment in time and those at a later one.

A longitudinal research design is inherent to ethnographic approaches, where months or years are spent in the field. An ethnographic approach, however, does not necessarily imply that the same group of individuals is being followed over time. Following people over time is essential to grasp the developments in the lives of these individuals. In this study, I selected a group of informants whom I continued to follow on their trajectories throughout and beyond the period of fieldwork. The longitudinal character of the research design involved a mix of a) 'spending time' with the same individuals, for weeks or months in a row, b) paying return visits at various intervals, and c) keeping in touch via telephone or the internet when I, or the informant, had left the primary field sites. This methodology meant that, on different occasions, I observed, talked and inquired about developments in the areas of interest for this study. By doing so, I could not only witness changes as they were taking place, but also test interpretations and develop hunches for future rounds of 
data collection. The last section of this chapter elaborates on the methodological challenges associated with longitudinal research and how I dealt with them.

\subsubsection{A multi-sited and mobile research approach}

While a longitudinal character accounts for changes over time, a mobile and multi-sited research approach is essential to grasp changes through space. International migration is by definition a process taking place across the borders of nation states. The transnational turn in migration studies, as discussed in the previous chapter, contributed to breaking down methodological nationalism, where the borders of a nation-state define the geographical scope of migration research (Castles, 2007; Wimmer \& Glick Schiller, 2002). In the same vein, Marcus (1995) called for multi-sited research designs incorporating the multiple localities in which migrants' lives are lived. This study contributes to a growing body of literature addressing the linkages and exchanges of ideas, goods and services between countries forged by migrants' exchanges with members of their transnational networks (Mazzucato et al., 2006).

However, the primary research interest of this study is not what is taking place between sending and receiving contexts, but how the trajectories and networks of migrants evolve through contexts provided by various sites. In line with Schapendonk (2011), a translocal, rather than a multilocal research design, was better suited. In a 'trajectory ethnography', as he advocates, it is up to the researcher to follow informants through time and space, not being bound by binary localities of a sending and a receiving context. This study builds on this line of research by letting the data collection depart from migrants' individual trajectories, and not the place they originated from or headed to. Similarly, data collection on migrants' networks is not bound by residence in origin and (potential) destination countries either.

Keeping track of the strategies of the informants required the adoption of a mobile research approach. This entails that I travelled to various places to meet informants, rather than meeting them once at a fixed location. This includes travels within the cities of Athens and Istanbul, where I visited informants in a wide variety of venues (see 3.4.1), but also to neighbouring towns or cities further away. This strategy has several advantages. New migration strategies, changes in networks and the experience of new critical events can be understood in relation to contextual information about the new geographical or social context. Furthermore, meeting informants in various places further contributes to the level of trust and familiarity between the researcher and informants. The approach is also challenging, as it adds to the complexity of the research subject: it is impossible to consider new contextual information that is gathered as the trajectory progresses. Furthermore, the approach is time-consuming and therefore choices to be made on which trajectories to follow in-depth. This potentially leads to a biased selection of trajectories that are rapidly changing in favour of those that evolve at a calmer pace. I dealt with these challenges by selecting cases based on theoretical saturation, where I strived for a diversity of trajectories in terms of pace and types of migration strategies. In order to enhance the process of 
theoretical saturation and deal with complex data gathered through data collection over time and space, I adopted a mixed method design, a third dimension of a research design fitted to study processes of change.

\subsubsection{Mixed methods}

I combined various research methods in the study: participant observation, semi-structured interviews and social network analysis (SNA). Participant observation served to reconstruct patterns of social interaction migrants are engaged in on a daily basis, to investigate how the migration process was socially constructed, and to identify critical events informants encountered. The semi-structured interviews allowed for more in-depth and focused questioning on these subjects, and for informants' own reflection of their migration process, critical events and social networks. SNA identified compositional and structural characteristics of the informants' personal social networks and the changes therein. Each method is described in more detail in section 3.4.

The observations, interviews, and SNA complemented each other in several ways. First, as the different methods sometimes revealed different network members, a complete image of the network could be reconstructed by combining methods. For example, certain network members were not mentioned during SNA, whereas participant observation revealed the presence and crucial influence of some of those members. Interviews then, provided an opportunity to reflect on these differences. It was, however, not required for all methods to lead to the same results; the fact that some network members were mentioned during one method and not the other reveals information about values subconsciously attributed to network members, or underlying motivations not to talk about specific members. Second, creating and discussing the network visualisations enabled the clarification of and reflections on the relationships mentioned or observed. Third, information from one method of data collection was helpful in order to better understand findings retrieved from another. When informants spoke of a certain critical event during an interview, it was helpful to contextualise observations.

Mixing methods was helpful to deal with the complexity of changing trajectories and networks: findings collected through one method could be complemented by using another method (Axinn \& Pearce, 2006). Interpreting and comparing results from various methods implied that the process of data collection and data analysis go hand in hand, which is the fourth dimension of the research design.

\subsubsection{Data collection and analysis: a cyclic process.}

The data collection and analysis were guided by three principles on qualitative research (Boeije, 2005). First was making constant comparisons between different data and theory. The initial data collection phase was informed by analytical concepts derived from theory and the initial research questions: mainly about migration strategies and social networks. As soon as I conducted new interviews or made new observations, I compared these with 
both previous cases and with the concepts. Through this constant comparison, I learned of a third concept essential to understanding the evolution of migration trajectories: critical events. Interviews and observations were increasingly focused on the association between trajectories, networks and critical events. The conceptual framework of the study thus evolved as rounds of data collection and analyses followed each other.

The second principle is that of analytical induction. While the initial rounds of data collection were informed by theory, the data itself also created starting points for finding new patterns. The introduction of some constructs, for example, resulted from new patterns the data brought forward. In this way, the fieldwork continued until a saturation in variation in the association between networks, critical events and trajectories was achieved. This became clear when repetitions of patterns in the collected data emerged. Because analytical induction was only partly used and in dialogue with the literature, this analytical method differs from grounded theory where analytical induction is the primary method of analytical inquiry (Bernard, 2002).

The third principle is that of theoretical sensitivity that connects data with theory to move beyond description and contribute to the building of theory. While studying the data of individual cases, I looked for patterns and mechanisms comparable with or the opposite of patterns in other cases. In this way, I laid the foundation for building the final analytical model.

While rounds of data collection and analysis intertwined and formed a cyclic process, in section 3.4 and 3.5 I discuss the collection and analysis techniques in two separate sections for readability. Before this, I introduce the fieldwork setting and ways of getting access to the field in section 3.2 and the research sample in section 3.3.

\subsection{Case selection and fieldwork setting}

The fieldwork was mainly conducted in two cities: Istanbul in Turkey and Athens in Greece (see Figure 3.1). Turkey and Greece were selected for the study because they form transit migration hubs for sub-Saharan African migrants who are travelling irregularly to and through these countries. Both hubs are characterised by volatile social and institutional structures which incites migrants to regularly adjust their migration strategies. Transit migration hubs are therefore well-suited to study the evolution of migration trajectories. Furthermore, Turkey and Greece are regarded as crucial locations in European migration policy-making processes, making them an excellent case study for how policies affect the evolution of trajectories. 
Figure 3.1 Fieldwork locations: Istanbul and Athens.

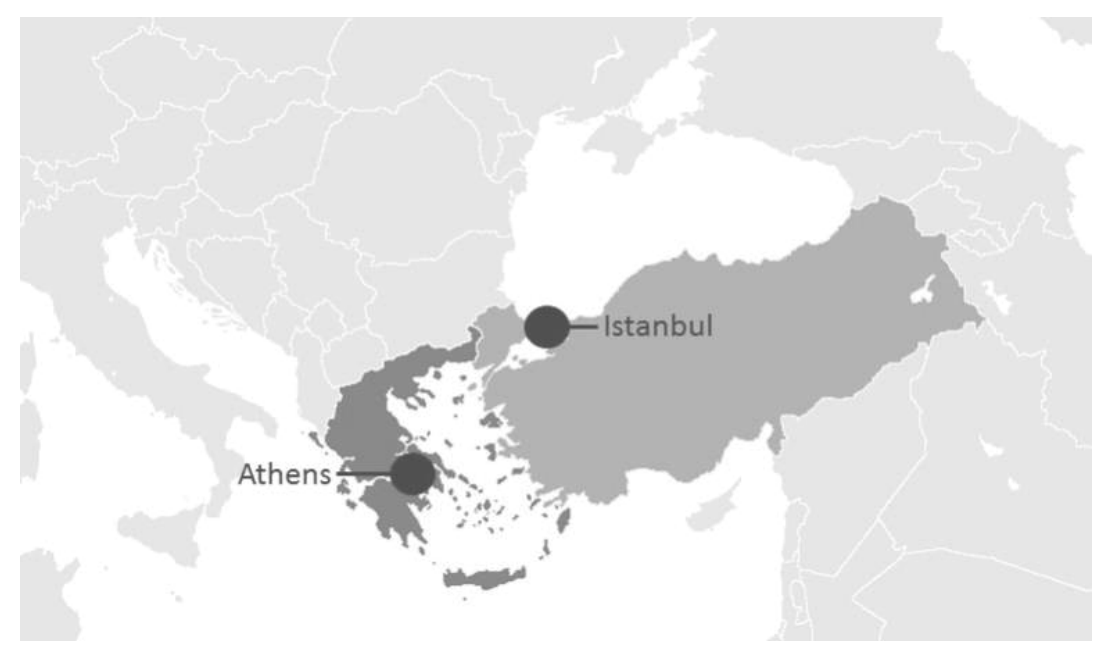

Source: Adapted from Wikipedia, 2017

The fieldwork took place in cities in two countries rather than in one because of the cross-border mobility and networks the study aimed to capture. In most cases, irregular sub-Saharan migrants in Athens travelled via Turkey. Similarly, the possibility of travelling onwards from Turkey to Greece is desired and attempted by numerous irregular migrants in Turkey. Even when migrants in Turkey did not anticipate travelling to Greece, the possibility of doing so, and seeing others do so, largely shaped the context in which their trajectories took shape. This is on the one hand because of the daily arrivals and departures of people, on the other by implementations of border policies and activities of NGOs. Chapter Four elaborates on the history of African migration in the Aegean region and discusses the mobility of African migrants in the region today. In this section, I paint a picture of the migration environment in the two cities, and subsequently how I gained access to the field. Table 3.1 indicates the time spent in each city.

Table 3.1 Fieldwork periods

\begin{tabular}{|c|c|c|c|c|c|c|c|c|c|c|c|c|c|c|c|c|}
\hline \multicolumn{12}{|c|}{2012} & \multicolumn{5}{|c|}{2013} \\
\hline Jan & Feb & Mar & Apr & May & Jun & Jul & Aug & Sep & Oct & Nov & Dec & Jan & Feb & Mar & Apr & May \\
\hline \multicolumn{4}{|c|}{ Istanbul } & \multicolumn{2}{|c|}{ Athens } & \multicolumn{2}{|c|}{ Istanbul } & \multicolumn{2}{|c|}{ Athens } & \multicolumn{6}{|c|}{$\begin{array}{c}\text { Follow-up via } \\
\text { social media / telephone }\end{array}$} & $\begin{array}{l}\text { Athens / } \\
\text { Istanbul }\end{array}$ \\
\hline
\end{tabular}




\subsubsection{The fieldwork setting in Istanbul}

In 2012, Istanbul was home to nearly 14 million registered residents and it constitutes one of the fastest growing metropolitan cities in the world (Istrate, Berube, \& Nadeau, 2012; Turkish Statistical Institute, n.d.). For both internal and foreign newcomers to the city, the district of Kumkapi has historically formed an attractive place to settle, notably because of the central location of the district - close to the old historical centre of Sultanahmet and the harbour -, the availability of cheap housing and the proximity to jobs in the harbour, trading centres and workshops (See for an elaborate analysis of diversity in this neighbourhood: Biehl, 2014). The fieldwork in Istanbul mostly took place in this and in neighbouring districts, such as Laleli, Beyazit and Aksaray. These districts are characterised by trade, informal business and high diversity in terms of ethnic backgrounds. In addition, the modern centre of Istanbul, Taksim, and the areas of Sisli and Mecidiyekoy up north, where higher segment textile traders are located, provided areas for me to meet with informants.

Various architectural characteristics typify the migration environment of the mentioned neighbourhoods, where the fieldwork predominantly took place. In particular in Laleli and Aksaray, the streets are lined with hotel and studio apartments, hosting newcomers to the city and traders and business people that stay for a short time. People living in the area for a longer time also use shared housing facilities, where people have private or shared rooms and shared facilities such as the kitchen and bathrooms (see also: Biehl, 2014; Şaul, 2014). Conditions were often rather bad; I frequently spent time in poorly ventilated rooms, typically with small windows and deteriorating conditions due to humidity. Several informants, ones whom I visited a year later and who had since found more stable jobs, moved to districts such as Fatih and Eminönü, where larger houses in better conditions were available.

In most central streets of the neighbourhoods, call shops and internet cafes determined the street image. Not only are these places to contact people abroad, they also served as meeting points and places to connect locally. Typically, people were standing at entrances, or on the pavement just next to it, to chat and meet with others. This was where the latest buzz, related to work, travel and regularisation opportunities, was shared. Some places were particularly visited by people from a certain ethnicity or nationality; some corners of the street were therefore named after the origin of people, such as "Moqadishu". In other areas, people from various nationalities met altogether.

One feature of the migration environment in Kumkapi was prominent: the foreigner's detention centre, a distinctive white building with visible bars and police officers walking in and out. Despite the severely criticised conditions of the detention centres and the debate it provokes among human right activists and NGOs, the daily life of migrants, including the undocumented ones, continues around the building, seemingly without anyone taking notice. Ironically, the detention centre became a regular meeting point for me and informants.

Because there are many foreigners and internal migrants from Turkey with various ethnic backgrounds, African migrants do not stand out as much as they do in other districts 
of the city. One informant described that when he is in Kumkapi, police officers do not question him as much as when he travels to the other side of the Bosphorus. The relative anonymity in Kumkapi comes with the advantage of engaging in informal (employment) activities, such as trade, home restaurants, working in small sweat shops and street vending. Biehl (2014) notes that because of this, Kumkapi has often been described as a "free zone".

The problematic side of this "free zone" is that rights are not protected or safeguarded, regularly leading to precarious and vulnerable situations. Street vendors were often confronted with seizure of their merchandise by the zabita (municipal guards). Women complained that the only way of finding employment in the sweat shops was through sexual exploitation. Also, racism and ignorance regarding the African continent contributed to a sense of vulnerability. Box 3.1 provides quotes describing how humour often served as a coping strategy for migrants to deal with this.

\subsubsection{The fieldwork setting in Athens}

Athens is the largest city of Greece and had a population of around 665.000 in 2011 (The Hellenic Statistical Authority, 2015). Omonia is to Athens what Kumkapi is to Istanbul: a port of arrival and settlement for newcomers to the city. I mostly conducted fieldwork in Omonia and surrounding neighbourhoods where most informants lived. Instead of the districts names, residents, including informants, commonly used names of various central squares in certain districts to indicate meeting points and to describe areas of residence: Platiou Viktorias, Platiou Kaliatsou, Platiou Amerikis, and Plateia Kipselis, and the street Acharnon.

Whereas the migrant neighbourhoods in Istanbul could, at their best, be described as "free zones", the perceived reality by migrants in the mentioned neighbourhoods in Athens could not be further from this description. The term of "ghetto" more accurately describes the atmosphere in these neighbourhoods. This is, first of all, due to heavily armed police and military officers at the entrance of each street leading into Omonia and some surrounding neighbourhoods. On a daily basis, I observed police officers publicly checking people's documents while they were forced to kneel down. As supported by various reports by human rights based organisations (Human Rights Watch, 2012; Pro Asyl, 2012), some state officials use excessive violence towards migrants in Greece. 


\section{Box 3.1 Humour as a coping strategy}

Ali has the ability to share stories in a very accurate and very funny way. Sometimes tears rolled over my cheeks of laughter. Today he shared various anecdotes.

“I rarely saw such ignorant people [...]. Usually, their first question is: 'Memleket nerede?' [What is your home country?] Then I usually start joking, and I say: Diyarbakir [a Kurdish city in the East side of Turkey]. After this, I ask, in Kurdish, what their name is. I learnt this from Kurdish friends. They react very surprised:

“'Sen Diyarbarkirlisin??' [Are you from Diyarbakir??].

“I answer: 'Vallahi, ben gercekten Diyarbakirdan geldim' [Upon my word, I really come from Diyarbakir] .

"Sometimes I also tell them I am from Mardin, or Urfa. Or I tell them I am from one of Turkey's neighbouring countries, such as Syria, Iran, Iraq. Really, those people have no idea. They have nothing in their heads [...]. The next thing they ask me, is whether I am Muslim or Christian. I always answer the opposite of what they expect. The other day I told someone I was Christian (he signs a cross), but that I know how to recite the Quran. Usually their jaws drop open by then. I tell them: 'I am not even Muslim, but I know the Quran better than you!' And when I say that I am Muslim, they ask me if I pray five times a day. 'Yes', I say, and I really do. And they don't even do that themselves!"

"The other day I saw this elderly couple. The man poked his wife, and it was clear to me he was trying to impress her. He asked me, in English, 'How are you?" So I said, "I'm fine." Upon this the man said to his wife: 'You see, I know their language!' Then the man said: 'Afrika'da yemek yok, degil mi! Yemek yok!' [In Africa there is no food, isn't it? No food!]. He then asked his wife to buy me food [...]. Well, if food was the only thing I needed, life was easy!"

"Sometimes people ask me how I have travelled to Turkey. 'Araba? Araba?' [Car, car?]. When I answer 'ucak' [plane], they burst out in laughter. They think we Africans cannot afford a plane, because in Africa 'para yok' [no money]. As if we fell from the sky!"

Side note: These types of anecdotes, usually shared with tears of laugher, indicate how humour can serve as a coping strategy to deal with their vulnerable and "outsider" position in Turkey. Laughing about the questions informants received helped people to preserve their self-esteem. Informants in Greece, when comparing these types of questions to the anti-immigration climate in Greece, typically reflected on these as a minor, relatively innocent type of racism originating from ignorance about Africa. Yet they give evidence of an underlying social inequalities and vulnerabilities. Some informantsdeemed it the responsibility of migrants themselves to educate the Turkish and Greek societies about their countries' histories and cultures. During the course of the fieldwork, various migrant associations have been founded which included this as one of their (long-term) objectives.

Source: Field notes 16-8-2012. Originally written in Dutch/English/French/Turkish. The informant used Turkish/ French. The notes are rewritten in English, but I left the original Turkish sentences to indicate Ali's switch from French to Turkish. Here, translations are provided in English.

In Istanbul, the migrant neighbourhood provided, for some, a relatively safe area to walk around without facing the fear of arrest. However, in Athens, most people only left their homes when this was required or necessary. The streets in the neighbourhoods where migrants lived were often desolated. Only late at nights, at some central squares, notably Platiou Viktorias, migrants of various background gathered and turned the squares into vibrant areas of playing children and chatting adults. This scene could be quickly 
interrupted when police officers arrived. In addition to violence executed by police officers, supporters of the extreme-right political party Golden Dawn provided a serious threat to migrants' safety. During the time of fieldwork, various marches had been organised by supporters of this party, in which police officers sometimes took part as well, which led to violent confrontations with migrants. Box 3.2 provides an excerpt of an interview with one informant, Tsgaye, on dealing with these conditions in Greece.

There is one district in Athens, Exarheia, which is known as a "free zone" as it is dominated by people who identify themselves as anarchists. Confrontations between anarchists and police had resulted in a situation where the police did not enter the neighbourhood. Migrants were relatively safe there, as they did not need to fear the police. It is also the neighbourhood where the Greek Council of Refugees is located, a prominent actor in providing legal services to asylum-seekers. Receiving legal assistance was, however, largely restricted to vulnerable groups such as families and sick persons because of a limited organisational capacity.

\subsubsection{Additional locations}

While Istanbul and Athens formed the main field locations, I visited various other locations during the period of fieldwork, mostly to meet with informants or migrants I knew who had travelled there. In Greece, I spent a weekend in Vresna, a beach town in the North of Greece. This is where mostly West African migrants head to in the summer to sell products to tourists on the beach, as did one whom I accompanied there. In Turkey, I spent a weekend in the satellite city of Karaman, and in one Ankara, as part of my actions to assist a Somalian woman (not one of the informants) with becoming reunited with her son in the United States (I reflect on my involvement in the field this in section 3.6). I also regularly visited the city of Izmir, where I kept relations with stakeholders such as NGO and UNHCR workers, and migrants because of my earlier fieldwork for my MSc thesis in the city. While visits to other cities in Turkey were not part of following the trajectories of informants, they did provide rich contextual information in which these trajectories could be situated because it revealed the volatility of the migration environment.

In three cases, I met with informants in a third country: two in the Netherlands, and one in Norway. It was beyond the purposes and scope of the study to physically follow people to other countries, and these meetings resulted from unplanned, coincidental events. Yet, they provided an excellent location to hear about the evolution of the migrants' trajectories after their residence in Turkey and Greece, and their reflections of their time in these countries.

\subsubsection{Gaining and sustaining access to the field}

Establishing and maintaining trustworthy relationships with informants was crucial to conduct the fieldwork. The first way to establish contact was my making use of the connections I already had. Before the start of this research, I had already lived and worked in Turkey, and I was still in contact with some migrants and people working in the field 


\section{Box 3.2. The impact of a violent environment.}

In Athens, life is extremely hard, Tsgaye told me. There is no work. He gets by because family and friends in Europe send him money every now and then. His parents do not ask for money, as long as he is safe. But he does not tell them everything, to make sure they don't worry. He said, "If I knew Greece was like this, I would have never come here." Now some Eritrean friends in Sudan ask me about the situation here. I tell them how it is, but since I managed to come here, they still want to try and see for themselves. It is their choice, I can do nothing about it [...]".

He experiences a lot of violence by the police. Several times a week he is arrested, they bring them to a police station, make them wait for 6,7 hours. The police don't even ask questions. Sometimes they only come to shout malaka [asshole], at them, and ask them why they don't go back to their own country. After this, they are taken to the immigration office. They have to line up, and the police make a notion of the number of men and women. Then they let them go again. "It is only for them to show their boss that they are working. Today they caught 10 men and 5 women. We do nothing, but they treat us like criminals."

"When they arrest us on the street, first they ask what we are doing here, and they ask for papers. I only have a white paper [paper indicating people must leave Greece within one month] which they gave me when I arrived. Then they ask for our belongings, we have to give them everything we have, money et cetera. Then they handcuff us. Also people with pink cards [asylum seeker residence permit], they don't care. They beat and kick us, and then we are put in a bus. It is awful. When they do that, I feel like I killed someone, or that I am a terrorist. But I didn't do anything, they just catch people when they are sitting in a park, or in the internet cafe, or if we are walking on the street.

There are many people in Athens using drugs [...]. They think all refugees are drug criminals. As if we have a sign on our forehead that we are carrying drugs. The police themselves carry drugs with them. They put it in our pocket when they arrest us. So they do as if we had the drugs with us. If the police find drugs in a park where we are sitting, we are arrested. But if Greeks are using or dealing drugs, the police sees them, but they don't do anything. The police are afraid of the Greeks and the Albanians. They use their power on us, the refugees. It is very bad, there is no end to it. I start to think about my life. Why is my life like this? I am young, but like this I cannot become 60,70 or maybe 100. I hate my life, I feel awful.

People are shouting to me at the street. People are accusing us of drugs. We are arrested, put to prison. But if someone tries to leave [Greece], they don't let us. Either don't let us in and let us leave. Or let us in and let us live our life. If not, why they don't send us back to Turkey?

Some people go to Patras. You know how people live there? In empty houses, without electricity, without water. A month ago, and Eritrean man died when he tried to get on a truck. People who have lost everything, their final way is to Patras. When they stay there a few months and don't manage, they come back to Athens. When you see their faces, you are shocked. All life is out of it. Nothing is left of them".

Source: Excerpt and notes from an interview with Tsgaye, 30-04-2012.

asylum and migration, in both Turkey and Greece. I was also familiar with the migration environment in both countries, making it relatively easy for me to get around and find new ways of getting to know people who could participate in the study. Relatively new for me were the cities; I had not yet been to Athens and in Turkey I had lived and worked with

migrants in Izmir. However, I knew of a few migrants from my time in Izmir who now lived in Istanbul or Athens. They functioned as gatekeepers and provided the first 'access 
to the field'. With some I stayed in touch over the years, while with others I had contact details or I knew how to reach them via others. Box 3.3 describes how I got back in touch with Yodet, an Ethiopian woman who also participated in my earlier study, twice when she was detained.

I met most informants through encounters in public spaces, such as on the street. This second way of establishing contact entailed that I started a conversation, or that people started a conversation with me. Being a tall, blond, woman, I usually attracted a lot of attention in the neighbourhoods I visited. My appearance even worked sometimes as a conversation starter where people would comment on my height. The conversation could be about anything, such as the surroundings or the activity one of us was involved in. To street vendors, their merchandise was an obvious conversation starter. Soon after getting to know each other, I would explain my reasons for coming to the city, and ask whether they might be interested in talking with me about this.

A third way of getting access followed from the first two ways: through contacts with people I knew, I was able to meet met with others. This happened by being invited to people's homes to spend time and share dinners, participate in events such as gatherings and church masses. Sometimes meeting new people went unplanned and spontaneously, in other cases I asked my informants if they could introduce me to people with a specific profile, notably women from Somalia and West African countries harder to reach for me in Athens. Similarly, I asked my informants in Turkey if they could introduce me to someone who had returned from Greece.

By asking informants to introduce me to others I was able to contact several women. However, contacting women remained difficult in Athens. Additionally, language barriers were sometimes problematic in my contacts with women in Athens, especially when conducting the 'name generator' (see section 3.4.3). I therefore asked three of my informants to act as research assistants, as a fourth way of getting access. I paid them a certain amount of money to help me find informants and translate. Section 3.6 considers the ethical issues involved in hiring informants.

A fifth way I gained access to the field was through contacts with NGOs. This has not been my primary and initial way to establish contacts. First of all, I did not consider it ethical to approach people coming to an NGO for other purposes. Second, selection through NGOs as the only way would lead to a biased selection. Third, selection through NGOs would put additional pressure on NGOs. However, because of difficulties with reaching female informants, I volunteered for the Istanbul Interparish Migrant Programme, where I contributed to the women and children playgroup one morning a week for four months. Here, however, I did not meet with women from the nationalities I aimed to include in the research, as mostly women from Turkey's neighbouring countries participated. I continued to volunteer because of the joy I experienced in doing it, and to learn about the lives of migrants in Istanbul from another perspective. As the fieldwork progressed, some of my female informants started to (re)join the group with their children. They knew about the 
women and children's group independent of me, but they were possibly encouraged to attend in response to my participation in this group.

\section{Box 3.3 Two prison reunions}

In April 2009, Yodet sent me a message from within a prison in the region of Izmir. She was arrested after having tried to leave Turkey by embarking on a small boat to one of the Greek Islands in the Aegean. It took me a few hours to find her in a local jandarme (Turkish military) station, because regular detention facilities for migrants were overcrowded. I introduced myself as a friend of hers, who was about to leave the country and wanted to say goodbye to her. I felt lucky being able to meet her, as well as two other women I had previously met in Izmir. They shared with me that the conditions were bad: they were kept with many women in one cell, most of whom suffered from skin infections. There were no mattresses, pieces of furniture or other objects, except for blankets. They spoke of a woman who miscarried after a three-month pregnancy and was only provided medical care three days later. Sanitary pads were scarce, causing hygiene and health problems when women menstruated. Legal aid was not available, as one of the jandarme officers would also confirm to me, explaining it was not their task but that of the police. The women had no idea what was going to happen. Conditions in the men's sections were worse, the women said. While women could make use of the toilet all day and shower every ten days, men urinated in bottles and were not allowed to take showers. Moreover, the men's cells were so crowded that they were unable to lay down on the floor at the same time. After a one-hour conversation, the women had to return to their cells. While I had a talk with the chief, they and thirty other women were, to my surprise, released. My conversation with the chief of the jandarme was, to say the least, intimidating both psychologically and sexually; he touched my body while holding his hand on his gun and breathing heavily. A few days later I met Yodet again in Istanbul, where she told me about frequent sexual abuse and harassment by the chief.

Like many of my female informants, Yodet had experience with sexual harassment and exploitation. She travelled to Athens in 2011, and could arrange her journey by becoming "a girlfriend" of one of the smugglers (see also for a description of this: Wissink et al, 2013). We had arranged to meet in May 2012 when I would come to Athens for the present research. Yet, via another informant, whom I also knew from my time in Izmir, I learned that Yodet was imprisoned in Athens. She was, most likely, arrested during Operation Xenios Zeus, where Greece arrested undocumented women suspected of prostitution. Again, I went to the detention center where I introduced myself as a friend who did not want to miss the opportunity to say goodbye. Again it worked. This time I was allowed to see her in a visitor's room, where we could speak over the phone and were separated by glass. She could not speak freely of the conditions in prison as she could in Turkey. But here I was able to see and experience some of it; police officers were shouting to visitors, mostly migrants themselves. Yodet was released a few weeks later, after which she introduced me to her life and her friends in Athens.

Source: Fieldwork 2009 (see: Wissink et al., 2013) \& Field notes May 2012

A trustworthy relationship was crucial in order to develop a positive and constructive relationship with the informants. I invested in a trustworthy relationship in various ways. Some were prepared, based on earlier experience, while others I developed throughout the fieldwork. Here I briefly summarise the main tactics:

Being open, clear and transparent: I always introduced myself as a researcher, studying the migration experience of African migrants in Turkey and Greece. As the relationship developed, I would elicit more details about the research design and specific interests. As 
soon as I entered a new phase of my research, such as the conducting the SNA interviews, I shared this with informants. I was similarly open about any doubts or considerations I had, and I sought the advice of informants in how to access people, for example by asking them to think with me why women were harder to reach, and how to build a relationship of trust with certain men without visiting their homes.

Informed consent: Informed consent is crucial to make informants aware of the research purposes they participate in, and what happens with the information they share. As $\operatorname{Sin}(2005)$ has argued, it is more important to adopt a reflexive approach and secure consent before, during and after the research, than to receive written consent to get an approval of an ethics committee ${ }^{2}$. In this vein, I asked people if they wanted to become involved in the study after having introduced the purposes of the study. I verified this at various stages throughout the research. At the time of fieldwork, written consent was not the status quo as it is today. Moreover, it is still better to recommended to get oral rather than written consent in the case of vulnerable populations: often this includes illiterate people for whom written consent has no meaning. Moreover, a signed document stating a person's real name or signature may provide risks regarding the person's anonymity, which is important in the case of irregular migrants wanting to remain undetected by the authorities (See also: Düvell, Triandafyllidou, \& Vollmer, 2009; Van Liempt, 2007; See: World Health Organisation Research Ethics Review Committee, n.d.).

Spending time: The biggest part of the fieldwork was spending time together. This could involve joining people's activities at their work place, or in people's homes. The sensitising concepts of the study (social networks, migration strategies and critical events) were not always the main focus during activities I joined, nor of the conversations I had. Learning Turkish together, shopping, eating, watching a movie, talking about politics contributed to a level of familiarity and the context in which the migration trajectory was evolving. Sometimes the trajectory or social networks only became a conversational topic after a few meetings. This is part of the method of participant observation, which I elaborate upon in section 3.4.1.

No recording: A voice recorder would immediately create a distance between me and my informants. Additionally, given the numerous conversations I had, it would have led to a tremendous amount of text. Instead, I took notes, either during the meeting or after. As mentioned above, I was always open when I wanted to write something down during a meeting or activity. Earlier fieldwork experiences taught me that recording does not necessarily enhance the quality of the data, as people become more aware and conscious of what they say. It furthermore contributes towards a more hierarchal relationship, something I wanted to avoid.

Informant-led conversation: During initial contact or the beginning of a meeting I followed the informants' conversational topics and limited the usage of prompting. I

${ }^{2}$ Which was also not required by Maastricht University at the time of this research 
realised that most people preferred conversation starters wherein they could talk about the present: the country they were in, the activity they were engaged in at that very moment. When the level of trust increased, either the person or I introduced more sensitive topics, such as ways of travelling or future ambitions. Whether or not this was a sensitive topic and how many meetings it took before it was addressed differed from person to person. Some topics remained sensitive for a long period, and sometimes informants would speak about a particular part of their trajectories only after a few meetings. In one extreme case, one informant, with whom I have spent numerous nights, told me a very different account of his story than his initial version (see box 3.4).

\section{Box 3.4 Trust and changing story lines}

I had spent numerous long nights with Ali, discussing religion, politics, life in Guinea and life in Turkey, usually while enjoying a meal of bread, tomato and egg. We got along very well, yet he did not want to talk much about his personal story. I respected his boundaries and did not push. After a few meetings, he mentioned how he had arrived to Turkey and what his initial plan had been:

He left on a boat from Senegal. He thought he was going to Europe, although he did not know what country. After 1,5 weeks on the boat, he disembarked near Istanbul; he was let off from the big ship and put on a smaller boat. He arrived in Turkey, but did not know that. Only after asking local villagers where they were, he realised that he was not in Europe. They took a bus to Istanbul, and there he asked around for the African community. (Excerpt from interview report, 25-02-2012).

However, during our last meeting in 16-08-2013, Ali gave a very different account of his journey. He had come to Turkey by plane with a valid, genuine visa. His migration towards Turkey had been part of a larger migration goal, with another intended destination overseas, far from Europe (which I choose not to reveal the actual trajectory to protect my informants' anonymity). At the end of his story, I thanked him for his trust in me and for wanting to share this with me. He answered: "Tu l'as pris" [you earned it].

A basis of equality: There are several differences between me and the people I wanted to include in the study, such as a (white/European) privilege, as well as a researcher potentially creating a distance or hierarchical relationship. Equality and mutual respect were guiding principles in the contact I established and maintained.

This section has summarised how I gained access to the field and built relationships of trust. Whether or not I subsequently asked someone to become part of the study depended on the selection criteria for the sample, as explained in the next section.

\subsection{The research sample}

The previous section described how I established contact with potential informants. Based on a sampling strategy, I subsequently selected whom to include in the study. The analysis 
is based on the trajectories and social networks of 40 informants, 19 in Athens and 21 in Istanbul. To distinguish between the group of informants and the numerous other migrants I have met, spoken to and kept in touch with, I refer to this group of 40 as the core sample. The next section elaborates on the sampling strategy and the criteria for inclusion in the core sample. The subsequent section presents several characteristics of the informants of the core sample.

\subsubsection{Sampling strategy}

The primary criteria for inclusion in the core sample are theoretically driven. The informants were selected based on the theoretical inquiry of the study, which is the link between migrants' trajectories and social networks. Hence, generalisations made based on this sample are primarily analytic, and not intended to represent the overall population of subSaharan migrants in Turkey and Greece. In order to maximise the chance of variation in trajectories and networks, I applied a selection framework inspired by the literature on the trajectories and networks of various migrant groups. The sampling frame allowed for selection on three levels: 1) region of origin, 2) gender, and 3) migration strategy. A fourth criteria of feasibility was added to maximise chances of following informants longitudinally.

While this study does not assess specific migration flows, a selection was made based on region of origin because migrants with a shared origin tend to share households in Turkey and Greece and live and travel together. This facilitated the immersion in migrant communities during fieldwork. For this reason, the region of origin of informants was limited to three countries in the Horn of Africa (Ethiopia, Eritrea and Somalia), and two countries in West Africa (Guinea and Senegal). Migrants from sub-Saharan Africa were selected as most research on irregular and transit migration in Turkey focuses on migrants from Turkey's neighbouring countries. Migrants from African countries are therefore an understudied group, yet the size of this group warrants the need for research on their migration trajectories and social networks. The selection for these countries allowed me to build further on my previous research and work experience (see section 3.6). Through these earlier experiences, I knew general differences in trajectories and transnational networks between migrants from West and Horn of Africa. By selecting informants from these two very diverse regions, I expected to find variations in the trajectories and networks of my informants.

I further aimed for an equal distribution of men and women in the sample. Several studies have illuminated the importance of gender for understanding migration processes and the networks people maintain (Curran and Saguy, 2001; Kanaiaupuni, 2000).

A third selection criterion was the current migration strategy that someone was pursuing at the time, in order to make sure I included informants whose trajectories took different turns. I considered the migration strategy applied during our first meetings, and the evolution of a person's trajectory until that point. For example, if I were to have already included two male migrants from the West of Africa who attempted to set up a business in 
Turkey, and I were to meet two others of whom one was setting up a business too and the other had applied for asylum, I would approach the latter to become involved in the study. However, it was not always clear what the migration strategy was or how the trajectory had evolved as such. Depending on the confidentiality of the setting of the first encounter, this phase could take a few meetings. Still, sometimes it was not shared with me, or people were not certain themselves of their trajectory or applied migration strategy. It was rather an indication than a 'hard' selection criteria. The trajectories analysed for the study represent many ways, but constitute no exhaustive list of possibilities.

While applying these three selection criteria, I aimed to construct a core sample of informants with maximum variation in their migration trajectories. I continued looking for new informants until I reached the level of theoretical saturation, where I did not encounter new patterns in the data regarding the evolution of trajectories until the point where we met. In addition to the theoretically driven criteria, feasibility was an important consideration. This entailed that it was possible for me to conduct interviews and keep in touch. Informed consent and the willingness to participate was the first and most important aspect (see section 3.6 on ethics). A second aspect was language: I spoke none of the migrants' mother tongues and was only able to converse directly in English or French. For obvious reasons, it was easier for me to get a better understanding of someone's trajectory when we could speak to each other in a language we could both understand. To limit the effect of a biased selection of informants, I purposely included some informants with whom I spoke through an interpreter. In these cases, however, the data collection is less in-depth (see section 3.6 for a reflection on the study's limitations).

My sampling frame differs from common frames in qualitative migration studies that focus on a particular country of origin or migrant typology. First, such a sampling frame would not fit the aims, nor the conceptual grounds on which this study is based. It was not my aim to generalise towards a larger population of migrants, nor to compare two or more groups. I do not contest that, on a general level, the trajectories and networks of, for example, Senegalese and Eritrean may differ. Yet, it was not my aim to illuminate or explain these differences. Instead, I aim to generalise the relation between networks and trajectories in a context of irregular migration.

Second, an inquiry aimed at either explaining the trajectories of a particular group of migrants or making comparisons requires a larger sample size than the methodology of this study allows. If I would have focused on Senegalese migrants only, it would still not have been possible to draw conclusions on "Senegalese migrants in Turkey and Greece". The research design is suited for a relatively small sample size which only allows for generalisations on a theoretical level.

Third, selecting informants based on country of origin underlies the assumption that this macro level factor is decisive for the evolution of migrants' trajectories and social networks. This study instead adopts a micro and subject-oriented approach to investigate what mechanisms help understand the evolution of migrants' trajectories. I believe that 
country of origin affects the outcome of a migration process: it is a fact that Eritreans have a higher chance of receiving a refugee status than Senegalese migrants. Moreover, there is an abundance of literature elaborating on the widespread diaspora of Somalian migrants, facilitating for example the construction of the hawala ${ }^{3}$ system (Lindley, 2009; Horst, 2008). The Guinean diaspora is likely to be different, if only in number. This contextual information is particularly helpful when the aim is to understand why the trajectories of Eritrean migrants differ from those of Guineans. Yet this is not the aim of the present study. Instead of predicting or understanding the outcomes of migration trajectories, I am interested in understanding the process of their evolution. Only in this way can we understand the exception or deviation from what is common: for example, Somalians who do not maintain a transnational network despite the presence of a diaspora, or Senegalese migrants who do apply for asylum. To do so, I looked at personal circumstances and preferences of migrants as their trajectories and networks evolve. Herewith, I moved beyond methodological nationalism, where the nation-state is regarded as the most meaningful distinction in social categorisations (Wimmer \& Glick Schiller, 2003) (see also Chapter Two).

Finally, I did not sample informants based on their legal status or the common categorisations they could be considered part of, such as 'asylum-seekers', 'refugees', 'undocumented migrants' or 'labour migrants'. These categorisations are strongly connoted with certain migratory intentions and entitlements, whereas they are often a mere snapshot at a specific moment in time (see: Wissink et al, 2013). Furthermore, they are often more indicative of the legal framework than of someone's intentions and aspirations. As trajectories evolve, so do categorical labels. Instead, I look at the migration strategy applied at the moment of initial contact to include diversity in the sample, but not to categorise migrants or their trajectories.

As stated in the previous section, I was already acquainted with some migrants in Turkey and Greece through earlier research and work experiences. I involved some of them in the current research project, as it extends the length and depth of the data collection. The previous research project was part of my master thesis, which resulted into the publication of an article (Wissink et al., 2013) to which I refer at several instances in this thesis. My master thesis investigated the mechanisms underlying the dynamics in migratory intentions, of migrants residing in a transit migration hub. It is there that I found hunches that this was related to changing social networks - indeed, my MSc thesis sparked the idea for the research on which this thesis is based. Section 3.6 discusses the ethical and methodological considerations that come with involving informants I knew prior to the start of the current research project.

3 A method of transferring money outside of the regular international banking system. 


\subsubsection{Sample characteristics}

The sampling frame resulted in a core sample of 40 informants. Table 3.2 summarises the demographic composition of the sample. Appendix I presents information on each informant in more detail, providing information on the duration of contact and an illustration of the migration trajectory. I strived for an equal distribution of informants per sub-category of gender and region of origin per city, yet, this deviates in some cases: in Istanbul I included more West African men at a later stage when I was able to contact people who had returned from Greece to Turkey. I included them in the sample as it contributed to the variety of migration trajectories. In Athens, I was unable to include more West African women in the sample and used the available time to invest in trustworthy relationships with three informants.

During the second round of fieldwork in 2013, I interviewed and visited 23 of the 25 informants still residing in Turkey or Greece. For 15 of the 17 informants who I did not meet during the second round, I traced how the trajectory evolved upon their departure. In seven cases, this was because I kept in touch via social media and phone, and in the other eight cases I was informed by network members. I kept in touch with 26 informants beyond the period of fieldwork until the writing of this chapters (and in some cases sometimes beyond this).

Table 3.2. Research sample

\begin{tabular}{l|l}
\hline Istanbul & Number of informants \\
\hline Horn of Africa & 8 \\
\hline Male & 4 \\
\hline Female & 4 \\
\hline West Africa & 13 \\
\hline Male & 8 \\
\hline Female & 5 \\
\hline Subtotal: & 21 \\
\hline Athens & \\
\hline Horn of Africa & 11 \\
\hline Male & 6 \\
\hline Female & 5 \\
\hline West Africa & 8 \\
\hline Male & 5 \\
\hline Female & 3 \\
\hline Subtotal: & 19 \\
\hline Total of informants: & 40 \\
\hline
\end{tabular}




\subsection{Data collection tools}

The mixed method design as described earlier implied that various techniques were applied to collect data: participant observation, semi-structured interviews and social network analysis. These three main techniques for data collection were specifically used to collect information among informants in the core sample. In addition, I was engaged in various other activities during and beyond the period of fieldwork, which endowed me with contextual information about the migration environment. This included volunteer work, meeting with NGO experts and membership of two organisations engaged with refugee and migrant rights. I elaborate on this in section 3.6.

\subsubsection{Participant observation}

Participant observation is a research methodology where a researcher not only observes but also participates in the daily activities of informants. It serves multiple purposes. It is first of all a way to build trust, by familiarising with people and their activities, and a way for them to familiarise themselves with me. This usually meant spending time together, either in daily household activities or joining on visits to friends or the work place. Sharing food was one of the main activities when visiting people in their homes. In many of my informants' cultures, it is common practice to eat together from one big plate on the floor. The hours that passed while jointly preparing food, enjoying it, and cleaning afterwards provided excellent opportunities to get to know each other. Conversations could be about anything, but usually about politics, histories and cultural practices of our countries and everyday experiences in Turkey or Greece.

Simultaneously, it enabled me to see how people spend their time, what dilemmas they encountered on a daily basis, and the people they would spend their time with. Participant observation is helpful in order to understand what remains unspoken during interviews: interaction between people and the places people do or do not visit. For example, some informants did not want to meet me in the city centre in Istanbul or Athens, while others preferred to. Another advantage of participant observation is to reduce reactivity: people change their behaviour if they learn they are being observed (Bernard, 2002). I would not have been able to gather the same information from interviewing and taking notes, creating a distance between me and the informants. Moreover, during interviews people reflect on their own opinions and behaviour, whereas they are experiencing and expressing this in a natural setting when I join activities. This became apparent when events occurred in my presence: receiving news that a family member died, for example, or when they were informed about the result of an asylum procedure. In these instances, I was able to immediately observe how people responded.

As the fieldwork progressed, participant observation increasingly centred on the lives of 40 informants whom I regularly visited in their homes. In Athens, I spent most of my Sundays with mixed groups of Eritrean and Ethiopian women. Box 3.5 describes a typical 
Sunday in Athens. I further accompanied people to various places such as hospitals, NGOs, lawyers, call shops, local authorities, airports, public transport stations, churches and mosques. Furthermore, participation in daily activities of a selected group of informants was also practised by joining them with selling watches and jewellery, working in sweat shops and shopping.

\section{Box 3.5 A typical Sunday in Athens}

Many Eritrean and Ethiopian women in Athens were living as domestic workers and were only free on Sundays. They typically spent half a day in church, joining one or two services, each lasting a few hours. After this, it was time for social gatherings. As Sunday is their only day off, typically many visits are paid on this one day.

Yodet called me few times today, but I missed her calls, I returned to her late afternoon, and she asked me to come immediately to catch up. A friend of hers picked me from the metro station, and invited me to her house. They had prepared injara, which we enjoyed while listing to gospel music on a DVD. They mostly spoke in Amharic, and sometimes translated topics for me: mostly about God, about their work, a friend who did not have money. We left one hour later, to visit another friend who has had a surgery. From there, we went to another friends' house, where about 10 women were enjoying a coffee ceremony. Half an hour later we left, in order to pay respect to a person whose brother had died in Ethiopia last week. When we were on our way, we saw many other Ethiopian women who were on their way as well. In the house, about 50 persons gathered. Friends of Yodet acted as a host. I, nor Yodet, got to meet the person whose brother died. Yodet explained that only being there was sufficient to pay our respects. From an outsider's perspective, it would have been difficult to guess what the occasion of the gathering was. After this, Yodet went to another house to meet other women and pray together.

(Excerpt from field notes 2 June 2013)

These various activities provided occasions to observe and experience types of critical events migrants encountered. Notably in Athens, I witnessed and experienced the violence by state officials towards immigrants at several occasions. When I was in the presence of some of my informants, I as well was ordered to show my ID, and I was questioned about my reasons for coming to Greece. In Athens, I also joined informants in lines waiting to speak with officers of the immigration centre or with NGOs. In this way I regularly observed the difficulty people faced with filing an asylum claim. By spending time, for example, with Senegalese street vendors, I experienced how they navigated through the city, as they sought safe spots to sell, away from the city police.

As I kept returning to the same group of people during the period of fieldwork in a 17-month time period, I observed change in migration trajectories and migrants' social encounters. Through continued participant observation, I observed changes in, for example, housing conditions, social encounters, working conditions and financial situations, and I was thus able to situate changes in trajectories and networks in a larger context. 
Participant observation comes with various challenges and ethical dilemmas related to relationships between me and informants, the gathering and processing of data, and my involvement in the activities of informants. I elaborate on this in section 3.6 of this chapter.

\subsubsection{Semi-structured interviews}

Semi-structured interviews were conducted with an interview guideline (see Appendix II). This guideline contained topical questions on my primary topics of interest: social networks and migration trajectories. In the earlier stages of the research, social networks were only one topic of a longer topic list. As the fieldwork progressed, the role of social networks and the dynamics in networks evolved into the main question of the study. Similarly, as soon as the data revealed the importance of critical events in understanding migrants trajectories and social networks, questions on critical events were added. The interview guideline, therefore, is not a rigid instrument, but a tool used to continuously look for patterns in the data and compare this with new information.

Typically, I reviewed my interview guideline before going to an informant. Sometimes, I would have a look during the interview. I hardly ever kept it in front of me during the actual interview. From previous experiences, I had learned that keeping an interview sheet in front of me would increase the reliability of the data, but that the researcher-informant relationship could be harmed. In that case, the actual paper becomes the focus of attention, instead of the conversation taking place. As I was interested in reflections, opinions, perceptions and memories, the character of a conversation rather than a structured interview was more suited for the information I aimed to retrieve.

The difference between informal conversations during participant observation and the semi-structured interview is that I took a clearer lead in the conversation topic and asked more questions. Depending on how much time there was for the interview, topics were discussed in the order and pace indicated by the informant. Beforehand, I asked the person for their consent in this interview and to take notes during the interview.

The semi-structured interviews were complementary to participant observation and social network analysis (see next section) as it created a venue to ask control and follow-up questions, and to invite informants to reflect on what they have done or said before. As the interview guideline contained questions on the main themes of the study, it served as a reference document for questions to ask throughout the fieldwork. Some topics were discussed elaborately during participant observation, and could therefore be discussed briefly, or omitted during the more formal interviews. The interview setting also provided a venue to discuss my research findings, hunches and queries with my informants. For example, I involved informants in research puzzles I encountered by asking for their opinion or interpretation. I did so, for instance, when most men from Eritrea and Senegal I encountered were Muslim, and most women from both countries Christian. I wondered about a religion-gender nexus in migration trajectories and invited informants to reflect on whether they believed this was the case. I similarly asked for input and advice to deal 
with certain situations, such as whether it was wise or not to visit single men in their homes for interviews or whether it would be better to meet in public places. When I had questions or remarks about the migration trajectory of informants, I asked for feedback to my interpretations of their trajectories and the relation with their networks. As part of the cyclic data collection and analysis process, I often included new pieces of information, ideas and suggestions in the guideline for future interviews.

\subsubsection{Social network analysis}

As Ryan et al. (2008) have argued, in the study of transnational social networks, little attention is paid to diversity in networks and the various sources and forms of support provided in networks. The heuristic value of social networks in migration studies is therefore undermined. In this study, I have built on theoretical and methodological approaches applied in the field social network analysis (SNA), which allows for the investigation of network configurations and the implications for the different resources that are being exchanged in networks. Among others, Mitchell (1969) has laid important foundations for the study of social networks in which grasping and analysing patterns of interaction are key. He, and others that were part of the Manchester School and the Rhodes Livingstone Institute, translated concepts used in mathematical graph theory into concepts that could be used in sociological research, such as the density of networks; describing how "complete" networks are.

Social networks analysis enables the study of social relationships, patterns and implications of these relationships (Wasserman \& Faust, 1994). It is built on the premise that social actors in society do not operate separately from each other, but that social processes arise because of the interactions between them. Social network analyses provide insights to and visualise these interactions through which network structures are discerned that can be analysed (Galaskiewicz \& Wasserman, 1994).

Wasserman \& Faust (1994) have distinguished between four assumptions on which social network analysis is based. First, actors and their actions are interdependent, autonomous units. Second, linkages between actors are channels for the flow of resources. Third, network structures provide opportunities for or constraints on individual action. Fourth, network models conceptualise structure as enduring patterns of relations among actors.

There are several manners in which networks and the interaction between them can be operationalised. In whole or complete social network analysis, the boundaries of the network have been predetermined either socially (e.g. within a family), or geographically (e.g. everyone in a village). In personal social network analysis, networks are open-ended, and the members of the social network (known in SNA as "alters") are bounded by the inquiry and the person's (known in SNA as "ego's") perception of his or her network (Wellman \& Berkowitz, 1988). As elaborated upon in Chapter Two, this study concerns the analysis of migrants' personal social networks. By identifying all the relevant alters of one's social network and the relationships between them, the structure of a social network is unpacked and can be visualised. This provides information on which members of the network are 
connected with each other and thus on how dense the social network is. Network closure theory suggest that denser networks can mobilise resources quicker, and have a stronger incentive for cooperation among network members (Coleman, 1988). Structural hole theory, on the other hand, sees a dense network as a source of rigidity hindering cooperation, also because the mobilisation of resources is controlled by many network members (Burt, 2001). Dense and scattered networks can thus have both advantages and disadvantages for the mobilisation of resources.

SNA also generates insight on the composition of the network: the individual attributes of the alters. With this study, information was gathered on the geographical location of the migrants' network members, their nationality, the relationship (e.g. kin versus non-kin), the means and frequency of contact. That people tend to create linkages with people similar to them is known as the homophily principle (McPherson, et al. 2001). When someone's social network is characterised by high degree of homophily, this person has less access to different resources.

From the above follows that the structural and compositional characteristics of social networks can generate insight in what sources of support are available in the network, and how easily they can be mobilised. Within SNA, a common distinction is made between four types of support: emotional, instrumental, informational and affectional/emotional (House, 1981). For this study, the identification of alters occurred by inquiring about the people with whom the interviewed migrant maintains a relationship in which any of the four types of support is or has been exchanged in relation to facilitating migration strategies and sustaining livelihoods. Literature suggests that different network types yield different supports (Chelpi-Den Hamer \& Mazzucato, 2010). Lubbers et al. (2010) found that highly dense networks account for stronger emotional support, as well as social control, whereas scattered networks yield more different information and privacy is better guaranteed.

A name generator (See Appendix III) aimed to elicit names of persons with whom the informants are engaged in a relationship of giving, receiving, or exchanging the four different types of support in the context of the migration process. Compositional attributes of the listed names (alters) were collected, as well as the connections between them to determine the structural features of the network (e.g. number of ties, density degree, network centralisation, and number of components and cliques).

All social network surveys were completed in 2012, followed by an interview reflecting on the role and importance of individuals and components of the network, which was visualised using EgoNet software (McCarty, 2003). I presented this visualisation to informants to reflect with them on its accuracy, meaning and to obtain more details about the relationships. The social networks and differences between migrants with different sociodemographic backgrounds were analysed using descriptive statistics, but this is, given the small number of observations, only meant to confirm or illustrate the qualitative data. The outcomes of social network survey were contextualised during participant observation and in-depth interviews during which also community ties and ties with people not mentioned 
in the network survey were discussed and observed. In 2013, follow-up interviews were held with 23 informants still present in Turkey and Greece, and with three others, follow-up interviews were conducted elsewhere or via Skype.

\subsubsection{Additional fieldwork activities}

During my residence in Istanbul and Athens, I engaged in various activities with other migrants who were not part of the core sample, but through which I gained insightful information about the context in which trajectories and networks evolve. For example, I was closely involved with the family reunification procedure of a Somalian woman whom I had met years earlier (see 3.6). During my stay in Athens, I met with acquaintances of some of my informants falsely accused of being involved in an internet scam. As their court case was pending, they could not leave Greece, while two aimed to reunite with family members elsewhere in Europe. If found guilty, they faced a prison sentence of about 20 years. Through my contacts with Pro Asyl, a German refugee rights organisation, I arranged for a lawyer who could defend them, and I followed them throughout the process. Later in 2013, I went back to Athens to testify about my knowledge of their living situation during the trial, but the hearing was postponed. Ultimately, the three suspects were acquitted.

I further maintained active contacts with representatives from the UNHCR and NGOs, including Mültecilerle Dayanışma Derneği, The Helsinki Citizens' Assembly, Human Resource Development Foundation, the Greek Council for Refugees, Doctors Without Borders and Doctors of the World. Besides, as a member of Kayiki, a network of people working on migration issues in Greece and Turkey, I participated in various meetings discussing the situation of migrants in both countries. These activities provided me with in-depth knowledge about the institutional constraints and opportunities for migrants in Turkey and Greece. Section 3.6 elaborates on the impact of my involvement in various activities during the fieldwork.

\subsection{Analysis techniques}

The analysis aimed to identify mechanisms guiding the evolution of migration trajectories, changes in social networks and the association between these. In order to do so, I consistently looked for overarching patterns in the data, and associations between them, which formed the building blocks of the final theoretical model proposed in the last chapter of this thesis. The analysis took place during the course of the fieldwork, where rounds of data collection and data analysis interchanged. Yet, as the fieldwork progressed, the analysis moved from explorative in nature to descriptive and explanatory. I used two main techniques during analyses: coding and social network analysis 


\subsubsection{Coding}

The several data collection tools resulted in three types of written material: interview reports, fieldwork reports and social network visualisations. Coding aided the analysis of the former two data types, which I did both manually and by using the software programme Atlas-TI. Coding entails that labels are assigned to text fragments, which refer to the content or interpretation of these fragments. In this way, I sorted and rearranged the data into categories that would aid comparison within and across cases, in order to use them in a later stage to generalise on a theoretical level (Maxwell and Joseph, 2005).

Coding is typically done in three phases (cf. Boeije, 2005). First, open coding, a descriptive way to label the described subject and explore the content of the data. I combined theoretically constructed codes with in vivo coding. The result was a list of codes, with their descriptions and preliminary analytical reflections on it. I did this for a few documents, before moving on to the next phase of data collection. Second, axial coding, where new codes were added, others eliminated. Here, I also clustered associated codes into "code families" to identify the overarching themes and the associations between them. Third, selective coding, where associations between code families are further explored, and to identify patterns that need further refinement and development (Strauss and Corbin, 1990).

While continuing to collect another set of data, I analysed the relations between the code families by studying which codes were assigned to the same text fragments and using the different documents to cross check how these family codes were related in the text. In this phase, I constructed "data displays"; where I drew relationships between (a selection of) the family codes (Miles \& Huberman, 1994). This implied that I looked for patterns in behaviour, relations with other family codes, consulted literature on these topics and compared it to my research question and initial conceptual model to enhance the theoretical coherence. This served develop more matured data displays and matrices. In these displays and matrices, I moved from the question of what is happening to why this is happening. As such, these displays and matrices presented a logical chain of evidence and the dynamics of informant behaviours. The new questions raised in the analysis served as a guideline for the collection of the next set of data. These displays ultimately led to the typologies and models presented in the various chapters as well as the analytical model presented in Chapter Seven. In the presentation of these models and typologies in the remaining chapters, I have selected some cases to show in detail how the models and typologies work. Yet, data collected among all informants was used to develop the typologies and models; during the analyses I consistently checked whether all patterns found in the data could be understood by applying the model and typology I was developing.

While consistently investigating the factors associated with a change in the migration trajectory, it emerged that there was a change in resources, as information or financial means played a crucial role. This finding incited me to look further for the conditions under which these resources change, and this is how the concept of critical events arose from the data. The next phase was the identification of various types of events by listing all the types 
of events that arose from the data. Throughout the analysis, it became clear that not the event itself, but the conditions in which they were embedded, incited a possible change in the trajectory. These conditions are, in part, formed by social networks. Yet social networks are not external factors, moderating the effect of an event; instead, the data showed that networks themselves are changing as well. Events themselves can also affect the network. Scrutinising these mechanisms incited the formation of follow-up questions for interviews and observation. In this way, step by step, various building blocks of the analytical model emerged.

\subsubsection{Social network analysis}

For each informant, I made a visualisation of their network, using the software programme EgoNet. Each individual visualisation portrays the outcome of the social network analysis interview. It displays characteristics of each network member (type of relationship, geographical location, frequency of contact, main mode of contact and gender). It further visualises the connections between each network member. A connection as identified by asking the informant whether the two network members knew each other. This could mean either by having met, or by having established contact via telephone or internet. This generated both information about the network in terms of the people and of relationships, as well as on the structure of the network. In this way I could analyse, for each informant, how scattered or dense his or her network was, and what types of relationships typify the network. Afterwards, I reflected on the network visualisation with the informant to control for any mistakes and additions, but also to see whether it matched informants' own views of their networks. In a subsequent phase, I analysed the network visualisations in relation to the data collected through interviews and field observations. I did this by observing practices that were related to the relationships identified during the social networks interviews and by reflecting on this with the informants. I repeated this process during the second round of fieldwork, where I presented the social network visualisation again and reflected on the current meaning of the relationships, and any changes therein.

In addition to the data provided by individual network visualisations, I aggregated the social network data to gain insights in the variety of the overall network compositions and structures. The outcomes provided hunches on the association between networks and trajectories, and new ideas for qualitative data collection and analysis. For example, the SNA provided insights in, among others, the geographical composition of migrants' networks, and the extent to which they involved kin and non-kin ties. The differences in the geographical network compositions incited me to look for associations with the currently applied migration strategy. Box 3.6 provides an example of how SNA enabled me to find these associations. 


\section{Box 3.6 Getting hunches through Social Network Analysis}

The analysis of the composition of networks resulted in the following findings:

1. On average, the geographical composition of migrants' networks was as follows:

- $35 \%$ of the network members were located in Turkey or Greece.

- $28 \%$ of the network members were located in the country of origin.

- $24 \%$ of the network members were located in the rest Europe (excl Greece).

- $13 \%$ of the network members were located in the rest of the world.

2. $18 \%$ of the relationships network members abroad were established prior to emigration. Relationships with network members are thus mostly formed en route.

3. $22 \%$ of the network members are family members.

These findings triggered the following questions to be explored during new rounds of fieldwork: to what extent have pre-migration and family ties been part of the social network involved in shaping the migration trajectory? What are the reasons for their share being relatively small? What is the role of network members residing elsewhere in the world, and who are less visible during observations in daily lives? By discussing this with informants, I was able to collect information on motivations to maintain or discontinue relationships with people with certain characteristics, for example with family in the country of origin. This resulted in the finding that those who migrated with the intention to return were less inclined to build local networks or networks in Europe. These aspirations are also associated with having few established pre-migration ties in Europe or elsewhere in the world. In situations where informants no longer maintained active relationships with family in countries of origin, I found that certain events had triggered a discontinuation. This prompted me to look for events impacting the continuation of relationships and the mechanisms these events set into motion.

By comparing the locations of network members and the type of relationships (kin/non-kin) with the types of support being exchanged, I found that geographical proximity, rather than a family relationship, was important for the exchange of emotional and affectional support. The analysis further revealed that instrumental support regularly came from abroad, whereas it would be plausible to assume this is more often provided by geographically proximate network members. Again, I followed up on these findings during subsequent interviews and participant observation to better understand the underlying mechanism.

As a last example, I looked into the structural characteristics of the networks and assessed variation in the density, number of components, cliques and isolates in networks. Comparisons with the currently applied migration strategy of informants suggested that informants whose focus was to survive the day rather than to migrate elsewhere had a lower degree of density, more components and fewer cliques. This finding supports the network closure theory, where the mobilisation of resources is harder in networks that are more scattered. This prompted the analysis of the composition and structure in a qualitative manner, where I used interview and fieldwork data to investigate how migration strategies and networks were related. In some cases, migrants had scattered networks because their migration objective did not work out as planned, while others purposely only maintained very specific components as they aimed to realise a specific migration goal. It also occurred that the lack of support prompted a certain migration strategy. Thus, while this cross-sectional analysis does not lead to the identification of a causal relationship between the migration strategy and the network characteristics, it did inspire me to look for underlying mechanisms explaining the multidirectional link between the two. 


\subsection{Ethical and methodological considerations}

The research approach and my background in the field of asylum and migration in Turkey created various ethical and methodological challenges. In this section, I reflect on these and their implications for the validity and quality of the data collection and analysis.

Attrition is a known risk in longitudinal research. Failing to follow up, for example when contact details are lost, or when people move elsewhere, lose interest or lose trust, impedes the collection of longitudinal data. Moreover, attrition is rarely random, as people with certain characteristics or in certain situations are more likely to drop out than others (Axinn and Pierce, 2006). I employed several techniques to diminish the chance of attrition, of which building and maintaining a relationship of trust and continuously securing informed consent were crucial, as well as following up trough social media and telephone calls. As a result, attrition was hardly a problem in this study, as, during the last round of fieldwork, only one informant whom I knew was still in Turkey could not be contacted.

Another challenge in longitudinal research is defining the time needed to grasp the processes under study. Longitudinal research could be infinite, as there is no ending to these processes. Apart from practical considerations such as the time I could invest during the 3,5 years of the research project, theoretical saturation was the leading principle in defining the amount of time needed. Throughout the fieldwork, I developed an analytical model explaining the mechanisms underlying changes in social networks and their association with the evolution of the migration trajectory. Theoretical saturation was reached when new patterns stopped emerging. Two rounds of data collection combined with the possibility to build on earlier contacts with informants dating back four years, and staying in touch for at least two years, was sufficient to achieve this.

Many informants were in rather vulnerable situations: some were busy arranging clandestine border-crossings, struggling to survive, and informants often faced challenges related to regularisation or asylum procedures. Their activities often took place out of sight of the authorities, or in a troubled interaction with the authorities. I studied how and why they are doing this, and how this relates to developments in their own personal social networks. This precarious topic could make people feel uncomfortable or even put them at risk. The anthropological principle of 'doing no harm' was guiding my research activities. I would report no illegal or obscure activity that I witnessed to authorities and will not report any information that can lead to the identification of my informants. Trust, informed consent, and providing a safe interview environment are crucial in preventing harm to happen as a consequence of the information shared through the researcher-informant relationship.

In section 3.2.4, I elaborated on ways I invested in a trustworthy relationship, such as being open and transparent about my goals, and spending time to familiarise with each other and avoiding a hierarchal research setting, as well as not making use of recording devices. Despite my investment in a trustworthy relationship, two ethical issues remain: an asymmetrical exchange of personal information and the informants' awareness of 
being part of a study. While at times I shared personal information about myself, I would sometimes hesitate to divulge personal information or opinions when I believed it could harm our relationship (e.g. during discussions about homosexuality, for many informants a controversial topic). Being in the position of a researcher, I asked many questions during the day, while informants did this to a much lesser extent. To some degree this is a natural consequence of people introducing an outsider to their lives, and possibly because of cultural differences where asking direct questions is not common.

During the semi-structured interviews and the SNA interview, my role as a researcher was clearer than during participant observation. Activities such as sharing dinners, participating in coffee ceremonies, just "hanging out", playing games or listening to music are likely less obviously perceived as research activities in the eyes of informants. During such activities, informants may forget or be unaware that they are participating in a study. Although this is a common challenge during participant observation, I deemed it unethical if informants believed I only gathered information during the more formal research settings, while the other activities seemed just a way of having fun. To secure continued informed consent, I always reminded informants during other activities that it was interesting for my research to get an understanding of how they lived their daily lives. If a relevant story or quote was shared, I asked permission to write it down, in order not to forget. In this way, people always knew I was busy conducting research. I did, however, also share a personal interest in the people I was with and simultaneously indicated that it was not merely for research I was interested in them. A methodological problem with reminding people of my role as a researcher, is that of 'reactivity'. Earlier I discussed that participant observation decreases this risk, but not when I reminded them of my researcher role. I therefore minimised this risk by, even when reminding them of my role, asking open-ended questions in order not to indicate an expected answer. I also asked questions as much as possible in a conversational style to attest to my genuine interest in their lives.

While I regularly took notes during interviews or participant observation, I did not always do this, in order not to jeopardise the relationship of trust and to minimise reactivity where informants would give socially desired answers. Often, I would only write afterwards, but I was open about this to my informants. Writing down afterwards poses a threat towards the quality of the data. After all, I could not remember everything that happened, what I have observed and what has been said. The problem then is a "selective memory", where I was focused on information I was hoping to find (i.e. based on the research design and / or the interview guideline) instead of on what actually occurred in the field. I dealt with this by writing the report immediately after I left, sometimes before reaching home. Furthermore, I only wrote down quotes if I was hundred percent certain that I remembered them correctly; otherwise, I used my own words. Earlier fieldwork experiences (Wissink et al, 2013) taught me that constantly taking notes or recording the interviews would not enhance the reliability of the data because it would frighten informants and increase the chance of reactivity. Thus, although not ideal, this method secured the highest possible quality of data documentation. 
Reflecting with informants on notes I took and checking if my interpretations were right further contributed to the quality of the data.

An important aspect of this study was to follow people over time and across space. However, people who are uncertain about how their migration trajectory will develop might not want to be followed. However, I experienced that throughout the fieldwork, informants continued to update me about any changes or considerations they were making on their own initiative. I believe that because of the high level of trust I secured in my relationships, people felt at ease sharing any development with me on the basis of based on equality and trust. Furthermore, people were generally very eager to respond to my questions and share information about their experiences, also because it provided a way of relief.

Sometimes, informants did not directly respond to my questions about their future plans or relationships with network members. In these instances, I did not push, and respected their indirect answers. It further occurred that throughout the fieldwork, informants gave different accounts of their histories and plans at different occasions. In one extreme case, one informant shared a very different story about his initially anticipated migration trajectory on the last day of my fieldwork (see box 3.4). It is important to note here, that the data retrieved through interviews and observations were not regarded as the objective truth or mistruth. Information provided during interviews was interpreted as "morally adequate accounts" (Jordan \& Düvell, 2002, p. 96), meaning that informants were regarded as knowledgeable and competent actors capable of assessing what information they would and would not share (Cuff, 1980; Jordan \& Düvell, 2002). Triangulation of research methods was an important way to deal with different accounts of stories given at different times. The longitudinal character of the study allowed me further to observe changes in behaviour. By constant comparison of (aspects of) the dynamic stories, I could identify patterns over time. If a single pattern stood out, I tried to explain why this was the case by comparing individual and contextual data to others to enhance the validity of the identified pattern. The continuous investment in a trustworthy relationship also opened the venue to ultimately present a more adequate account of the migration history. In this way, informants shared their stories in different settings, and in different periods of time; therefore, I could control for similarities and discrepancies and as such enhance the quality of the data (Bernard, 2002; Flick, 2007; Miles \& Huberman, 1994).

In some cases I hired informants to act as a connecter and translator. I did so to be able to diversify my research sample as much as possible. Notably in Athens, West African and Somalian women were harder for me to reach because of a language barrier. As I had the budget available for field assistants, I received help with contacting and translation with four informants. I asked informants to act as an interpreter instead of as strangers because of the high level of trust I had secured with them and because of their knowledge of the research methods (notably the name generator and network visualisation). I gave them a financial reward because of the large time investments they made to realise this. In all cases, I had already conducted the SNA with the informants who acted as translators and approached 
them to act as a research assistant months after our initial contact. In this way, I secured a confidential relationship and their understanding of the research approach and purposes. This enhanced the reliability of their translations in favour of other translators I would have to contact and train.

During the time of fieldwork, I received various requests for help and information from informants and others. Through my knowledge of the Turkish, Greek and Dutch asylum and migration systems and that of the EU in general, I constituted a relevant source of information for some of my informants. People asked me, for example, whether it was possible to apply for asylum in multiple countries, and whether an asylum case in Turkey could jeopardise an asylum claim in the EU. Sometimes people would test certain beliefs with me, for example whether refugees in the Netherlands receive housing, or ask me which European country would be the better choice. Besides information requests, people asked me to accompany them to lawyers and NGO appointments, as they deemed the chance of getting assisted higher in my presence. In the same vein, people asked me if I could contact the UNHCR on their behalf, or checking the results of the refugee status determination procedure in Turkey online if they did not know how to do this. In addition to requests, I also sometimes initiated contact with a lawyer or NGO. I did not respond to requests that would require me to disrespect laws, such as accompanying people on planes travelling with forged papers.

The ethical issue at stake here is whether my direct involvement in people's lives could have a negative effect, for example when this involvement was unintentionally incorrect, incomplete or misinterpreted by the informant. Methodologically, the issue is whether my involvement impacts the evolution of one's trajectory by contributing to the decisionmaking process or to realising certain strategies. I dealt with the ethical and methodological challenge by adhering to humanitarian principles; sharing knowledge contributes to an equal and trustworthy relationship from human to human. The establishment and maintenance of a longitudinal engagement makes becoming part of someone's network inevitable. While informants shared their thoughts, doubts and dreams with me, I acted as an active listener where my questions and responses not only provided me with information, but informants with food for thought. In this sense, any researcher effect cannot be ruled out and interventions and assistance from my side could constitute a critical event affecting people's social networks and trajectories. This does, however, not make me unable to less objectively observe these mechanisms. Moreover, my familiarity with the migrant community, which I gained through living and working in Turkey in the field of migration for several years before starting the fieldwork, has had several advantages for this study.

One advantage was that I immediately knew where and how to contact informants. Building on my earlier contacts extended the knowledge of (part of) their migration trajectories and social networks up to four years. While I did not apply the same data collection tools in the early stages of our contact, I knew for many of them how their trajectories had evolved and knew particularities of their social networks. The high level of trust I had secured years before were valuable for the present study: it brought me to places 
commonly hard to visit, such as detention centres (see box 3.3), and it allowed me to collect in-depth information about their trajectories in a shorter timeframe.

I deliberately chose to not involve all my contacts in the sample in order to enhance variation in the trajectories, and I only selected those who met the other sampling criteria. I furthermore excluded cases where I was involved in providing legal assistance. Prior to the fieldwork, I was assisting Somalian woman with reunifying with her son in the United States. I had started this since 2009, and continued in 2012 during my fieldwork. Because of my heavy involvement in her case (e.g. writing to institutions, arranging medical checks and visits to the US Embassy), I did not include her in my core sample. However, this experience provided me with tremendous contextual information about the volatile asylum and migration environment in Turkey. We developed a close relationship, and it was invaluable to hear her insights and reflections on topics I studied.

\subsection{Limitations}

The research design has three main limitations. First, not all informants, and thus their trajectories, were followed over time in similar depth. On the one hand this is, as stated above, due to the inevitable challenge in longitudinal research where not everybody can be traced or reached. On the other hand there was a possible partial self-selection of informants: it was easier to get and stay in touch with some informants than with others and reflect on their migration experiences because of language barriers, personality traits and time. This led to a possible self-selection of informants with whom contact was better preserved. I dealt with this by not only following the "easy leads", and making extra efforts to follow up on others, for example by visiting them in detention, working with research assistants who could help me to reach and talk to people in different languages, and by keeping in touch with people in the network of my informants.

Second, the study included both men and women from both West and the Horn of Africa, and the number of West African women and of Horn of African men is less. While the study did not aim to generalise on gendered patterns or differences between regions of origin, including more West African women and Horn of African men could have led to richer data on the role of gender mechanisms underlying the evolution of networks, trajectories and the experience of critical events. Nevertheless, given the difficulty in encountering and involving especially women from West Africa, this study did include a few of them.

Third, the fieldwork mostly took place in Athens and Istanbul, and while I made occasional visits to other cities, migrants who predominantly resided in these other cities were not part of the study. It might be that migrants residing elsewhere adopt other migration strategies than those living in Athens and Istanbul. For example, asylum-seekers in Turkey are obliged reside in so-called satellite cities, and migrants who attempt to leave Greece by boat typically reside in harbour cities in the West of Greece. I did not conduct 
fieldwork in these satellite or harbour cities, as this would hamper the time-intensive participant observation in Istanbul and Athens. Therefore, I did not observe and talk with people who adopted these specific migration strategies at that moment in time. However, in many cases informants in Istanbul and Athens had lived in other cities before because of the migration strategies they were pursuing there, or left Athens and Istanbul to do so. I have visited some satellite cities, too. In this way, it was possible to include migration experiences in other cities in the analysis of people's trajectories.

Despite these limitations, the research design has enabled the study of the evolution of trajectories, social networks and the association between these. This has been possible because of a longitudinal, multi-sited and mobile approach in which interviewing, participant observation and social network analysis were combined. 



\section{Chapter 4}

\section{Navigating the Aegean: Trajectories of sub-Saharan African migrants in Turkey and Greece}

A slightly different version of the Chapter has been published as: Wissink, M., \& Ulusoy, O. (2016). Navigating the Eastern Mediterranean: The Diversification of sub-Saharan African Migration Patterns in Turkey and Greece. In T. Bloom \& B. Gebrewold (Eds.), Understanding Migrant Decisions: From Sub-Saharan Africa to the Mediterranean Region (pp. 120-138). London: Routledge. 



\section{Chapter 4: Navigating the Aegean: Trajectories of sub-Saharan African migrants in Turkey and Greece}

\subsection{Introduction}

Boubakar flew from Senegal to Turkey, from where he travelled to Greece in a small boat. After a few months in Greece, his parents suggested that he should come back to Senegal, as he had not yet found a job in Greece. Instead Boubakar returned to Turkey. Not just because there were better job opportunities, but also because he wanted to escape the racism he was violently confronted with in Greece.

Filemon, from Eritrea, was recognised as a refugee by the UNHCR in Turkey. Years passed by as he was waiting to be resettled to a third country. His girlfriend, who had been working as a housekeeper in Dubai, joined him in Turkey in 2011. A year later their baby was born. In 2013, when resettlement was still not in sight, Filemon re-established contact with former class mates who now lived in Europe. Together they started an import-export business. With the money they earned he applied for a visa to go to Canada where his girlfriend's cousins lived.

In common representations of migration from Africa, Europe is considered the intended destination and its neighbouring countries as 'transit countries'. These are nourished by images in the media of overcrowded boats and political rhetoric of "influxes" of migrants, which foster the idea that migrants are heading en masse for Europe. The stories of Boubakar and Filemon illustrate that the migration trajectories of African migrants in the Mediterranean Region do not necessarily evolve along straightforward lines following the decision to migrate (Schapendonk, 2011; Wissink et al., 2013). Neither is Europe always the intended final destination. Moreover, their experiences indicate that migratory decisions are not only taken at the beginning of the journey; migration is a process which involves various moments of decision-making.

Numerous persons have nevertheless migrated from sub-Saharan Africa to Turkey and Greece with the aim travelling onward to Europe. Yet, this chapter portrays a variety of other ways in which the trajectories of sub-Saharan African migrants in Turkey and Greece have evolved, notably during the past decade. Boubakar's return from Greece to Turkey and Filemon's on-going residence in Turkey to become an entrepreneur instead of awaiting resettlement are two examples of the various turns trajectories can take. They show that migration trajectories may evolve in various directions, both geographically as well as by means of the migration strategies applied in situ, and challenge common distinctions between categories of migrants that guide policy and research, such as asylum-seekers, 
labour migrants and irregular migrants, which only capture a snapshot of the migration process as statuses and migration strategies can change day by day (Wissink et al., 2013).

The aim of this chapter is twofold: first it describes how a diversification of African migration trajectories has emerged in the Aegean Region (i.e. Turkey and Greece) during the past decade, in terms of the evolution of migration trajectories. Secondly, it argues how this diversification can be understood in relation to three societal developments. The first is a reverse economic development in Turkey and Greece. While Turkey's economy was growing, Greece experienced a severe financial crisis. The second concerns an increase in xenophobic sentiments in Greece, which is expressed in violent public attacks on migrants. The third is a securitisation of migration that is visible in migration policies. A securitisation of migration entails that migration is being framed and debated as an existential threat and a security problem (Huysmans, 2006). Consequently, migration policies are externalised which entails that states deal with migration as much as possible outside of the territory to which it is perceived as a threat. Earlier studies have discussed whether and how securitised migration policy measures have impacted on migration processes, in particular with respect to the effect of border controls on migration flows (Baldwin-Edwards, 2006; Carling, 2007; Kiza, 2008; Pugh, 2004; Spijkerboer, 2007). These studies have shown that these policies do not deter migration but, in fact, lead migrants to choose other, more dangerous routes. In this chapter, I do not merely assess whether migration has been reduced as a consequence of policies, or whether there are any perverse effects. Instead, we assess how a securitisation of migration, along with the other two societal developments, has contributed to a rather volatile migration environment in which a diversity of migration trajectories has emerged. A volatile migration environment entails that opportunities and constraints that are produced by social and institutional structures fluctuate on a daily basis. This creates a context in which migrants have to often rapidly adjust their migration intentions and strategies.

In addition to fieldwork conducted for the present thesis, this chapter builds on three other sources. First, it draws on findings from the project entitled "Border Policies and Sovereignty. Human rights and the right to life of irregular migrants", a research project headed by Prof. Thomas Spijkerboer at VU University Amsterdam, which was coordinated by Orçun Ulusoy, co-author of this chapter. This project aims to analyse the link between border control policies and migrant fatalities at the border. Second, we draw from shared working experience at the Association for Solidarity with Refugees (Multeci-Der) in Izmir (Turkey), and third, from our membership of Kayiki - a network of professionals, activists and academics with the aim of raising awareness and sharing information on migration on both sides of the Aegean.

The chapter is organised as follows. The next section introduces the migration context in Turkey and Greece to and through which migrants from sub-Saharan Africa have migrated historically. This is followed by a description of empirical case studies illustrating the diversity of sub-Saharan African migration trajectories in Turkey and Greece. The subsequent sections 
describe the societal developments, in which we will later situate the diversification of migration trajectories.

\subsection{Sub-Saharan African Migration in Turkey and Greece}

With frequently changing borders and demographics, Turkey and Greece have witnessed internal and international human movement throughout history (İçduygu, 2000). Crossborder migration in this part of Europe is therefore not a phenomenon that has reached unprecedented levels, as political rhetoric and some media images have suggested during the past decade (De Haas, 2008). In the same vein, African migration to and through the Aegean Region is not new. Documented historical relations and human movement between sub-Saharan Africa and the Aegean Region date back to the Ottoman Empire. Several subSaharan African countries, including Sudan, Ethiopia, Eritrea and Nigeria were colonised or befriended by the Ottoman Empire and Greece, fostering migration corridors between the regions (Özkan \& Akgün, 2010; Wheeler, 2011).

The type of migration from Africa towards Turkey and Greece has, however, changed over the past decade. The number of people clandestinely crossing Europe's southern borders to seek asylum or move onward to other European countries has grown since the 1990s (Düvell \& Vollmer, 2009). This rise is commonly associated with more restrictive migration policies that were adopted in the European Union at that time, which made it harder to travel to Europe (De Haas, 2008; Düvell \& Vollmer, 2009; İçduygu, 2000; Joly, 1998). It has been argued that migrants from sub-Saharan Africa who migrated to seek better living conditions, therefore, engaged in alternative migration strategies, such as travelling by small fishing boats, or by hiding in trucks (Carling, 2007; De Haas, 2008). At first, this notably happened in the Western and Central Mediterranean, but when border controls intensified, it shifted towards the Eastern Mediterranean (Brewer \& Yükseker, 2009; Düvell \& Vollmer, 2009; İçduygu \& Yükseker, 2012).

In the little scholarly work that is available on African migrants in Turkey and Greece, it is indeed a common presumption that migrants intend to move on to Northern and Western Europe. Brewer \& Yükseker (2009) argue based on their 2005-2006 study that most African migrants aspire to reach Western Europe. Referring to migrants from Asia and Africa, İçduygu (2003, p. 8) reported that: "the overwhelming majority of migrants intended to stay in Turkey only temporarily before moving on to western and northern European countries." Similarly, Suter (2013, p. 12) notes that most studies on Africans in Turkey depart from "an understanding of a temporarily limited stay", but refers to some more recent studies mention settlement of sub-Saharan African nationals (De Clerck, 2013; Fait, 2013; Suter, 2012a; Wissink et al., 2013). Part of the explanation for the finding that African migrants in the Aegean intend to migrate to Europe can be found in the widely reported malfunctioning 
asylum systems, limited possibilities to regularise, and failure to offer protection in both countries on which we will elaborate later.

While migrants indeed continue to take enormous risks to cross Europe's southern borders, field observations and recent studies give at the same time another image of changing migration strategies of African migrants in this Region. For many, Europe is no longer the intended destination, and business opportunities incite prolonged stay in Turkey, or an entire change of direction, for example to Dubai or China (De Clerck, 2015; Şaul, 2014; Schapendonk, 2015). These various trajectories are presented in the next section.

\subsection{A diversification of migration trajectories}

We distinguish between migration trajectories based on the geographic direction in which migration processes unfold, in order to nuance the common presumptions that migration is commonly directed at Europe. Indeed, migrants continue to aspire to migrate to Europe and numerous migrants take risks to do so. Yet, the examples of various alternative trajectories presented below show that there is a diversity of ways in which they can evolve from Turkey and Greece. The trajectories are exemplified based on individual cases that were encountered during fieldwork and working experience, and not in any way exhaustive.

Trajectory example 1: From wanting to leave Turkey to wanting to stay

Mohamed travelled from Guinea to Turkey with the idea of moving onwards to Greece, and from there to Western Europe. Once in Turkey he realised that in order to travel to Greece, he needed more money than anticipated. Furthermore, from others who already travelled from Turkey to Greece, he understood that he would need to already save money in Turkey before coming to Greece, as in Greece it would be very difficult. Based on this, Mohamed decided to explore possibilities to make a living in Turkey instead. In May 2013, a year after Wissink's first meeting with Mohamed, he no longer aspired to go to Greece. Instead he was in the process of starting his own successful business by assisting business people who had come from West Africa or Europe to Turkey to purchase goods. For now he was content to stay in Turkey. His dream for the future is to live in Guinea and become like some of the traders he assists: living in Guinea and only coming to Turkey to purchase goods and resell them at home.

Mekdes, from Ethiopia, made the choice to stay in Turkey only after she had already tried several times to leave Turkey clandestinely to Greece. Before coming to Turkey she had been living in Syria for a few years where she worked as a domestic worker. At the end of her contract she developed the plan of going to Europe via Turkey, as she believed the chances of finding a job would be higher in Europe than in Ethiopia. Twice she was arrested at the Turkish-Greek border. When she fell pregnant she decided to stay in Turkey. Her partner then successfully started a cargo business in Turkey and Mekdes no longer saw the need 
to take the risk of crossing the border to Greece with a child. Occasionally she works in a restaurant and does not struggle much to make ends meet. She does, however, aspire to leave Turkey if opportunities to regularise her son are not forthcoming.

\section{Trajectory example 2: Reorienting away from Europe and Turkey}

The example of Filemon in the introduction illustrates that migrants are seeking alternative strategies to leave Turkey when resettlement is not in sight. He believed it would be easier to obtain a visa for Canada than for a European country. "Europe? That is definitely over" - said Moussa, from Senegal, as well, while sitting in a living room in Istanbul that was stuffed with merchandise such as bags, shoes, perfumes, watches and jewellery. When we met he was on his way from Senegal to Dubai from where he would continue to China. He only stopped by in Istanbul to meet some of his old friends from the time he used to live there. He had returned to Senegal to start a trading business. Senegal was his base, but for many months he was on the road looking for trading opportunities. In his opinion it is no longer possible to do business in Europe because they do not grant visas. He alleged that it is much easier for Dubai and China. During his stay in Istanbul he was encouraging his friends to do the same.

Not only China, but also other countries are becoming new (intended) destinations for migrants in Turkey. Maryam, from Senegal, intended to go to Morocco. She explained that an acquaintance of hers lives there and sells goods in public spaces without being troubled by the police. Maryam sold goods in Turkey, but her goods were regularly taken by the zabitha; the city surveillance which controls whether street vendors have a license. This happened at least once a week. Maryam has family in Spain: two uncles and their children. She does not initiate contact with them, but when they call she always answers. During our first meetings in 2012 her family in Spain encouraged her to join them. Maryam did not consider this option as she believed it would be easier to sell in public spaces in countries such as Turkey and Morocco. Indeed, the zabitha constitutes a big problem for her, but in Europe it would not even be possible to try, she reckoned. A year later, she said her family now understood she is really not interested in going to Spain, or any European country anymore.

\section{Trajectory example 3: Returning from Greece to Turkey}

Boubakar's story in the introduction is not an isolated case. In 2012, and even more in 2013, groups of returnees from Greece would arrive in Istanbul on a daily basis. Abdu, from Senegal, arrived in Greece in 2007 after having only spent one day in Turkey. After three months in Greece, he found a job in an electronics company where he worked for about 1,5 years, but was fired when the crisis started. He explained that: 
"After the crisis, life in Greece became harder. Before the crisis, the police and the original Greeks were ok. But after the crisis, they caused many problems, and they became racists. Sometimes, the racist people organise themselves. They go inside our community and they shoot. My friend was killed by them. They don't come every time, but you just don't know when they come". (Abdu, Istanbul, June 2012).

As Boubakar, Abdu heard from fellow migrants in Istanbul that conditions were better there, both economically as well as safety and he decided to return.

Safiye, from Somalia, returned from Greece to Turkey as well. She applied for asylum in Turkey in 2008. She wished to be resettled in Norway where her son lived and from whom she was separated about 15 years before, but the Norwegian Embassy rejected her application. Upon this, Safiye decided to travel to Norway by herself. With financial help from her son, she crossed the land border and spent a few months in Greece, where she contacted the Norwegian Embassy, as well. Also the Embassy in Greece could not help her. Next, Safiye tried leaving Greece several times with fake documents, but was arrested each time. One day she reckoned her only chance would be to go back to Turkey, try to reopen her file at the UNHCR that had been closed, and wait for resettlement elsewhere. Safiye took a train to the land border with Turkey and crossed the Evros river which forms the border by foot. She walked through a forest for days and survived by eating wild fruits. Once in Turkey, the jandarme (the Turkish military police) found her and put her in detention. Two weeks later she was released, and travelled to the city where she used to live, and moved back to her old house. She reported herself to the UNHCR who ultimately reopened her case.

\section{Trajectory example 4: Leaving Greece through the Balkans}

Until 2012, common ways by which migrants tried to leave Greece are by plane and boat. Ibrahim from Somalia attempted to leave Athens by plane several times. Almost each time, he was violently confronted with the police who escorted him to a basement where he claims to have been punched in his face, a claim that was made by various interviewees (e.g. Ilyaas). One day, Mohamed decided that he would not want to try and leave Greece again by this means. Instead, he started walking from Greece to Macedonia, Serbia and Hungary. Patrick from Senegal travelled the same route, and described his journey as follows: "I thought I had seen it all when I was beaten at the airport. But that is nothing compared to the mafia you meet in Macedonia. When I was in the woods, I wished I had stayed in Greece."

Osman from Eritrea had tried leaving Greece by climbing under trucks that would be loaded on ships to Italy. He tried applying for asylum in Greece, but his application was not taken. He lived in a forest nearby the harbour so that he could try regularly to climb under a truck. He said during an interview in May 2012: "when I lived in the forest, I felt like a free man. I did not need to worry about paying the rent, or being attacked by someone. Most importantly, when I lived in the forest I still had hopes that one day it would be better". 
One day, he broke his arm and had to return to Athens. A year later, he started walking, as Ibrahim and Mohamed did: through Macedonia, Serbia and Hungary.

\subsection{Societal developments and the creation of a volatile migration environment}

We argue that three societal developments in Turkey and Greece (The Aegean Region) are associated with the diversification of migration trajectories: reverse economic developments, xenophobia in notably Greece, and a securitisation of migration policies. We first describe these developments, after which we reflect on how this has created a rather volatile migration environment. The subsequent section situates the evolution of migration trajectories in this environment.

\subsubsection{Reverse economic developments and xenophobia in the Aegean}

The economic power balance in the Aegean region has taken a remarkable turn during the past decade. Whereas Greece has suffered from one of its severest economic crises since WW II, Turkey has witnessed its largest economic growth. In this section we describe the parallel developments in both countries and relate this to increased xenophobic violence in Greece.

In 2009 a large budget deficit marked the onset of Greece's economic crisis. Since then, Greece has implemented strict austerity measures to be able to qualify for loans. Despite these measures, Greece' debts continued to increase while unemployment rates went up (Kentikelenis et al., 2011; Matsaganis, 2011). Kasimis (2012) argues that the harshened labour conditions have in particular had negative implications for the immigrant population, although Triandafyllidou and Lazarescu (2009) note that, in Greece, migrants' labour conditions have always been harsh. When the Greek court acquitted farmers who shot 28 Bangladeshi strawberry pickers in July 2014, anti-racist groups saw this as another sign of the degrading conditions migrants are kept in in the country (H. Smith, 2014).

The economic crisis paved the way for the electorate to turn away from mainstream parties towards the far-right anti-system and anti-immigrant party the Golden Dawn (cf. Ellinas, 2013). The Golden Dawn aims to radically transform the Greek State by excluding non-Greeks to form a democracy which they define as "[the] state of the demos, that is of the People, made up of individuals of common descent" (Golden Dawn, 2012). Until the late 2000s, the nationalist ideology was not very popular in Greece. Yet, when mainstream political parties lost their legitimacy and Greece faced challenges with managing migration, the anti-systemic profile of the Golden Dawn attracted a relatively large part of the electorate (Ellinas 2013); it received $0.29 \%$ of the votes in 2009 and nearly 7\% in 2012.

Doxiadis and Matsaganis (2012) argue that by 2012, xenophobic nationalism had become the mainstream ideology in Greece. Interviews and observations in the field showed 
what this meant for the everyday realities of migrants in Greece: Tsgaye, from Eritrea, for example explained:

"When they arrest us on the street, first they ask what we are doing here, and they ask for papers. [..] Then they ask for our belongings, we have to give them everything we have, our money. Then they handcuff us. Also people with pink card [asylum documents]. They beat and kick us, and then we are put in a bus. It is awful. When they do that, I feel like I killed someone, or that I am a terrorist. But I didn't do anything; they just catch people when they are sitting in a park, or in the internet cafe, or when are walking on the street." (Tsgaye, Athens, 5 May 2012).

By 2012, migrants did not only increasingly face xenophobic and aggressive behaviour by state officials; most informants in Greece claimed to have faced aggression and exclusion on almost a daily basis. Ilyaas from Somalia, for example, explained how his daughters were banned access from the playground in the neighbourhood by local residents. Yodet, from Ethiopia, explained that access to the church was prohibited when Greek flags were drawn on the tiles in front of the entrance. The loss of a friend in a racist street rally was for Patrick a main reason to leave Greece. Indeed, Human Rights Watch (HRW) (2012) reported various accounts of violence against immigrants where groups of people used bare-feet or bottles as weapons in public attacks. The HRW further found that the police failed to effectively protect victims and bring the perpetrators to justice (Human Rights Watch, 2012).

Contrary to Greece, Turkey has experienced a strong economic growth during the past decade. This is expressed in a nearly doubling of the GDP since 2002, and a steep decline in unemployment figures (World Bank Commission on Growth and Development, 2009). Moreover, Turkey has drawn the attention of international investors, expressed in Turkey's first investment-grade credit rating in two decades (Peker, 2014). The growing economy and expanding investment climate in Turkey has gone hand in hand with an expanding informal economy, mainly in the trade, textile and cargo sectors. Working opportunities in trade and petty jobs for migrants have risen as a consequence (Şaul, 2014; Schapendonk, 2013). An increase of $68 \%$ in the granting of working permits to third country nationals further points to improved employment opportunities in Turkey (Toksöz, Erdoğdu, \& Kaşka, 2012).

Seen from an economic perspective the developments in Turkey seem positive. Yet, from a human rights perspective there is much to be desired. Working conditions in informal petty jobs are challenging, and migrants are prone to exploitation (Toksöz et al., 2012). During the fieldwork, notably women, but not exclusively, gave frequent accounts of sexual exploitation on the work floor. In Istanbul, informants indicated that sexual intercourse with sweatshop owners was in fact the only entrance to finding employment. Furthermore, the expansion of the informal labour market mostly concerns Istanbul, and to a lesser extent Ankara and Izmir. Asylum-seekers and refugees residing in satellite cities (see section 4.4.2) continue to have much fewer opportunities to benefit from economic development. 
Many have therefore travelled to Istanbul, Izmir and Ankara in order to participate in the informal economy. While this jeopardizes their asylum procedure or resettlement process, it enabled them to become self-reliable and provide for their families both in Turkey as well as elsewhere. The informal economy does not only attract migrants residing on other towns in Turkey: it is also draws attention from migrants in Greece. First, because there was hardly an informal market remaining and because of growing xenophobic violence migrants hesitated to leave their house and look for remaining opportunities. Second, informants have pointed out that they are aware of fewer opportunities for informal market opportunities in other European countries through their social networks, as Maryam pointed out in her argument for not wanting to go to Spain.

\subsubsection{The securitisation of migration in the EU, Turkey and Greece}

It is a widely accepted view in scholarly literature on migration and asylum in the EU that European public policies are characterized by a securitisation of migration (Buonfino, 2004; Huysmans, 2006; Léonard, 2010; Marcelino, Ferreira, \& Mazzagali, 2016; van Munster, 2009), although critical views are put forward, too (Boswell, 2007). Securitisation means that migration is being framed in political and societal arenas migration as a threat to security issues, which is expressed in policy measures that are aimed at deterring migration (van Munster, 2009). In this section, we first briefly describe what this entailed in the European Union, and then how this has impacted on the migration systems in the Aegean Region. The type of migration we are referring to is irregular migration; policies on other forms of migration, such as high skilled labour migration, are less often regarded from a security perspective (although it could be argued that the distinction between "wanted" and "unwanted" migration is in itself a manifestation of the securitisation discourse).

The securitisation of migration in the $E U$

Notably in the early 2000s, the management of irregular migration in Europe and at its external borders had become a controversial topic in political and societal debates. The securitisation process gained momentum after 9/11 2001 and the Madrid and London bombings on $11^{\text {th }}$ March 2004 and $7^{\text {th }}$ July 2005, respectively, when migration became associated with terrorism and criminality (Neal, 2009). Yet, the need for greater legislative action regarding the external borders and the treatment of third-country nationals is also analysed as a consequence of the abolishment of the internal borders within the EU, and the decision to develop an Area of Freedom, Security and Justice (AFSJ) (Cardwell, 2013; European Council, 1999).

FRONTEX was established in 2004 to coordinate external border management. Among its activities are the assessments of the 'risk' of migration towards the EU. Marcelino et al. (2016) argue that the framing of migration as a risk is a demonstration of securitisation. This was also concluded by Léonard (2010), who further demonstrated that FRONTEX constitutes securitising practices by conducting activities that are traditionally used to tackle 
security issues and extraordinary measures, such as the training of national border guards, the coordination of joint surveillance and control and joint return operations.

Policies with respect to irregular migration and asylum policies are further securitised in the EU by the establishment of EUROSUR in order to coordinate surveillance at the maritime borders; the signing of readmission agreements by which undocumented thirdnationals can returned to neighbouring transit countries and countries of origin; and the creation of mobility partnerships where development funding was exchanged for measures preventing irregular migration (Bloom, 2016).

\section{The securitisation of migration in Turkey and Greece}

Our analysis of the securitisation of migration in Turkey and Greece starts from the observation of three shared characteristics of migration systems in both countries: a) they are based on a national security approach $b$ ) the development of policies follows a reactive instead of a proactive rationale, and c) they operate in the shadow of the EU. The first two have been shaping the migration system since the establishment of both countries, while the EU has predominantly been leaving its mark on the migration systems in the Turkey and Greece since the past 20 years.

The national security approach in both countries can be explained by their history of nation-building (Cizre, 2003; Karaosmanoğlu, 2000). While Greece declared independence from the Ottoman Empire in 1822, the First World War (1914-1918) and the Greco-Turkish War (1919-1922) shaped the borders and international relations of present day Greece and Turkey. One of the most defining events for the process of nation-building in both countries was the population exchange between Turkey and Greece, which followed the Convention Concerning the Exchange of Greek and Turkish Populations, signed in Lausanne on 30 January 1923. The exchange involved the expulsion of Anatolian Greeks to Greece, and Greek Muslims to Turkey (Long, 2008). Clearly, by the forced population exchange, national security concerns were separated from human rights (Long, 2008). Because of the "un-mixing of peoples" (Long, 2008, p. 10) key political figures considered the exchange as a contribution towards "long-term stability of the Aegean through the nationalisation of political power structures and thus the exclusion of difference" (Long, 2008, p. 10, building on Barutciski, 2003). The 'successful' execution of the Treaty of Lausanne thus paved the way for both governments to implement reforms for the nation building process, without the threat of internal minorities, or external interventions related to their protection (Oran, 2007; Pentzopoulos, 2002).

Related to the national-security approach is the reactive way in which both countries develop migration policies (Triandafyllidou, 2012). For the past two decades, main migration policies were realised only after unanticipated arrivals of migrants. In Greece, the first law on immigration was implemented in 1992 to address the irregular migration flows from Albania (Triandafyllidou, 2012). Almost simultaneously, Turkey faced a humanitarian crisis at the southern borders when hundreds of thousands of Kurds fled from their homes in Iraq 
to escape Saddam Hussein's threats (İçduygu, 2000). Until then there was an absence of legal instruments and policies on migration, but the sudden political and humanitarian crisis forced Turkey to issue the first regulation on migration and asylum in 1994 (Kirişci, 2000).

We argue that the reactive, rather ad-hoc, migration policies in Turkey and Greece stem from a political gap that was created on purpose to deregulate migration, in particular irregular migration. As argued above, migration is in both countries closely connected to national security concerns (Oran, 2007). Therefore, the management of migration was left to bureaucratic elites and security forces, such as police or coast guards. In the absence of asylum and migration legislation, their responses to the arrival of migrants would not be bound by existing regulations and hence not be held liable. This legal vacuum enabled the prevalence of human security concerns over human rights concerns.

The national security based and reactive approach in both countries was sustainable until the 2000s. While the irregular migration flow from Africa and Asia to Europe via Turkey and Greece already existed, until then the relatively low numbers meant that the situation was under control. However, with the changes in EU migration policies, the migration system in the Aegean Region became the subject of international migration policy making. As a consequence, migration in the Region became regulated following a logic of securitisation.

The logic of securitisation in the Aegean migration system is visible at three levels: EU intervention, Turkish-Greek bilateral relations, and national Turkish and Greek asylum and migration policies. Late 2010, Greece called upon the EU for assistance with protecting its borders. The original Regulation $2004 / 2007$ by which Frontex was established was amended, to be able to employ rapid border intervention teams (RABIT). These teams consisted of border guards from all Member States which could be rapidly employed to provide operational assistance to Member States "facing a situation of urgent and exceptional migratory pressure" (European Commission, 2007, p. 3) The RABIT operation was followed by Operation Poseidon, and Poseidon Sea in 2013, to further "[combat] illegal migration flows from Turkey and North Africa towards Greece" (FRONTEX, 2014a np.). Border control in the Turkish-Greek border region was further strengthened in 2013 by EUROSUR providing surveillance technology, such as drones and night-vision cameras.

One way in which Turkey and Greece have strengthened cooperation on the bilateral level was by implementing a readmission protocol. This had already been signed in 2001, but was put into effect in 2010 as a response to increasing numbers of migrants crossing the Turkish-Greek border. İçduygu (2011) calculated ${ }^{4}$ that between 2002 and 2010 2,425 migrants were readmitted by Turkey, yet in 2010 both countries agreed that Turkey would take up at least 1000 migrants per year. The first group of 30 migrants was readmitted by Turkey in 2010. At that time we (Wissink and Ulusoy) worked in for a local $\mathrm{NGO}^{5}$ in Izmir, to where the readmitted migrants were brought. The planned readmission centre had not yet

\footnotetext{
${ }^{4}$ Based on statistics provided by the Bureau for Foreigners, Borders and Asylum, at the Directorate of General Security of the Ministry of Interior of Turkey.

5 Mültecilerle Dayanışma Derneği; www.multeci.org.tr
} 
been established (see also: Crépeau, 2013). Furthermore, we received testimonies from this group of migrants claiming that Greece reported them as Syrian, whereas in fact only 3 were. Considering that Turkey has a readmission agreement with Syria, a readmission protocol between Turkey and Greece could lead to violations on the non-refoulement principle, where persons in need of international protection are returned to Syria. Turkey has also approached African countries, including Sudan, Ethiopia and Nigeria to sign readmission agreements, which implies that the non-refoulement principle could become at risk in the future for African migrants as well (Dervis, Emerson, Gros, \& Ülgen, 2004).

Besides the readmitted migrants, several NGOs have reported the systematic occurrence of 'push-backs', where persons are being returned to Turkey from Greece without court decisions or formal agreements between Turkey and Greece, and "that they were not afforded an opportunity to request international protection or to challenge their illegal removal" (Pro Asyl, 2013, p. X). These push-backs are often violent, of which the incident in the Greek island of Farmakonisi in January 2014 during which 12 persons died is a tragic example (Pro Asyl, 2014).

On the national level, action plans were drafted in both countries to strengthen external borders and asylum systems. For Turkey this was done in the context of the TurkeyEU Twinning project on Integrated Border Management (IBM) which commenced in 2010 (Pierini, 2010) and meeting the European acquis in admission negotiations. The IBM project distinguished between the challenges of creating "open borders" for people and "secure borders" to diminish crime, and by regarding irregular migration as a common interest to be "tackled" by the EU and Turkey (Pierini, 2010).

Turkey has adopted its first law on undocumented migrants and asylum-seekers in 2013, which was put into effect in April 2014. Until then, and thus during the time of fieldwork for this study, the migration and asylum system in Turkey was regulated by policy directives which lack legislative power. Although Turkey has ratified the 1951 Geneva Convention on the international protection of refugees, it applies a geographical limitation such that nationals from non-European countries cannot receive refugee status and permanent residence in Turkey. With the adoption of its first asylum law, Turkey did not lift this geographical limitation. As before, the UNHCR will continue to assess the asylum claims of non-European asylum-seekers and request their resettlement to third countries (e.g. the United States and Canada). In reality, only a small percentage will eventually be resettled (Blaser, 2014). During the asylum procedure carried out by the UNHCR, asylum-seekers are obliged to reside in one of the 50 'satellite cities' - normally rural towns where normally no accommodation is provided and asylum-seekers are not allowed to work.

In June 2012, Turkey offered the opportunity for visa over-stayers to obtain a 6-month residence permit after paying a fee and a penalty ${ }^{6}$. Migrants who applied for this claimed to have been instructed by police officers to return to their countries of origin to be able

${ }^{6}$ Based on policy circular 37 issued by the Ministry of Interior dated 07.06.2012. 
to renew their visas upon return. This seemed to be a widespread belief among migrant communities, although no formal instructions have been communicated by the Turkish authorities. In December 2012, this residence permit turned out not to be renewable, and was therefore perceived by many as a way for the Turkish government to collect money and expel migrants.

Greece implemented several measures aiming to stop irregular migration towards and within Greece, including operation Aspida that deployed police officers and equipment to the Evros region, and operation Xenios Zeus that focused on "inland detections of illegal stays and their return" (FRONTEX, 2014b,np). The rhetoric used by Frontex to describe this mission points out a highly securitised and criminalised approach towards migrants in Greece. Greece further attempted to protect its borders through the establishment of a 12 $\mathrm{km}$ fence along the Evros River. Because this only covers $10 \%$ of the border, Tsitselikis (2013) analyses this as a response to a "xenophobic audience" in Greece, rather than as a measure to curb migration. It nevertheless indicates Greece's inclination to deter irregular migration.

Greece has a legislative framework to assess asylum claims and host non-European refugees in accordance with EU law, yet, it is largely dysfunctional. In a court ruling by the European Court of Human Rights, Greece was found to be a country where asylum-seekers face inhuman and degrading treatment ${ }^{7}$. Most Member States, therefore, do not return asylum-seekers to Greece despite the Dublin Regulation in which Members States agreed to return people to the first country of arrival in the EU. In 2012, Greece had a backlog of 45,000 asylum applications, whereas it is almost impossible for new asylum-seekers to file an asylum claim (Human Rights Watch, 2013). During the time of fieldwork in 2012-2013, it was observed that hundreds of people queue up for days in front of the Immigration Office in Athens, where once a week only about 20 applications are taken, seemingly in a random way. They wait their chances on a road in an industrial area, lacking basic facilities such as benches, sanitation or shelter from the sun (see: Kehayioylou, 2012).

In conclusion, whereas migration in Turkey and Greece has always been a security issue, their responses towards migration flows had been purposefully left to the discretion of bureaucrats. However, when the Turkish-Greek migration context became an object of European security concern, migration policies, including asylum and border policies, became regulated. To maintain the valued protection of national security concerns, this regulation followed the logic of securitisation that was already prevalent in the EU.

\subsection{The creation of a volatile migration environment}

The reverse economic developments, the widely present xenophobia and the securitised migration environment contribute to a volatile migration environment in various ways. First,

\footnotetext{
7 M.S.S. vs Belgium and Greece, European Court of Human Rights (ECtHR) Case no: 30696/09 Judgment Date: $21 / 01 / 2011$
} 
opportunities to find work could change on a daily basis, due to labour market competition, a deterioration or improvement of working conditions, and by work opportunities such as selling spots, small boutiques, cargo businesses and domestic work places that were disappearing, emerging or being threatened by anti-immigrant actions from other residents or authorities. Second, the xenophobia and anti-immigrant policies in Greece contributed to a highly restricted area for free movement: many informants only left their houses in case they really needed, or when they relatively felt safe in the company of others. This diminishes the chances for social interaction and the maintenance of relationships beyond the household. In Turkey, too, many informants did not leave the areas in which they lived in order to avoid confrontations with the authorities. Third, opportunities to travel and regularize were highly fluctuating, either by the adoption of new policies, or by random implementations thereof. For example, sweep operations in public spaces could be followed by regularisation rounds; arrests could lead to imprisonment of hours, days or years; borders could be severely controlled on one day, and not on another. Fourth, these conditions have incited people to redecide on their migration motives, as well as their opportunities to be mobile or immobile. As a consequence, a context of "temporal" migration emerges where many people depart and arrive on a daily basis.

The migration environment in both Turkey in Greece for irregular migrants is thus characterized by rather volatile social and institutional structures. This, as will be analysed in the subsequent chapters of this thesis, is expected to contribute to a the emergence of rather non-linear evolution of migration trajectories.

\subsection{Navigating the societal developments in the Aegean Region}

From the reviewed studies and the field work the image emerges that until the late 2000s, most migrants from Africa (and elsewhere) perceived both Turkey and Greece as transit countries on their way to Western and Northern Europe, either through own arrangements or resettlement programmes. The reversed economic developments, xenophobic violence, and securitised migration policies have reshaped opportunities and constraints for migrants in terms of their geographic mobility in the Region. Migrants navigate these opportunities and constraints by rethinking migration goals and strategies. As they do so in various ways, a large variety in migration trajectories has emerged in the Region.

The reversed economic developments in both countries have incited new preferences and options concerning moving to or staying in Turkey and Greece. In Turkey, the economic growth has, for some, created the opportunity to gain an income with business activities, notably in the cargo and textile business. While some have accordingly adapted their original migration goal of travelling onwards to Europe, for others moving on was no longer necessary to realize their initial migration objective to set up a business. For some, the growing business opportunities in Turkey provided a reason to return from Greece. As these 
opportunities were mainly unfolding in Istanbul, also migrants residing in satellite cities were drawn to the city. In particular prolonged stays in satellite cities without the opportunity to work and no resettlement prospects incited migrants to pull out from the asylum procedure and reside in Istanbul instead. Changing economic opportunities and constraints in Turkey and Greece as such impact on original migratory goals, as well as on available financial resources to pursue desired migration strategies.

Strengthened border controls between Turkey and Greece, and between Greece and its bordering countries have resulted in higher apprehension risks and increased smuggler's fees. For migrants in Turkey, this often implied that more funds had to be mobilised and higher risks to be accepted in order to leave Turkey. As in Greece the economic situation was worse and xenophobia widespread, for many the incentive to mobilise more funds disappeared. At the same time, a permanent state of limbo in Turkey made that for some the challenges foreseen in Greece were acceptable, if only because there was still a chance of individual success.

For migrants in Greece, the securitised borders entailed that leaving the country by air or boat was increasingly challenging. Nevertheless, nearly all migrants we spoke to aimed to leave Greece, including migrants who had stayed in Greece for up to 20 years until the crisis broke out in 2008. Intended departure from Greece was commonly incited by a perceived inability to maintain a livelihood and find protection in Greece due to economic hardship and xenophobic violence. Two types of trajectories have emerged as such: migration over land via the Balkans and return to Turkey. The Balkan-route is experienced as extremely dangerous: several migrants we spoke to claimed that if they had known the dangers in advance, they would have stayed in Greece and accepted living in fear of violent attacks and remaining undocumented instead. Return to Turkey is a recent phenomenon that to our knowledge has not yet received attention within scholarly literature. It was remarkable that whereas migrants in Istanbul spoke rather critically of the local residents in the neighbourhoods where they lived because of their perceived ignorance of foreign cultures, migrants in Greece remember the residents of the same neighbourhoods as tolerant, welcoming and open-minded.

The societal developments have created a volatile migration environment, yet, they do not determine or predict migrants' ways to navigate these. Which of and whether these developments are decisive in re-deciding upon migration strategies, varies among persons and their personal circumstances. It was beyond the scope and purposes of this chapter to discuss individual decision-making processes, which will be further scrutinised in the remaining chapters. The findings suggest, however, that migrants are not deprived of agency in reacting and acting upon opportunities and constraints created through the societal developments. For some, the outcome of having to navigate securitisation effects is more positive than what was originally anticipated, for example when business opportunities unfold in Turkey after attempts to cross the border to Greece were in vein. 


\subsection{Conclusion}

For the past decade Turkey and Greece have constituted one of the main entry points of irregular migration to the EU. While today numerous migrants from sub-Saharan Africa and other continents continue to intend and travel this route, recent societal developments have largely reshaped the context in which African migrants in the Aegean (re-)decide upon their migration trajectories. The developments we described in this chapter concern a rise in xenophobic violence in Greece, a securitisation of migration policies, and reversed economic developments in Turkey and Greece. These developments bring about opportunities and constraints for the way trajectories evolve. As migrants respond to these in various ways, a diversification of migration trajectories has emerged, where in fact some are returning from Greece to Turkey, some are choosing to reside in Turkey instead of migrating to Europe, and others aim to migrate elsewhere or engage in new routes out of Greece.

The findings have illuminated the migratory decision-making process is ongoing and is based on earlier migration experiences and ways to combat risks, knowledge and available resources. Also, developments in other life domains, such as the birth of children, shape the continuation of migration processes. These factors are highly associated with migrants' personal social networks. Thus, in order to understand how exactly migrants navigate the volatile migration environment as their trajectories evolve, the subsequent chapters will analyse the nature of migrants' networks and how these are associated with how migrants' trajectories evolve.

This chapter analysed the link between migration trajectories and regional societal developments, but a diversification of trajectories naturally arises in interactions with constraints and opportunities that unfold beyond the Aegean. This is especially so for the observed pattern where migrants in the Aegean reorient from Europe and Turkey, notably to the Middle and Far East. Also developments in countries of origin, such as the increasingly widespread awareness of the realities of migration in Europe, influence the creation of new trajectories.

Restrictive migration policies are often aimed at discouraging and deterring irregular migration, and evaluations of policy are concerned with the question whether this is achieved or desired. The diversification of migration trajectories shows that migration needs to be conceptualised as a process, rather than as a straightforward movement from one country to another that can be stopped or deterred; decisions are often taken on the spot, where current opportunities and constraints are guiding the continuation of the migration process. It furthermore challenges common distinctions between migrants based a currently applied migration strategy: irregular versus labour migrants versus refugees and asylum-seekers. While navigating societal developments, migrants can be or become all as their trajectories evolve. The conceptualisation of migration as a process will generate new policy and research questions. Instead of asking only why migrants move from one place to another, it raises the question of by what mechanisms and under what circumstances 
migrants re-decide upon routes, intentions and strategies. This will ultimately yield more in-depth insights in the shaping of migration processes. 



\section{Chapter 5}

\section{In Transit: Changing Social Networks of sub-Saharan African migrants in Turkey and Greece}

A slightly different version of this Chapter has been published as: Wissink, M., \& Mazzucato, V. (2018). In transit: Changing social networks of sub-Saharan African migrants in Turkey and Greece. Social Networks, 53, 30-41. https://doi.org/10.1016/j.socnet.2017.03.005 



\section{Chapter 5: In Transit: Changing Social Networks of sub-Saharan African migrants in Turkey and Greece}

\subsection{Introduction}

Early 2009, one of us met with Senait, an Eritrean woman in her late twenties, while she was in-between attempts to clandestinely cross from Turkey to Greece by boat. At that time, she kept her family in Eritrea and Europe well informed about her journey. Over the following years we regularly met and kept in touch with Senait. When in 2012 we met in Athens, Senait had changed her communication patterns. She was no longer in touch with her family abroad. She would not respond to their phone calls and she had closed down her Facebook account in order to avoid contact. Yet a year later, while still in Athens, Senait's ties with her family and friends were restored, while her local network in Athens had been changing on a weekly basis. Essentially, over this five-year period, Senait's social network underwent considerable changes. This paper explores why changes occur in the social networks of irregular migrants residing in transit migration hubs in Turkey and Greece. In particular, we analyse migrants' transnational social networks, that is, networks composed of relationships that are created and maintained beyond the borders of nation-states (Bilecen et al., 2018; Glick Schiller et al., 1995; Mazzucato, 2004; Vertovec, 2004).

The literature on migrants' transnational social networks has highlighted the crucial role transnational social networks play in inciting and facilitating migration processes, yet the composition of these networks is often taken for granted (Ryan et al., 2008; Schapendonk, 2015) and, in part due to a lack of longitudinal data, hardly any attention is given to the fact that they change over time (Hollstein, 2003; Lubbers et al., 2010; Mazzucato, 2009). This study contributes to an emerging literature on the dynamics of network change by investigating why migrants' networks change.

Our study was situated in the transit migration hubs of Istanbul (Turkey) and Athens (Greece). Transit migration hubs in Europe's border regions differ from origin-destination contexts in which migrants' networks are commonly studied, because of their highly volatile social and institutional environment (Düvell, 2012; Wissink et al., 2013). This volatility entails critical events that bring about rapid and radical changes to a migrant's social environment, or personal circumstances. Examples of such critical events are policy implementations regarding access to asylum, continuous and sudden arrivals and departures of other migrants, or getting caught at the border by migration police. Such critical events alter migrants' ability to manage their social networks and subsequently lead to network changes.

The association between critical events and network changes is central in social network analysis (SNA), which has only been scarcely applied in a migration context (Bilecen, 2016; Lubbers et al., 2010; Ryan et al., 2008). Most SNA studies aim to predict or explain specific network outcomes by assessing the characteristics of individuals, the network members, 
or the relationships among them. Little scholarship exists on why changes take place. This is crucial for understanding why, after experiencing a similar event, people's networks do not always develop in a similar way (Hollstein, 2003). Furthermore, unpacking the process of network change is essential for understanding how migration processes and networks interact. We study the process of network change by investigating the factors that affect the relationship between critical events and network changes (Hollstein, 2003).

\subsection{Transit migration in Turkey and Greece}

The study was situated in transit migration hubs in Turkey and Greece. Transit migration hubs are places frequently transited by substantial numbers of migrants on their way to a third country (Düvell, 2012; Papadopoulou-Kourkoula, 2008). While in the literature common reference is made to 'transit migrants', we do not apply the concept of transit to individuals because a state of being in transit can only be identified after someone has migrated elsewhere, and migration intentions fluctuate. The classification of an individual as a 'transit migrant' could therefore incorrectly presume that he or she will migrate elsewhere or intends to do so.

The concept of transit migration remains helpful to understand a context of temporal migration in which individuals shape their migration processes, but not to determine the direction and outcome of these processes (Wissink et al., 2013). A context of temporal migration entails that the presence of people can change on a daily basis; migration brokers offer their services; and policies are in place to manage onward migration. The social and institutional environment in transit contexts is therefore rather volatile, which, as we will argue, helps to understand why migrants' social networks change. A transit context is therefore a very suitable context to study network changes.

Transit migration in Turkey and Greece is often irregular in nature, which entails that parts of the migration process (e.g. entry, residence, employment and departure) are clandestine (Jordan \& Düvell, 2002). In Turkey and Greece, options for sub-Saharan African migrants to obtain and sustain travel and residence documents are scarce. Turkey's application of a geographical limitation towards the 1951 Geneva Refugee Convention, means that nonEuropean asylum seekers cannot qualify for a refugee status and a permanent residence permit. Recognised refugees need to be resettled to a third country, and legally remain asylum-seekers until then (İçduygu \& Yükseker, 2012). In practice, only few refugees are resettled. Asylum-seekers are appointed to reside in a 'satellite city', usually a rural town. Because asylum-seekers are not allowed to work and are usually themselves responsible for arranging accommodation in the satellite cities, many leave their satellite cities and reside in Istanbul where some find work in the informal economy.

Access to asylum in Greece is problematic: while hundreds of people line up weekly, the Immigration Office in Athens only takes 20 applications per week in consideration 
(Kehayioylou, 2012). There are no asylum seeker centres in Greece, and most asylumseekers reside in the bigger cities of Athens or Thessaloniki. Positive decisions over cases are almost non-existent, and a second review in case of an appeal, is virtually impossible (Human Rights Watch, 2008). In both countries, NGOs have reported severe violations of migrants' rights, in particular related to indefinite periods of detention, restricted access to asylum, push-backs, and violence by state officials (Amnesty International, 2009; Human Rights Watch, 2008; Pro Asyl, 2012). Notably in Greece, institutionalised and widespread xenophobic sentiments across the country further contribute to precarious circumstances for non-European migrants in the country.

In a context of dysfunctional asylum systems, restrictive EU-supported border regimes, the rules of the game pertaining to asylum and migration rapidly change. The volatile social and institutional environments that characterise these two countries is manifested in migrants' daily lives through events such as constant arrivals and departures of people, arrests, displacements, resettlement, and decisions on the refugee status determination procedure.

While studies have shown that in precarious contexts where state and civil society support is weak, migrants often depend on social networks for their daily survival (Broeders \& Engbersen, 2007; Chelpi-den Hamer \& Mazzucato, 2010; Engbersen, van San, \& Leerkes, 2006; Koser Akcapar, 2010; Suter, 2012a), we expect that these events can be critical for the management of and change in local and transnational social networks.

\subsection{A dynamic perspective on migrants' social networks}

It is widely recognised that migrants' social networks play a crucial role in inciting and facilitating migration processes through the circulation of support. Networks inform migration plans and foreseen destinations (Faist, 1997; Fawcett, 1989; Massey, 1987), reduce the risks and costs of migration (Faist, 1997; Pries, 2004), enable the crossing of borders (Böcker, 1994), and assist with finding employment and accommodation (Boyd, 1989). In particular for migrants for whom legal channels to migrate are inaccessible, social networks have been crucial to assist them with their migration strategies (Broeders \& Engbersen, 2007; Collyer, 2007; Devillanova, 2008; Koser Akcapar, 2010; Suter, 2012a; van Wijk, 2010).

Yet not always do networks explain migration processes or facilitate migration. For example, networks cannot explain migration when people migrate to countries where they did not have a network, or vice versa, when they do not migrate despite the presence of networks (Collyer, 2005; De Haas, 2010; Kalir, 2005). Furthermore, migration policies can hamper the role of networks, for example due to border controls and restrictive family reunification policies (Broeders \& Engbersen, 2007). Likewise, social networks can impede instead of facilitate migration, for example when migrants do not assist newcomers due to job market competition (De Haas, 2010). 
Both when networks are seen as explaining and facilitating migration as well as when they are not, there is a tendency to view networks as static and independent factors (Somerville, 2015). More recently, studies have argued that networks are both shaping and shaped by migration, suggesting that the relation between the two is interdependent (Krissman, 2006; Pathirage \& Collyer, 2011; Ryan, 2011; Schapendonk, 2015). This implies that migrants' networks change as the migration process evolves. Thus in order to understand the relation between networks and migration it is essential to analyse the inherently changeable nature of networks (Lubbers et al., 2010; Ryan et al., 2008; Schapendonk, 2015).

Thus far, the changeable nature of social networks has mainly been demonstrated by cross-sectionally comparing the networks of migrants in different migration phases, such as emigration, transit, immigration, settlement, integration and return (Chelpi-den Hamer \& Mazzucato, 2010; Haug, 2008; Hiller \& Franz, 2004; Massey, 1987; Muanamoha et al., 2010; van Meeteren et al., 2009). These studies show that relationships are formed in accordance with opportunities and needs associated with the particular phase of the migration process. While these studies suggest that networks change over time, their results cannot be disaggregated at the level of individual migrants to explain why their networks change over time. This would presume that migration processes of individuals, and hence the evolving of their networks, follow a predictable, step-wise development along defined migration phases. Research has shown that this is not the case: migration is often nonlinear, particularly in the context of irregular migration in transit contexts (Schapendonk, 2015; Wissink et al., 2013).

In his study of African migrants heading to Europe, Schapendonk (2015) found that timing and opportunities to connect with others contribute to the dynamics in migrants' social networks. This entails that, aside from deliberate action, luck and chance influence how social networks evolve. An unexpected encounter with someone, or being in a certain place at a specific time, can, for example, lead to changes in someone's social network, regardless of the migration phase (see also: Gladkova \& Mazzucato, 2017). We extend these lines of research on how and why networks change by exploring how critical events that migrants experience while in transit relate to the way relationship and network characteristics evolve over time. To this end we adopt a longitudinal research design, which only recently is becoming applied in the context of migration studies (Lubbers et al, 2010; Schapendonk, 2015).

\subsection{Critical events and network changes}

In this paper, we propose a framework for understanding changes in the networks of migrants in transit contexts. To this end, we draw on longitudinal personal network analysis which enables the study of network changes over time (Bidart \& Lavenu, 2005; Lubbers et al., 2010; Suitor et al., 1997; Wellman, Wong, Tindall, \& Nazer, 1997). 
In longitudinal social network analysis, network changes are commonly explained in relation to critical events in the personal or institutional environment of individuals (Suitor et al., 1997). These events can be life course events, such as marriage and childbirth (Bidart \& Lavenu, 2005), divorce (Terhell, Broese van Groenou, \& van Tilburg, 2007) and widowhood (Hollstein, 2003; Morgan, Neal, \& Carder, 1997) or effects of societal transitions. Examples of the latter are economic recession (Suitor et al., 1997), the introduction of information and communication technologies (Dekker \& Engbersen, 2014), and political transformations as studied in Russia (Lonkila, 1997), Eastern Germany (Völker \& Flap, 1995), Hungary (Angelusz \& Tardos, 2001), and China (Ruan, Freeman, Dai, Pan, \& Zhang, 1997).

Critical events have, amongst others, been associated with changes in network size, sources of support and the type of people relationships were formed with. Mollenhorst et al. (2014) explain this by the new social context such events bring forward. In transit contexts, the volatile social and institutional environment produce critical events that potentially lead to changes in migrants' networks. Examples include the continuous sudden arrivals and departures of other migrants, results of refugee status determination procedures, border control interventions, regularisation rounds, and referrals to satellite cities in Turkey. In this paper we will analyse how events as these are associated with changes in migrants' social networks.

Associations between critical events and network changes alone are not sufficient to reveal why network changes occur. After the experience of a similar critical event, people's networks do not necessarily develop in the same way. For example, after settling, some migrants may develop more local ties over time and lose contact with people abroad, while others develop more transnational ties (Portes \& Zhou, 1993). Lubbers et al. (2010) found that while migrants themselves ascribed changes in their networks to the experience of events, such as change in job or marital status, this could not explain the variation in ways migrants' networks evolved. Hollstein (2003) showed that individual orientations are important for understanding the way in which a critical event, losing a spouse, determined how networks of widows evolved. Widows who were more "(social-) environmentoriented", developed larger networks than those who were not. In this paper, we aim to develop an analytical model indicating the factors that affect the relationship between critical events and network changes that occur in a transit context. In doing so, we aim to grasp the mechanisms underlying network changes, without aiming to predict specific kinds and directions of these changes.

\subsection{Empirical Study and Methodology}

I followed 40 sub-Saharan African informants residing in either Athens or Istanbul during two fieldwork periods within 17 months between early 2012 and late 2013. The total period that I maintained contact with informants ranges between 3 and 90 months: 8 informants 
were involved in earlier projects I conducted, and I maintained contact beyond the period of fieldwork with 26 informants, while in 12 cases the contact lasted less than 17 months. Nineteen sub-Saharan African migrants in Athens and 21 in Istanbul formed the main research sample. The sample was limited to migrants from the West and Horn of Africa to allow for immersion in migrant communities during the fieldwork and some homogeneity in origin regions. The informants were approached using various gateways: in public places such as squares and markets and snowball sampling techniques. The choice for sample inclusion was primarily based on theoretical saturation where we aimed to capture variation in the variable of interest, migration strategies, in order to link these to variation in networks in a later stage of the study. We strived for an equal distribution of Horn and West Africans and men and women.

We used participant observation, in-depth interviews and social network analysis (SNA). Triangulation between these methods minimised measurement and interpretation errors, and complemented each other in reconstructing network change (Bilecen, 2016; Denzin, 1970). Nearly three decades ago, Boyd (1989) called for the incorporation of SNA in migration studies, which has since been repeated by various scholars (Gurak \& Caces, 1992; Krissman, 2006; Ryan et al., 2008; Vertovec, 2004). Still, little migration scholarship exists which includes SNA, especially in longitudinal research designs.

Participant observation enabled the identification of critical events and the observation of how social relationships were managed. Observations were conducted in public places, private houses, and common meeting points such as internet café's, call shops, restaurants and coffee houses. As the fieldwork progressed, participant observation increasingly centred on the lives of the 40 informants whom I accompanied to hospitals, NGOs, lawyers, call shops, local authorities, airports, public transport stations, churches and mosques and visited at home and in detention facilities. I further participated in numerous daily activities of a selected group of informants by selling watches and jewellery, working in sweat shops, shopping, and having dinners. These activities provided occasions to observe and experience how migrants in transit contexts create, manage, and break social relationships, and what role networks played in sustaining livelihoods. Because I repeatedly visited the same informants during different periods separated by intervals of time and maintained contact through telephone and internet in between, I was able to witness changes in their interactions and activities, and to contextualise these by considering changes in living conditions, migration strategies, and policy changes.

Semi-structured interviews were conducted to obtain the informants' own accounts of their personal social networks, which enabled the identification of what network changes were perceived as relevant. An interview guide was used which contained questions on the importance, maintenance, nature and role of various types of social relationships and the experience of critical events. The interviews further invited informants to share and reflect on their networking experiences and practices. 
Informed by the literature, participant observation and in-depth interviews, a social network survey was designed to analyse the composition and structure of migrants' personal social networks. A multiple name generator questionnaire containing questions on various kinds of support was developed to identify the persons with whom the informants exchanged four types of support: emotional/affective, instrumental, informational and financial (Amelina, Bilecen, Barglowski, \& Faist, 2012; Bilecen, 2016; House, 1981). After the survey was completed, a visualisation of the network was created by means of the software programme EgoNet (McCarty, 2003). This was presented to each informant, with whom I discussed the accuracy and meaning of each relationship. Twelve months later, 17 informants who were still present in Turkey and Greece were invited to look the same visualisation, and to reflect on the changes that took place in the past year, in order to identify the changes that had occurred. Informants were asked about each network member that was mentioned the year before, if he or she was still present and whether the nature of the relationship had changed. In addition to this, more general question were asked, such as whether the informant believed certain network members had appeared, disappeared, or gained or lost importance. Changes in the networks were further investigated though observation of social interactions.

The observations, interviews, reflections and the network survey were conducted during various field visits, as indicated in Chapter 3. During these field visits, multiple weekly visits were paid to the informants. In between, contact was maintained through telephone, Skype and Facebook.

This allowed for a longitudinal follow-up of their migration processes and changes in social networks. The aims of the research were openly discussed with the informants and consent to participate was asked. The qualitative study was based on establishing trusting relationships between me and the informants. The longitudinal design of the study enabled me to spend time together and enhance the quality of our relationship. I made sure that informants understood the purpose of the research and discussed this repeatedly over the course of the fieldwork.

Our aim was to reconstruct and explain the process of change in migrants' social networks. The results of the observations, interviews, reflections and the network visualisations were analysed in a qualitative manner. Field notes and interviews were analysed through inductive coding and compared with network visualisation and informants' reflections on the changes their networks had incurred.

The various methods complemented each other in various ways. First, as the different methods sometimes revealed different network members, a more complete image of networks could be reconstructed by combining the data from each of the tools. The social network survey focused on relationships based on clearly defined support exchanges. Other relevant relationships are herewith potentially left out but were revealed through observations and interviews. Second, discussing the network visualisations enabled the clarification of and reflections on the relationships mentioned. Third, as commonly 
acknowledged in social network studies, social network surveys suffer from recall problems and bias. Through observations, support relationships could be identified that were not mentioned during the survey. Triangulation thus enabled informants to explain certain additions or omissions of network members that were revealed during a particular method, making the results of other methods more accurate and interpretable.

\subsection{The changing networks of sub-Saharan migrants in Istanbul and Athens}

The framework we develop in this paper is based on the analysis of 40 informants. We illustrate our analysis by presenting two in-depth cases of network changes in relation to critical events. The two cases were selected because they were the most variegated, allowing us to illustrate the full variety of factors found across all cases. For all cases, we assessed what factors come into play after the experience of a critical event in the production of network changes.

Mohamed is a man who directly travelled from Senegal to Turkey in 2011. Senait is a woman who left Eritrea in 2008, and arrived in Greece in the fall of 2011. Both Mohamed and Senait moved to Turkey in their 20's with the intention of going to Greece and to support their families in their countries of origin with whom both initially maintained close contact. Both developed more intense ties with a sibling in a year's time, but the process of change occurred in different ways

Table 5.2 illustrates common critical events experienced by our 40 informants. Below we describe and visualise the changes that took place in the networks of the two illustrative case studies. In a second sub-section, we embed the changes in the case-study individuals' experience of critical events. In Senait's case we build on fieldwork data from 2009, when she took part in a similar study (Wissink et al., 2013). Finally, we reflect on the associations between critical events and network changes by scrutinizing what factors affect the associations found. 
Table 5.2 Critical events experienced by informants

\section{Related to the asylum procedure}

Filing an asylum application (or failing to do so)

Referral to a satellite city (in Turkey)

Resettlement to a third country (or lack thereof)

Results of the refugee status determination procedure (RSDP)

(Not) being given asylum documents after application

(Not) being provided with updated information on the RSDP

Obtaining/losing asylum documents

\section{Related to travelling}

Accidents while travelling, witnessed or experienced

Disappeared/arrested smuggler

Arrests at the border

Detention

(Not) arriving at point of destination

Related to Residence/work

Arrest in public or work space

Detention

Seizing of merchandise

(Not) obtaining a residence permit or visa

Sexual harassment at work

Finding/losing a job

\section{Related to communication and exchanges}

Asking/being asked for social support

(Not) receiving/providing social support

Arrival/departure of fellow migrants (i.e. leaving from or returning to the house, neighbourhood or country due to detention, release or travelling).

Stopped/revived usage of telephone/social media (i.e. losing phones, changing phone numbers, closing Facebook accounts)

Being unexpectedly separated from family members

Chance encounters

\section{Related to the societal environment}

Racist violence, witnessed or experienced

Encounters with migrant solidarity movements

(Not) receiving support from charities, religious organisations or NGOs.

\section{Life course events}

Marriage

Getting a child

Death of network members

Source: fieldwork 2012-13. 


\subsubsection{Changes in Mohamed's network}

Mohamed migrated in his mid-twenties from Guinea to Istanbul after his grandmother, with whom he grew up, passed away. His family had advised him to go to Europe to help provide for his younger brother. His uncle in Guinea arranged a passport, visa and flight ticket to Turkey, while an uncle in Germany would finance the journey to Europe via Greece.

Figure 5.1 visualises Mohamed's network in 2012. Figure 5.2 visualises the changes that took place in his network between February 2012 and May 2013 (see Table 5.3 for a legend explaining both Figures). In 2012, his network mainly consisted of one component of family members in or from Guinea and another component of mostly Guinean migrants in Turkey. At that time, Mohamed maintained frequent contact with his family. He bought telephone cards or visited call shops to call several of his family members on a daily basis, mostly his younger brother and sisters and his mother's brothers. Important relationships in Istanbul included one with a local shopkeeper who allowed him to sell in front of his shop, a woman who offered him accommodation during the first months, and her husband Boubakar. Abdu was also a key person in his network; he was one of the elder Guineans in Istanbul, and his house functioned as a meeting point for Guineans. Mohamed's youth friend Amadou connects the components in Turkey and Guinea; Mohammed had lost touch with him years before, but late 2011 they coincidentally met again in Istanbul. Whereas Amadou knew Mohamed's family, they were not in touch.

In May 2013, Mohamed was still in Istanbul. An important change in his network was that relationships with people in Guinea weakened; apart from his brother and cousin with whom his relation intensified, he rarely called his family anymore. Meanwhile, Boubakar and Abdu had become more central persons in his network. Through them, he met with other, mostly elder Guinean men in Istanbul. Furthermore, his network expanded with contacts in Europe, some he knew from Guinea, and others were people he met in Turkey and had travelled onwards. The connection between Turkey and Guinea became stronger when Boubakar visited Mohamed's family during a trip to Guinea. 
Figure 5.1 Mohamed's network in 2012

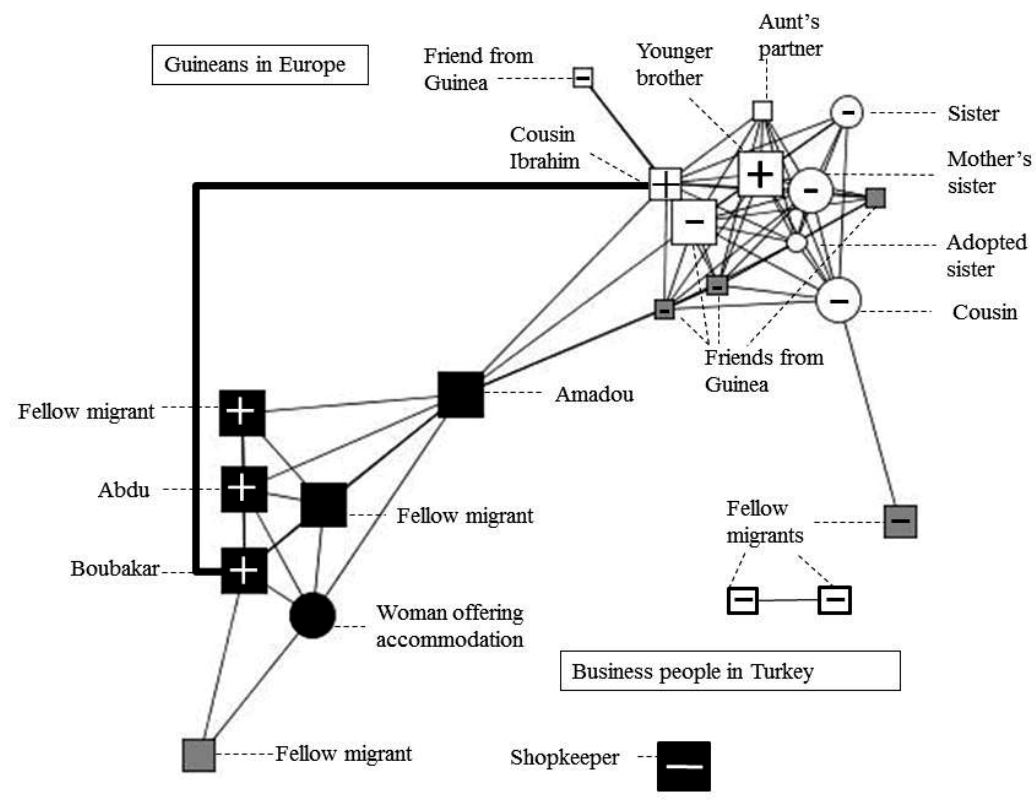

Source: own fieldwork data

Figure 5.2 Mohamed's network in 2013

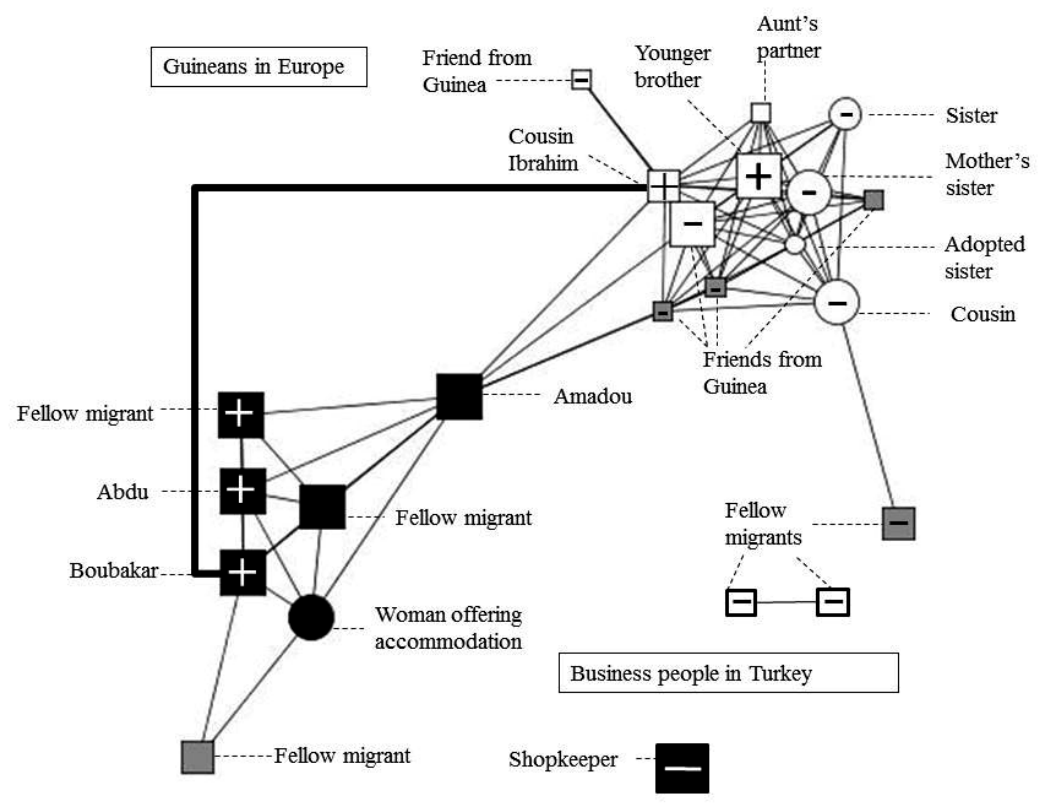

Source: own fieldwork data 
Table 5.3 Legend belonging to Figures $5.1-5.4$

\begin{tabular}{ll} 
Network member lives in country of residence (Turkey or Greece) \\
Network member lives in Europe or the US \\
Network member lives in region of origin \\
Male \\
Female \\
Size & Frequency of contact (Daily/weekly-monthly-less) \\
+ in node & Network member is more important in 2013 than in 2012 \\
No sign in node & Network member is less important in 2013 than in 2012 \\
\hline & No noted change in importance of network member \\
\hline abc & Connection is new in 2013 \\
\end{tabular}

\subsubsection{Mohamed's experience of critical events}

We situate the changes in Mohamed's network in several critical events he experienced during a year's stay in Istanbul. Some of these events were directly caused by his social network, such as the absence of promised support from family and friends in Europe, or financial requests made by his family and fellow migrants in Istanbul involving him in business activities. There were also critical events outside the realm of social networks, including an increase in smuggler fees, growing business opportunities, a referral to a city far away from Istanbul and a termination of an asylum procedure. These are explained below.

Soon after Mohamed arrived in Istanbul, he found out that the smugglers' fees increased as a consequence of stricter border controls at the Turkish-Greek land border. Mohamed's available financial resources were not sufficient to travel onwards to Greece immediately, as he had planned. He expected to receive support from his uncle and friends in Europe, but this had not materialised. Several other informants had experienced similar critical events, which commonly changed the preferences they had regarding the maintenance of these social relationships. For Mohammed, the absence of support that was promised incited feelings of anger and disappointment. To cope with and avoid such feelings, Mohammed preferred to no longer maintain contact with people who did not keep their promises, while not providing an explanation or apology. These relationships with friends and family in Europe thus dissolved.

While Mohamed sought ways to finance his journey to Greece, his younger brother informed him about the death of his uncle and their family's need for financial assistance to 
organise the funeral. This event was critical, as it confronted Mohammed with his changed position in his family: being the eldest grandson, in Guinea he was always the first person to hear about big events, to inform others about these, to coordinate any possible action that needed to be taken, and to mediate in cases of disagreement among family members. Now that he was in Turkey, his younger brother had taken over this role. Mohammed had a strong preference for safeguarding his traditional position in the family as much as possible, as he still felt the same responsibility for his family as he did when he was in Guinea. This was also a source of feeling of self-worth for him. He did so by staying in frequent touch and calling daily to ensure he was informed and involved in the organisation of the funeral and to be able to give advice to his family. He used the money he earned by selling watches to make calls abroad. Sometimes this went at the cost of paying the rent, creating tensions in the relationship with his roommates. As he focused on preserving his ties with his family, staying informed and providing advice to his family, Mohamed did not invest much in creating local ties, other than instrumental relationships with the people who provided him accommodation, and the shopkeeper who allowed him to sell in front of his house, and his youth friend Amadou. As such, he preferred to no longer give priority to establishing contact with smugglers and acquiring information about travel routes to Europe.

During the next few months, two other events were critical for the way his network evolved. The first is Mohamed's application for asylum, which included a referral to a satellite city, and the subsequent termination of the procedure. The second is Mohamed's growing involvement in Boubakar's and Abdu's cargo businesses.

Mohamed applied for asylum in order to regularise his unintended prolonged stay in Turkey. He was referred to a satellite city, about a 10 hour drive away from Istanbul. Like many satellite cities, this city did not have an established asylum seeker community. Referrals to satellite cities in Turkey, often implied limit access to communication infrastructures due to the limited availability of internet cafes and call shops. Mohamed explained that without a "black community" he would not be able to survive. The exchange of resources, such as clothing, food and information about policy implementations among the migrant communities was essential for him to ensure his livelihood. He therefore chose to stay in Istanbul even though this meant that his asylum procedure was terminated and he became undocumented.

The event of becoming undocumented entailed that Mohamed needed to mobilise his resources in the informal sector for which he reasoned he had to stay close to other African migrants. In order to avoid the risk of getting arrested, he hardly left the city district where most migrants lived. Although police raids occurred there too, his presence drew less attention than elsewhere in the city. As such the area in which he moved was rather narrow. He spent most of his free time in a street full of call shops, a known meeting point for traders. There, his relationships with Boubakar and Abdu intensified. Boubakar and Abdu had meanwhile become successful in the cargo and textile sectors. As Mohamed had learnt 
to speak Turkish in the meantime, Boubakar and Abdu involved him in their business by referring their foreign customers to him for guidance and translation.

The more Mohamed got involved, the less time he could use to maintain daily contact with his family in Guinea. Moreover, he was now able to regularly send money to his family. With this new way of exchanging with his family, he had another source through which to gain respect amongst his family thus maintaining his role as a mediator and information distributer in the family was no longer a priority. Instead, he only kept contact with his cousin and brother whom he now regarded as his companions in distributing financial resources and supervising whether these were spent carefully. The nature of the relationship with his brother gradually changed and became more intense. He continued visiting call shops, but this time not to speak with his family in Guinea but to re-establish contact with people in Europe to mobilise potential customers.

In short, between 2012 and 2013, Mohamed's social network changed in terms of both the presence and nature of relationships in Turkey versus those in Guinea. This was associated with a combination of events that occurred within the realm of his network (e.g. the death of his uncle and the non-materialised support, getting involved in other people's businesse), as well as within the institutional environment (e.g. the referral to a satellite city and dropping out of the asylum procedure).

\subsubsection{Changes in Senait's network}

Senait left Eritrea in her late twenties, to escape from compulsory military service. She aimed to study in the UK, where her brother lived. With the help of her sister in Germany, she paid smugglers to travel to Turkey, from where she planned to travel to Greece. We met for the first time in January 2009 in Turkey. At that time, she was in regular contact with her family in Africa and Europe. Figure 5.3 visualises the Senait's network in 2012. Figure 5.4 visualises the changes that took place in her network between May 2012 and September 2013. In 2012, she was in Athens. Her network at the time did not include any family members or friends in Eritrea, and a few Eritrean who had already migrated. Most people in her network were Eritrean and Ethiopian migrants whom she met in Athens, or with whom she travelled together from Turkey, including Adam whom she already knew from Eritrea. The only family member she interacted with at this time was her brother's son who lived in Sudan.

While in 2012 Senait did not remain in touch with her family in Eritrea and Europe, in 2013 they were the centre of her social network. In 2012 Senait avoided contact with her sister in Germany, but they regularly spoke on the phone in 2013. At the same time, aside from a few exceptions, relationships with fellow migrants and travel companions in Greece with whom she maintained close relationships a year before, dissolved. She only follows Adam on Facebook, but they did not remain in active contact. 
Figure 5.3 Senait's network in 2012

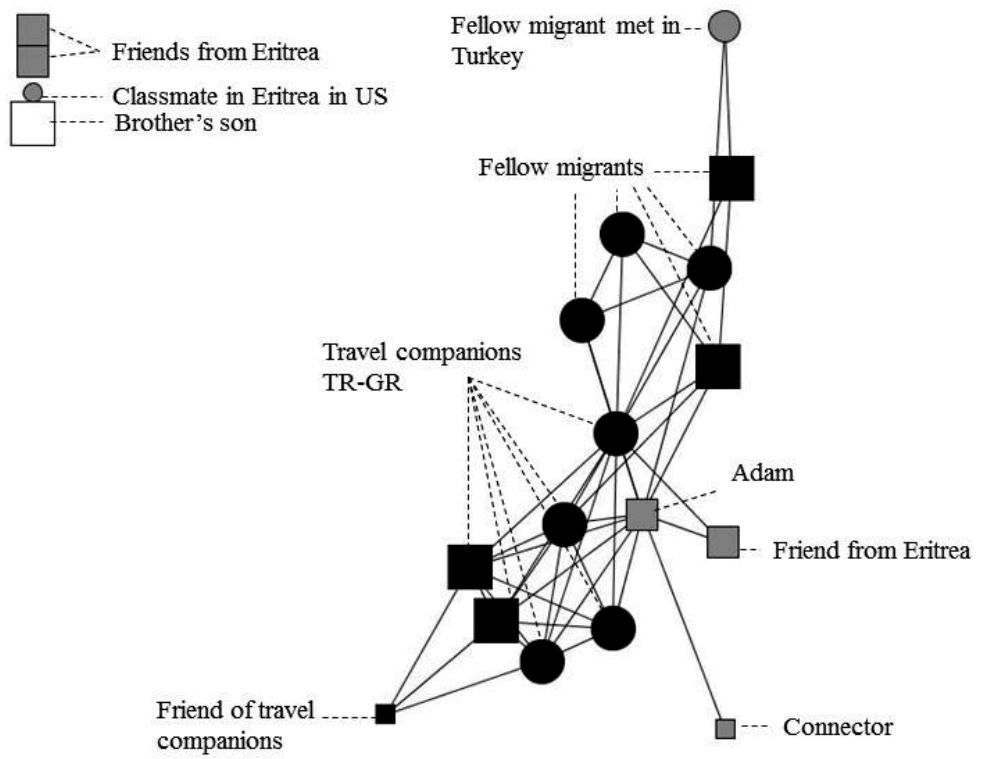

Source: own fieldwork data

Figure 5.4 Senait's network in 2013

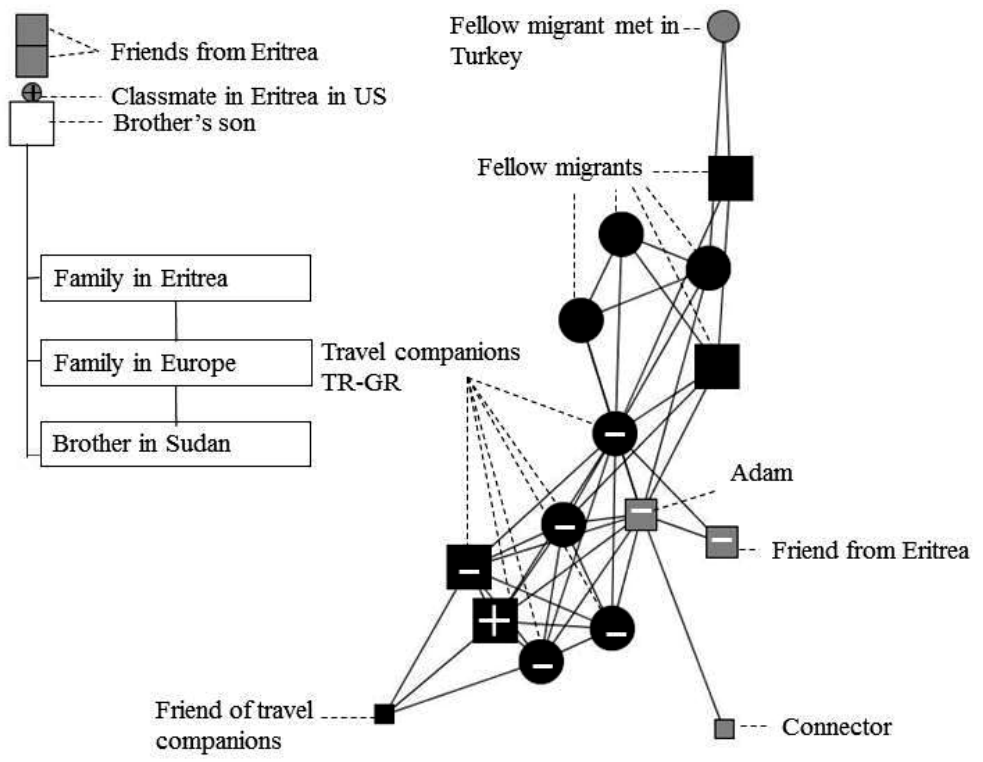

Source: own fieldwork data 


\subsubsection{Senait's experience of critical events}

Critical events that evolved from the transit context which shaped the evolution of Senait's network include lacking resettlement opportunities, failed attempts to leave Greece and confrontations with xenophobic behaviour. Critical events that took place within the realm of her social network involved requests and offers for support by her family and friends and departures of fellow migrants from Greece.

After several failed attempts to travel to Greece, Senait applied for asylum in Turkey in 2010. She was the only African asylum-seeker in the satellite city she was referred to, and seemingly for many locals the first dark skinned person they had met: she faced many incidents where people pinched her skin, followed her on the street and made racist comments. Because the lack of meeting venues with fellow migrants and of accessible internet facilities, her communication infrastructure was restricted, resulting in a decline of social contact. While she was soon recognised as a refugee by the UNHCR, resettlement was not available to her. She moved to Istanbul in 2011 to reconnect with people in a similar situation and to accumulate new resources to continue her journey. Not much later, the UNHCR closed her file.

In Istanbul, she met with Adam, a friend she had known since high school in Eritrea, by chance in a neighbourhood where many migrants lived. He had just escaped from an overcrowded detention centre and persuaded Senait to try and leave Turkey once more and he offered to pay the smugglers' fees. Senait regarded moving to Greece as a chance to regain autonomy in her migration process and agreed. In Greece, Adam helped Senait in preparing their departure to another European country, but one day he succeeded alone. Months passed, in which Senait was confronted with xenophobic attitudes and police raids, during which migrants were arrested and imprisoned, sometimes for indefinite periods of time. For many migrants this meant that leaving their homes in order to meet with other migrants or to go to internet cafés and call shops had become risky, and many stayed at home as much as possible, limiting access to communication infrastructures and the mobilisation of resources, and herewith the possibility of managing networks.

While Senait was faced with challenging circumstances in Greece, she received hopeful requests for information about how to travel to Greece from friends and former colleagues in Eritrea. Senait advised them not to come to Greece, but she claimed they did not believe her. At the same time, her family continued asking questions about her travel plans, and what was keeping her from travelling to the UK. The constant requests for information were critical events taking place within her network confronting her with her precarious situation and with the fact her migration project was not developing as she had hoped. Accordingly, she developed a preference to not maintain contact with her family and friends in Eritrean and Europe and closed her Facebook account and changed her phone number. She further no longer accepted her sister's financial support. The only person she communicated with was her brother's son in Sudan, as he did not ask her questions about her journey. As such, relationships with family members dissolved or weakened. 
Senait's preference to retreat from contact served as a way to cope with feelings of not being able to move forward and the emotional burden it formed. On her free Sundays, she immersed herself first in the local church community and preferred creating new ties with fellow migrants over maintaining contact with family members abroad. Among them were migrants with whom she had travelled from Turkey to Greece. In sharing new joint experiences as domestic workers, with xenophobia in public places, and on the risks of getting arrested, she felt a sense of recognition and belonging, something her family could not offer her.

During the following year, most women Senait had spent her time with had left Greece. Others had been imprisoned. When she became the only one remaining from the group with whom she crossed the border from Turkey to Greece, she had more than before the feeling she was not moving forward. In a need for emotional support she preferred reviving her family relationships as she realised she could not rely on relationships with other migrants as they were not available continuously. The transiency of these relationships incited the preference to reconnect with her family, in particular with her parents in Eritrea and her sister in Germany with whom she now regularly spoke on the phone.

Thus, when critical events hampered her migration process prior to 2012 (e.g. accidents and lack of resettlement options), Senait chose to distance herself from her family to avoid questions about her whereabouts. Yet after 2012, when critical events still hampering her migration, this incited Senait to reconnect with her family for emotional support when at a time that her local relationships continuously dissolved.

\subsection{Individual opportunity structures}

For two cases, above we have seen how changes in networks are embedded in the experience of critical events. Based on data from all informants in the overall study, we derive three factors that explain how critical events and network changes are associated: communication venues and infrastructures, available resources, and relationship preferences.

We have seen that critical events can impact the availability and accessibility of communication venues and infrastructures, which are essential to form or maintain relationships and support exchanges (Urry, 2003). Certain critical events, such as referrals to satellite cities in Turkey, in both the case of Mohamed and Senait, constrain the opportunity to communicate when internet cafes, call shops and an established migrant community are lacking. In cases of arrests and imprisonment, communication is virtually impossible. Access to available communication venues and infrastructures can be blocked, for example when migrants limit visits to public places in order to avoid racist violence.

Critical events can further transform the availability and accessibility of resources, such as money, information and instrumental, affectional and emotional support. This may require modifying one's relationships either by maintaining, creating or dissolving them (van 
Meeteren et al., 2009). We know from SNA studies that in homogenous networks, there is a limited variety in available resources (McPherson et al., 2001). Furthermore, networks in which members are not well connected, may pose difficulties in mobilising resources. Such weak ties, however, prove to be beneficial for mobilising resources beyond one's inner circle of strong relationships (Granovetter, 1973). When Senait was mostly connected with other migrants in Greece, most of whom were in a similar financial position as her, she was unable to mobilise resources to continue her journey to the UK as planned. The tie with her cousin, who was isolated in her network, proved to be highly beneficial for receiving emotional support when contact with all other family relationships at that moment were cut off.

Another crucial factor shaping the association between a critical event and changes within networks are relationship preferences. Critical events can evoke emotional or deliberate reflections on the purpose of social relationships, and herewith inform motivations to maintain, create, dissolve or alter the intensity of social relationships (Hollstein, 2003). This could for example result in wanting to concentrate on the maintenance of specific relationships only, and break with others, as was the case for Mohamed who focused on building a local network when business opportunities in Turkey expanded and he was not able to migrate further to Greece.

Critical events can further incite feelings of abandonment or encouragement, failure and success, and a need for distance or socialisation and herewith create certain relationship preferences. Senait immersed herself first in the local church community in order to socialise with fellow migrants, and disconnected from her family to avoid the confrontation with the feeling of not moving forward. Yet, when others migrated or were imprisoned, Senait reconnected with her family abroad. The meaning attributed to social relationships can thus transform when critical events occur.

The characteristics of communication venues and infrastructures, resources and relationship preferences differ for each individual, because they depend on a person's actual circumstances. This implies that the impact of a critical event on opportunities and preferences with respect to the management of social networks is not the same for each person. We therefore employ the concept of individual opportunity structure (IOS) to refer to the three factors shaping the association of critical events and network changes. Figure 5.5 presents our analytical framework. This framework is proposed to explain the association between critical events and changes in the presence and nature of relationships in migrants' social networks over time. Unlike most network studies, it does not predict a certain network change. Instead, it aims to provide an analytical lens to understand why networks are dynamic in the context of migration. The framework shows that critical events lead to network changes (arrow $a$ ) because they affect the IOS (arrow $b$ ), which then impacts on the presence and nature of relationships within social networks (arrow $c$ ). 
Figure 5.5 Analytical framework for understanding network changes

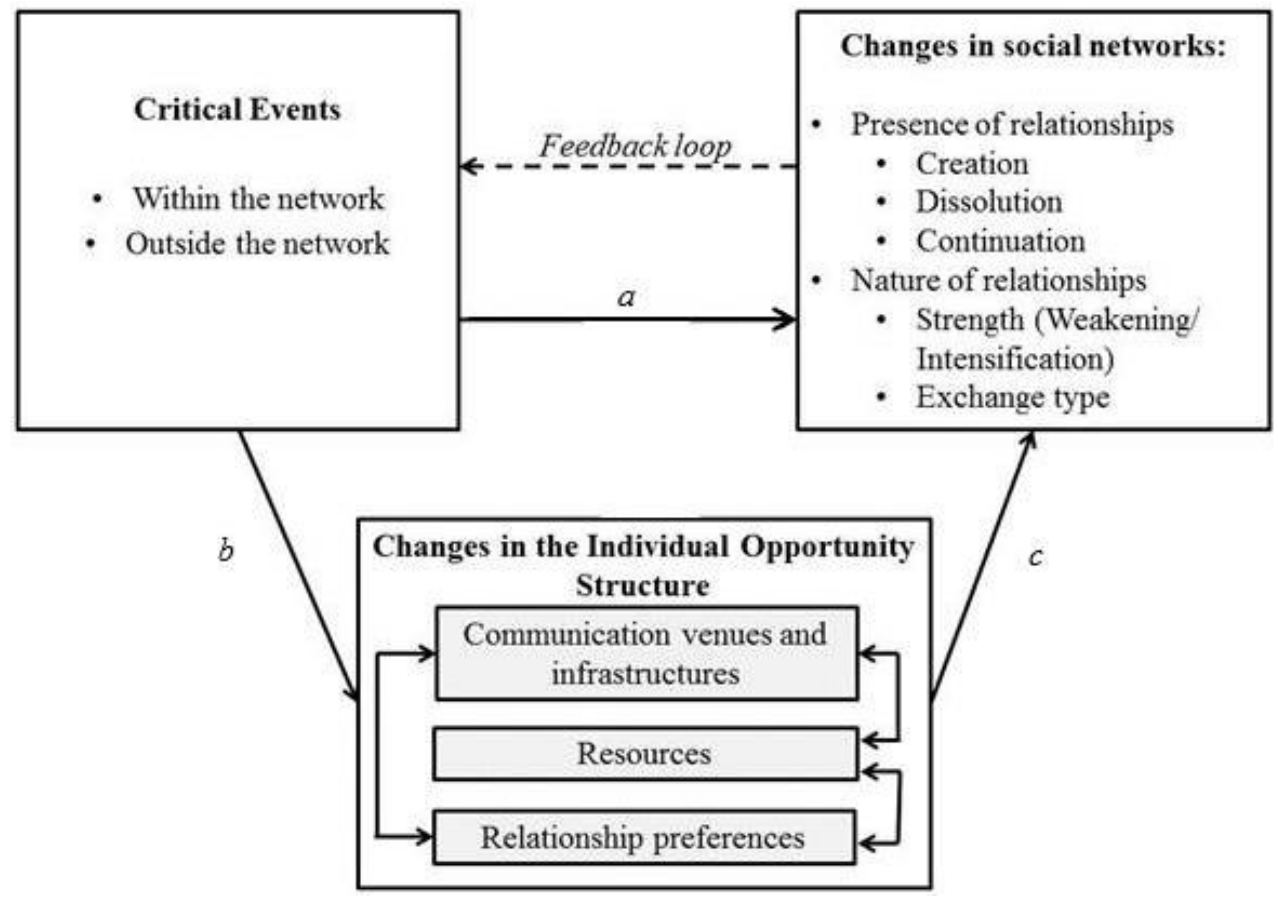

There are three ways in which critical events affect changes in individual opportunity structures. First through a direct impact; for example, when critical events directly impede or enhance the access to communication infrastructures, such as arrests, imprisonments and referrals to satellite cities. Second, as a result of how migrants choose to respond to events and exert agency. This is what Senait did when she deliberately chose to abstain from using communication tools, after repeated requests for support and information by friends and family outside of Greece. Third, critical events may bring forward new constraints and opportunities that affect individual opportunity structures. For example when Mohamed became undocumented and could move around less freely in Istanbul, this resulted in the creation of closer ties with businessmen whom he chanced upon due to his restricted movement in one district of the city.

The effect of the IOS differs from person to person and over time because of interactions that takes place among the three factors that constitute it. For example, relationship preferences inform how resources and communication tools are used. Mohamed had a strong preference to preserve the type of family interaction he was used to in Guinea. He therefore spent most of his money in call shops. A need for information about asylum policies and travel routes or for financial assistance incited some informants to spend hours in internet cafes to maintain or re-establish contact with friends and family members in Europe and elsewhere in the world who could provide them with these resources. Other 
informants developed closer relationships with local migrants when financial resources limited migrants' access to internet and call shops.

Network changes themselves can incite or constitute critical events. This is indicated by the feedback loop in Figure 5.5. This is the case when a change in the network makes migrants more prone to experience certain other events, or when this directly impacts on the elements of the opportunity structure. The fact that Senait stopped contact because of the emotional burden it constituted had as consequence that she no longer received her sister's financial support. Thus, dissolutions of transnational relationships imply that certain resources that were embedded in these relationships are not available anymore. This can in turn provide a new incentive to re-establish these or other relationships. Through the continuous experience and co-occurrence of critical events, the IOS is subject to change, and so are migrants' social networks. In our analytical framework, the critical events are thus not considered as ex ante, and networks as ex post. Instead, they co-occur and coevolve.

\subsection{Conclusion}

This chapter analyses why changes occur in the personal transnational social networks of African migrants residing in the transit hubs of Turkey and Greece. We found that these changes occur in interaction with critical events that are brought forward by the highly volatile social and institutional environments in transit migration hubs. These critical events could take place within or outside the realm of social networks. Critical events within the realm of social networks include the departure of fellow migrants or network members refusing or initiating contact. Critical events occur outside the realm of social networks concern institutional changes, including implementations of migration policies such as arrests and decisions on the refugee status determination procedure.

Based on a combined ethnography and network analysis with forty migrants within a period of 17 months, we have developed an analytical framework to assess the association between critical events and changes in migrants' personal social networks. This association was explained by providing an in-depth analysis of two cases. These two cases exemplified the phenomena that were observed in the overall sample. Our framework explains that critical events impact on the presence and nature of relationships in migrants' networks through what we have labelled migrants' individual opportunity structures (IOS). The IOS consist of three factors: relationship preferences, resources and communication infrastructures. These factors shape whether relationships are formed or continue to be maintained, how strong they are, and what type of support exchange takes place through the relationship. The paper showed two in-depth cases illustrating how critical events evoke changes in the IOS, and lead to changes in networks accordingly. 
Our findings revealed that critical events shape the IOS in three ways: First, by directly enhancing or impeding the availability of resources and communication infrastructures, for example following imprisonment or release. Second, by bringing forward opportunities and constraints through indirect or unanticipated outcomes of critical events, for example when restricted movement leads to chance encounters, which we know can be fundamental for shaping migration trajectories (Gladkova and Mazzucato 2017). Third, when migrants are able to make a deliberate choice on how a critical event impact on their IOS, for example by accepting a loss of a relationship or resource. Our findings showed a strong interplay between the three factors: one factor could incite an increase or decline of importance of another. We further found that through the continued experience of critical events, the characteristics of the IOS fluctuate over time. This explains why the nature and presence of relationships in migrants' social networks are subject to change, too.

Because the factors constituting the IOS are continuously subject to change and interact, migrants' social networks evolve, but not according to predefined or evolutionary phases of the migration process, as conceptualised in previous migration studies (Chelpi-den Hamer \& Mazzucato, 2010; Haug, 2008; Hiller \& Franz, 2004; Massey, 1987; Muanamoha et al., 2010; van Meeteren et al., 2009). Studies based on such conceptualisations focus on predicting or explaining network outcomes following the experience of a critical event, or a phase in the migration process, such as arrival, integration and settlement. It is then investigated, for example, whether social networks develop in specific ways according to particular characteristics such as sex and length of stay of the migrant. One assumption often tested is whether migrants develop more interethnic and local ties as their length of residency increases (Martinovic, van Tubergen, \& Maas, 2009; Snel et al., 2006). Instead of an explanation of network outcomes, our study investigates how changes in migrants' networks are produced. We do not aim to predict network outcomes, but rather identify elements that help to explain processes of network change. The model we develop serves the analytical purpose of distinguishing between various processes that take place when networks change.

We were able to investigate processes of network change because of our longitudinal research design, which we highly encourage for future research on network change. Longitudinal research designs enable the collection of data on network change, which does not evolve according to predictable steps. Data thus needs to be collected prospectively. While a disadvantage of longitudinal studies is the heavy time investment, the longterm character of the research design allows for the building and maintaining of trusting relationships with informants, enhancing the data quality.

One of the study's limitations is that it does not relate processes of network change to migrants' socio-demographic characteristics, such as gender, ethnicity and religion. It is likely that such characteristics shape the individual opportunity structure. A larger-scale study than this one could investigate these relationships. Another limitation is that we could only analyse changes in networks in terms of dyadic relationships, and from the perspective 
of our informants (ego). Further research could include the role of network structure by considering the evolving interrelationships between network members.

Despite these limitations, our analysis has implications for the understanding of how social networks change over time. First, our framework helps to understand the individual variation that exists in the way migrants manage their networks and how critical events elicit changes in networks. This in turn helps to understand phenomena that are related to network change, such as migratory decision-making. Second, in migration studies, networks are commonly conceptualised as potential facilitators of migration, where networks in Europe facilitate the migration of newcomers, while migrants in transit are driven by expectations and motivations of their families in countries of origin. This implicitly assumes that networks are static, composed of specific people who serve specific and unchanging purposes: they either help or hinder migration. Our study shows that as networks change their purpose and the expectations and motivations that shape them also shift throughout the migration process. Future research thus should not only focus on whether networks can explain migration, but rather on how the role of networks fluctuates over time due to changes in individual opportunity structures throughout the migration process. 



\section{Chapter 6}

\section{The evolution of migration trajectories of sub-Saharan African migrants in Turkey and Greece: The role of changing social networks and critical events}

A slightly different version of this Chapter has been published as: Wissink, M., Düvell, F., \& Mazzucato, V. (2017). The evolution of migration trajectories of sub-Saharan African migrants in Turkey and Greece: The role of changing social networks and critical events. Geoforum. Doi: https://doi.org/10.1016/j.geoforum.2017.12.004 



\section{Chapter 6: The evolution of migration trajectories of sub-Saharan African migrants in Turkey and Greece: The role of changing social networks and critical events}

\subsection{Introduction}

Migration trajectories of irregular migrants are characterised by non-linear moves and frequent changes in routes and applied migration strategies. These non-linear trajectories are commonly explained through micro-level factors, such as dynamic aspirations and intentions, and macro-level factors, such as restrictive migration policies obstructing straightforward moves. This paper investigates the meso-level, focusing on migrants' personal social networks. It investigates how migrants' embeddedness in their social networks is associated with the way their trajectories evolve over time. In doing so, it will demonstrate that the non-linearity of migrants' trajectories is associated with the changeable nature of their networks.

The explanatory power of networks for migration has been widely discussed in the literature, and opposed to other explanatory factors such as migration policies (Carling, 2008; Collyer, 2005; De Haas, 2010; Durand et al., 1999; Heering, van der Erf, \& van Wissen, 2004; Massey, 1987; Mckenzie \& Rapoport, 2007; Muanamoha et al., 2010; Pathirage \& Collyer, 2011; Pries, 2004; Snel et al., 2006). In most studies, networks are conceived of as the linkages between people in origin and destination countries, whose role in initiating and sustaining migration flows is investigated. Rather, this paper focuses on the role of networks during the actual process of migration in the case of irregular migrants. It takes a broader perspective on the composition of migrants' networks by considering network members beyond origin and destination countries. Moreover, it employs a longitudinal research design to investigate the changes that take place in networks over time (Wissink \& Mazzucato, 2018). In this way, we aim to critically examine the role of social networks for understanding how migration trajectories evolve over time.

The study was situated in the transit migration hubs of Istanbul (Turkey) and Athens (Greece). Transit migration hubs are characterised by a highly volatile migration environment, which is manifested in the daily lives of migrants through the experience of 'critical events'. We investigated how changing social networks helped to understand how migration trajectories evolve after the experience of a critical event. Data was collected between 2012 and 2013, and for 8 informants data collection started in 2009 because of their involvement in other projects Wissink conducted (Wissink et al, 2013). While the analysis in this paper does not consider the more recent larger migration flows and policy developments in Turkey and Greece since 2015, our analytical model addresses the mechanism underlying the relation between migration trajectories and events resulting from changes in the migration 
environment. As such, our model can be applied in order to understand these recent developments. We discuss this further in the conclusion.

The next section explains how we conceptualise migration trajectories of irregular migrants, and is followed by a discussion of the concept of critical events and a theoretical inquiry into the role of social networks for understanding migration. Subsequently, we explain the data and methods. In section four, we present a typology of ways social networks affect the migration trajectory following the experience of a critical event, which is followed by the analysis of three case studies in section five. Section six ends with a conclusion.

\subsection{Theoretical framework}

\subsubsection{The evolution of non-linear migration trajectories}

When large numbers of people move between the same countries, it is common to speak of migration flows. Often studied migration flows are those between Mexico and the US (Durand et al., 1999; Massey, 1987; Mckenzie \& Rapoport, 2007; Pries, 2004) and between various African and European countries, often linked through post-colonial or otherwise historical ties (Carling, 2008; Collyer, 2005; De Haas, 2010; Faist, 1997; Heering et al., 2004; Snel et al., 2006; Toma \& Vause, 2014). Many of these studies aim to explain the causes, continuation and decline of particular migration flows. In this vein, migrants' individual trajectories are considered against the background of these migration flows: for Mexicans it is investigated whether and how they aim to travel to the US; and Africans to Europe. Such images of migration flows and individual trajectories represent a rather linear and Western oriented notion of migration. This paper contributes to a growing body of literature contesting a) the notion of migration as a linear movement, and b) the interpretation of an individual migration trajectory against the background of a migration flow, supposing a certain intended destination of one's trajectory.

Several studies have shown that migration is often far from a straightforward, linear move. This is particular the case for trajectories that involve irregular practices in domains such as entry, residence, labour or exit (Düvell, 2011; Jordan \& Düvell, 2002). In his vein, Collyer (2007) speaks of "fragmented journeys" and Schapendonk (2011) of "turbulent trajectories" to describe the unexpected twists, long stays in places people intended to transit only. The trajectories of irregular migrants are both changing in terms of the geographical direction in which they develop, as well as in terms of their migratory intentions and strategies in one place of residence (Wissink et al., 2013).

Several scholars have explained this non-linearity by considering mobility regimes and geopolitics. Schwarz (2018) argues that trajectories evolve as migrants are navigating opportunities and constraints brought forward by mobility regimes. Restrictive migration policies, for example expressed through border arrests and rejected visa applications, may incite interruptions of journeys or alternative, often riskier, ways of travelling (Carling, 2008; 
De Haas, 2010; Mainwaring \& Brigden, 2016; Schapendonk, 2011). Policies may also offer opportunities, for instance through regularisation rounds. Over time, policies generate fluctuating opportunities and constraints, contributing to changing motives and modes of travelling, and thus the evolution of migrants' trajectories (Wissink \& Ulusoy, 2016).

Fluctuating opportunities are typical in transit migration hubs, which are characterised by volatile social and institutional structures (Wissink \& Mazzucato, 2018). Transit migration hubs, therefore, provide excellent locations for studying the evolution of non-linear migration trajectories. A volatile social structure entails that the social composition is frequently changing as a consequence of daily arrivals and departures. A volatile institutional structure entails that the rules of the game pertaining to asylum and migration are subject to change. In Turkey and Greece, it was observed that sweep operations by the police could be followed by regularisation rounds; that border controls moved from one border region to the other and that seemingly random apprehension rounds on the street in Athens could lead to a detention period of a few hours, or even result in indefinite confinement (Tsitselikis, 2013; Wissink et al., 2013).

While the evolution of non-linear migration trajectories has thus been associated with fluctuating opportunities, it is unlikely that they have the same impact on everyone. After all, not everyone makes use of opportunities offered, or handles constraints in the same way. Not much scholarly attention is given to the underlying mechanism explaining how and why it is that fluctuating opportunities result in changing trajectories. In order to empirically study this, the next section introduces what we have called 'critical events' as a way to operationalise how fluctuating opportunities manifest themselves in the everyday lives of individuals.

\subsubsection{Critical events}

We use the notion of critical events to describe pivotal moments potentially fostering a change in or secure a continuation of an ongoing process, because of new opportunities or constraints they bring forward. A change can entail a change of plans, but also a new direction when there was no prior plan. Critical events thus form potential turning points during the migration trajectory. We distinguish between three types of critical events: events taking place within the realm of social networks, outside the realm of social networks in the institutional structure, and in the personal lives of migrants. Examples of critical events within the realm of social networks are meeting someone new, losing someone's contact details, or receiving a request for help. Manifestations of the volatile institutional structure are for example the rejection of acceptation of a visa application, an arrest at the border, or the experience of an accident while travelling. Life events such as getting a child and getting married are a third type of critical events.

Whether an event is critical and how big its impact is differs from person to person and from time to time. A critical event, therefore, does not occur in a vacuum of space and time. As (Rajchman, 1991) argues, it is not a mere external variable inserted into the 
ongoing everyday lives of people. Rather, it "occurs in the midst of a history, causing us to redistribute our sense of what has gone before it, and what might come after" (Rajchman, 1991, p. xi). It thus depends on the conditions at a given moment in time, whether the factors that make up the potential event set other mechanisms in motion, or not (Kaiser, 2012). This implies that to understand when, why and how events become critical for the way trajectories evolve, it is important to embed them in the context in which they are occurring. We will analyse how the nature of migrants' social networks at the timing of the event, explains how the trajectories evolve. It is thus not our aim to analyse which types of critical events matter for the way migrants' trajectories evolve. Rather, we use the concept of a critical event to mark turning points in the trajectories of our informants as revealed throughout the fieldwork.

Several studies have demonstrated that to understand how migrants deal with opportunities and constraints, we need to consider how migrants make use of information and communication technologies (ICT). Indeed, ICT potentially enable migrants to deal with constraints imposed by restrictive policies, and herewith greatly contribute to the mobility of migrants (Benítez, 2012; Collyer, 2010; Dekker \& Engbersen, 2014; Hiller \& Franz, 2004; Zijlstra \& Liempt, 2017). After the experience of a critical event, such as a failed attempt to cross the border, it is easier to make and receive quick money transfers and contact people for assistance when migrants have access to ICT facilities. Yet, the mere presence of ICT is not sufficient. Social relationships need to be created or maintained that are able and willing to provide a source of support through ICT (Dankyi, Mazzucato, \& Manuh, 2017; Mazzucato, 2011; L. Smith \& Mazzucato, 2009). This, as we will argue, cannot be taken for granted. Similarly, the fact that technologies have stretched out over the globe does not necessarily imply that social relationships are maintained or have similarly expanded (De Bruijn, Nyamnjoh, \& Angwafo, 2010). Thus, in order to understand the evolution of migrants' trajectories, we examine how migrants react to and act upon critical events, and assess how the nature of their social networks at that moment in time, helps to understand this reaction.

\subsubsection{Social networks}

Social network approaches to migration have helped to embed the behaviour of individual migrants in larger macro structures (Boyd \& Nowak, 2012; Gurak \& Caces, 1992). According to migration network theory, migration is more likely to occur when social networks are prevalent between people in origin and destination counties (Massey, 1987). It stipulates that through networks, migration becomes a self-sustaining process where earlier migrants facilitate the migration of newcomers. Social networks thus constitute channels through which resources, such as information, goods, ideas and money, can be exchanged across the borders of nation states (Faist, 1997; Fawcett, 1989; Massey, 1987; Pries, 2004). Such 
transnational social networks have been found to be crucial providers of various support types during migration processes: emotional, instrumental, financial and informational support (Bilecen, 2016; House, 1981). Studies have demonstrated that this is particularly so for migrants who cannot rely on state support, such as irregular migrants in a transit context (Broeders \& Engbersen, 2007; Collyer, 2007; Devillanova, 2008; Koser Akcapar, 2010; Muanamoha et al., 2010; Suter, 2012a; van Wijk, 2010).

Despite the demonstrated importance of social networks, scholars have warned for a network bias (Schapendonk, 2015); a tendency to explain migration predominantly through the lens of networks, while negative feedback-loops within networks (De Haas 2010) or other factors, such as labour market outcomes, remain neglected (Boyd \& Nowak, 2012; Carling, 2008; Snel, Engbersen, \& Faber, 2016; Taylor, 1999). A growing body of literature questions the explanatory power social networks have for understanding migration processes (Broeders \& Engbersen, 2007; Collyer, 2005; Kalir, 2005; Krissman, 2006). For example, the mere existence of transnational social networks does not automatically lead to migration, neither can it explain to where people migrate. Collyer (2005) showed, for example, that Algerians preferred to move to the UK instead of to France to be away from their families. Similarly, Kalir (2005) demonstrated in his study of Ecuadorians in Israel that migrants move to countries where they do not maintain any strong relationships. Additionally, the facilitating role of social networks can be hampered through migration policies that hinder the transfer of resources and of communication and visits, such as strict family reunification procedures or the presence of a fence (Broeders \& Engbersen, 2007; Grillo \& Mazzucato, 2008). Moreover, network members sometimes deliberately choose not to help newcomers, for example due to labour market competition (Broeders \& Engbersen, 2007; De Haas, 2010). Another criticism of network studies is that networks often remain loosely conceptualised and it is not clear why some actors are considered part of networks, and others are not (Krissman, 2006). It is therefore not clear how exactly networks play a role in migration.

These critical perspectives on the role of networks have helped to recognise that networks are not self-evident factors in migration processes. However, this does not mean that social network approaches to migration studies should be dismissed. Instead, in order to grasp the value of networks for understanding migration processes, we have to look at them differently than along the lines of a particular migration flow, as has been common in migration studies.

Conceptualisations of networks along the lines of migration flows, entail that they are considered as linkages between people in particular origin and destination countries. Such conceptualisations refer to a known pre- and post-migration context. We know that in particular in the case of irregular migrants, trajectories evolve in unanticipated and unknown directions. Defining network members by virtue of a destination context is not helpful when this destination is unknown. 
Furthermore, an origin-destination country conceptualisation of networks does not allow for the inclusion of influential network members residing elsewhere in the world; in the places people transit, but also in other parts of the world. Especially when people make use of ICT it is not required for a network member to live in a particular (foreseen) destination country in order to exchange resources that may affect the migration trajectory. What is more, in line with conceptualisations of networks as the linkages between origin and destination countries, most studies focus on the role of strong ties between family and friends in either one of the locations (Haug, 2008; Ryan et al., 2008). Recent studies have addressed the role of weaker ties in migration processes (Gladkova \& Mazzucato, 2017; Ryan et al., 2008; Suter, 2012a). Suter (2012a) found, for example, that fellow migrants in transit contexts are crucial providers of instrumental support. And Gladkova and Mazzucato (2017) illustrate the effect chance (coincidental) encounters can have on the turn migrants' trajectories take.

By predefining the geographical locations of network members and the relationship strength, we not only risk missing out on other influential network members, but we also fail to notice the dynamics in networks. From longitudinal social network analysis (SNA) studies we know that the presence and nature, such as the relationship strength, of relationships with network members can change over time (Feld et al., 2007; Lubbers et al., 2010). Migration studies have only recently begun to recognise and analyse changes in migrants' networks (Ryan et al., 2008; Schapendonk, 2015; Somerville, 2015; Wissink \& Mazzucato, 2018). This implies that over time, relationships are dissolved, and (re-)created. This is the case both for relationships that existed prior to migration, as well as for relationships that are formed along the journey. As the nature of networks is not constant over time, nor can it be expected that their role in the migration process is.

In our conceptualisations of migrants' trajectories and social networks, we move from an origin-destination country perspective on networks to a subject-oriented one (see: Schwarz, 2018). This implies that we lift all time, strength and geographical restrictions when qualifying network members. A subject-oriented approach identifies relationships based on interaction that has taken, is taking, or can potentially take place between the migrant and anyone else (in SNA this is known as personal network analysis, see: Lubbers et al., 2010). Following SNA studies, interaction is defined as an exchange of contact or of a type of support, where we distinguish between instrumental, financial, informational and affectional/emotional support (House, 1981; Bilecen, 2016). We thus understand social networks as the changeable collection of all people with whom migrants exchange instrumental, financial, informational or affectional support, can, or have done so. We further recognise that the presence of people in a network may change, as well as the type and intensity of interaction that takes place between them. 


\subsection{Methodology}

\subsubsection{Transit migration hubs as primary field sites}

The fieldwork for the study was conducted in Istanbul, Turkey and in Athens, Greece. Contact with informants who left these cities was maintained using social media and telephone. With some informants, follow-up interviews were held in other places, including Norway and the Netherlands. Both Istanbul and Athens form transit migration hubs for migrants trying to (often clandestinely) continue their journey elsewhere. The transit character of both cities is visible in migrant neighbourhoods through the large numbers of hotels and other shared accommodation facilities, shops with travel equipment such as life vests (only Istanbul and Izmir) and suitcases, call shops and internet cafes, civil society organisations offering services to migrants and sometimes employment opportunities. It is also visible through the presence of smugglers and "connectors" who link migrants with them (Suter, 2012; Wissink et al., 2013).

Both Turkey and Greece are under pressure from the EU to curb irregular bordercrossings, as the border between them forms one of the main entry points for irregular entry into the EU over land and sea. The presence of the EU, amongst others through FRONTEX missions or EU-funded projects, contributes to the volatility of the migration environment in the region. The volatile policy is also the result of migration policies lacking statutory power, as was the case in Turkey at the time of study, leaving decisions on, for example, granting residence permits and detention to the interpretation of local authorities (Wissink \& Ulusoy, 2016).

Uncertainties and vulnerabilities created by migration and asylum policies contribute to a perceived sense of temporariness in the region: access to asylum and a fair assessment is not guaranteed, and the noticeable threat of apprehension can be felt through the abundant presence of armed police, notably in Athens. Informants reported feeling they were in a state of transit due to these conditions, even if this did not imply they had actual plans to move. In this context, migratory intentions and strategies are highly subject to change (Wissink et al., 2013).

\subsubsection{Sample and data collection}

Fieldwork took place over 17 months in 2012 and 2013. We also build on an earlier field study in 2009 and contacts that were made starting from late 2008 by one of the authors, prolonging data on 8 informants up to four years (Wissink et al., 2013). With most informants contact was maintained via social media and telephone until 2015 or 2016 . The main research sample is composed of nineteen sub-Saharan African migrants in Athens and 21 in Istanbul. It includes only migrants from the West and Horn of Africa to enhance the variety in migration trajectories, while simultaneously allowing for immersion in migrant communities during the fieldwork. We included both men and women in the sample to enhance variation in the trajectories. The choice for sample inclusion was primarily based on theoretical 
saturation where we aimed to capture variation in applied migration strategies. To do so, informants were approached using various gateways: in public places such as squares and markets and snowball sampling techniques. People were asked to participate in the study and its purposes were discussed repeatedly to ensure informed consent. The longitudinal approach of the study entailed that informants were repeatedly contacted and visited. It was possible people to drop out at any time of the study. In two instances, contact with the informants was lost after the first SNA interview, as keeping in touch was challenged through a language barrier.

Data was collected using a triangulation of methods: participant observation, semistructured interviews and personal network analysis. Participant observation enabled the identification of critical events and the observation of how relationships were managed and how migration strategies changed over time. Observations were conducted in public places, private houses, and common meeting points such as Internet cafés, call shops, restaurants and coffee houses. As the fieldwork progressed, participant observation increasingly centred on the lives of 40 informants whom the first author regularly visited in their homes and in some cases in detention facilities, and accompanied to various places such as hospitals, NGOs, lawyers, call shops, local authorities, airports, public transport stations, churches and mosques. Furthermore, participation in daily activities of a selected group of informants was also practiced by selling watches and jewellery, working in sweat shops, shopping, and having dinners together with respondents. These activities provided occasions to observe and experience the critical events migrants encountered, what the role was of social networks in dealing with these and how this shaped the way the course of migration evolved next.

The same informants were repeatedly visited during different periods and contact was maintained in between periods by telephone and the Internet. This allowed witnessing changes in their interactions and activities, and contextualising these within living conditions and policy changes.

Semi-structured interviews were designed to get a longitudinal perspective of the trajectories of informants until the time we met, and to reflect on observations of their migration process and social networks. The interviews also helped obtain informants' own accounts of their personal social networks, which enabled the identification of what network changes were perceived as relevant. An interview guide was used which contained questions on the importance, maintenance, nature and role of various types of social relationships and the experience of critical events. The interviews further invited informants to reflect on their migration process and networking experiences and practices.

A social network survey was designed to analyse the composition and structure of migrants' personal social networks. A multiple name generator questionnaire containing questions on various kinds of support was developed to identify the persons with whom the informants exchanged four types of support: emotional/affective, instrumental, informational and financial (Amelina et al., 2012; Bilecen, 2016; House, 1981). A year later, 
we reflected on changes in the outcome of this survey with 21 out of 23 migrants who remained and could be reached in Istanbul and Athens.

\subsubsection{A mobile research approach}

Research on migration trajectories can be conducted in various ways. One is to follow informants to the various countries to and through which they move (for example: Schapendonk, 2011). Another way is to study how trajectories evolve during residence in a particular site, as trajectories not only evolve in terms of the geographical direction, but also in term of migratory intentions and migration strategies. This study concerns a combination of these two approaches: I met with some informants in both Turkey and Greece, or included their onward or backward movement between Turkey and Greece in the analysis. Within Turkey and Greece, several places were visited to follow the migrants' journeys. Within Istanbul and Athens, we followed changes in migrants' trajectories in terms of the aspired or adopted migration strategy. Finally, we maintained in touch with informants who had left Greece or Turkey, or returned again after a journey to a third country.

Keeping track of the various locations and strategies of our informants, required the adoption of a mobile research approach. This has several advantages. First, data on trajectories evolve was collected as it was evolving, rather than retrospectively. Second, new migration strategies, changes in networks and the experience of new critical events could be understood in relation to contextual information about the new geographical context. Third, meeting informants in various places further contributes to the level of trust and familiarity between the researcher and informants. The approach is also challenging; it adds to the complexity of the research subject: it is impossible to take all new contextual information into account that is gathered as the trajectory progresses. Furthermore, the approach is time consuming and therefore choices need to be made on what trajectories to follow indepth. This potentially leads to a biased selection of trajectories that are rapidly changing in favour of those that evolve at a calmer pace. We dealt with these challenges by selecting cases based on theoretical saturation, where we strived for a diversity of trajectories in terms of pace and adopted migration strategies.

\subsection{The evolution of trajectories and networks}

As we will demonstrate, the fieldwork revealed a relation between the type of interaction and support exchanges that are taking place in a migrant's network, and the ability to pursue the trajectory as desired following the experience of a critical event. Support exchanges and interaction in the network, or the lack thereof, can be both enabling and constraining this ability. This led to the construction of a typology of ways in which migrants' networks are associated with the evolution of trajectories following the experience of a critical event (see Table 6.1). 
Table 6.1 Typology of network roles for dealing with critical events

\begin{tabular}{|c|c|c|c|}
\hline & \multicolumn{2}{|c|}{ Ability to pursue desired trajectory following a critical event } \\
\hline & & ENABLING & DISABLING \\
\hline \multirow{2}{*}{ 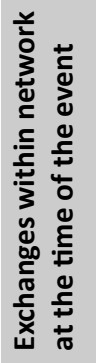 } & $\begin{array}{l}\text { Interaction/support } \\
\text { exchanges are taking place } \\
\text { and are sufficient }\end{array}$ & $\begin{array}{l}\text { Type 1: } \\
\text { The interaction/exchanges } \\
\text { enable a desired continuation } \\
\text { of the trajectory }\end{array}$ & $\begin{array}{l}\text { Type 2: } \\
\text { The interaction/exchanges } \\
\text { disable a desired continuation } \\
\text { of the trajectory }\end{array}$ \\
\hline & $\begin{array}{l}\text { Interaction/support } \\
\text { exchanges are lacking or } \\
\text { insufficient }\end{array}$ & $\begin{array}{l}\text { Type 3: } \\
\text { Lacking interaction/exchanges } \\
\text { enable a desired continuation } \\
\text { of the trajectory }\end{array}$ & $\begin{array}{l}\text { Type 4: } \\
\text { Lacking interaction/ } \\
\text { exchanges disable a desired } \\
\text { continuation of the trajectory }\end{array}$ \\
\hline
\end{tabular}

Below we discuss each type. In section 6.5, we subsequently we explain that as networks continue to change and new events continue to occur, several types may be at play at different times during the evolution of the migration trajectory of individuals.

Type 1: The interaction/support exchanges enable a desired continuation of the trajectory This type of network role implies that interaction and support exchanges that are taking place at the time of a critical event enable the continuation of the trajectory as desired. This implies that, because of the existing interaction and support exchanges, migrants are able to make use of opportunities, or combat constraints brought forward by critical events. This is the case, for example, when following an arrest at the border and the confiscation of travel documents, which are examples of two critical events, migrants can mobilise support in their networks to arrange a second attempt to cross the border. Another example is when results of the asylum procedure are not forthcoming and migrants are not allowed to work but receive continuous support from network members to cover living expenses.

Type 2: The interaction/support exchanges disable the desired continuation of the trajectory

The presence of interaction or exchanges with certain network members can also constrain the evolution of the trajectory as desired. This is the case, for example, when perceived expectations and obligations directed the way migrants allocated their resources following a critical event. The objective of providing for family members was in several cases prioritised over continuing journeys to Europe. In other instances, we observed that support provided to informants was conditional; support was only provided if it was used for specific purposes, which not necessarily matched the informants' desires. This is the case for example when financial support is offered to travel to Europe and not to sustain a livelihood on Turkey as some informants aspired. The exchange of notably information support, could lead to a continuation of the migration trajectory in a way that was initially not desired. 
Type 3: Lacking interaction/support exchanges enable the evolution of a desired trajectory Contrary to type 2, sometimes the absence of interaction in networks meant the absence of related constraints, expectations or obligations vis-à-vis others because of which people were better able to deal with critical events and continue their trajectories as desired. Some, for example, did not want to maintain in touch with family members when his living conditions deteriorated, in order to be better able to emotionally cope with the way his trajectory evolved. We observed various other cases where turning down offers for support enhanced the informants' feeling of self-worth and autonomy in shaping one's trajectory.

Type 4: Lacking interaction/support exchanges disable the evolution of a desired trajectory This last type entails the opposite scenario of type 1, where a lack of support exchanges constraints the evolution of the trajectory in a desired fashion. Ultimately, crossing a border, waiting for asylum results and finding a job, require some kind of resources that are mobilised through relations with others. These relations do not need to be strong or present for a long time; moreover, they can as well result from a chance encounter with someone sharing a valuable resource with you in a crucial point in time. Yet, when required resources are absent, this can result in rather precarious and vulnerable situations where the trajectory is mainly shaped by survival strategies.

Over time, migrants experience a variety of critical events whilst their networks continue to change. This implies that the nature of migrants' relationships with network members is not constant. Over time, various types of network roles can explain how migrants deal with critical events and shape their migration trajectory accordingly. Therefore, investigating migrants' changing embeddedness in their social networks over time is key in understanding the impact of critical events on migrants' evolving trajectories. We illustrate this by presenting three case studies.

\subsection{Case studies}

We present three case studies to illustrate how our typology of network roles help to explain how trajectories evolve in relation to critical events and changes in social networks. The three cases were selected because they jointly illustrate how over time various network roles are at play. Each case is introduced by a short vignette, explaining how a migration trajectory has evolved. We subsequently show that the way migrants have dealt with critical events explains how the migration trajectory evolves and how this is embedded in how their networks have evolved until that point in time. Next, we show that as the migration trajectory evolves, migrants' networks continue to do so as well. This in turn affects how they deal with subsequent critical events. For all cases, data were collected over a longer period of time than is presented. Here we focus on the part of the trajectory that illustrates how networks and trajectories co-evolve to affect the way migrants deal with critical events. 


\subsubsection{The case of Osman}

Osman had fled from Eritrea to Sudan after a colleague informed him that the authorities were after him. In 2009, he travelled via Turkey to Greece, from where he first attempted to move to Albania, and later to Italy. Eventually, he applied for asylum in Greece. When his application was rejected, he continued his journey to various other countries in Europe where he applied for asylum.

Osman and I met in 2012 when he was awaiting the results of the asylum procedure. Earlier on, he had lived in an informal settlement on a hill, from where he and others had been trying to leave Greece by climbing under a truck that would be shipped to Italy. He had to abort his attempts after he dislocated his shoulder during an accident. This formed a critical event because of which he was unable to continue trying to leave Greece in this way. Even though this is what he desired, he continued to live on a hill for another fourteen months. Because of his dislocated shoulder he was unable to work and thus would need to mobilise financial support among others to pay for less risky ways to leave Greece. Yet, as Osman had been living on the hill for months, away from communication infrastructures to reach out to others, he did not maintain any other relationship beyond the hill than with his brother in Sudan, who occasionally sent a bit of financial support. The lack of sufficient, mainly financial support, constrained him to find an alternative way of leaving Greece as he desired. As a consequence, he continued to reside on the hill. This is an example of type 4 of the network role, were lacking support disables the continuation of the trajectory as desired after the experience of a critical event, in this case an accident.

Fourteen months later, the hill was raided by the police. This formed another critical event after which Osman's trajectory took a new turn: he applied for asylum. Many others who had been living in the informal settlement continued trying to leave Greece one way or another or stayed on irregularly in Greece. A chance encounter explains Osman's new turn: When the police raided the hill, activists from migrant solidarity groups support the people living on the hills. Among them was Despina, who would later introduce me to Osman in Athens. She was well connected to NGOs and human rights lawyers. Hearing about the accident, Despina offered to take Osman to Athens to get medical care. Moreover, she offered to assist him with filing an asylum claim. Being a single man, this would have been virtually impossible without Despina's help, as the Immigration services only accepted 20 applications a week, while hundreds of people would gather in from of their building (see: UNCHR, 2012). NGOs mainly assisted families and single women with filing an asylum claim. Because of his application he obtained a "pink card", which is an asylum seeker's residence permit which allowed him live and to move around Athens legally and thus relatively free. This is an example of a type 1 role of networks, where a chance encounter provided him with a source of support, enabling him to find a way to deal with the event of the police raid because of which he was unable to stay on the hill. 
As his length of stay in Athens extended, Despina's role in his life became bigger: she assisted with finding accommodation, accompanied him to the immigration services for interviews, and connected him to NGOs. When I met Despina, she always inquired about him, and asked me to send him her regards when I was going to meet him. The friendship that had grown between them was a vital source of both instrumental and emotional support to Osman. Among the other migrants Osman knew in Athens, he was one of the few ones with a pink card, and who was not attempting to leave Greece because his prospects in Greece improved (type 1).

The critical events of the accident, the police raid and the encounter with Despina and the type and amount of support that was available in his network at those times informed the change in Osman's trajectory from attempting to leave Greece to applying for asylum. Tides turned again after the experience of two subsequent critical events: the rejection of his asylum claim and the confiscation of his pink card. This resulted in a situation where all his actions and daily activities were directed at daily survival. Critical events that meanwhile occurred in the realm of his network explain why these two events immediately contributed to a rather precarious situation.

First, when Osman learned his asylum application was rejected and his pink card was confiscated, he was unable to reach Despina. He hoped that she would have been able to provide him with access to lawyers to start the appeal procedure and retrieve his pink card. Yet, she was not answering phone calls, nor did she stop by in his neighbourhood as she used to. I maintained in touch with Despina, who explained to me that she felt overwhelmed by the number of migrants she assisted at that time. Combined with events in her personal life, she took the decision to step back. The second change was that Osman's brother could no longer send him financial support as he used to, because of the devaluation of the Sudanese dollar.

The lack of instrumental support from Despina and the financial support from his brother, constrained Osman in dealing with the event of his pink card being confiscated. Without it, he risked arrest and imprisonment and therefore he hardly left his house. His actions were directed at daily survival; the absence of support disabled him to continue his trajectory by settling in or leaving Greece. This is an example of a type 4 network role, where a lack of support disables Osman to deal with the rejection of his pink card and the loss of income.

Consequently, he prioritised buying food over buying phone cards, and he abstained from contact with his family in Sudan and Eritrea. While his brother continued calling him, Osman asked him to stop doing this, as he did not want to face the confrontation of missing his family in this already precarious situation. To stop the interaction with his family enabled him to cope emotionally with the way his migration trajectory progressed, and take time for deliberation on how to proceed. This is an example of type 3, where the lack of interaction enabled him to focus on his trajectory. Meanwhile, his roommates continued trying to find ways to leave Greece. Because of the strategies this involved, the day and night rhythms of Osman and his roommates were opposites. Therefore, Osman had less and less interaction 
with others. He abandoned strategies to leave Greece or regularise and was only focused on daily survival. This is again an example of type 4, where lacking support exchanges disable to continuation of the migration strategy as desired.

Osman's case shows that opportunities to deal with a critical event, such as an accident and losing documents, are associated with opportunities to mobilise support within networks. These opportunities fluctuate when contacts become unavailable or unable to provide support. At the same time, Osman withdrew from his existing contacts, as a way of emotionally coping with the challenges he was facing in Greece. Thus, not only the opportunity to contact others, also the willingness to maintain these contacts inform how networks play a role with dealing with critical events. Osman's case further demonstrates that that relationships formed en route, rather than merely pre-migration networks, can have a vital impact on how people deal with critical events. In Osman's case, it meant the difference between being irregular without having a prospect of leaving Greece, and having a chance to apply for asylum.

\subsubsection{The case of Ibrahim}

Ibrahim was born to Somali parents in Saudi-Arabia. When he was 17 years old, he and his family were deported to Somalia. Ibrahim felt he did not belong there and he decided to return to Saudi-Arabia. Via Yemen and Turkey, he arrived to Greece in 2012. From there, he tried to leave Greece various times, he considered moving back to Turkey, worked as a connector and later left Greece by plane.

On his way to Saudi-Arabia Ibrahim travelled through Yemen, where he got engaged. When the Yemeni war broke out in 2011 , the couple decided that Ibrahim would travel to a safer country in Europe, and that his fiancée would join him afterwards. Ibrahim travelled to Turkey, where we met first. Friends in Yemen had helped him to accumulate the financial resources he needed to travel. In Turkey, he was busy arranging his journey to Greece, where we met a few months later. At that moment in time, he had run out of his financial resources. Ibrahim had not intended to stay in Greece for a very long time, but the lack of financial support constrained his opportunity to travel onwards. This is hence an example of a type 4 network role.

As months passed by, the family of his fiancée was getting impatient about their marriage. Running out of resources and the conversations with his fiancée inquiring about his whereabouts formed critical events as Ibrahim had to urgently find a way to leave Greece. The pressure he felt from his fiancée and her family constrained him in taking time to accumulate resources to continue his journey, after he had lost the financial support of his friends. Ibrahim could think of one potential source of financial support: his cousins in the USA. During several of our meetings, he told me that he deemed asking for support would be impolite. However, by telling them about the living conditions in Greece via Facebook, he hoped that they would develop the idea to support him. Indeed: his cousins had offered a 
type of instrumental support which enabled Ibrahim to try and leave Greece by plane. This is a type 1 network role where the existence of support exchanges enable Ibrahim to deal with the fact he had run out of financial resources and with the pressure he felt to migrate further.

Ibrahim's attempt to leave Greece with the support of his cousins was unsuccessful and traumatic to him: when police officers at the gate realised there were inconsistencies in his travel documents, he was handcuffed and taken to a room in the basement of the airport. There he was severely beaten by the police officers, after which he was send back to Athens. Ibrahim felt devastated about what happened. He described it as if his only road to achieve something had been blocked. Although his cousins promised to help him again, this did not materialise. The critical events of failing to leave Greece and the physical abuse at the airport coincided with another critical event only a few days later: a phone call from his fiancée in Yemen telling him that her parents had arranged a marriage for her because it took too much time to wait for Ibrahim. By then, she had refused to marry someone else twice, but this time her family went through with arranging a marriage.

Ibrahim was even more devastated because of this, he exclaimed. Until these events, Ibrahim's network had a rather transnational character: he occasionally received some financial support from friends in Yemen and Saudi-Arabia; he had received help from his cousins in the USA who helped him to arrange a journey, and he exchanged information about travelling routes with other Somali migrants he had met on his way. Due to the critical events of the failed attempts to leave Greece, the physical abuse he experienced, and the marriage of his fiancée with someone else, he lost both his incentive and resources to travel to Europe. It was painful for him to talk with friends and his former fiancée in Yemen, and he did not see a reason to stay in touch with his cousins of whose promise to support once more did not materialise. At the same time, more and more acquaintances of his in Athens, including his roommates, were arrested and imprisoned because of their irregular status. One year after Ibrahim told me about the arrest of his roommates, they were still in prison. As a result, Ibrahim's network became smaller and more local.

Lacking support exchanges after a series of critical events directed Ibrahim's trajectory in a new direction: he considered moving back to Turkey as he had seen others do. This type 3 network role enabled Ibrahim to regain control over his migration trajectory. Meanwhile, in order to save money for a journey, he began working as a "connector": someone who brings migrants in touch with smugglers. Yet, he did not feel this work was moral and it distracted him from focusing on his own journey. Above all, it was very risky. He therefore quit, but was indecisive about his next strategy.

A few months later Ibrahim met a Somalian businessperson who was touched by Ibrahim's bad luck regarding his engagement. This was an exceptional experience to Ibrahim, as he never felt he fit into the Somalian community, because Arabic was his first language and not Somalian. This businessperson helped him with getting travel documents, by which Ibrahim managed to get on board of a plane to another European country. This 
type 1 network role was constituted by a chance encounter that enabled him to proceed with his desired departure from Greece.

Ibrahim's case shows that the possibility to form or activate relationships in other parts of the world are potentially helpful to act upon critical events experienced in Greece. These relationships would have remained undetected if his network would have been defined by relationships in the country of origin and destination only. Moreover, being born in SaudiArabia and having lived in Somalia and Yemen and not having a clear destination in mind, in Ibrahim' s case the country of origin and destination would have been hard to identify. The way Ibrahim's trajectory evolved next shows the importance of timing: because his journey lasted longer than anticipated, his fiancée married with someone else and therefore took a different position in his network. It further shows that while contacts abroad may be activated to mobilise support, this support is not permanently available. How Ibrahim eventually dealt with a rather hopeless perspective in Greece, was largely influenced by a chance encounter with the businessperson who enabled his journey out of Greece. This illustrates the role of chance, luck and the influence of weak ties.

\subsubsection{The case of Isa}

As a jewellery maker from Senegal, Isa had the chance to travel to various countries before coming to Turkey in 2011. He intended to travel to other Europe to give workshops in jewellery making. However, he applied for asylum in Turkey instead. Later, he dropped out of the procedure, obtained a residence permit later on and travelled to the Balkans. Afterwards, he returned to Turkey, from there he went to Senegal and again back to Turkey.

When Isa and I met, his Turkish tourist visa had just expired. This formed a critical event for Isa, as it turned his status into an irregular one; this was not planned, and as he put it, "the first illegal act of his life". According to a friend of his with whom I met later in Greece, Niaye, Isa initially planned to travel to join him in Greece. Yet, Niaye had advised him not to come to Greece because he deemed the living conditions there harsher than in Turkey. Moreover, he believed that in times of financial crisis, no one in Greece would be interested in taking jewellery classes. Upon this informational support from his friend in Greece, Isa stayed in Istanbul. This can be considered as a type 2 network role, where the exchange of information implies that the migration trajectory is not continued as initially desired. His roommates in Istanbul recommended him to apply for asylum in Turkey instead in order to regularise his stay. His roommates thus provided a type of informational support enabling Isa's to deal with the fact he had become irregular, making this an example of a type 1 network role.

As part of the asylum procedure, Isa was referred to a so-d satellite city, which was about a 10-hour drive from Istanbul. This referral formed a new critical event and his trajectory took a new turn: he withdrew from the asylum procedure and became again irregular. The city was far away from Istanbul and he had no active network there, which 
would make it hard to arrange jewellery making workshops. At the same time, his wife in Senegal expected him to regularly send goods. He had to make sure he could make an income, chances of which were lesser in the satellite city. He therefore decided to stay in Istanbul, and as a consequence was expelled from the asylum procedure and became again irregular. This is an example of a type 2 network role where expectations regarding support exchanges disable the continuation of his migration trajectory as desired following the event of the referral to the satellite city.

For Isa, the closure of his asylum procedure formed a critical event, as he was unable to regularise his stay which he deemed necessary to make a career in Turkey. Yet, at the same time, he had met with an American jewellery maker in Istanbul, who involved him in jewellery making workshops. Although this meant Isa's status remained irregular, it would potentially contribute to achieving his goal of earning a living and supporting his family by giving workshops in jewellery making. Yet, this did not materialise quick. Meanwhile, he felt his mother and wife in Senegal to whom he promised to send financial support, were getting impatient. Their phone calls to Isa formed critical events because he put his career as a jewellery maker on hold and concentrated on selling watches on the street in order to support his family. In this way, his trajectory was taking longer than anticipated and Isa remained indecisive for a while whether he should return to Senegal, move to the satellite city and reopen his asylum case in order to gain more time for finding a durable solution.

In June 2012, the government of Turkey issued an unprecedented policy directive: visa overstayers could pay a fine and apply for a temporary residence permit that would be valid for six months. The amount of the fine depended on the length of the irregular stay in Turkey. For Isa it meant he had to pay a few hundred liras, which he did not have as he sent all money he earned to his mother and wife. The policy directive, was therefore not immediately a critical event, because it did not directly impact on Isa's opportunities. However, soon after this Isa met with a well-known Turkish jewellery artist in Turkey who was willing to invest in Isa's career. He offered to help him getting the temporary residence permit by paying the fines and fees. With the residence permit he obtained, Isa could travel to various other countries, and visit his family in Senegal. This illustrates a type 1 network role event, where the availability of support enables the continuation of a migration trajectory.

Isa's trajectory has shown that how the way he dealt with critical events following from migration and asylum policies is informed by constraining or enabling interaction with members of his network at that moment in time: the available instrumental and informational support, and expectations to provide support, informed his decision not to follow the official procedure to relocate to a satellite city, and to instead stay in an irregular fashion. Furthermore, his case illustrates that not merely the policy directive informed how Isa's trajectory evolved from being in a undocumented to a regular position, but the fact he had met an artist on his way who was willing to support him by paying the fees and fines to make use of the opportunity the directive offered. Had the directive been issued months earlier or later, or had Isa met with the jewellery maker at a different moment in time, it 
would not have been likely that Isa could regularise his stay in Turkey. This case shows the importance of timing of events and changes in networks.

The analysis of the cases, of which three are presented above, indicates that the way migrants deal with critical events is associated with the nature of their network at the timing of the event. This nature entails what types of support relationships migrants are engaged in, which can be both enabling and constraining the way migrants deal with critical events and how the trajectory evolves next.

Whether support exchanges are taking place or not, depends on two main factors: the opportunities and willingness to do so on both the side of the migrant and the network member (Wissink et al, 2013). First, the opportunities to connect, interact and exchange support need to be there. This means having the actual contact, being able to reach this contact and being able to exchange resources. Second, there needs to be a willingness to interact and to make use of support offers. Both the opportunities and willingness to interact and exchange fluctuate over time. Opportunities change when the presence of certain relationships in networks alter: migrants meet new people on their way, while others leave. Also the presence of a communication infrastructure impacts on the opportunity to keep in touch vary over time and place: informal settlements without internet connections or a mobile phone network hamper the mobilisation of support elsewhere. The willingness to interact alters as the nature of the relationships change, for example when people feel they have depended on the support of others for too long, and break the contact to regain a sense of autonomy.

We found that the dimension of timing and chance is crucial in understanding how the willingness and opportunities to exchange support change, and whether this has an enabling or constraining effect on how migrants deal with critical events and thus on how their trajectory proceeds accordingly. Thus, to understand the impact of a critical event on the migration trajectory, it is necessary to be aware of what networks looked like at that specific moment in time.

\subsection{Conclusion}

This paper studied the role of social networks in the evolution of the migration trajectories of irregular migrants in Turkey and Greece. This role has long been subject to debate in the migration literature, and often opposed to the effect of (restrictive) migration policies. In the literature, networks are commonly understood as the (potential) linkages between people in origin and destination countries that are typical for certain migration flows. We argue that this conceptualisation is not adequate for understanding how networks are associated with the evolution of migration trajectories. A network conceptualisation based on migration flows assumes that migration trajectories evolve in line with these flows, and that often strong ties with people in origin and destination countries influence the trajectory most. 
These assumptions give strong explanatory power to macro level factors such as colonial or other historical ties between two countries, for the evolution of individual migration trajectories. While we do not dismiss these factors, the diversification of migration patterns between Africa and Europe of the past decades (Grillo \& Mazzucato, 2008; Wissink \& Ulusoy, 2016) show that such macro level factors are not sufficient, nor adequate to explain the evolution of individual trajectories.

Instead, we adopted a subject-oriented approach to conceptualise migrants' networks to investigate how they matter for the way individual trajectories evolve. This entailed that network members were not identified through their geographical location or strength of the relationship with the migrant, but through the type of interaction between migrants and others. In this way, we were able to grasp the variety and changeability of network members that played a role in shaping the migration trajectory: weak relationships, including chance encounters, and network members in various parts of the world could equally, and sometimes better, explain the turns in trajectories than relationships with people in origin and (anticipated) destination countries.

We demonstrated that migrants' changing social networks explain how migrants deal with critical events they encounter in their daily lives. As social networks change over time, the availability of resources fluctuates, as do opportunities to act upon events. The continuous experience of critical events and the constantly changing social networks contribute to fluid migratory intentions and decisions and result in the creation of nonlinear migration trajectories (Wissink et al., 2013).

Our approach further allowed for a different consideration of the relation between the explanatory powers of social networks vis-a-vis that of migration policies: instead of investigating which best explains the evolution of migration trajectories, we investigated how they interact as the migration trajectory evolves over time. We demonstrated that not merely policy outcomes such as arrests at the border, the results of asylum procedures or regularisation rounds shape the non-linearity trajectories, but whether network interactions enable or constrain the way migrants act upon this. It is thus important to also analyse and contextualise policy effects by examining the meso-level, meaning migrants' social networks.

It was beyond the scope of this paper to describe to what extent migrants negotiate the role of their networks in dealing with critical events. Further research could aim to provide more insight into the agency migrants exert while interacting with network members when dealing with critical events. Future research could further build on the present study by examining how the various roles networks play differ across ethnicity and gender.

Our paper has shown that the value of a social network approach for understanding how migration trajectories evolve becomes evident when the changeable nature of networks is considered, which has only been possible through our longitudinal research design. In the same vein, we show that research designs need to move beyond linear depictions of migration trajectories suggesting moves from $A$ to $B$ and the rather dualistic question of whether social networks facilitate migration or not. By considering migration trajectories 
and social networks as co-evolving over time, we become more aware of the complexities of contemporary migration, such as the more recent events in Turkey and Greece. In 2015, a large number of people fled to Turkey and Greece. One year later, the EU-Turkey deal was concluded, where Turkey agreed to readmit migrants from Greece in return for EU support in dealing with refugees in Turkey, including resettlement. The larger number of people and the EU-Turkey deal are likely to constitute critical events in the lives of individual migrants, such as increased smuggler's fees, or a readmission to Turkey. Whether or not this informs people's choices to stay in refugee camps in Turkey, move to Turkish cities and work in the informal sector, move elsewhere, or how they act upon readmissions to Turkey (i.e. by having access to legal support) is expectedly associated with what their social networks looked like at the timing of such events. 

Chapter 7

The co-evolution of migration trajectories and social networks 



\section{Chapter 7: The co-evolution of migration trajectories and social networks}

Migration research is predominantly engaged with pre- and post-migration questions, such as why and to where people migrate, and what the socio-economic and political consequences are for countries of origin and destination and for the linkages between them. Instead, this study contributes to an emerging scholarly field investigating the migration process itself once migration has commenced but not yet ended (Schapendonk, 2011; Wissink et al., 2013). This brings forward new research questions, such as the research question of the present thesis: By what mechanisms do the migration trajectories of irregular Sub-Saharan African migrants in Turkey and Greece evolve? The answer to this question yields insights in the dynamics of migration process and will advance our understanding of how migration processes evolve, as well as the development of policies to manage them.

The literature on pre- and post-migration phenomena has extensively addressed the explanatory power of social networks. For example, studies on the role of networks in migrant decision-making have demonstrated that the likelihood of migration increases when people maintain social networks in potential destination countries (Fussell, 2010; Massey, 1990). It has been shown, however, that this role can be hampered through migration policies, for example when they obstruct cross-border visits or the transfer of resources (Broeders \& Engbersen, 2007; Mazzucato, 2009). Furthermore, the facilitating role of networks declines when labour market competition discourages earlier migrants to help newcomers (Collyer, 2005; De Haas, 2010). Changes in the networks after migration have been studied in order to understand integration processes and the formation of transnational social networks (Lubbers et al., 2010; Snel et al., 2006). In this study, instead, I have examined the role of networks during the migration process in order to understand the evolution of trajectories.

Each of the preceding chapters has provided a partial answer to the research question, and each serves as a building block of the analytical model presented later in this chapter. Chapter Four illustrated the association between societal and institutional developments and the migration trajectories of Sub-Saharan African migrants in Turkey and Greece. In Chapter Five, these developments were operationalised as potentially occurring critical events in migrants' daily lives. There, I described how critical events are associated with changes in the nature of migrants' social networks. Critical events produce transformations in migrants' individual opportunity structures (IOS), which consist of relationship preferences, resources, and communication infrastructures. In Chapter Six, changes in migrants' social networks were considered in order to analyse the impact of critical events on migration trajectories. The chapter showed how the way the network has evolved explains how critical events are being dealt with, and explains the way the trajectory evolves. It revealed that resource exchanges in social networks can both enable and constrain the way migrants deal with critical events, and both can lead to a change or a continuation of the trajectory's evolution. Jointly, the previous chapters have illustrated various mechanisms linking social networks 
and migrants' trajectories through the experience of critical events. Figure 7.1 presents these various mechanisms in the analytical model.

Figure 7.1. The co-evolution of migration trajectories and social networks

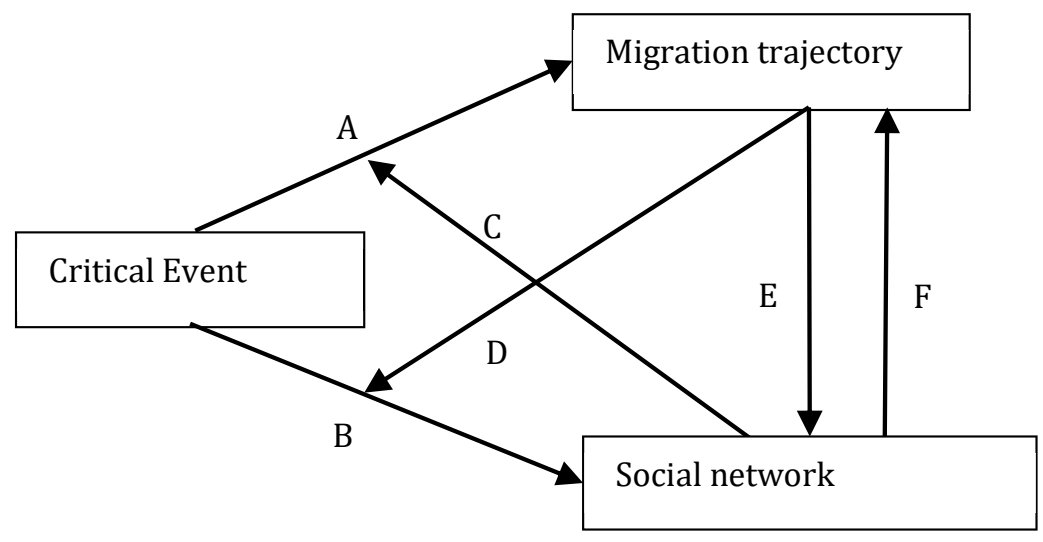

There are two mechanisms explaining the evolution of migration trajectories, and two explaining that of social networks:

\section{Migration trajectories:}

1) The nature of a migrant's social network informs how the trajectory evolves following a critical event. (arrows $C+A$ )

2) A critical event informs how social networks evolve, which leads to a change in the evolution of the migration trajectory. (arrows B + F)

Social networks:

3) The migration trajectory informs how the social network evolves following a critical event. (arrows D + B)

4) A critical event informs how trajectories evolve, which leads to a change in the evolution of the social network. (arrows $A+E$ )

Mechanisms 1 and 3 are moderating effects: the impact of one critical event on social networks or migration trajectories is influenced by the other factor. Mechanisms 2 and 4 are indirect effects: the transformation of the social network or migration trajectory due to one critical event, fosters a change in the other factor.

Two other potential mechanisms are left out of the discussion: the effect of social networks and the migration trajectories on critical events. The type of social network and the phase of the migration trajectory influence the type of critical events a person can 
encounter. The primary concern of this study is the evolution of migration trajectories and the role of networks therein. While I assess the importance of critical events, it is beyond the scope and purposes of this study to explain the type of those critical events.

In this synthesising chapter, I bring these various mechanisms together in the analytical model explaining the central argument of the thesis: migrants' trajectories and their social networks co-evolve through the continued experience of critical events. I illustrate the model by returning to some trajectories presented in the previous chapters and explaining their co-evolution with their networks as critical events continue to occur.

In Chapter Four, I introduced the migration trajectory of Mohamed from Guinea. He intended to go to Greece, but stayed in Turkey instead. The increased border controls between Turkey and Greece had caused a rise in smugglers' fees which Mohamed could not pay, which hence formed a critical event. At first sight, this indicates a direct effect of border policies on a migration trajectory. In Chapter Five, it becomes clear that network dynamics explain how Mohamed dealt with the increased smugglers' fees: he used the financial resources to stay in touch with his family instead of paying the smugglers' fees. In this way, he sustained his role as a mediator in his family. His trajectory did not evolve towards Europe, as he originally intended, and he stayed in Turkey instead. Thus, the nature of his relationships with his family in Guinea informed how he acted upon the critical event of having to pay higher fees due to strengthened border controls (mechanism one). His ongoing residence in Turkey then helped expand his local network (mechanism four). His ongoing residence in Turkey and encounters with local business men changed his ties with his family in Guinea (mechanism three). Ultimately, because of these changes, his trajectory evolved towards starting his own business in Turkey (mechanism three).

Chapter Four also portrays part of the trajectory of Safiye, a Somalian woman who travelled from Turkey to Greece and back to Turkey in hopes of reuniting with her son in Norway. When resettlement in Turkey was not in sight, she travelled to Greece. There, she made several attempts to leave the country, which were unsuccessful as she was stopped by the border police. After each failed attempt, she was able to try again because of the financial support of her son (mechanism one). Meanwhile, she contacted the Norwegian Embassy to apply for family reunification. When this application was rejected and after failed attempts to leave Greece, she contacted people in Turkey. I, through my network, informed her that her asylum case with the UNHCR in Turkey was still active. She further heard from people with whom she used to work in Turkey that they would welcome her back and assist her with housing. These two pieces of information from her network incited her to go back to Turkey following the events of being arrested at the border and the negative answer from the embassy (mechanism one). She indicated that she was "free to travel" because the only network member she attached value to was her son. Over the years, while she was negotiating strict family reunification and resettlement procedures and pending asylum applications in Turkey, her network had become very scattered and 
ultimately centred around her son only, influencing her decisions to move between Turkey and Greece (mechanism four).

Chapter Four briefly discusses the trajectory of Patrick from Senegal. After having been confronted with violence by police officers in Greece at the airport, he continued his trajectory by walking to Macedonia. His decision to leave Greece was influenced by the diminishing protection he used to receive from students of a university in Athens (mechanism one). This decision had consequences for the relationship with his parents, whom he could no longer financially support, as he needed his money for his journey (mechanism three).

The findings illuminate that trajectories and social networks are co-evolving through the continuous experience of critical events. The analytical model helps to unpack the mechanisms underlying this co-evolution. Through critical events, migrants' individual opportunity structures for managing the nature and presence of relationships in their social networks can change. The nature and the presence of social networks, in turn, explains how subsequent critical events are dealt with and how migrants act upon opportunities and constraints these events bring forward. This can result in the continuation or a change of the migration trajectory as it is evolving.

Thus, what matters for the evolution of the migration trajectory is not necessarily the manifestations of border, asylum and migration policies in daily life, but rather how this is mediated through migrants' social networks. This mediation can be characterised by the presence or absence of resource exchanges, originate from social network members or from the individual migrant, all of which can have an enabling or constraining impact. The 'role of the social network' is thus neither self-evident nor constant over time, on the one hand because the presence and nature of ties within the network change, on the other hand because migrants have different needs, intentions and expectations from members of their network over time.

The analytical framework, and the findings on which it is based, challenge dominant scenarios of the impact of networks on migration processes in the migration literature, where the role of networks is either contested, or it is argued that it is time to move beyond the network in seeking explanations for the evolution of migration processes (Bakewell et al., 2016; Snel et al., 2016). The framework further argues for a dynamic view on network, where specific roles of networks are not strictly related to specific components within a network. For example, the often-cited idea that network members in Europe facilitate migration and that relationships with families in origin countries dissolve if support is not forthcoming and migrants as a result cannot return does not hold when looking at networks dynamically. The conclusion elaborates on the wider implications of this research for the study of social networks and migration trajectories and the linkages between them. 



\section{Chapter 8 \\ Conclusion}





\section{Chapter 8: Conclusion}

\subsection{Introduction}

This thesis analyses how migration trajectories of irregular sub-Saharan migrants in Turkey and Greece evolve over time, and how this evolution is associated with changes in migrants' social networks and critical events. Migration trajectories are defined as the sequence of the migration strategies which migrants adopt during their journeys. Migration strategies are ways in which migrants enact their migratory aspirations at a specific moment in time and can refer to both mobile and immobile parts of their journeys. Examples include crossing a border, applying for asylum or sustaining undocumented residence. 'Irregular' implies that parts of the trajectories are unauthorised in the domains of residency, labour, entry or exit of a country (cf. Jordan \& Düvell, 2002). This thesis has studied mechanisms underlying the non-linear evolution of irregular migration trajectories.

Senait's migration trajectory, described at the opening of this thesis, illustrates a non-linear evolution of a migration trajectory: she first resided in Turkey temporarily and attempted to migrate to Greece, after which she first worked irregularly in Turkey, where she later on applied for asylum (in Turkey) and was recognised as a refugee. Later she migrated to Greece, where she stayed a few years before attempting to migrate further to Western Europe. While trajectories or irregular migrants are thus commonly not constituted of straightforward moves from one country to another, migration studies and policies generally treat trajectories as if they are - if only by migrants' intentions (cf. Schapendonk, 2011). This thesis contributes to a better understanding of irregular migration trajectories by analysing the factors and mechanisms underlying their evolution.

\subsection{Main findings and implications for research}

This section summarises the main findings of the study according to four topics: a) migration trajectories, b) social networks, c) critical events and d) the co-evolution of migration trajectories and social networks.

\subsubsection{Migration trajectories}

This study has shown the variety of ways in which trajectories can evolve. Whereas some migrants intended to move on to (other) European countries from Turkey and Greece and did so, indeed others never intended to do so and continued to stay in Turkey and Greece. Others initially never intended to migrate onward, but did so at a later stage. Many informants intended to migrate elsewhere but continued to stay in Turkey and Greece, and they did not necessarily perceive this as a failed attempt to reach Europe. Some eventually 
returned from Greece to Turkey or planned journeys elsewhere, such as Canada, the Middle East or China. These observations challenge the common assumption that migrants are heading for Europe at all times and raises the question of what mechanisms underlie the evolution of non-linear migration trajectories.

Throughout their trajectories, migrants may switch between their migration strategies, such as applying for asylum, deciding to stay on irregularly or attempting to cross the border. While sometimes migratory intentions remained the same while changing the migration strategy changed, in other cases the migratory intention changed, too. The case of Senait, introduced in the beginning of this thesis, has shown that while she initially aspired to travel to Europe and finally did, her intentions and migration strategies frequently changed during the six years she stayed in Turkey and Greece. Thus, the non-linearity of migration trajectories refers to both the geographical direction in which the trajectory evolves as well as to the type and sequence of applied migration strategies.

The study has described three societal developments in Turkey and Greece that are associated with a variety of trajectories: a highly securitised migration environment in both Turkey and Greece, resulting in restrictive migration policies; a severe economic recession in Greece compared to economic growth in Turkey; and a rise in xenophobic sentiments and violence in Greece in particular. These developments contribute to a volatile migration environment, implying that the social and institutional structures offering opportunities and constraints to enact migration strategies can fluctuate on a daily basis. While these developments shape the context in which migration trajectories evolve, they do not determine or explain the direction of their evolution. Neither can they explain the variation in individual trajectories which evolve in varying ways despite the similar circumstances. Therefore, to understand how migration trajectories of individuals evolve in relation to a volatile migration environment, it is necessary to analyse how this environment manifests itself in migrants' daily lives, that is, on a micro level. The study found that migrants' embeddedness in their personal social networks and the experience of critical events help to show how individual trajectories evolve in a volatile environment. This is further described in sections 8.2.2 and 8.2.3.

The findings that migration trajectories may evolve non-linearly, where Europe is not always or no longer the aspired destination and that strategies can be replaced by others while en route, have four implications for the study of migration trajectories. First, an initial migratory decision does not explain or predict how the migration trajectory subsequently evolves. Second, the evolution of the trajectory is not necessarily guided by an anticipated destination, if there was one in the first place. Third, ongoing residence in transit countries such as Turkey and Greece is not necessarily a direct result of implementations of restrictive migration policies such as strengthened border controls, but often can be the result of interaction between social networks and the experience of critical events, informing how migrants deal with policy implementations (see 8.2.2 8.2.3). Fourth, when people do move further to Europe after initial failed attempts, the time spent between attempts cannot be 
simply dismissed as waiting to cross the border: later attempts to move are not necessarily motivated by the same reasons as those which people had during earlier attempts. Decisionmaking is thus an ongoing process as the trajectory evolves, which may involve luck and ad hoc decisions.

Migration studies, however, generally focus on the initial decision to migrate taken in countries of origin in order to better understand how migration evolves (Schapendonk, 2011; Wissink et al., 2013). Such an 'origin-destination perspective' on migration trajectories suggests that people move linearly from countries of origin to countries of destination, if only by intent. As a consequence, the evolution of migration trajectories is commonly interpreted against the background of a migration flow. In cases where migrants do not move onward from a transit country, trajectories are commonly interpreted as having been stranded or as deviant (Collyer, 2010; Schapendonk, 2011; Yükseker \& Brewer, 2011). This is often explained in relation to restrictive migration policies in place in Europe's border regions (Yükseker \& Brewer, 2011). Considering migrants who continue to reside in transit countries as "stranded" presumes that ongoing residence in such countries is involuntary, and that Europe remains the intended destination. While some migrants were found to regard their own trajectory as having stranded, this study also showed that it cannot be assumed that residence in transit countries is per definition involuntary, nor that a state of being stranded is indefinite. Moreover, by presuming that all migrants in transit countries intend to eventually move onward, can lead to a lack of attention to migration strategies as they develop while in situ, something this study has shown happens.

The findings reveal that while an origin-destination perspective in migration studies is helpful to analyse migration flows between countries of origin and destination on a macro level, it cannot be simply applied to show the evolution of individual migration trajectories on a micro level. Doing so causes the mechanisms guiding the evolution of trajectories to be undetected. This study instead used a subject-oriented approach to reveal these mechanisms. That is, instead of predefining the parameters of where trajectories begin or (are supposed to) end, the evolution of trajectories was studied by following the migrant. This study contributes to the theorisation of migration trajectories, rather than of migration flows.

Another implication of the study's findings on migration trajectories is that we should be wary of overemphasising the meaning and importance of Europe in understanding the evolution of trajectories of migrants in the vicinity of Europe. The study has shown how other regions have attracted migrants' interest. Moreover, the fieldwork revealed that migrants are not necessarily interested in reaching Europe, but rather in sustaining a livelihood, possibly starting a family and supporting family members located elsewhere. These objectives are often more relevant than the location where this is done. 


\subsubsection{Social networks}

The fieldwork revealed four variations in migrants' networks, explaining their varying role in the migration trajectory:

a. Cross-sectional variation: both the structure and composition of the informants' networks varied heavily across the sample: while some networks involved members in countries of origin, the country of residence and various other countries in the world, other networks consisted of local relationships only. In the same vein:], some had networks that consisted of relationships established prior to migration, only after migration, or a mix.

b. Longitudinal variation: 17 informants reflected on their network interview one year later. While some networks proved rather stable, others had evolved into a composition of more local and fewer transnational ties or vice versa. The network changes were intrinsically linked with the evolution of migration trajectories (see finding 8.2.4) Furthermore, the fieldwork revealed that changes are not necessarily permanent: contacts with network members could be lost, actively abandoned and restored later on.

c. Key persons: The characteristics of network members regarded as influential for the shaping of the migration trajectory because of the support that was or was not exchanged, differed among the group of informants. While for some, relationships with fellow migrants were crucial in realising a preferred migration strategy, for others this was a relationship with a person who lived overseas, away from the current or intended place of residence. Various informants received financial support from people in countries of origin instead of the other way around, as has often been described in the migration literature. While an association was found between having aspirations to migrate elsewhere and having a transnational network, whether someone actually migrated did not depend on this. There were cases where migrants with extensive networks in Europe could not leave Turkey and Greece when this was so desired, and other cases where these networks were inexistent but where people nevertheless moved. In these cases, often a new or chance encounter made a difference in the turn a trajectory would take, for example, with a migrant solidarity activist or a passerby who provided a very specific type of support.

d. Enabling/disabling support: In the literature, the support of social networks is typically found crucial for the facilitation of migration. Indeed, this study found that whether or not support was available affected the opportunity to pursue a migration strategy as desired. However, the study also showed that support could constrain the desired migration strategy, for example when support was conditional. The other way around, migrants were sometimes better able to pursue a migration strategy when support was unavailable or not made use of. 
The findings imply that the characteristics of migrants' social networks and their roles in shaping the migration trajectory change over time. They further indicate that, in addition to or instead of network members in countries of origin and in that of (intended) destination (if there is one), new and chance encounters, as well as relationships with people in other parts of the world, can be of crucial importance. Furthermore, the often-cited examples in the literature where relationships with family members dissolve when migrants cannot send financial support, or when migrants cannot move forward because their anticipated support is not materialised, are partial and do not help show how networks and trajectories evolve when the exchange of support is absent. The findings revealed other possible scenarios where relationships did not dissolve when financial support was not forthcoming, and where people were asked by family members to return. Moreover, the findings showed that available support is not always enabling and can be constraining instead.

The findings of this study reveals nuance in the roles commonly assigned to specific components of migrants' networks, such as where families in countries of origin are depicted as (anticipated) receivers of support, or network members in Europe as providers. As with migration trajectories, such views on the role of networks are derived from the macro level observation that migrants' networks exist between countries of origin and destination. This origin-destination country perspective on networks obscures any other possible relationships elsewhere in the world that may affect the evolution of migration trajectories, including those residing elsewhere in the world and people that migrants chance upon. Moreover, the study finds that support is exchanged in multiple directions: in various cases, families in countries of origin were providers of support to migrants in Turkey and Greece.

This study adopted a subject-oriented perspective on networks and departed from the individual migrant and not from the dominant migration flow in order to identify network members. This perspective also enabled the adoption of a dynamic perspective on networks, by which variation in and changeability of networks and their role during migration could be illuminated. Thus, rather than questioning whether networks play a vital role in migration and whether it is time to move beyond the network or not, as has been recently debated in the literature (Bakewell et al., 2016), this thesis has shown the value of questioning under what circumstances networks play what type of role during the evolution of migration trajectories, and to recognise that this is subject to change.

\subsubsection{Critical events}

The study found that the experience of critical events affect the evolution of trajectories and networks Critical events are pivotal moments, potentially fostering a change in or secure a continuation of an ongoing process, because of new opportunities or constraints they bring forward. A change can entail a change of plans, but also a new direction when there was no prior plan. A volatile social and institutional structure, as is typical for transit migration hubs, produces critical events, inciting migrants to reconsider migration strategies at a rapid pace. A distinction was made between three types of critical events: a) events taking place within 
the realm of social networks, such as meeting someone new, losing someone's contact details or receiving a request for help; b) events taking place in the institutional structure, such as manifestations of policy implementations (for example, the rejection or acceptance of a visa application, an arrest at the border, or an accident while travelling. Other examples of critical events in the institutional structure are changing business opportunities and activities of the migration broker industry, such as smugglers' activities); and c) family and life events such as getting married or having a child. The empirical analysis predominantly focused on the first two events as these were more prevalent in my sample.

The study has found that migrants' trajectories are shaped by unexpected and sometimes seemingly small and random events. Examples are when a chance encounter leads to meeting someone who can help with arranging a journey or with filing an asylum claim, which would not have been possible otherwise. Such meeting could mean the difference between leaving or staying in Greece. Moreover, the study found that the order and timing of events, as well as the possible concurrence with other events may affect how an event is dealt with and how it shapes the migration trajectory. For example, the passing of a family member in the country of origin can moderate the effect of an arrest at the border on the trajectory of an individual person, by not trying again if resources need to be allocated to the funeral. The way events are acted upon is further embedded in migrants' social relationships and the exchange of support: attempting to cross the border again after an arrest is a choice shaped by the encouragement, disapproval, information and financial support received through a migrant's network.

In this research, events were not selected prior to the study. Instead, events were identified from the perspective of a migrant on the basis of their everyday experiences. In the migration literature on critical events, studies commonly focus on one or more particular type of event, such as policy implementation, and analyse its effect on the prevalence and scope of migration flows. The focus then lies on the effect of a particular policy event on initial departures from countries of origin or from countries of transit.

Identifying events based on migrants' everyday experiences is best done by adopting a processual and longitudinal research approach, where daily experiences can be witnessed and reflected upon, as opposed to cross-sectional data focusing on one event or moment in time. This approach where events are identifying events from the perspective of migrant' experiences has several implications. First, it shows the importance of embedding events in a (social) context in order to understand their impact on migrants' trajectories. In the example above, the decision not to cross the border is connected to a policy-induced event such as arrest at the border, but it is also connected to the event of losing a family member. Focusing only on policy in this case would lead to the wrong conclusion that policy is the guiding force behind people's decisions and that migration can "be turned on and off like a tap through laws and policies" (Castles, 2003, p.12).

Second, identifying critical events from the perspective of a migrant allows for the identification of very specific, minor events. While researchers are generally interested in 
the impact of big policy changes, migrants' trajectories can be shaped through seemingly minor and unexpected events, such as a chance encounter or receiving someone's recommendation. This remains unnoticed when migration is explained from a top-down approach based on predefined events.

The thesis does not contest that policy implementations impact migration flows. Yet, whether an event brought forward by policy implementations is critical for the evolution of individual trajectories (and social networks), depends on the conditions in that specific moment in time. A critical event, therefore, does not occur in a vacuum of space and time (Rachjman, 1991). Therefore, to understand when, why and how events become critical for the way trajectories evolve, one should embed them in the context in which they are occurring. The ongoing experience of critical events is central in the explanation of the co-evolution of social networks and migration trajectories. Whereas migration studies are commonly based on cross-sectional approaches, studying particular movements (e.g. border-crossings) or effects of particular policy instruments (e.g. strengthened border controls), this study argues for a processual approach to analyse this ongoing experience of critical events.

\subsubsection{The co-evolution of migration trajectories and social networks}

The study found that the experience of critical events affects the opportunity structure available to individuals. This individual opportunity structure consists of relationship preferences, resources and communication infrastructures. Relationship preferences indicate the value that migrants attribute towards maintaining a certain relationship and therefore preserving contact. Resources refer to informational, financial, instrumental and emotional means, and communication infrastructures are venues, means and opportunities to communicate. These factors shape whether relationships are formed or continue to be maintained, how strong they are and what type of support exchange takes place through the relationship. This support exchange, or the lack thereof, enables or constrains how subsequent events are dealt with, thus shaping the migration strategy someone adopts next. This can cause the continuation or a change of the migration trajectory as it was evolving before the critical event. Migration trajectories and social networks co-evolve in four ways:

a. The nature of a migrant's social network informs how the trajectory evolves following a critical event.

b. A critical event informs how social networks evolve, which leads to a change in the evolution of the migration trajectory.

c. The migration trajectory informs how the social network evolves following a critical event.

d. A critical event informs how trajectories evolve, which leads to a change in the evolution of the social network. 
The study demonstrates that migrants' changing social networks explain how migrants deal with critical events they encounter in their daily lives. As social networks change over time, the availability of resources fluctuates, as do opportunities to act upon events. The continuous experience of critical events and the constantly changing social networks contribute to fluctuating migratory intentions and adopted strategies. This ultimately results in the emergence of non-linear migration trajectories. Other than suggested by previous research focusing on the impact of networks or on specific (types of) events on the evolution of flows at the macro level (Bakewell et al., 2016; Carling, 2007; Carrera, 2007; Czaika \& De Haas, 2014; De Haas et al., 2018; İçduygu, 2011), this study concludes that at the micro level, the above-mentioned four mechanisms contribute to shaping migration trajectories, and that this process is thus more dynamic than assumed so far.

These last findings have three main implications. First, while the literature has discussed the explanatory power of networks in general, (Bakewell et al., 2016; Collyer, 2005; Krissman, 2006), the study shows that networks do not have one single, generalisable effect on the trajectories of migrants and this may change over the course of one's trajectory. Second, in the literature, the role of migration policies and social networks are often compared to each other (Bakewell et al., 2016; Broeders \& Engbersen, 2007; Krissman, 2006). The findings demonstrate that policies and networks interact: to see how policy interventions impact migration trajectories, it is helpful to understand what migrants' social networks look like. The reverse is also true: to see how social networks have evolved, it is helpful to understand what (policy-induced) critical events have affected this. Thus, while network studies and policy analyses commonly constitute distinct bodies of literature, this thesis calls for combining both approaches, so social networks are taken into consideration in order to show policy effects and vice versa. This will lead to a better understanding of how migration trajectories evolve.

\subsection{Implications for policy}

This thesis has argued that individual migration trajectories do not necessarily follow a linear rationale. Policies are, however, based on macro level trends and cannot be based on individual cases. Moreover, the continuous arrival of migrants in Europe gives evidence of underlying macro level processes driving migration from Sub-Saharan Africa towards Europe via Turkey and Greece (De Haas et al., 2018). This evidence is not refuted by the fact that individual trajectories do not follow a linear logic. Nevertheless, the findings of this thesis challenge several assumptions and approaches on which migration policies and research designs are commonly based and recommends taking other perspectives on the analysis of trajectories in relation to migration policies. 


\subsubsection{Centralising migrants' needs instead of behaviours in outreach activities, interventions and samples.}

Policy interventions and outreach programmes of NGOs often target migrants on the basis of the migration strategy they adopt at a specific moment in time. NGO representatives in Turkey have, for example, expressed during interviews that they do not assist migrants who did not apply for asylum and who instead attempt to move onwards to Greece. However, the difference between a person who attempts to cross the border from Turkey and another person who applied for asylum could be explained by the fact that the latter could mobilise resources in a transnational social network to secure a living in Turkey while awaiting the procedure, whereas the former could not. The protection needs and migration motives, however, could be the same for both. This implies that whether or not a person attempts to cross a border can be a mere reflection of personal circumstances, which are shaped by the experience of critical events and the characteristics of his or her personal social networks. By only considering specific migratory behaviour, it is crucial to recognise these are possibly only "snapshots" of a broader trajectory. Policy makers, NGO workers and researchers need to constantly challenge the assumptions based on which the interpretations of migrant behaviour (e.g. staying in or leaving Turkey/Greece) is based. Thus, rather than basing targeting strategies on migrant behaviour (e.g. those who stay versus those who leave Turkey or Greece), it is more relevant to do so based on expressed intentions and needs by assessing the circumstances leading towards the enacted migration strategy. A first step in doing so would be to reach out to broader target groups within the migrant community by offering humanitarian or legal assistance in case they could benefit from this, regardless of legal status or assumed adopted migration strategies. Moreover, by taking time to get to know clients through multiple interviews, informal conversation and possibly home visits, a more elaborate view of intentions and needs could be identified than through interviews focusing on migration objectives alone.

\subsubsection{A subject-oriented versus an origin-destination country perspective on trajectories}

Migration policies designed to "manage" and "curb" irregular migration depart from an "origin-destination" perspective of migration and treat this as an intended linear endeavour. In this way, trajectories are understood against the background of an existing migration flow, implying that deviations are explained as a mere result from policy interventions, obstructing people to move forward. Such view hides the possibility that the evolution of trajectories results from a more complex process involving chance luck and everyday experiences. This is not to deny that many Sub-Saharan African migrants in Turkey and Greece aspire to migrate to (Northern/Western) Europe and jointly constitute a flow. Yet, such aspirations cannot be assumed to be constant. Studies indicate that Europe is not always the aspired destination, or that migrants leave without a clear destination in mind (De Clerck, 2015). Furthermore, 
over time, aspiration may be replaced by others, inciting people to adopt other migration strategies than the crossing of a border.

The focus of migration policies to manage migration from Africa to Europe via Turkey and Greece obscures other possible ways migration trajectories can evolve. This hampers the interpretation and illumination of experiences migrants had during their trajectories. The following example illustrates this point: today, most newly arrived refugees in Europe come from Eritrea and Syria, groups being compared primarily due to country of origin information. The adoption of a binary origin-destination perspective obscures that it is likely that many Eritrean women have fled the Syrian war, as well: almost all Eritrean women I have spoken to in Turkey and Greece had lived in the Middle East, including Syria, for years before coming to Turkey and Greece. Some have been recognised as refugees by the UNHCR in Turkey, but moved on to Greece when resettlement was not available. This latter example shows linkages between the geographical limitation on the 1951 Geneva Refugee Convention and the lack of resettlement options in Turkey and onward migration towards Greece. However, the migration trajectories of Eritrean women as well as the assessment of refugee claims are almost exclusively explained in relation to conditions in Eritrea only. A subject-oriented approach enables the identification of the interlinkages between policy implementations in various countries and on different levels.

\subsubsection{Adopting a social network perspective to understand policy effects}

Commonly, policy analyses aim to establish whether there is a specific direct effect of policy instruments on migration flows. The findings of this study show that to understand the effects of policy, it is insufficient to look for a direct effect only, in other words, it is not enough to explain the effects of a policy instrument solely by looking at direct effects of the instrument itself. Instead, this study shows that the effects of policies can be explained by considering the interaction between policies and migrants' personal circumstances that are largely shaped by their social networks.

In the case of the 'EU-Turkey Statement' ${ }^{8}$, for example, the question at stake is whether the agreements lead to a decline in irregular migration flows between Turkey and Greece. For the EU, the relevance of this question lies in the wish to conclude similar deals with other neighbouring countries in the near future. However, Ulusoy and Battjes (2017) show that the effects of the EU-Turkey deal for individual migrants who have been readmitted by Turkey largely depend on the personal connections they have: the authors mention, almost in passing, that detained readmitted migrants only have a chance of applying for international protection when they are able to contact an NGO or a lawyer. To do so, they often need informational, instrumental and financial support of friends and relatives. The

\footnotetext{
${ }^{8}$ On March 18, 2016 (after the time of fieldwork), the EU and Turkey released a statement indicating their willingness to increase cooperation to stop irregular migration to Europe as a response to ongoing "migration crisis" at the southeast borders of EU. See: http://www.consilium.europa.eu/en/press/press-releases/2016/03/18eu-turkey-statement
} 
fact this support is required, implies that the effect of the EU-Turkey deal is mediated by the role that social networks can play.

Furthermore, while research has established that the effectiveness of migration policies to reduce migration flows is undermined by redirections of migration flows (De Haas et al., 2018), social networks will help show which migrants do redirect the migration trajectory and which do not, as well as how much risks they take. Thus, in order to know how migration policies affect migration flows, it is crucial to consider the role of migrants' social networks in acting upon events imposed by policy. It is equally essential to realise that social networks are not a static condition: their characteristics change and assistance of a network following a critical (policy-induced) event cannot be taken for granted.

While policy designers and evaluators cannot simply take the wide variety and changeability of network characteristics of migrants into consideration when assessing polices, they could be more aware of how policy effects result from an interaction with migrants' social networks. For example, to understand why asylum-seekers drop out of the asylum procedure in Turkey and continue to migrate to Greece despite strengthened border controls, social network analysis may reveal, as it did in this study, this is because of lack of support for basic needs in satellite cities. This reveals that if conditions to secure a livelihood in satellite cities are lacking, border controls between Turkey and Greece will not be effective.

Ultimately, whether people can await the results on the asylum procedure in satellite cities or have access to lawyers after readmission should not depend on whether they can mobilise support from social networks. Instead, this should be facilitated by effective and accessible institutional procedures. The findings of this thesis not only suggest that the effects of policies can be better understood by embedding them in social network analysis, but this could lead to improvements of protection measures, too.

\subsection{Avenues for further research}

This thesis contributes to migration studies by opening the "black box" of mechanisms that affect the evolution of migration trajectories. This study has made several methodological and conceptual contributions to the study of networks and trajectories. Methodologically, by the longitudinal and prospective character of the study, it was possible to acquire processual rather than cross-sectional data on both networks and trajectories. Furthermore, by integrating SNA approaches with ethnographic research methods in the field of migration, the thesis contributed to an emerging body of literature discussing the benefits of using SNA as an analytical tool to advancing the understanding of migration processes (Bilecen et al., 2018). Conceptually, the thesis has underlined the importance of moving beyond dichotomous approaches in migration studies and policies such as origin versus destination; refugees versus non-refugees; migrants "successfully moving to Europe" versus migrants 
"getting stranded"; networks facilitating versus networks hampering migration, and the role of policy versus the role of networks in explanations of migration.

The findings of the study indicate four avenues for further research. First, as the methodology chapter explains, SNA was used to inform and enhance the qualitative data collection and analysis. Future research could enlarge the sample size to statistically analyse network characteristics, both cross-sectionally and longitudinally, by repeating the social network interview at a later time. This would allow more insight in changes in the compositional and structural characteristics of social networks.

Second, the scope of the study could further be expanded by involving network members in the study. This would enable the study of changing social networks from both the perspective of the migrants and from network members (see: Mazzucato, 2006, 2011; Gladkova \& Mazzucato, 2017). In this way, the mechanisms could be expressed in terms of an interaction between two people, instead of from the migrant's perspective only.

Third, the study has demonstrated that critical events are an important component of the mechanisms underlying the co-evolution of social networks and trajectories. Future research could explore how this mechanism operates for specific events. In the case of life events, for example, the effect of specific life events, such as marriage or the birth of a child, and their relation with migration trajectories. While the association between life events and initial migration decisions and social networks have been analysed, to my knowledge there is no academic inquiry on the association between life events and the course of migration trajectories for irregular migrants. The mechanisms could be further used to analyse the effect of specific policy events and how this is mediated by migrants' social networks. This could be done by performing SNA prior to and after introducing this instrument.

Fourth, the role of gender and country of origin in affecting the way the mechanisms operate could be further explored. The study found relations between critical events, changes in social networks and the evolution of the migration trajectory among all informants, regardless of country of origin or gender. However, the events and social network changes may differ for migrants with varying characteristics, herewith potentially explaining differences in the direction in which trajectories evolve. The sample was too small to confidently analyse and explain variations across country of origin and gender. However, the cases seem to suggest that Eritrean women more often came to Turkey via the Middle East, whereas Eritrean men had mostly travelled via Sudan. Moreover, the data suggest that more men than women intended to move on to Europe upon arrival in Turkey, and that more Eritrean women than men worked in Greece, and the latter more often received financial support from abroad. The mechanisms identified in this study could be applied in future research to explore the way they operate among migrants with varying sociodemographic characteristics.

A famous saying goes, "Life is what happens to you while you are busy making other plans" (Saunders, 1957, p. n.n.). As with life, it is impossible to predict how migration trajectories evolve, yet this is what migration studies generally aims to do, by adopting 
a binary origin-destination approach and emphasising the outcome of a trajectory. It is however both possible and relevant to show by what mechanisms trajectories evolve, as this thesis has done. Migration is part of people's life trajectories, which can take unexpected and uncalculated turns and needs to be analysed processually. The field of migration studies would thus benefit from more longitudinal approaches. 

References 



\section{References}

Åkesson, L. (2011). Remittances and relationships: Exchange in Cape Verdean transnational families. Ethnos, 76(3), 326-347. https://doi.org/10.1080/00141844.2011.577229

Amelina, A., Bilecen, B., Barglowski, K., \& Faist, T. (2012). Ties that protect? The significance of transnationality for the distribution of informal social protection in migrant networks. SFB 882 Working Paper Series. Bielefeld.

Amnesty International. (2009). Refugees in Turkey denied protection. London.

Angelusz, R., \& Tardos, R. (2001). Change and stability in social network resources: the case of Hungary under transformation. In N. Lin, K. Cook, \& R. S. Burt (Eds.), Social capital: theory and research (pp. 297-323). New Jersey: Aldine Transaction Publishers.

Axinn, W. G., \& Pearce, L. D. (2006). Mixed method data collection strategies. New York: Cambridge University Press.

Bakewell, O. (2011). Conceptualising displacement and migration: processes, conditions, and categories. In K. Koser \& S. Martin (Eds.), The migration-displacement nexus: patterns, processes, and policies (pp. 14-28). Oxford: Berghahn Books.

Bakewell, O., Kubal, A., \& Pereira, S. (2016). Introduction: Feedback in migration processes. In O. Bakewell, G. Engbersen, M. L. Fonseca, \& C. Hors (Eds.), Beyond networks: feedback in international migration (pp. 1-17). London: Palgrave Macmillan UK. https://doi. org/10.1057/9781137539212_1

Baldwin-Edwards, M. (2006). 'Between a rock \& a hard place': North Africa as a region of emigration, immigration \& transit migration. Review of African Political Economy, 33(108), 311-324. https:// doi.org/10.1080/03056240600843089

Barutciski, M. (2003). Lausanne revisited: Population exchanges in international law and policy. In R. Hirschon (Ed.), Crossing the Aegean: an appraisal of the 1923 compulsory population exchange between Greece and Turkey (pp. 23-38). New York: Berghan Books.

Benítez, J. L. (2012). Salvadoran transnational families: ICT and communication practices in the network society. Journal of Ethnic and Migration Studies, 38(9), 1439-1449. https://doi.org/10.10 80/1369183X.2012.698214

Bernard, H. R. (2002). Research methods in anthropology: qualitative and quantitative methods (Third). Walnut Creek: AltaMira Press.

Bidart, C., \& Lavenu, D. (2005). Evolutions of personal networks and life events. Social Networks, 27(4), 359-376. https://doi.org/10.1016/j.socnet.2004.11.003

Biehl, K. S. (2014). Migration, urban space and diversity: A case from Istanbul. Insight Turkey, 16(4), $55-63$.

Bilecen, B. (2016). A personal network approach in mixed-methods design to investigate transnational social protection. International Review of Social Research, 6(4), 233-244. https:// doi.org/10.1515/irsr-2016-0025 
Bilecen, B., Gamper, M., \& Lubbers, M. J. (2018). The missing link: social network analysis in migration and transnationalism. Social Networks, 53, 1-3. https://doi.org/10.1016/j. socnet.2017.07.001

Bivand Erdal, M., \& Oeppen, C. (2018). Forced to leave? The discursive and analytical significance of describing migration as forced and voluntary. Journal of Ethnic and Migration Studies, 44(6), 981-998. https://doi.org/10.1080/1369183X.2017.1384149

Blaser, N. (2014). Turkey's "other" refugees languish in limbo. Retrieved April 5, 2017, from https://www.aljazeera.com/news/middleeast/2014/11/turkey-other-refugees-languishlimbo-2014111083938134850.html

Bloom, T. (2016). Privatised migration management in the Mediterranean region and Sub-Saharan migration decision-making. In T. Bloom \& B. Gebrewold (Eds.), Understanding migrant decisions: from Sub-Saharan Africa to the Mediterranean region (pp. 113-133). London: Routledge.

Böcker, A. G. M. (1994). Chain migration over legally closed borders: settled immigrants as bridgeheads and gatekeepers. Netherlands' Journal of Social Sciencess, 30(2), 87-106.

Boeije, H. R. (2005). Analyseren in kwalitatief onderzoek: denken en doen. Amsterdam: Boom Koninklijke Uitgevers.

Boswell, C. (2007). Migration control in Europe after 9/11: explaining the absence of securitization. JCMS: Journal of Common Market Studies, 45(3), 589-610. https://doi.org/10.1111/j.14685965.2007.00722.x

Bourdieu, P., \& Wacquant, L. (1992). An invitation to reflexive sociology. Chicago: University of Chicago Press.

Boyd, M. (1989). Family and personal networks in international migration: recent developments and new agendas. International Migration Review, 23(3), 638-670. https://doi. org/10.1177/019791838902300313

Boyd, M., \& Nowak, J. (2012). Social networks and international migration. In M. Martiniello \& R. Jan (Eds.), An introduction to international migration studies: European perspectives (pp. 79-106). Amsterdam: Amsterdam University Press.

Brewer, K. T., \& Yükseker, D. (2009). A survey on African migrants and asylum seekers in Istanbul. In A. Içduygu \& K. Kirişçi (Eds.), Land of diverse migrations: challenges of emigration and immigration in Turkey (pp. 637-723). Istanbul: Istanbul Bilgi University Press.

Broeders, D., \& Engbersen, G. (2007). The fight against illegal migration: identification policies and immigrants' counterstrategies. American Behavioral Scientist, 50(12), 1592-1609. https://doi. org/10.1177/0002764207302470

Buonfino, A. (2004). Between unity and plurality: the politicization and securitization of the discourse of immigration in Europe. New Political Science, 26(1), 23-49. https://doi. org/10.1080/0739314042000185111

Cardwell, P. J. (2013). New modes of governance in the external dimension of EU migration policy. International Migration, 51(6), 54-66. https://doi.org/10.1111/imig.12078 
Carling, J. (2002). Migration in the age of involuntary immobility: theoretical reflections and Cape Verdean experiences. Journal of Ethnic and Migration Studies, 28(1), 5-42. https://doi. org/10.1080/13691830120103912

Carling, J. (2007). Migration control and migrant fatalities at the Spanish-African borders. International Migration Review, 41(2), 316-343. https://doi.org/10.1111/j.17477379.2007.00070.x

Carling, J. (2008). The human dynamics of migrant transnationalism. Ethnic and Racial Studies, 31(8), 1452-1477. https://doi.org/10.1080/01419870701719097

Castles, S. (2003). Towards a sociology of forced migration and social transformation. Sociology, 37(1), 13-34. https://doi.org/10.1177/0038038503037001384

Castles, S. (2007). Twenty-First-Century migration as a challenge to sociology. Journal of Ethnic and Migration Studies, 33(3), 351-371. https://doi.org/10.1080/13691830701234491

Castles, S., \& Miller, M.J. (2009). The age of migration: International population movements in the morden world (Fourth edit). New York: Palgrave Macmillan.

Castles, S., De Haas, H., \& Miller, M. J. (2014). The age of migration: International population movements in the modern world (Fifth edit). New York: Palgrave Macmillan.

Chapman. M. \& Mansell Prothero, R. (1985). Themes on ciruclation in the third world (pp 126). In: R. Mansell Prothero and M. Chapman (Eds), Circulation in Third World Countries. Londen: Routlegde and Kegan Paul. Chelpi-den Hamer, M., \& Mazzucato, V. (2010). The role of support networks in the initial stages of integration: the case of West African newcomers in the Netherlands. International Migration, 48(2), 31-57. https://doi.org/10.1111/j.14682435.2009.00545.x

Cizre, Ü. (2003). Demythologyzing the national security concept: the case of Turkey. Middle East Journal, 57(2), 213-229.

Collyer, M. (2005). When do social networks fail to explain migration? Accounting for the movement of Algerian asylum-seekers to the UK. Journal of Ethnic and Migration Studies, 31(4), 699-718. https://doi.org/10.1080/13691830500109852

Collyer, M. (2007). In-between places: trans-Saharan transit migrants in Morocco and the fragmented journey to Europe. Antipode, 39(4), 668-690. https://doi.org/10.1111/j.1467-8330.2007.00546.x

Collyer, M. (2010). Stranded migrants and the fragmented journey. Journal of Refugee Studies, 23(3), 273-293. https://doi.org/10.1093/jrs/feq026

Collyer, M., Düvell, F., \& de Haas, H. (2012). Critical approaches to transit migration. Population, Space and Place, 18(4), 407-414. https://doi.org/10.1002/psp.630

Crawley, H., Düvell, F., Jones, K., McMahon, S., \& Sigona, N. (2017). Unravelling Europe's "migration crisis": Journeys over land and sea. Policy Press.

Crawley, H., \& Skleparis, D. (2018). Refugees, migrants, neither, both: categorical fetishism and the politics of bounding in Europe's 'migration crisis.' Journal of Ethnic and Migration Studies, 44(1), 48-64. https://doi.org/10.1080/1369183X.2017.1348224

Crépeau, F. (2013). Report by the Special Rapporteur on the human rights of migrants, François Crépeau, on his mission to Turkey (25-29 June 2012). 
Cuff, C. E. (1980). Some issues in studying the problem of versions in everyday situations (Occasional Paper 3). Manchester: Department of Sociology, University of Manchester.

Dahinden, J. (2009). Are we all transnationals now? Network transnationalism and transnational subjectivity: the differing impacts of globalization on the inhabitants of a small Swiss city. Ethnic and Racial Studies, 32(8), 1365-1386. https://doi.org/10.1080/01419870802506534

Dankyi, E., Mazzucato, V., \& Manuh, T. (2017). Reciprocity in global social protection: providing care for migrants' children. Oxford Development Studies, 45(1), 80-95. https://doi.org/10.1080/13600 818.2015.1124078

De Bruijn, M., Nyamnjoh, F., \& Angwafo, T. (2010). Mobile interconnections: Reinterpreting distance, relating and difference in the Cameroonian Grassfields. Journal of African Media Studies, 2(3), 267-285. https://doi.org/10.1386/jams.2.3.267_1

De Clerck, H. M.-L. (2013). Sub-Saharan African migrants in Turkey: a case study on Senegalese migrants in Istanbul. Ankara Üniversitesi SBF Dergisi, 68(1), 39-58.

De Clerck, H. M.-L. (2015). Europe is no longer the only 'El Dorado' for sub-Saharan Africans: the case of contemporary Senegalese migration to Turkey. Migration and Development, 4(2), 272-290. https://doi.org/10.1080/21632324.2015.1022086

De Haas, H. (2008). The myth of invasion: the inconvenient realities of African migration to Europe. Third World Quarterly, 29(7), 1305-1322. https://doi.org/10.1080/01436590802386435

De Haas, H. (2010). Migration and development: a theoretical perspective. International Migration Review, 44(1), 227-264. https://doi.org/10.1111/j.1747-7379.2009.00804.x

De Haas, H., Czaika, M., Flahaux, M., Mahendra, E., Natter, K., Vezzoli, S., \& Villares-Varela, M. (2018). International migration: Trends, determinants and policy effects (IMIn Working Paper Series No. 142). Oxford.

De Jong, G. F., Root, B. D., Gardner, R. W., Fawcett, J. T., \& Abad, R. G. (1985). Migration intentions and behavior: decision making in a rural Philippine province. Population and Environment, 8(1-2), 41-62. https://doi.org/10.1007/BF01263016

Dekker, R., \& Engbersen, G. (2014). How social media transform migrant networks and facilitate migration. Global Networks, 14(4), 401-418. https://doi.org/10.1111/glob.12040

Denzin, N. K. (1970). The research act; a theoretical introduction to sociological methods. Chicago: Aldine Pub. Co.

Dervis, K., Emerson, M., Gros, D., \& Ülgen, S. (2004). The European transformation of modern Turkey. Brussels: CEPS.

Devillanova, C. (2008). Social networks, information and health care utilization: Evidence from undocumented immigrants in Milan. Journal of Health Economics, 27(2), 265-286. https://doi. org/10.1016/j.jhealeco.2007.08.006

Doxiadis, A., \& Matsaganis, M. (2012). National populism and xenophobia in Greece. In C. Fieschi, M. Morris, \& L. Caballero (Eds.), Populist fantasies: European revolts in context (pp. 31-98). Berkeley: Counterpoint.

Durand, J., Massey, D. S., \& Parrado, E. A. (1999). The new era of Mexican migration to the United States. The Journal of American History, 86(2), 518. https://doi.org/10.2307/2567043 
Düvell, F. (Ed.). (2006). Illegal immigration in Europe: beyond control? London: Palgrave Macmillan UK. https://doi.org/10.1057/9780230555020

Düvell, F. (2011). Paths into irregularity: the legal and political construction of irregular migration. European Journal of Migration and Law, 13(3), 275-295. https://doi. org/10.1163/157181611X587856

Düvell, F. (2012). Transit migration: a blurred and politicised concept. Population, Space and Place, 18(4), 415-427. https://doi.org/10.1002/psp.631

Düvell, F., Triandafyllidou, A., \& Vollmer, B. (2009). Ethical issues in irregular migration research in Europe. Population, Space and Place, 16(3), n/a-n/a. https://doi.org/10.1002/psp.590

Düvell, F., \& Vollmer, B. (2009). Irregular migration in and from the neighbourhood of the EU. A comparison of Morocco, Turkey and Ukraine.

Ellinas, A. A. (2013). The rise of Golden Dawn: the new face of the far right in Greece. South European Society and Politics. Taylor \& Francis. https://doi.org/10.1080/13608746.2013.782838

Engbersen, G. (2013). Networks and beyond: feedback channels and the diminutive causation of international migration (Theorizing the Evolution of European Migration Systems (THEMIS)). Oxford.

Engbersen, G., van San, M., \& Leerkes, A. (2006). A room with a view: irregular immigrants in the legal capital of the world. Ethnography, 7(2), 209-242. https://doi. org/10.1177/1466138106067057

European Commission. (2007). FRONTEX and RABITS: the European Union is stepping up its operational efforts combating illegal immigration. Brussels.

European Commission. (2015). EU Action Plan against migrant smuggling (2015 -2020). Brussels.

European Council. (1999). Presidency Conclusions, Tampere 15-16 October 1999. Retrieved April 5, 2018, from http://www.europarl.europa.eu/summits/tam_en.htm

Faist, T. (1997). The crucial meso-level. In T. Hammar, G. Brochmann, K. Tamas, \& T. Faist (Eds.), International migration, immobility and development: multidissciplinary perspectives (pp. 187219). Oxford: Berg.

Faist, T. (2000). Transnationalization in international migration: implications for the study of citizenship and culture. Ethnic and Racial Studies, 23(2), 189-222. https://doi. org/10.1080/014198700329024

Fait, N. (2013). African migrations toward Turkey: beyond the stepping stone. Ankara Üniversitesi SBF Dergisi, 68(1), 21-38.

Fawcett, J. T. (1989). Networks, linkages, and migration systems. International Migration Review, 23(3), 671-680. https://doi.org/10.2307/2546434

Feld, S. L., Suitor, J. J., \& Hoegh, J. G. (2007). Describing changes in personal networks over time. Field Methods, 19(2), 218-236. https://doi.org/10.1177/1525822X06299134

Flick, U. (2007). Managing quality in qualitative research. London: SAGE Publications, Ltd. https:// doi.org/10.4135/9781849209441

FRONTEX. (2014a). Archive of operations; Poseidon. Retrieved September 20, 2014, from http:// frontex.europa.eu/operations/archive-of-operations/ZCQzCe 
FRONTEX. (2014b). Eastern Mediterranean Route. Retrieved September 20, 2014, from http:// frontex.europa.eu/developments-and-routes/eastern-mediterranean-route

Fussell, E. (2010). The cumulative causation of international migration in Latin America. The ANNALS of the American Academy of Political and Social Science, 630(1), 162-177. https://doi. org/10.1177/0002716210368108

Gardner, R. W., De Jong, G. F., Arnold, F., \& Cariño, B. V. (1985). The best-laid schemes: an analysis of discrepancies between migration intentions and behavior. Population and Environment, 8(1-2), 63-77. https://doi.org/10.1007/BF01263017

Gladkova, N., \& Mazzucato, V. (2017). Theorising chance: capturing the role of ad hoc social interactions in migrants' trajectories. Population, Space and Place, 23(2), e1988. https://doi. org/10.1002/psp.1988

Glick Schiller, N., Basch, L., \& Blanc, C. S. (1995). From immigrant to transmigrant: Theorizing transnational migration. Anthropological Quarterly, 68(1), 48-63. https://doi. org/10.2307/3317464

Gluckman, M. (1942). Analysis of a social situation in modern Zululandd. The Rhodes-Livingstone Papers No. 28. Manchester: Manchester University Press for The Rhodes-Livingstone Institute.

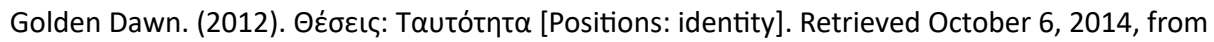
http://www.xryshaygh.com/index.php/kinima

Granovetter, M. S. (1973). The strength of weak ties. American Journal of Sociology, 78(6), 13601380.

Grillo, R., \& Mazzucato, V. (2008). Africa < > Europe: a double engagement. Journal of Ethnic and Migration Studies, 34(2), 175-198. https://doi.org/10.1080/13691830701823830

Gurak, D. T., \& Caces, F. (1992). Migration networks and the shaping of migration systems. In M. M. Kritz, L. L. Lim, \& H. Zlotnik (Eds.), International migration systems: A global approach (pp. 150176). Oxford: Clarendon Press.

Hamood, S. (2006). African transit migration through Libya to Europe: the human cost. American University in Cairo Forced Migration and Refugee studies. Cairo.

Harris, J. R., \& Todaro, M. P. (1970). Migration, unemployment and development: a two-sector analysis. The American Economic Review, 60(1), 126-142.

Haug, S. (2008). Migration networks and migration decision-making. Journal of Ethnic and Migration Studies, 34(4), 585-605. https://doi.org/10.1080/13691830801961605

Heering, L., van der Erf, R., \& van Wissen, L. (2004). The role of family networks and migration culture in the continuation of Moroccan emigration: a gender perspective. Journal of Ethnic and Migration Studies, 30(2), 323-337. https://doi.org/10.1080/1369183042000200722

Hernandez, E. E. (2002). Power in remittances: Remaking family and nation among Salvadorans. University of California, Faculty of Social Science, Irvine.

Hess, S. (2012). De-naturalising transit migration. Theory and methods of an ethnographic regime analysis. Population, Space and Place, 18(4), 428-440. https://doi.org/10.1002/psp.632

Hiller, H. H., \& Franz, T. M. (2004). New ties, old ties and lost ties: the use of the internet in diaspora. New Media \& Society, 6(6), 731-752. https://doi.org/10.1177/146144804044327 
Hollstein, B. (2003). Netzwerkveränderungen verstehen. Zur Integration von Struktur- und akteurstheoretischen Perspektiven. Berliner Journal Für Soziologie, 13(2), 153-174. https://doi. org/10.1007/BF03204573

House, J. S. (1981). Work stress and social support. Reading: Addison-Wesley Educational Publishers Inc.

Human Rights Watch. (2008). Stuck in a revolving door. Iraqis and other asylum seekers and migrants at the Greece/Turkey entrance to the European Union. New York.

Human Rights Watch. (2012). Hate on the streets: xenophobic violence in Greece. New York.

Human Rights Watch. (2013). Unwelcome guests: Greek police abuses of migrants in Athens. New York.

Huysmans, J. (2006). The politics of insecurity: fear, migration and asylum in the EU. London: Routledge.

İçduygu, A. (2000). The politics of international migratory regimes: transit migration flows in Turkey. International Social Science Journal, 52(165), 357-367. https://doi.org/10.1111/1468-2451.00265

İçduygu, A. (2003). Irregular migration in Turkey (IOM Migration Research Series No. 12). Geneva.

İçduygu, A. (2011). The irregular migration corridor between the EU and Turkey: is it possible to block it with a readmission agreement? (EU-US Immigration Systems No. 2011/14). San Domenico di Fiesole.

İçduygu, A., \& Yükseker, D. (2012). Rethinking transit migration in Turkey: reality and re-presentation in the creation of a migratory phenomenon. Population, Space and Place, 18(4), 441-456. https:// doi.org/10.1002/psp.633

Istrate, E., Berube, A., \& Nadeau, C. A. (2012). Global MetroMonitor 2011: Volatility, growth and recovery. Washington D.C.

Joly, D. (1998). Temporary protection within the framework of a new European asylum regime. The International Journal of Human Rights, 2(3), 49-76. https://doi.org/10.1080/13642989808406746

Jordan, B., \& Düvell, F. (2002). Irregular migration. The dilemmas of transnational mobility. Cheltenham: Edward Elgar.

Kaiser, R. J. (2012). Performativity and the eventfulness of bordering practices. In T. M. Wilson \& H. Donnan (Eds.), A companion to border studies (pp. 522-537). Chichester, UK: John Wiley \& Sons, Ltd. https://doi.org/10.1002/9781118255223.ch30

Kalir, B. (2005). The development of a migratory disposition: explaining a "new emigration." International Migration, 43(4), 167-196. https://doi.org/10.1111/j.1468-2435.2005.00337.x

Karaosmanoğlu, A. L. (2000). The evolution of the national security culture and the military in Turkey. Journal of International Affairs, 54(1), 199-216.

Kasimis, C. (2012). Greece: illegal immigration in the midst of crisis. Washington D.C.

Kehayioylou, K. (2012). UNHCR - Dozens queue every week in Athens to apply for asylum. Retrieved July 14, 2014, from http://www.unhcr.org/4f6c8b6a6.html

Kentikelenis, A., Karanikolos, M., Papanicolas, I., Basu, S., McKee, M., \& Stuckler, D. (2011). Health effects of financial crisis: omens of a Greek tragedy. The Lancet, 378(9801), 1457-1458. https:// doi.org/10.1016/S0140-6736(11)61556-0 
King, R. \& Skeldon, R. (2010). 'Mind the gap!' Intergating approaches to internal and internationa migration. Journal of Ethnic and Migration Studies, 36(10), 1619-1646.

Kirişci, K. (2000). Disaggregating Turkish citizenship and immigration practices. Middle Eastern Studies, 36(3), 1-22. https://doi.org/10.1080/00263200008701316

Kiza, E. (2008). Tödliche Grenzen - Die fatalen Auswirkungen europäischer Zuwanderungspolitik. Zürich/Berlin: LIT Verlag.

Koser Akcapar, S. (2010). Re-thinking migrants' networks and social capital: a case study of Iranians in Turkey. International Migration, 48(2), 161-196. https://doi.org/10.1111/j.14682435.2009.00557.x

Krissman, F. (2006). Sin coyote ni patrón: Why the "migrant network" fails to explain international migration. International Migration Review, 39(1), 4-44. https://doi. org/10.1111/j.1747-7379.2005.tb00254.x

Langford, L. M. (2013). The other Euro Crisis: rights violations under the Common European Asylum System and the unraveling of EU solidarity. Harvard Human Rights Journal, 26, 217-264.

Langley, A., Smallman, C., Tsoukas, H., \& Van de Ven, A. H. (2013). Process studies of change in organization and management: unveiling temporality, activity, and flow. Academy of Management Journal, 56(1), 1-13. https://doi.org/10.5465/amj.2013.4001

Léonard, S. (2010). EU border security and migration into the European Union: FRONTEX and securitisation through practices. European Security, 19(2), 231-254. https://doi.org/10.1080/096 62839.2010 .526937

Long, K. (2008). State, nation, citizen: Rethinking repatriation (RSC Working Paper Series No. 48).

Lonkila, M. (1997). Informal exchange relations in Post-Soviet Russia: a comparative perspective. Sociological Research Online, 2(2), 1-20. https://doi.org/10.5153/sro.94

Lubbers, M. J., Molina, J. L., Lerner, J., Brandes, U., Ávila, J., \& McCarty, C. (2010). Longitudinal analysis of personal networks. The case of Argentinean migrants in Spain. Social Networks, 32(1), 91-104. https://doi.org/10.1016/j.socnet.2009.05.001

MacDonald, J. S., \& MacDonald, L. D. (1964). Chain migration ethnic neighborhood formation and social networks. The Milbank Memorial Fund Quarterly, 42(1), 82-97. https://doi. org/10.2307/3348581

Mainwaring, $\dot{C}$., \& Brigden, N. (2016). Beyond the border: clandestine migration journeys. Geopolitics, 21(2), 243-262. https://doi.org/10.1080/14650045.2016.1165575

Marcelino, P., Ferreira, M., \& Mazzagali, N. L. (2016). Liminality and migrant decision-making in the aftermath of the political and refugee crises in the Mediterranean, 2010-2013. In T. Bloom \& B. Gebrewold (Eds.), Understanding migrant decisions: from Sub-Saharan Africa to the Mediterranean region (pp. 37-59). London: Routledge.

Marcus, G. E. (1995). Ethnography in/of the world system: the emergence of multi-sited ethnography. Annual Review of Anthropology, 24(1), 95-117. https://doi.org/10.1146/annurev. an.24.100195.000523 
Martinovic, B., van Tubergen, F., \& Maas, I. (2009). Dynamics of interethnic contact: a panel study of immigrants in the Netherlands. European Sociological Review, 25(3), 303-318. https://doi. org/10.1093/esr/jcn049

Massey, D. S. (1987). Understanding Mexican migration to the United States. American Journal of Sociology, 92(6), 1372-1403. https://doi.org/10.1086/228669

Massey, D. S. (1990). Social structure, household strategies, and the cumulative causation of migration. Population Index, 56(1), 3-26.

Matsaganis, M. (2011). The welfare state and the crisis: the case of Greece. Journal of European Social Policy, 21(5), 501-512. https://doi.org/10.1177/0958928711418858

Mazzucato, V. (2004). Transcending the nation. In D. Kalb, W. Pansters, \& H. Siebers (Eds.), Globalization and development: Themes and concepts in current research (pp. 131-162). Dordrecht: Kluwer Academic Publishers. https://doi.org/10.1007/1-4020-2475-4_6

Mazzucato, V. (2009). Informal insurance arrangements in Ghanaian migrants' transnational networks: the role of reverse remittances and geographic proximity. World Development, 37(6), 1105-1115. https://doi.org/10.1016/j.worlddev.2008.11.001

Mazzucato, V. (2011). Reverse remittances in the migration-development nexus: two-way flows between Ghana and the Netherlands. Population, Space and Place, 17(5), 454-468. https://doi. org/10.1002/psp.646

Mazzucato, V., Kabki, M., \& Smith, L. (2006). Transnational migration and the economy of funerals: Changing practices in Ghana. Development and Change, 37(5), 1047-1072. https://doi. org/10.1111/j.1467-7660.2006.00512.x

McCarty, C. (2003). EgoNet. Personal Network Software.

Mckenzie, D., \& Rapoport, H. (2007). Network effects and the dynamics of migration and inequality: Theory and evidence from Mexico. Journal of Development Economics, 84(1), 1-24. https://doi. org/10.1016/j.jdeveco.2006.11.003

McPherson, M., Smith-Lovin, L., \& Cook, J. M. (2001). Birds of a feather: homophily in social networks. Annual Review of Sociology, 27(1), 415-444. https://doi.org/10.1146/annurev. soc.27.1.415

Miles, M. B., \& Huberman, A. M. (1994). Qualitative data analysis: an expanded sourcebook (Second edi). Thousand Oaks: Sage Publications.

Mitchell, J.C. (ed.) (1969). Social Networks in Urban Situations: Analyses of Personal Relations in Central African Towns. Manchester: Manchester University Press.

Mollenhorst, G., Völker, B., \& Flap, H. (2014). Changes in personal relationships: How social contexts affect the emergence and discontinuation of relationships. Social Networks, 37, 65-80. https:// doi.org/10.1016/j.socnet.2013.12.003

Morgan, D. L., Neal, M. B., \& Carder, P. (1997). The stability of core and peripheral networks over time. Social Networks, 19(1), 9-25. https://doi.org/10.1016/S0378-8733(96)00288-2

Muanamoha, R. C., Maharaj, B., \& Preston-Whyte, E. (2010). Social networks and undocumented Mozambican migration to South Africa. Geoforum, 41(6), 885-896. https://doi.org/10.1016/j. geoforum.2010.06.001 
Neal, A. W. (2009). Securitization and risk at the EU border: the origins of FRONTEX. JCMS: Journal of Common Market Studies, 47(2), 333-356. https://doi.org/10.1111/j.1468-5965.2009.00807.x

Oran, B. (2007). Minority concept and rights in Turkey: the Lausanne Peace Treaty and current issues. In Z. F. K. Arat (Ed.), Human rights in Turkey (pp. 35-52). Philadelphia: University of Pennsylvania Press.

Özkan, M., \& Akgün, B. (2010). Turkey's opening to Africa. The Journal of Modern African Studies, 48(04), 525-546. https://doi.org/10.1017/\$0022278X10000595

Papadopoulou-Kourkoula, A. (2008). Transit migration: the missing link between emigration and settlement. London: Palgrave Macmillan UK. https://doi.org/10.1057/9780230583801

Pathirage, J., \& Collyer, M. (2011). Capitalizing social networks: Sri Lankan migration to Italy. Ethnography, 12(3), 315-333. https://doi.org/10.1177/1466138110362013

Peker, E. (2014). Turkey exits junk status. Retrieved September 15, 2014, from http://online.wsj.com/ news/articles/SB10001424052970204349404578100614003177302

Pentzopoulos, D. (2002). The Balkan exchange of minorities and its impact on Greece. (Second edi). London: Hurst and Company Publishers Ltd.

Pierini, M. (2010). Turkey-EU Twinning project on Integrated Border Management (IBM) opening ceremony, Speech outline of Ambassador Marc Pierini, Head of the EU Delegation. Retrieved September 15, 2014, from https://www.avrupa.info.tr/en/news/integrated-border-managementtwinning-project-2511

Portes, A., Guarnizo, L. E., \& Landolt, P. (1999). The study of transnationalism: pitfalls and promise of an emergent research field. Ethnic and Racial Studies, 22(2), 217-237. https://doi. org/10.1080/014198799329468

Portes, A., \& Zhou, M. (1993). The new second generation: segmented assimilation and its variants. The ANNALS of the American Academy of Political and Social Science, 530(1), 74-96. https://doi. org/10.1177/0002716293530001006

Pratsinakis, M., Hatziprokopiou, P., \& King, R. (2017). Beyond migration binaries and linear transitions: the complexification of Greece's migratory landscape at times of crisis (No. 92).

Pries, L. (2004). Determining the causes and durability of transnational labour migration between Mexico and the United States: Some empirical findings. International Migration, 42(2), 3-39. https://doi.org/10.1111/j.0020-7985.2004.00279.x

Pro Asyl. (2012). "I came here for peace": the systematic ill-treatment of migrants and refugees by state agents in Patras. Frankfurt.

Pro Asyl. (2013). Pushed Back: systematic human rights violations against refugees in the Aegean Sea and the Greek-Turkish land border. Frankfurt/Main.

Pro Asyl. (2014). 12 refugees die during alleged push-back operation off Greek island. Retrieved August 11, 2014, from https://www.proasyl.de/en/pressrelease/12-refugees-die-during-allegedpush-back-operation-off-greek-island/

Pugh, M. (2004). Drowning not waving: boat people and humanitarianism at sea. Journal of Refugee Studies, 17(1), 50-69. https://doi.org/10.1093/jrs/17.1.50

Rajchman, J. (1991). Philosophical events: Essays of the 80's. New York: Columbia University Press. 
Ravenstein, E. G. (1889). The laws of migration. Journal of the Royal Statistical Society, 52(2), 241. https://doi.org/10.2307/2979333

Ruan, D., Freeman, L. C., Dai, X., Pan, Y., \& Zhang, W. (1997). On the changing structure of social networks in urban China. Social Networks, 19(1), 75-89. https://doi.org/10.1016/S03788733(96)00292-4

Ryan, L. (2011). Migrants' social networks and weak ties: accessing resources and constructing relationships post-migration. The Sociological Review, 59(4), 707-724. https://doi.org/10.1111/ j.1467-954X.2011.02030.x

Ryan, L., Sales, R., Tilki, M., \& Siara, B. (2008). Social networks, social support and social capital: The experiences of recent Polish migrants in London. Sociology, 42(4), 672-690. https://doi. org/10.1177/0038038508091622

Şaul, M. (2014). A different kargo: sub-Saharan migrants in Istanbul and African commerce. Urban Anthropology and Studies of Cultural Systems and World Economic Development, 43(1/2/3), 143-203.

Saunders, A. (1957, January). Quotable quotes. Reader's Digest.

Schans, D., Mazzucato, V., Schoumaker, B., \& Flahaux, M.-L. (2018). Changing patterns of Ghanaian migration. In C. Beauchemin (Ed.), Migration between Africa and Europe (pp. 265-289). Cham: Springer International Publishing. https://doi.org/10.1007/978-3-319-69569-3_10

Schapendonk, J. (2011). Turbulent trajectories: sub-Saharan African migrants heading North. Radboud University Nijmegen.

Schapendonk, J. (2013). From transit migrants to trading migrants: development opportunities for Nigerians in the transnational trade sector of Istanbul. Sustainability, 5(7), 2856-2873. https:// doi.org/10.3390/su5072856

Schapendonk, J. (2015). What if networks move? Dynamic social networking in the context of African migration to Europe. Population, Space and Place, 21(8), 809-819. https://doi.org/10.1002/ psp. 1860

Schapendonk, J., \& Steel, G. (2014). Following migrant trajectories: the im/mobility of Sub-Saharan Africans en route to the European Union. Annals of the Association of American Geographers, 104(2), 262-270. https://doi.org/10.1080/00045608.2013.862135

Schmalzbauer, L. (2004). Searching for wages and mothering from afar: the case of Honduran transnational families. Journal of Marriage and Family, 66(5), 1317-1331. https://doi. org/10.1111/j.0022-2445.2004.00095.x

Schulz, R., \& Tompkins, C. A. (1990). Life events and changes in social relationships: examples, mechanisms, and measurement. Journal of Social and Clinical Psychology, 9(1), 69-77. https:// doi.org/10.1521/jscp.1990.9.1.69

Schwarz, I. (2018). Migrants moving through mobility regimes: the trajectory approach as a tool to reveal migratory processes. Geoforum. https://doi.org/10.1016/j.geoforum.2018.03.007

Simmons, A. B. (1985). Recent studies on place-utility and intention to migrate: an international comparison. Population and Environment, 8(1-2), 120-140. https://doi.org/10.1007/BF01263020 
Sin, C. H. (2005). Seeking informed consent: reflections on research practice. Sociology, 39(2), 277294. https://doi.org/10.1177/0038038505050539

Skeldon, R. (2015). Temporary, seasonal circular migration: a critical appraisal, In: A. Triandafyllidou, Routlegde Handbook of Immigration and Refugee Studies (pp 104-109). Londen: Routlegde.

Smith, H. (2014). Greek court acquits farmers who shot 28 Bangladeshi strawberry pickers. Retrieved September 15, 2014, from http://www.theguardian.com/world/2014/jul/31/greek-court-acquitsfarmers-shot-strawberry-pickers

Smith, L., \& Mazzucato, V. (2009). Constructing homes, building relationships: migrant investments in houses. Tijdschrift Voor Economische En Sociale Geografie, 100(5), 662-673. https://doi. org/10.1111/j.1467-9663.2009.00571.x

Snel, E., Engbersen, G., \& Faber, M. (2016). From bridgeheads to gate closers: How migrant networks contribute to declining migration from Morocco to the Netherlands. In O. Bakewell, G. Engbersen, M. L. Fonseca, \& C. Horst (Eds.), Beyond networks: Feedback in international migration (pp. 134155). London: Palgrave Macmillan UK. https://doi.org/10.1057/9781137539212_7

Snel, E., Engbersen, G., \& Leerkes, A. (2006). Transnational involvement and social integration. Global Networks, 6(3), 285-308. https://doi.org/10.1111/j.1471-0374.2006.00145.x

Somerville, K. (2015). Strategic migrant network building and information sharing: Understanding 'migrant pioneers' in Canada. International Migration, 53(4), 135-154. https://doi.org/10.1111/ j.1468-2435.2010.00671.x

Spijkerboer, T. (2007). The human costs of border control. European Journal of Migration and Law, 9(1), 127-139. https://doi.org/10.1163/138836407X179337

Stark, O. (1991). The migration of labor. Cambridge: Basil Blackwell.

Suitor, J. J., Wellman, B., \& Morgan, D. L. (1997). It's about time: how, why, and when networks change. Social Networks, 19(1), 1-7. https://doi.org/10.1016/S0378-8733(96)00287-0

Suter, B. (2012a). Social networks in transit: experiences of Nigerian migrants in Istanbul. Journal of Immigrant \& Refugee Studies, 10(2), 204-222. https://doi.org/10.1080/15562948.2012.674327

Suter, B. (2012b). Tales to transit : sub-Saharan African migrants' experiences in Istanbul. Linköping University Electronic Press, Malmö.

Suter, B. (2013). Asylum and migration in Turkey: an overview of developments in the field 19902013 (MIM Working Papers Series No. 13). Malmö.

Taylor, E. J. (1999). The new economics of labour migration and the role of remittances in the migration process. International Migration, 37(1), 63-88. https://doi.org/10.1111/14682435.00066

Terhell, E. L., Broese van Groenou, M. I., \& van Tilburg, T. (2007). Network contact changes in early and later postseparation years. Social Networks, 29(1), 11-24. https://doi.org/10.1016/j. socnet.2005.11.006

The Hellenic Statistical Authority. (2015). Greece in figures. Athens.

Thielemann, E. R. (2010). The Common European Asylum System: in need of a more comprehensive burden-sharing approach. In A. Luedtke (Ed.), Migrants and minorities: The European response. Newcastle-upon-Tyne: Cambridge Scholars Publishing. 
Todaro, M. P. (1969). A Model of labor migration and urban unemployment in less developed countries. The American Economic Review, 59(1), 138-148.

Toksöz, G., Erdoğdu, S., \& Kaşka, S. (2012). Irregular labour migration in Turkey and the situation of migrants workers in the labour market.

Toma, S., \& Vause, S. (2014). Gender differences in the role of migrant networks: Comparing Congolese and Senegalese migration flows. International Migration Review, 48(4), 972-997. https://doi.org/10.1111/imre.12150

Triandafyllidou, A. (2012). Greece: how a state in crisis manages its migration crisis? (Note de l'Ifri). Paris.

Triandafyllidou, A., \& Lazarescu, D. (2009). The impact of the recent global economic crisis on migration. Preliminary insights from the south eastern borders of the EU (Greece) (CARIM Analytic and Synthetic Notes No. 2009/40). San Domenico di Fiesole.

Tsitselikis, K. (2013). Sticks, not carrots: immigration and rights in Greece and Turkey. Southeast European and Black Sea Studies, 13(3), 421-434. https://doi.org/10.1080/14683857.2013.824666

Turkish Statistical Institute. (n.d.). The results of address based population registration system 2012. Retrieved May 5, 2017, from http://www.turkstat.gov.tr/PreHaberBultenleri.do?id=13425

Ulusoy, O., \& Battjes, H. (2017). Situation of readmitted migrants and refugees from Greece to Turkey under the EU-Turkey Statement (No. 15). VU Migration Law Series. Amsterdam.

Urry, J. (2003). Social networks, travel and talk. British Journal of Sociology, 54(2), 155-175. https:// doi.org/10.1080/0007131032000080186

van Geel, J., \& Mazzucato, V. (2017). Conceptualising youth mobility trajectories: thinking beyond conventional categories. Journal of Ethnic and Migration Studies, 1-19. https://doi.org/10.1080/1 369183X.2017.1409107

Van Hear, N. (1998). New diasporas: The mass exodus, dispersal, and regrouping of migrant communities. London: UCL Press.

Van Hear, N. (2006). "I went as far as my money would take me": conflict, forced migration and class. In F. Crepeau, D. Nakache, M. Goetz, A. Hansen, R. Modi, A. Nadig, ... M. Willigen (Eds.), Forced migration and global processes: A view from forced migration studies (pp. 125-158). Oxford: Lexington Books.

Van Liempt, I. (2007). Navigating borders: inside perspectives on the process of human smuggling into the Netherlands. Amsterdam University Press.

Van Meeteren, M., Engbersen, G., \& van San, M. (2009). Striving for a better position: Aspirations and the role of cultural, economic, and social capital for irregular migrants in Belgium. International Migration Review, 43(4), 881-907. https://doi.org/10.1111/j.1747-7379.2009.00788.x

Van Munster, R. (2009). Securitizing immigration: The politics of risk in the EU. London: Palgrave Macmillan UK. https://doi.org/10.1057/9780230244955

Van Wijk, J. (2010). Luanda - Holanda: Irregular migration from Angola to the Netherlands. International Migration, 48(2), 1-30. https://doi.org/10.1111/j.1468-2435.2008.00485.x

Vertovec, S. (2004). Cheap calls: the social glue of migrant transnationalism. Global Networks, 4(2), 219-224. https://doi.org/10.1111/j.1471-0374.2004.00088.x 
Völker, B., \& Flap, H. (1995). Amitié et inimitié sous communisme d'Etat: Le cas de l'Allemagne de I'Est. Revue Française de Sociologie, 36(4), 629. https://doi.org/10.2307/3322449

Wallerstein, I. (1974). The rise and future demise of the world capitalist system: Concepts for comparative analysis. Comparative Studies in Society and History, 16(04), 387. https://doi. org/10.1017/S0010417500007520

Wasserman, S. (1994). Advances in social network analysis: research in the social and behavioral sciences. Sage.

Wellman, B., Wong, R. Y., Tindall, D., \& Nazer, N. (1997). A decade of network change: Turnover, persistence and stability in personal communities. Social Networks, 19(1), 27-50. https://doi. org/10.1016/S0378-8733(96)00289-4

Wheeler, A. T. (2011). Ankara to Africa: Turkey's outreach since 2005. South African Journal of International Affairs, 18(1), 43-62. https://doi.org/10.1080/10220461.2011.564426

Wilson, G. (1941). The economics of detribalization in Northern Rhodesia. The Rhodes-Livingstone Papers, No. 5.Livingstone, Northern Rhodesia: Rhodes-Livingstone Institute.

Wilson, G. (1942). The economics of detribalization in Northern Rhodesia. The Rhodes-Livingstone Papers, No. 6.Livingstone, Northern Rhodesia: Rhodes-Livingstone Institute.

Wimmer, A., \& Glick Schiller, N. (2002). Methodological nationalism and beyond: nation-state building, migration and the social sciences. Global Networks, 2(4), 301-334. https://doi. org/10.1111/1471-0374.00043

Wissink, M., Düvell, F., \& van Eerdewijk, A. (2013). Dynamic migration intentions and the impact of socio-institutional environments: a transit migration hub in Turkey. Journal of Ethnic and Migration Studies, 39(7), 1087-1105. https://doi.org/10.1080/1369183X.2013.778026

Wissink, M., \& Mazzucato, V. (2018). In transit: changing social networks of sub-Saharan African migrants in Turkey and Greece. Social Networks, 53, 30-41. https://doi.org/10.1016/j. socnet.2017.03.005

Wissink, M., \& Ulusoy, O. (2016). Navigating the Eastern Mediterranean: the diversification of SubSaharan African migration patterns in Turkey and Greece. In T. Bloom \& B. Gebrewold (Eds.), Understanding migrant decisions: From Sub-Saharan Africa to the Mediterranean Region (pp. 120-138). London: Routledge.

World Bank Commission on Growth and Development. (2009). Post-crisis growth in the developing world. Washington D.C.: The World Bank. https://doi.org/10.1596/978-0-8213-8165-6

World Health Organisation Research Ethics Review Committee. (n.d.). The process of obtaining informed patient consent. Retrieved from https://www.who.int/rpc/research_ethics/Process_ seeking_IF_printing.pdf

Yükseker, D., \& Brewer, K. T. (2011). Astray and stranded at the gates of The European Union: African transit migrants in İstanbul. New Perspectives on Turkey, 44, 129-159. https://doi.org/10.1017/ S0896634600005963

Zijlstra, J., \& Liempt, I. Van. (2017). Smart(phone) travelling: understanding the use and impact of mobile technology on irregular migration journeys. International Journal of Migration and Border Studies, 3(2/3), 174. https://doi.org/10.1504/IJMBS.2017.083245 


Appendix I

Overview of sample and

fieldwork locations 


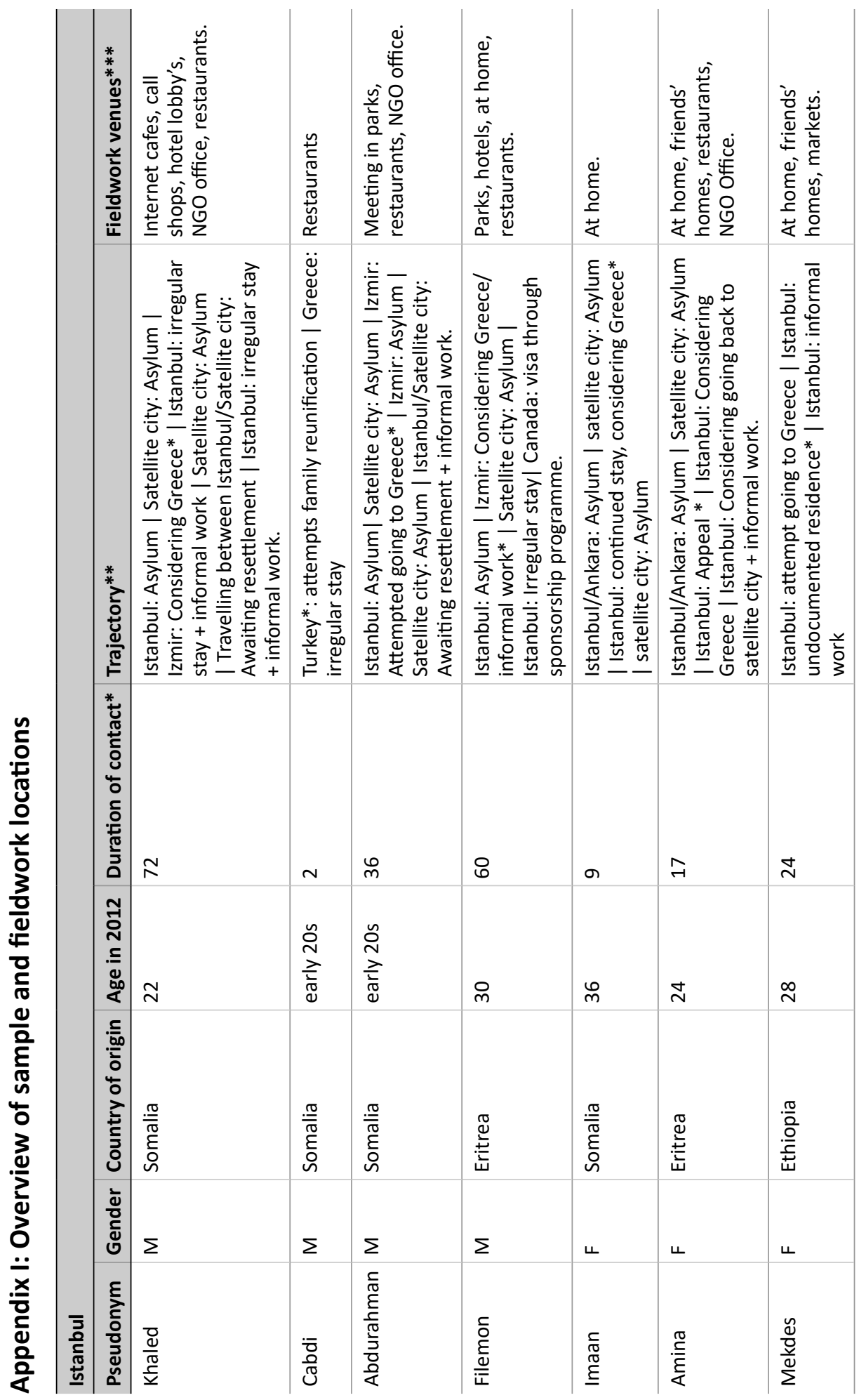




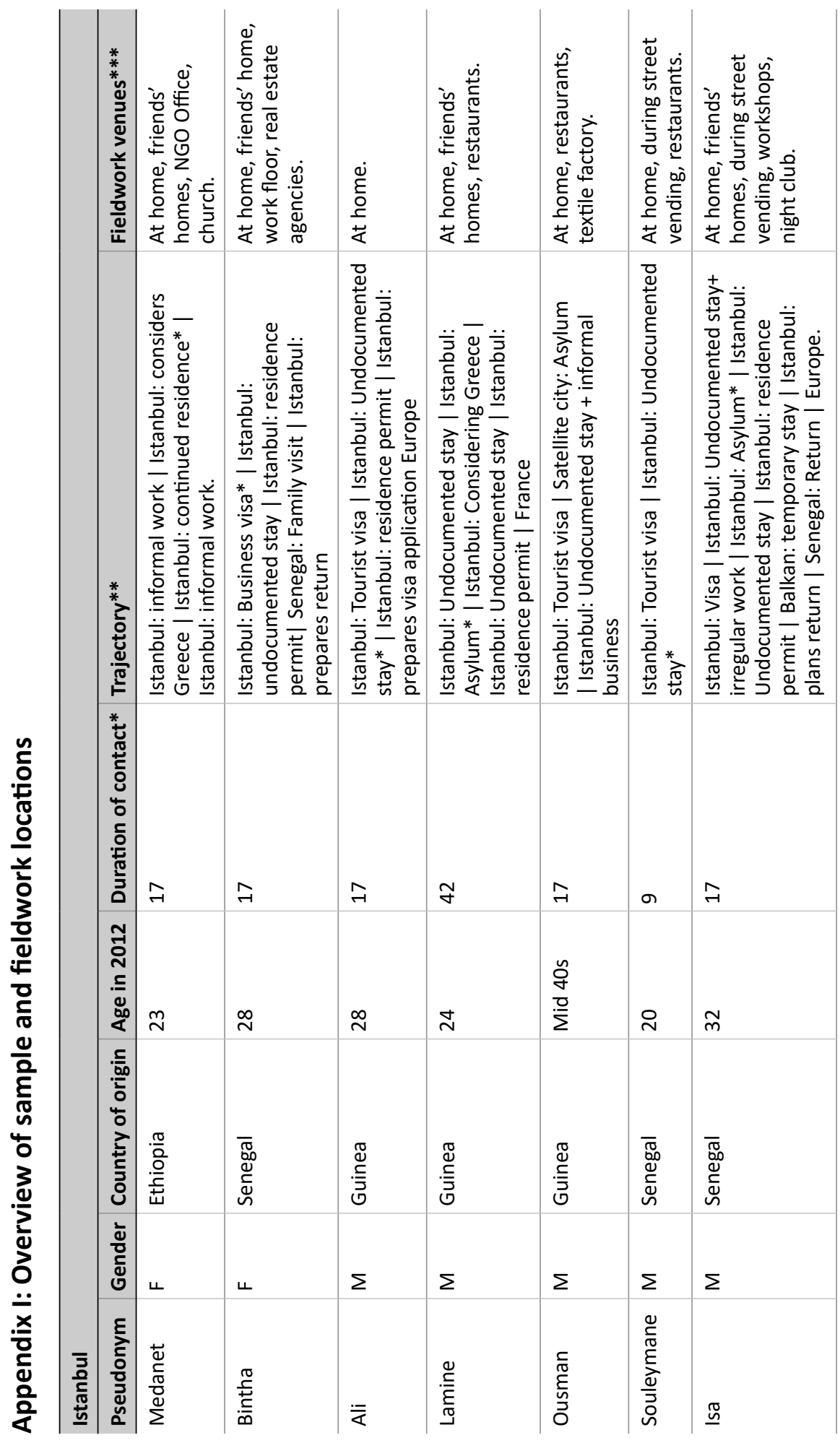




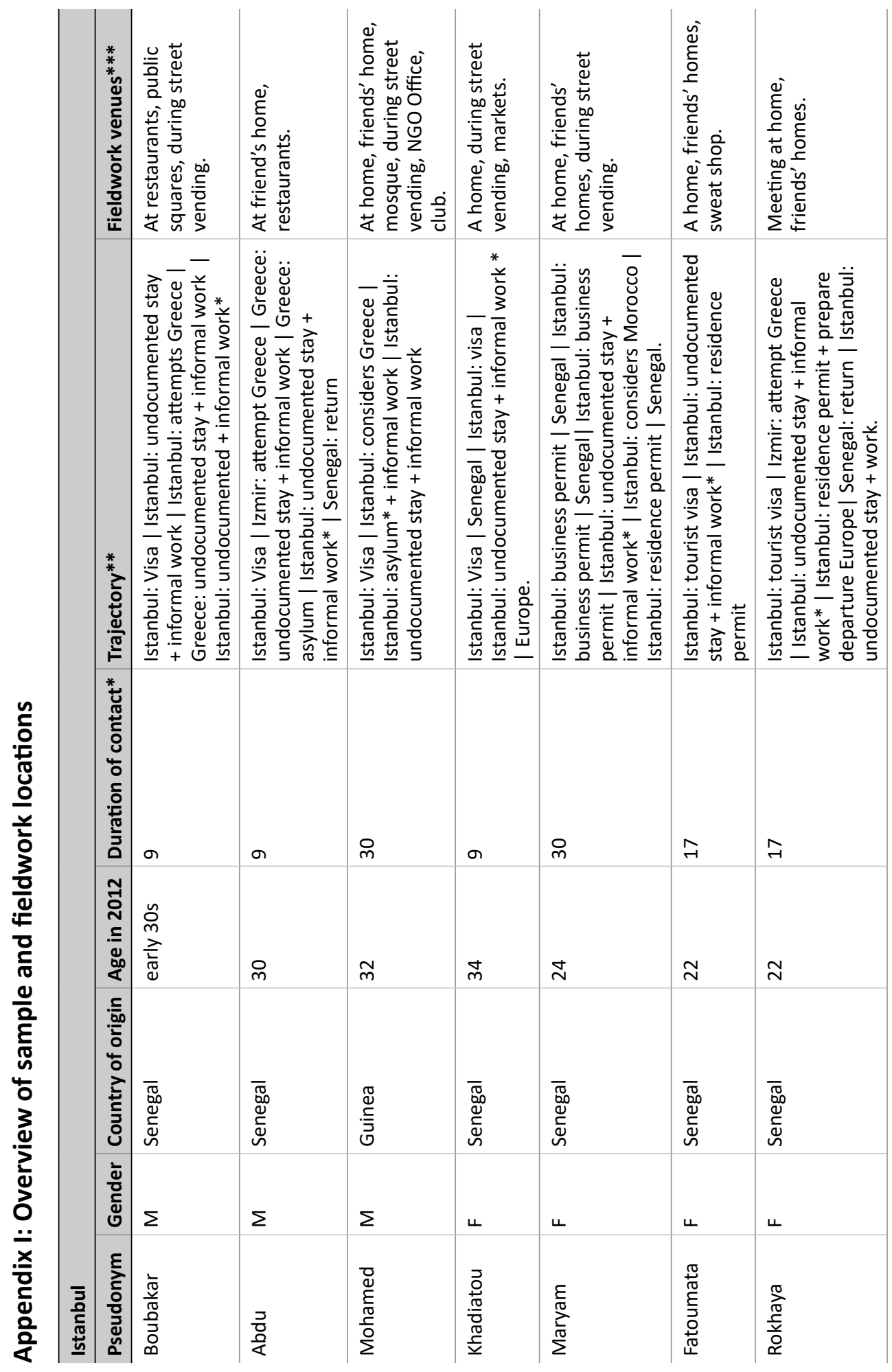




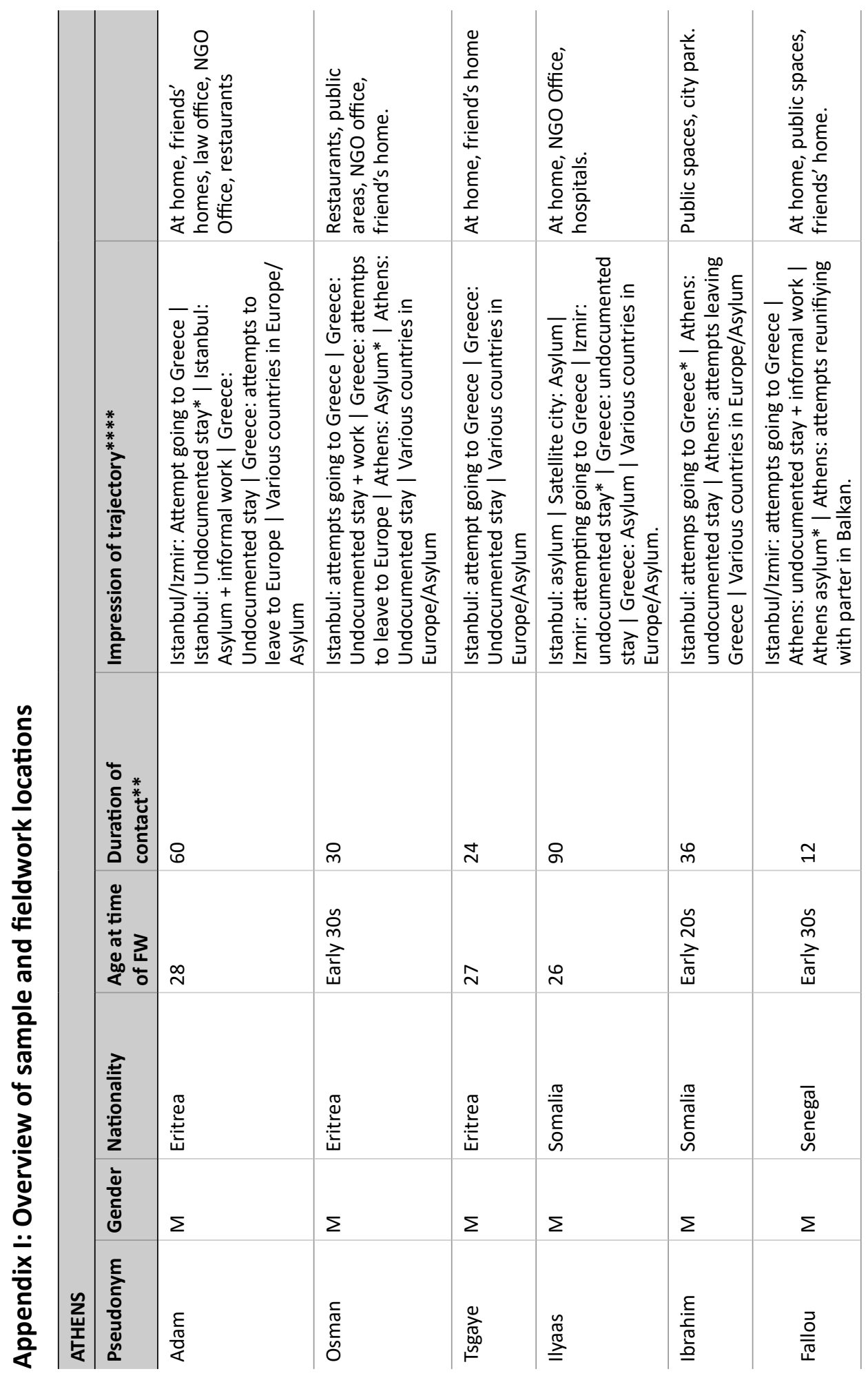




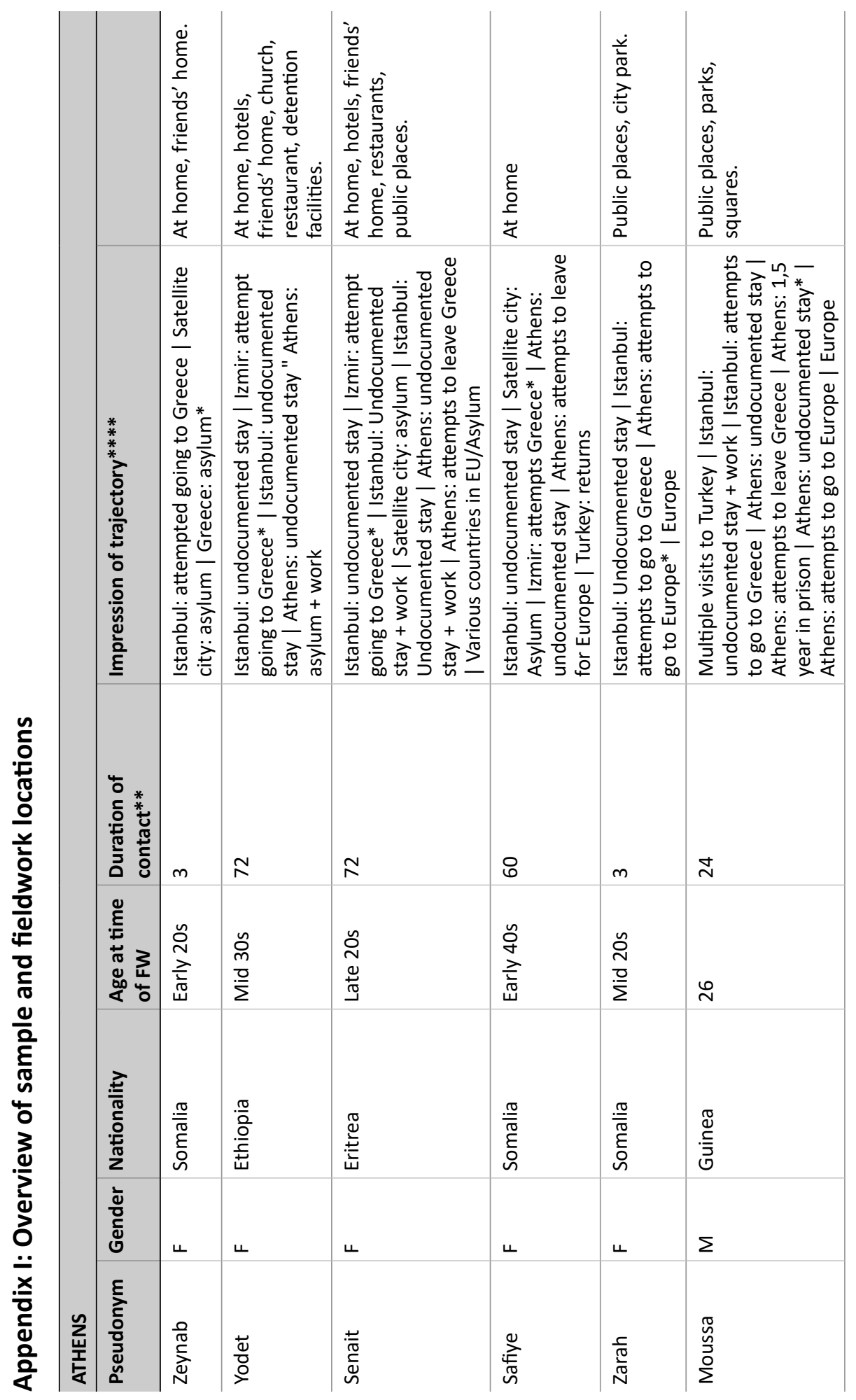




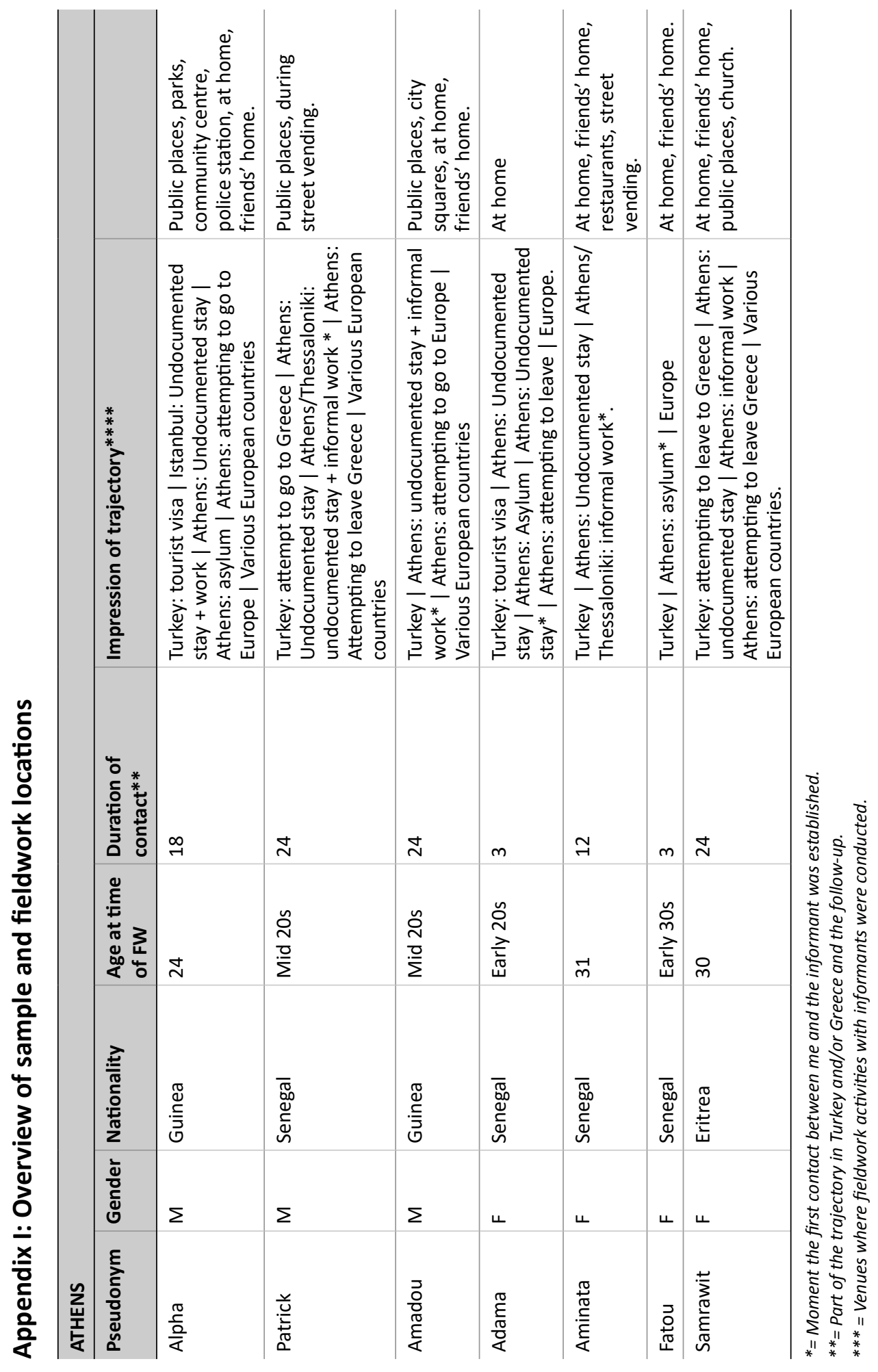



Appendix II Interview guide for semi-structured interviews 



\section{Appendix II: Interview guide for semi-structured interviews}

A. Life in Turkey/Greece

1. How in general do you experience life in Turkey/Greece?

a. How are your experiences with encounters with local people?

b. What are your experiences with the local authorities?

c. Can you describe what you do on a daily basis?

d. Did you have any prior knowledge about Turkey/Greece before you arrived?

2. Do you remember any specific event which led you to decide to <currently applied migration strategy>

\section{B. Aspirations}

1. What were your hoping to achieve when you left your country of origin?

2. What would you currently like to realise?

3. Have your dreams changed between the moment you left your country of origin and this moment in time?

4. Do you remember any specific event which has affected your dreams?

\section{Resources}

1. How do you make a living here in Turkey/Greece?

2. Have you found any employment here?

3. Have you had any contact with organisations, lawyers or authorities who have helped you with sustaining a livelihood here?

a. Have they supported you? In what way?

4. Have there been any persons here in Turkey/Greece who have supported you in any way?

a. Has there been anyone abroad?

5. Compared to when you have just arrived, has it become more easy or more difficult to sustain a livelihood?

6. Have your available resources changes during your residence in Turkey/Greece?

a. How come?

7. Do you remember any specific event which has influenced what resources you had available?

8. What do you know about the asylum procedure?

D. Migration experience before coming to Turkey/Greece

1. How was your life in your country of origin?

2. Why have you decided to leave your country of origin?

a. When was this?

b. What was the immediate cause preceding your departure? 
3. By what means have you left your country of origin?

4. Did you have any specific destination in mind?

5. What countries have you crossed on your way to Turkey/Greece?

a. How much time have you spend in each country?

b. What made you decide to leave these countries?

6. Did you have any previous migration experience before this one?

7. Did you have any prior information about the asylum procedure in Turkey/Greece?

a. How have you acquired this?

8. Did you have any prior information about how to travel to Turkey/Greece?

a. How have you acquired this?

9. What were your expectations and hopes about Turkey/Greece/Europe?

\section{E. Migration towards Turkey/Greece}

1. By what means have you arrived in Turkey/Greece?

2. In what town did you arrive?

3. Did you have any financial means available the moment you arrived?

4. With whom have you arrived?

5. What is the first thing you did upon your arrival?

a. Where did you go?

b. How have you found accommodation?

6. Have you approached the authorities, or were you approached by the authorities?

a. Have you spend time in detention?

b. How has this affected your current experience in Turkey/Greece?

7. Have you been informed about the possibility to apply for asylum? (in case of irregular entry)

a. By whom and when?

8. Did you have any plan to stay here or to continue your journey upon arrival?

9. At that moment in time, what were your expectations and hopes about Turkey/Greece/ Europe?

10. What have you decided to do next in terms of your journey?

11. Do you remember any specific event which influenced this decision?

\section{F. Currently applied migration strategy.}

1. When have you decided to stay in Turkey/Greece / apply for asylum / etc.?

2. What would you like to achieve in the near future?

a. What steps do you take to achieve this?

3. Are there any risks involved in this?

a. Is there anything you can do to combat these?

4. Have you considered any other options? (going to Greece, staying in Turkey, returning, going elsewhere). 
5. Has your idea about your current strategy changed during the course of your stay in Turkey/Greece?

a. Why is that?

\section{G. Previous applied migration strategies.}

1. Have you attempted to leave Turkey/Greece at some point?

a. How long have you been in Turkey/Greece before trying?

b. What were your experiences?

2. Have you applied for asylum in Turkey/Greece?

a. How long have you been in Turkey/Greece before doing so?

b. Before applying for asylum, have you tried leaving Turkey/Greece

c. What are/were your experiences with the asylum procedure?

d. Have you been to your satellite city (in Turkey)?

e. Why are you not residing in your satellite city?

f. What has happened between going to Greece/applying for asylum/etc?

3. Why do you consider the <previously applied migration strategy> not an option (anymore) at this moment?

4. Has your opinion about these other options changes during the course of your stay in Turkey/Greece?

a. Why (not) so?

5. Do you remember any particular event which incited you to change your <previously applied migration strategy>?

6. Under what circumstances can you imagine you would change your strategy?

\section{H. Role of social networks}

1. Did someone advice you on going to Turkey/Greece?

2. How did your family at home or in Europe/elsewhere support your journey?

3. Did you already know someone in Turkey/Greece before coming here?

4. How important is it that your family abroad supports you / gives directions to realize your goals?

5. How has the (lack of) support by these family members influenced your choice to $<<$ change of migration strategy >>

6. Would you consider << other migration strategy >> if your family members /acquaintances would tell you to do so?

a. Was this ever the case?

7. What was your family and acquaintances at home / abroad reaction to your decision to, $<$ change of migration strategy $>>>$

8. How have your contacts in Turkey/Greece informed your perception of going to Turkey/ Greece? 


\section{Creation of social networks}

1. When did you get in touch with the people in Turkey/Greece?

a. Did you approach them, or were you approached by them?

b. Why did you contact them at this particular time?

c. By what means did you approach them?

2. How did you find out about their contact details?

3. How did they react to your first initial contact?

4. Are there people in Europe you know of, but who you did not yet contact?

a. Are you planning on doing so? When?

5. How actively are you looking for people abroad who could help you?

a. How hard is it to find these?

\section{J. Support and Mutual Expectations}

1. Do you think the people in your network expect something from you?

2. Do you feel pressure from people in your network to do something in return?

3. How do you feel about having to ask family or friends for support?

a. How do they generally react to you?

4. What will happen if you don't meet these expectations?

5. Did you make any agreements on what you would do in return for people who have helped you?

6. How do people react if you explain them you cannot do something in return at this moment?

7. Do your friends and relatives abroad advice you on the <<currently applied migration strategy>>

a. How do you take this advice? (helpful, disturbing)

\section{K. Changes in social networks}

1. Do you feel people have ever let you down?

2. Have you actively broke with someone?

3. How do you think your relationships have changed since you left your country of origin?

4. How do you think your relationships changed now that you are in Turkey/Greece?

5. Has the level of support you received from others changed before coming to Turkey/ Greece, and now?

a. How is this related to the fact that you <<currently applied migration strategy >>?

6. Do you remember any particular time or event when you family or friends abroad stopped contacting you, or ignored your attempts to contact them?

7. How has this impacted on your options to <currently applied migration strategy>> in Turkey/Greece? 


Appendix III SNA Interview 



\section{Appendix III: SNA Interview}

\section{Name Generator}

\begin{tabular}{|l|l|l|}
\hline Name: & Informant no: & \\
\hline Country of Origin: & Date: & \\
\hline City: & Duration of interview: & \\
\hline Location of Interview: & Number of alters: & \\
\hline
\end{tabular}

1. Who do you usually spend your free time with, for example by having a cup of tea/ coffee or a nice chat?

Name

Gender

Relationship

2. Who do you consult with when you need to take a major decision in your life? E.g. staying in Turkey/Greece, moving to another city or country.

Name Gender Relationship

3. Since your arrival in Greece, who has helped you with food, accommodation, or took otherwise care of you?

Name

Gender

Relationship

4. Is there someone you took care of, for example by sharing/giving food, accommodation or another kind of support?

Name

Gender

Relationship

5. Is there anyone who has helped you financially, since you arrived in Turkey/Greece? Name Gender Relationship

6. Have you provided financial support to anyone, since you arrived in Greece? Name Gender Relationship

7. Is there someone to whom you would like to provide financial support in the future? Name

Gender Relationship 
8. Where there any critical incidents related to your journey from your country of origin when someone has been of great help to you? E.g. by providing directions, financing the journey, making connections)
Name
Gender
Relationship

9. Have you been contacted by someone abroad who asked for your advice on how to travel to Greece?
Name
Gender
Relationship

10. Who did you consult with concerning your trip to Greece before you arrived here?
Name
Gender
Relationship

11. Suppose you want to go to Europe, do you know anyone there, here, or elsewhere, who could advice you on how to arrange this?
Name
Gender
Relationship

12. With whom, out of Greece, have you talked mostly on phone or skype during the past two months?
Name
Gender
Relationship

13. With whom have you interacted most using email and social media during the past two months?
Name
Gender
Relationship

14. Is there someone who has neglected/refused your request for contact, for example by not answering phone calls, or not responding to emails?

Name Gender Relationship

15. A. Is there someone abroad you were in touch with while you were in Turkey, but not anymore now you are in Greece? (Greece only)

Name Gender Relationship

16. B. Or the other way around; someone abroad you only contacted once you were in Greec?

Name Gender Relationship 
17. Is there anyone else, who you haven't mentioned yet who is important to you and to whom you feel close?

Name Gender Relationship

18. Do you receive support from any kind of (religious) organization?

Name Type of Organization Location Type of support received

19. Do you provide support to any kind of (religious) organization?

Name Type of Organization Location Type of support received

2. Name grid- who knows who

\begin{tabular}{|c|c|c|c|c|c|c|c|c|c|c|c|c|c|c|c|c|c|}
\hline & 1 & 2 & 3 & 4 & 5 & 6 & 10 & 11 & 12 & 13 & 14 & 15 & 16 & 17 & 18 & 19 & 20 \\
\hline 1 & & & & & & & & & & & & & & & & & \\
\hline 2 & & & & & & & & & & & & & & & & & \\
\hline 3 & & & & & & & & & & & & & & & & & \\
\hline 4 & & & & & & & & & & & & & & & & & \\
\hline 5 & & & & & & & & & & & & & & & & & \\
\hline 6 & & & & & & & & & & & & & & & & & \\
\hline 7 & & & & & & & & & & & & & & & & & \\
\hline 8 & & & & & & & & & & & & & & & & & \\
\hline 9 & & & & & & & & & & & & & & & & & \\
\hline 10 & & & & & & & & & & & & & & & & & \\
\hline 11 & & & & & & & & & & & & & & & & & \\
\hline 12 & & & & & & & & & & & & & & & & & \\
\hline 13 & & & & & & & & & & & & & & & & & \\
\hline 14 & & & & & & & & & & & & & & & & & \\
\hline 15 & & & & & & & & & & & & & & & & & \\
\hline 16 & & & & & & & & & & & & & & & & & \\
\hline 17 & & & & & & & & & & & & & & & & & \\
\hline 18 & & & & & & & & & & & & & & & & & \\
\hline 19 & & & & & & & & & & & & & & & & & \\
\hline 20 & & & & & & & & & & & & & & & & & \\
\hline
\end{tabular}

NB: During fieldwork a larger grid was used allowing for the required number of alters. 
3. Alter details

\begin{tabular}{l|l|l|l|l|l}
\hline Name & Nationalit & $\begin{array}{c}\text { Country } \\
\text { of residenc }\end{array}$ & $\begin{array}{c}\text { City } \\
\text { of residenc }\end{array}$ & $\begin{array}{c}\text { Mode } \\
\text { of contac }\end{array}$ & $\begin{array}{c}\text { Frequency } \\
\text { of contac }\end{array}$ \\
\hline & & & & & \\
\hline & & & & & \\
\hline & & & & & \\
\hline & & & & & \\
\hline & & & & & \\
\hline & & & & & \\
\hline & & & & & \\
\hline & & & & & \\
\hline & & & & & \\
\hline & & & & & \\
\hline
\end{tabular}




Nederlandse samenvatting 



\section{Inleiding}

Dit proefschrift onderzoekt de wijze waarop migratietrajecten van Afrikaanse migranten in Turkije en Griekenland verlopen en wat de rol daarin is van hun steeds veranderende sociale netwerken. Een migratietraject is in dit proefschrift gedefinieerd als de aaneenschakeling van migratiestrategieën die migranten onderweg toepassen, zoals asiel aanvragen, een grens oversteken zonder toestemming van autoriteiten en ongedocumenteerd verblijf.

In Europa is al jaren veel aandacht voor migratie naar Europa via het Mediterrane gebied. Via de media worden dikwijls schrijnende foto's gedeeld van overvolle boten en mensen die de overtocht over zee niet hebben gehaald. Het maatschappelijk debat hierover is gepolariseerd: waar sommige politici en opiniemakers strijden voor strengere migratiewetten en aangescherpte grensbewaking, pleiten anderen voor een meer humaan grensbeleid en opengestelde grenzen.

Ondanks deze uiteenlopende opvattingen wordt doorgaans aan beide kanten van een aantal vooronderstellingen uitgegaan dat in dit proefschrift nader is onderzocht. Zo roepen de beelden van de vele migranten aan de grenzen van Europa het idee op dat zij, in het land van herkomst, allen ooit hetzelfde doel hadden, namelijk Europa te bereiken. Van migranten die in Turkije verblijven, en al dan niet geprobeerd hebben om de oversteek naar Griekenland te maken, wordt vaak aangenomen dat zij zijn "gestrand" en dat hun migratietraject nog niet is voltooid. In heersende opvattingen bestaat verder een strikt onderscheid tussen vluchtelingen en andere migranten en worden aan beide groepen andere rechten en plichten toegekend. Met betrekking tot de rol van sociale netwerken is de veelgehoorde aanname dat families in het land van herkomst grote druk leggen op migranten voor financiële steun, en dat familie en bekenden die al zijn gemigreerd anderen aanmoedigen hetzelfde te doen. Migratiebeslissingen onderweg zouden worden gedreven door het wel of niet behalen van dit doel.

Deze vooronderstellingen zijn niet per se onwaar. De vraag is echter in hoeverre zij, in de wijze waarop ze in het maatschappelijk debat worden ingezet, een volledig beeld geven van de verscheidenheid aan motivaties, migratiestrategieën, sociale netwerken en keuzes die mensen maken onderweg en hoe zij daartoe gekomen zijn. Bovendien ontstaat het beeld dat migratie min of meer rechtlijnig of lineair verloopt, al dan niet met enkele hobbels onderweg. De praktijk laat echter zien dat migratietrajecten vaak een grillig verloop hebben en dus allesbehalve rechtlijnig zijn.

De introductie van dit proefschrift beschrijft het voorbeeld van de Eritrese Senait, die vanuit Turkije geprobeerd heeft om Griekenland te bereiken per boot, daarna ongedocumenteerd verbleef en werkte in Turkije, er vervolgens asiel aanvroeg en wachtte op hervestiging in Canada of de Verenigde Staten. Jaren later vertrok zij vanuit Turkije naar Griekenland. Na een verblijf van enkele jaren daar reisde zij verder en kwam uiteindelijk terecht in Nederland. Het moge duidelijk zijn dat het migratietraject van Senait geen lineair verloop had. Gedurende haar migratietraject kon zij afwisselend gekenmerkt worden als 
een ongedocumenteerde migrant, asielzoeker en vluchteling. Hoewel zij uiteindelijk wel naar Europa is gegaan, kunnen de zes jaren die zij doorbracht in Turkije en Griekenland niet simpelweg weggezet worden als tijd die zij heeft doorgebracht in afwachting van haar doorreis naar Europa, alleen al omdat Europa niet altijd meer haar doel was in deze periode. Dit proefschrift onderzoekt hoe een dergelijk non-lineair migratietraject zich ontwikkeld en stelt daarin de volgende onderzoeksvraag centraal: Welke mechanismen vormen het verloop van migratietrajecten van irregulier ${ }^{9}$ migranten uit sub-Sahara Afrika?

\section{Theoretisch kader}

De nadruk in de migratieliteratuur en theorievorming ligt op de start van migratie in het land van herkomst, het vervolg in het land van aankomst, de gevolgen voor beide landen en voor de relatie ertussen. Deze nadruk sterkt de (al dan niet impliciete) aanname dat migratietrajecten van individuen zich idealiter ontwikkelen volgens reeds bestaande migratiepatronen tussen landen van aankomst en herkomst. Vanuit dit perspectief zou makkelijk de voorbarige conclusie getrokken kunnen worden dat het voorgestelde land van aankomst voor individuele migratietrajecten een zeer bepalende rol heeft in de aangenomen migratiestrategieën. Die lijn volgend kan de - eveneens voorbarige - conclusie zijn dat wanneer dit voorgestelde land van aankomst niet wordt bereikt, het migratietraject niet succesvol is geweest. Bovendien wordt het beeld dat migratie een rechtlijnig verloop heeft - en een eenduidig resultaat of einddoel, nog eens versterkt door het denken in termen van herkomst en aankomst.

Dit proefschrift draagt bij aan de ontwikkeling van migratieliteratuur en theorievorming over de wijze waarop individuele migratietrajecten kunnen verlopen. Een van de speerpunten hierin is het loskomen van het dominante beeld van migratietrajecten als waren het rechte lijnen van A naar B, tussen vooraf bepaalde landen van herkomst en aankomst. Vandaar dat in dit onderzoek het individu als vertrekpunt wordt genomen, om het verloop van zijn of haar migratietraject waarachtig te kunnen te onderzoeken, en niet een geografisch startpunt of bestemming.

In de migratieliteratuur is de mogelijke rol van de sociale netwerken van migranten uitgebreid beschreven en bediscussieerd. Waar een stroming beschrijft dat de steun van sociale netwerken essentieel is om te kunnen migreren, beschrijft andere literatuur dat de rol van sociale netwerken overschat wordt en andere factoren, zoals migratiebeleid, beter zouden verklaren waarom mensen migreren. In beide gevallen worden sociale netwerken geconceptualiseerd als netwerken tussen migranten en potentiele migranten in het land

\footnotetext{
9 De toevoeging "irregulier" betekent dat de rechtspositie met betrekking van aankomst, verblijf, reizen, werk en vertrek niet op alle vlakken en op alle momenten legaal zijn en kan fluctueren gedurende het migratietraject. De term irregulier geniet de voorkeur ten opzichte van de meer gangbare term "illegaal”, omdat dit suggereert dat mensen geen bestaansrecht hebben en op alle fronten te allen tijde niet-wettelijk zijn, wat zelden het geval is.
} 
van herkomst. Voortbouwend op literatuur over sociale netwerkanalyse, wordt in dit proefschrift op een andere manier naar sociale netwerken gekeken, namelijk als persoonlijke netwerken van migranten. Elk individu heeft een netwerk, groot of klein. Hiervan kunnen andere migranten en mensen in het land van herkomst of voorgenomen bestemming (als die er is) deel uitmaken, maar tevens mensen aan de andere kant van de wereld. Het proefschrift bouwt verder voort op literatuur waarin de veranderlijkheid van netwerken wordt beschreven. Tot slot wordt een transnationaal perspectief gehanteerd, waardoor de rol van grensoverstijgende praktijken wordt meegenomen in het in kaart brengen en duiden van de netwerken en handelingen van migranten.

\section{Onderzoeksopzet}

Om de veranderlijkheid in migratiestrategieën tijdens de vorming van migratietrajecten te kunnen onderzoeken, evenals de veranderlijkheid in sociale netwerken en de samenhang ertussen, waren vier kenmerken van de onderzoeksopzet essentieel.

1) Een longitudinale aanpak waar informanten door de tijd heen werden gevolgd om veranderingen in migratiestrategieën en sociale netwerken te kunnen waarnemen terwijl ze voltrekken. Ik heb een groep van 40 migranten door de tijd heen gevolgd, variërend in duur van 3 tot 24 maanden met enkele uitschieters tot 90 maanden omdat zij deelnamen aan het onderzoek voor mijn Masterscriptie over een verwant onderwerp.

2) Het doen van onderzoek op meerdere plaatsen en onderzoeksmobiliteit, wat betekent dat ik migranten volg tussen de verschillende plaatsen waarin zij zich begeven binnen de stad, de regio en het lan alsook in verschillende landen

3) Een diversiteit aan gehanteerde onderzoeksmethoden: in het veldwerk combineerde ik drie onderzoeksmethoden: participatieve observatie, semi-gestructureerde interviews en sociale netwerkanalyse. De combinatie van verschillende onderzoeksmethoden zorgden ervoor dat de verschillende type data elkaar konden complementeren en valideren.

4) Dataverzameling en data-analyse vormen een cyclisch proces: door rondes van dataverzameling en data-analyse af te wisselen kon ik uit gemaakte analyses nieuwe informatie halen om in vervolgfasen van datacollectie nieuwe en aanvullende vragen te stellen en observaties te doen.

De 40 informanten die de onderzoeksgroep vormen (19 in Athene en 21 in Istanbul) waren afkomstig uit de Hoorn van Afrika en uit West-Afrika. De groep bestond uit 23 mannen en 17 vrouwen. Voor deze regio's is gekozen omdat in de bestaande literatuur over migratie in en naar Turkije de focus ligt op haar buurlanden. De groeiende aantallen van Afrikaanse 
migranten in Turkije nodigen uit tot het doen van onderzoek onder deze groep. Ook stelde deze selectie mij in staat voort te bouwen op mijn reeds bestaande netwerk. Het doel was niet zozeer om vergelijkingen tussen de regio's van herkomst en gender te maken, maar om een diversiteit aan migratietrajecten op te nemen in de onderzoeksgroep.

Istanbul in Turkije en Athene in Griekenland vormden de veldwerklocaties. Beide steden zijn zogeheten 'transit migratie hubs', welke worden gekenmerkt door een hoge mate van veranderlijkheid van sociale en institutionele structuren die de context kenmerken waarin beslissingen met betrekking tot migratie worden gemaakt. Deze kenmerken worden in het proefschrift aangeduid met het begrip volatiliteit. Dit wil zeggen dat de wegen van vele mensen er kruisen en er dus veel beweging zit in locale netwerken. Ook wijst het op een grillig karakter in de aard en toepassing van lokaal migratiebeleid. Over de migratiecontext in beide landen zijn de afgelopen jaren zeer kritische rapporten verschenen van mensenrechtenorganisaties, met name met betrekking tot de toegang tot asiel, rechtsbescherming en het gebruik van geweld tegen migranten in met name Griekenland.

\section{Resultaten}

Om tot inzicht te komen in het verloop van migratietrajecten, werden drie deelonderwerpen beschreven in drie empirische hoofdstukken. De bevindingen van deze afzonderlijke hoofdstukken werden in een laatste hoofdstuk samengebracht om tot een model te komen waarmee het verloop van migratietrajecten begrepen kan worden.

Hoofdstuk vier beschrijft hoe maatschappelijke trends in Turkije en Griekenland een migratiecontext met een hoge mate van volatiliteit hebben gecreëerd, welke heeft bijgedragen aan een grote diversiteit aan migratietrajecten. Deze trends betreffen de tegengestelde economische ontwikkelingen in Turkije en Griekenland ${ }^{10}$, het verworden van migratie tot een vraagstuk van nationale veiligheid en de opmars van xenofobie in voornamelijk Griekenland. De fluctuerende kansen en belemmeringen die uit deze ontwikkelingen voortvloeien maken dat er naast het bekende traject waarin Europa als eindbestemming wordt gezien en al dan niet bereikt nog minstens vier andere manieren zijn waarop het migratietraject zich zou kunnen ontwikkelen. Ten eerste is een beweging zichtbaar waarbij migranten die eerder ten doel hadden door te reizen vanuit Turkije een voorkeur ontwikkelen om in Turkije te blijven. Ten tweede werd opgemerkt dat er door migranten in Turkije zowel naar Europa als naar andere bestemmingen gekeken en gereisd wordt, waaronder China, het Midden-Oosten en Noord-Afrika. Ten derde is opgevallen dat migranten "terugkeren" van Griekenland naar Turkije. Ten vierde werd zichtbaar dat migranten uit Griekenland begonnen weg te trekken via de Balkan, wat nieuwe en hogere risico's met zich meebracht dan de tot dan toe meer gebruikelijke manieren om Griekenland te verlaten. Het hoofdstuk besluit dat niet iedereen

\footnotetext{
${ }^{10}$ Ten tijde van het veldonderzoek (2012-2013) maakte Griekenland een zware economische recessie door, terwijl er in Turkije sprake was van economische groei.
} 
op dezelde manier omgaat met de volatiliteit in de onderzochte 'transit migration hubs'. Waarom dit zo is, komt in de volgende hoofdstukken aan bod.

Hoofdstuk vijf gaat in op de veranderlijke aard van de sociale netwerken van migranten. Dit hoofdstuk laat zien hoe drie elementen een rol spelen in de aard en vorming van de sociale relaties die migranten hebben: persoonlijke relatievoorkeuren, aanwezige hulpbronnen en communicatie-infrastructuren. Deze zijn aan voortdurende verandering onderhevig door het meemaken van kritieke gebeurtenissen. Hieronder worden gebeurtenissen verstaan die voortkomen uit de sociale netwerken zelf (bijvoorbeeld het verliezen van een bepaald contact), vanuit de institutionele omgeving als zijnde manifestaties van migratiebeleid (bijvoorbeeld een arrestatie of toekenning van een vluchtelingenstatus), en levensgebeurtenissen (bijvoorbeeld het krijgen van een kind). Deze gebeurtenissen kunnen een grillig, onvoorspelbaar verloop hebben waardoor ook sociale netwerken onvoorspelbare en plotse veranderingen kunnen ondergaan. Echter wordt in de migratieliteratuur vaak veronderstelt dat de netwerken van migranten zich ontwikkelingen volgens stapsgewijze fasen in het migratieproces, waarbij migranten na verloop van tijd meer lokale relaties onderhouden. Een andere aanname is dat de netwerken van migranten uit bepaalde componenten bestaan die een min of meer duidelijke rol hebben, zoals het faciliteren van migratie of het sturen of ontvangen van financiële steun. Door de veranderingen in netwerken inzichtelijk te maken, wordt ook duidelijk dat deze componenten en de bijbehorende interacties niet als gegeven en vanzelfsprekend moeten worden beschouwd.

Hoofdstuk zes bouwt hierop voort door te laten zien hoe veranderende sociale netwerken een rol spelen in het verloop van het migratietraject. Het hoofdstuk laat zien dat de aard van het sociale netwerk op het moment dat een kritieke gebeurtenis zich aandient helpt te begrijpen hoe erop deze gebeurtenis gereageerd wordt en tot welke gehanteerde migratiestrategie dit leidt. Bijvoorbeeld: wanneer iemand gearresteerd wordt bij een poging om een grens over te steken, zal de manier waarop hij hierop reageerde (aan de ene kant van de grens blijven of het later nogmaals proberen) afhangen van de hulpbronnen die hij uit het netwerk kan mobiliseren. Wanneer echter relatievoorkeuren of communicatieinfrastructuren veranderd zijn, kan dit na een tweede arrest weer anders zijn. Het hoofdstuk laat verder zien dat de aard van het netwerk en of er al dan niet hulpbronnen kunnen worden aangeboord, zowel faciliterend als hinderend kan zijn. Met andere woorden, de aanwezigheid van hulpbronnen is niet altijd positief, net zoals de afwezigheid ervan niet altijd negatief is.

Hoofdstuk zeven brengt de bevindingen van de voorgaande hoofdstukken samen om tot een model te komen waarmee het verloop van migratietrajecten begrepen kan worden. Het wordt gedreven door het principe dat migratietrajecten en sociale netwerken coevolueren door de constante ervaring van kritieke gebeurtenissen: Kritieke gebeurtenissen vormen de relatievoorkeuren, hulpbronnen en communicatie-infrastructuren, die op hun beurt de kansen en belemmeringen vormen om sociale netwerken te vormen en te onderhouden. Andersom beïnvloedt de aard van het sociale netwerk hoe er op kritieke 
gebeurtenissen gereageerd wordt en hoe migranten reageren op kansen en belemmeringen die daaruit voortkomen. Dit kan vervolgens leiden tot een voortzetting of aanpassing van de toegepaste migratiestrategie.

\section{Conclusie}

Dit proefschrift heeft een bijdrage geleverd aan het beter begrijpen van het verloop van irreguliere migratietrajecten. $\mathrm{Er}$ is aangetoond dat de oorspronkelijk genomen beslissing in het land van herkomst om te migreren niet altijd bepalend is voor het verloop van een migratietraject. Ook wordt dit verloop niet altijd gevormd door een verwachte eindbestemming en is die er bovendien niet altijd. Daarnaast is voortdurend verblijf in Turkije en Griekenland niet in alle gevallen het gevolg van een gefaalde poging om Europa te bereiken en daarmee het effect van restrictief grensbeleid. Als migranten na enkele pogingen toch verder reizen, kan de tussentijdse periode niet worden gezien als tijd die wachtend is doorgebracht. Besluitvorming is een continu proces en keuzes om later door te migreren worden niet zonder meer ingegeven door dezelfde motieven als tijdens eerdere poging. Het proefschrift brengt hiermee nuance aan in het doorgaans aangenomen verloop van een migratietraject, en stelt dat begin- en eindpunten niet als leidend genomen moeten worden in het duiden van dit traject.

Het proefschrift stelt daarnaast een aantal bestaande aannames over de rol van sociale netwerken ter discussie en laat de waarde zien van het conceptualiseren van netwerken als persoonlijke netwerken in het duiden van de rol ervan in migratietrajecten. Tevens benadrukt de studie dat netwerken geconceptualiseerd moeten worden als zijnde aan verandering onderhevig. Dit betekent dat er bijvoorbeeld niet te allen tijde en niet door iedereen in het netwerk in het land van herkomst verwacht wordt dat er financiële middelen worden teruggestuurd. Andersom waren er diverse voorbeelden waar migranten op gezette tijden juist steun ontvingen vanuit het land van herkomst. De vraag wordt hiermee niet of sociale netwerken wel of geen rol spelen in migratieprocessen, maar eerder hoe, op welke manier, en hoe verandert deze door de tijd heen. In plaats van te onderzoeken of sociale netwerken of migratiebeleid beter het verloop van migratietrajecten bepalen zoals in de literatuur wordt bediscussieerd, is het van waarde is te onderzoeken hoe deze twee samenhangen.

Naast de theoretische bijdrage over het verloop van het migratietraject heeft het proefschrift een methodologische bijdrage aan de migratieliteratuur geleverd door het combineren van etnografisch veldwerk en interviews met sociale netwerkanalyse in een longitudinale onderzoeksopzet.

Tot slot biedt het proefschrift enkele beleidsaanbevelingen. Beleidsinterventies en hulporganisaties bepalen hun doelgroep doorgaans op basis van een door deze groep toegepaste migratiestrategie. In Turkije werd bijvoorbeeld door een NGO onderscheid gemaakt tussen mensen die asiel aanvroegen en mensen die dat niet deden. Van de 
laatste groep werd aangenomen dat zij niet uit zijn op - of behoefte hebben aan - een bepaalde (rechts)bescherming. Echter kan het verschil tussen iemand die wel of geen asiel aanvraagt het verschil zijn in mogelijkheden om met kritieke gebeurtenissen om te gaan. Migratiestrategieën moeten dus niet automatisch worden gezien als een reflectie van behoeftes en intenties. In plaats van doelgroepen enkel te bepalen op basis van gedrag (migratiestrategieën) is het relevanter dit te doen op basis van een assessment van de omstandigheden.

Een tweede suggestie is dat er minder nadruk wordt gelegd op het binaire karakter van een verondersteld migratietraject in het ontwikkelen van migratiebeleid. Door te focussen op het land van herkomst in het duiden van verschillen tussen bijvoorbeeld Syrische en Eritrese vluchtelingen, wordt niet opgemerkt dat mogelijk veel Eritreeërs ook zijn gevlucht voor de oorlog in Syrië, omdat zij in eerste instantie daar naartoe zijn gemigreerd.

Een derde suggestie is dat het sociale netwerk in ogenschouw genomen wordt bij het analyseren van de effecten van beleidsinterventies. Er wordt momenteel bijvoorbeeld veel onderzoek gedaan naar de effecten van de EU-Turkije deal, waarbij de EU en Turkije afspraken hebben gemaakt over het terugsturen van migranten naar Turkije. Wat er vervolgens met migranten in Turkije gebeurt hangt hoogstwaarschijnlijk af van de mogelijkheden die zij hebben om hulpbronnen aan te boren via sociale netwerken. Het kunnen mobiliseren van sociale netwerken is dan een belangrijke bijdrage die NGO's kunnen leveren aan de ondersteuning van teruggestuurde migranten. Een ander voorbeeld is de observatie dat veel mensen die asiel hebben aangevraagd in Turkije, hun verplichte verblijf in een toegewezen stad alleen kunnen bekostigen wanneer zij financiële steun krijgen uit hun netwerken. Wanneer deze steun niet voorhanden is, leidt dit er vaak toe dat mensen proberen Turkije te verlaten. Het analyseren van de rol van netwerken laat zien dat er een link is tussen het Turkse asielsysteem van verplicht verblijf in bepaalde steden en doormigratie naar Griekenland. Sociale netwerkanalyse brengt hiermee interacties aan het licht die anders niet direct zouden zijn opgemerkt.

Het proefschrift besluit met de bekende uitspraak dat "het leven is wat je gebeurt terwijl je andere plannen maakt" (Allan Saunders). Ditzelfde geldt voor het migratietraject, dat uiteindelijk onderdeel is van een levenspad, met daarin onverwachte en onberekende veranderingen en stappen. Migratie verloopt niet alleen niet rechtlijnig vanwege moeilijkheden in het bereiken van een volgende stap, maar ook omdat levens door de tijd heen vorm krijgen, omdat nieuwe, onvoorziene kansen zich aandienen, en omdat mensen op hun levenspad nu eenmaal meestal geen uitgetekende route tot hun beschikking hebben. Tot slot is het in het doen van onderzoek, het opstellen van beleid en het ontwerpen van hulpprogramma's van groot belang om mensen niet te reduceren tot hun migrant-zijn alleen, maar het migratieaspect in de grotere context van het leven van deze individuen te begrijpen. 

Valorisation

Addendum 



\section{Valorisation Addendum}

Valorisation concerns the societal value created from knowledge produced by the study. In one of its most concrete outcomes in the case of social sciences, these result into policy recommendations, which have been presented in the conclusion of this thesis. In this addendum, I illustrate the societal value of the study by explaining how it contributes to the societal and political debates about irregular migration. This is continued by describing various activities I have employed to disseminate the insights from the thesis.

\section{Societal relevance}

On June 29 2019, the captain of rescue ship from the organisation SeaWatch was arrested after bringing in migrants rescued from the Mediterranean Sea into an Italian harbour town ${ }^{11}$. Her arrest made it to the headlines all over the world and sparked debates on whether her act was criminal or one of heroism ${ }^{12}$. The Italian Minister Salvini claimed that: "[the Italian government] will use every lawful means to stop an outlaw ship which puts dozens of migrants at risk for a dirty political game"13, and he called her act one "of war"14. The European Union takes the stance that rescuing migrants at sea provides incentives for people to migrate and cross the Mediterranean Sea, hereby facilitating smugglers and encouraging this type of migration ${ }^{15}$. Others have argued, however, that SeaWatch admirably acted upon the alleged failure of the European Union to provide humanitarian corridors for people travelling to and seeking refuge in Europe, and that there is no link between rescue acts and smuggling ${ }^{16}$.

These contrary views are illustrative for the divided lines along which public debates on, notably undocumented, migration take place. While migration is of all times, and therefore not a new topic of societal concern and debate, debates are held on a larger scale and have become more polarised in the past decade ${ }^{17}$. Views clash on whether migration is a national security threat, or an inevitable phenomenon and basic human right. An extreme example

\footnotetext{
${ }^{11}$ See: https://www.theguardian.com/world/2019/jun/29/sea-watch-captain-carola-rackete-arrested-italian-blockade

${ }^{12}$ https://www.euronews.com/2019/07/01/heroine-or-criminal-sea-watch-3-captain-carola-rakete-dividesopinion

${ }^{13}$ See: https://www.theguardian.com/world/2019/jun/29/sea-watchcaptain-carola-rackete-arrested-italian-blockade

${ }^{14}$ See: https://www.euronews.com/2019/07/01/heroine-or-criminal-

sea-watch-3-captain-carola-rakete-divides-opinion

${ }^{15}$ See: https://www.theguardian.com/world/2017/feb/27/ngo-rescues-

off-libya-encourage-traffickers-eu-borders-chief

${ }^{16}$ See: https://theintercept.com/2017/04/02/new-evidence-undermines-eu-report-tying-refugee-rescue-groupto-smugglers/

${ }^{17}$ See: https://www.europeansocialsurvey.org/docs/findings/IE_Handout_FINAL.

pdf; https://www.iemed.org/observatori/arees-danalisi/arxius-adjunts/anuari/

med.2017/IEMed_MedYearbook2017_media_migration_crisis_Matar.pdf;
} 
of this polarisation are the two instances of shutdowns of the American administration, when President Trump did not receive support from Congress to finance the establishment of a wall between the United States and Mexico - one of his main election promises.

Debates on migration take place on a variety of levels and among a variety of actors: from community members discussing the arrival of migrants in their neighbourhood in the local coffee house, to municipality councils designing local integration strategies, to nongovernmental organisations (NGOs) implementing rescue actions and public awareness campaigns, and to the European Commission where minimising security threats versus the right to protection is discussed.

Debates are not only polarised in terms of opposing opinions of groups in society but also in terms of the rather dichotomous approach towards the debated policy solutions: people can either get access or not; they have either genuine motivations or not; migration can be banned or it cannot; the stay "in the region" or come to Europe. The societal value of the knowledge produced by this thesis lies in bringing nuance to the rather polarised and dichotomous debate on migration, hereby enhancing the understanding of not only the process of migration, but also the people who are migrating. I will illustrate this by addressing four themes that are present in societal and political debates on migration:

\section{Migration is a process, not a single decision to migrate taken in the country of origin.}

In political and societal debates on migration in Europe, there is a strong assumption that migrants take the decision to migrate to Europe in the country of origin, and that, ideally, migration follows in a stepwise fashion from there. While people may not be successful in their attempt to reach Europe, it is assumed that Europe remains the anticipated destination. This assumption is evident, for example, in campaigns discouraging migration the EU by providing negative information to people in countries of origin. Such campaigns are based on the assumption that there is a direct link between reasons to emigrate and the view that people have of the European Union; and that the European Union is the anticipated goal. This study showed that this is not necessarily the case. Ideas about Europe and the anticipated destination are highly subject to change as the migration trajectory evolves. The focus on the start of the migration trajectory and the emphasis on the anticipated destination in public and policy debates undermines the course of the trajectory following from there.

\section{Categorisations of migrations should not be used to 'fix' migrant attributes, needs and intentions.}

Understandably, policy-makers and researchers as well as the general public need categorisations to make the world understandable and manageable. Categories used to label migrants (e.g. refugees versus undocumented migrants) have fixed definitions, but are not necessarily fixed attributes of people. We should be wary of letting these categories become 
a new reality, disqualifying the underlying complexities. It is the ultimate challenge as well as contribution of the social science to constantly debunk these underlying complexities.

For example, whether or not someone meets the legal criteria to get official recognition as a refugee is determined in the 1951 Geneva Convention of the United Nations. Often. This is put forward as an objective measure to distinguish between refugees and non-refugees. However, the applied legislation is not necessarily objective: Turkey applies a geographical limitation to the definition of a refugee according to the Convention, implying that anyone from outside of Europe cannot be qualified as a refugee under Turkish law. Moreover, while some may meet the criteria laid out in the Convention, others may not apply for asylum - for example because they do not have the means to sustain a livelihood during the application procedure. These persons would then be categorised as an irregular or transit migrants and not be eligible for support from refugee organisations, as I have observed in Turkey.

This value of this finding is to challenge how common categories of migrants - such as asylum-seekers, labour migrants and irregular migrants - guide policy and research, as if they concern different people. This thesis has shown that, instead, migrants can be or become different types of categories throughout their migration trajectories. Categories can be used to label people's circumstances, not the people themselves.

\section{Migration is not a goal or distinctive feature of people, but inherently part of their walk of life.}

Where migration is the topic of debate, logically this aspect of people's lives is being analysed. Yet, for people migrating themselves, it is more plausible that migration is not a goal, but rather a means or side effect of their overall lives. Their goal is, for example, to find safety, adventure, a stable income or family. To interpret migrant behaviour, it is crucial to contextualise this in other life domains, and not narrow the scope of analysis and vision to migratory acts. For this reason, migration is not a topic or a policy challenge that can be solved, curbed or managed on its own - as it is not a phenomenon operating in isolation. This thesis calls for an approach where the role of migration in people's overall lives is analysed. This will help to understand why trajectories evolve in the way they do, and why they cannot be explained predominantly through factors that are directly related to migration (e.g. policy measures, means of travelling, et cetera).

\section{Needs and intentions are defined by opportunities and constraints, not vice-versa.}

A common fear in migrant-receiving societies is that migrants put a lot of pressure on the social welfare system, either by intention or because these systems can simply not cater to this extra "burden". In the same vein, migrants are either conceptualised as victims in need of support, or as abusers of our social welfare system, by intent or otherwise. Either way, there is a tendency to regard this as a fixed attribute, and to disregard that needs and intentions, as well as capabilities to act upon them, can change over time: a person who is in need of social assistance today may not be tomorrow. A call for social assistance is 
rather a reflection of the person's opportunities and constraints at that moment in time, than indicative of his or her genuine intentions. In order to lower the alleged pressure on the social welfare system, not merely migrants' intentions should be addressed, but their constraints and opportunities. The thesis revealed that these are shaped though critical events and social networks. Municipalities responsible for social welfare should thus invest in enhancing capabilities and positive effects of social networks.

\section{The importance of a historical and transnational perspective.}

This thesis calls to put policy questions in a larger historical and transnational perspective. During my work for an NGO in the Netherlands, in close cooperation with a local municipality there was a large emphasis on the 'fresh start' of permit holders. Yet, there are not a tabula rasa. The highly bureaucratic context they had to deal with (e.g. by providing an integration plan to the municipality justifying every three months how they spent four days each week in order to achieve their integration goals) stood in sharp contrast to the absence of bureaucratic involvement when it comes to integration in countries they have passed through, such as Turkey and Greece. People who did not adhere to this were addressed as if they had to learn a lesson or whose intentions were not to be trusted. On the other hand, permit holders who participated well or who no longer depended on social assistance, were addressed as "pearls" and often used as indicative examples of the successful integration programme. Both instances disregard the history prior to the arrival to this city, explaining difficulties with intensive interference of authorities, but also disqualifying the capabilities that people possess and have gained independent of the integration programme. It is likely that counselling programmes by NGOs and municipalities will be more successful taking this historical perspective into account.

A greater sensitivity towards the historical development of the migration trajectory is also helpful to understand the impact of a person's past on the current circumstances. Since the relatively high number of arrivals of Eritrean and Syrian refugees in the Netherlands, these groups are often compared based on country of origin information. It is then easily overlooked that it is likely that many Eritreans have spent a long time in Syria, before coming to Europe and are also fleeing the same war.

This thesis has adopted a transnational perspective on migration, implying that the social network and resources that migrants can mobilise may stretch beyond the borders of the country a person resides in. Persistent images exist in public discourses where specific roles are attributed to specific parts of the network, notably in countries of origin and (anticipated) destination. This study revealed that also network members in other parts of the world can have a valuable impact on the evolution of the migration trajectory. Moreover, this study found that the location, type and character of social networks changes over time.

Time and money restrictions are often provided as reasons for not expanding the scope of analyses, especially when policy makers are confronted with immediate policy questions. Yet, had a historical perspective been applied, the arrival of these people would 
not have been "sudden" or "unexpected". This is also true for the so called "Balkan route" which surprised European politicians in 2015. Yet, already in 2012 (see Chapter 4), people had started to leave Greece on foot through the Balkan, when durable solutions in Greece and other ways out of Greece were not in reach. Also today, when integration programs for newcomers are scaled down in Dutch municipalities due to fewer arrivals - often attributed to the success of the EU-Turkey deal - no attention is given to the fact that still no durable solutions are at hand in Turkey and Greece, which will likely lead to new arrivals in the future.

\section{Valorisation activities}

I have engaged in several activities to disseminate the viewpoints explained in the previous section in an effort to contribute to the societal and political debate on migration. These can be divided into six different types of activities, each directed at various or mixed target groups.

\section{Media activities}

In 2015 I wrote an opinion piece for the ${ }^{18}$ Volkskrant, entitled "Excluding asylum-seekers does not lead to stopping their arrival"19. This was a response to the proposal of the liberal political party VVD to inhibit non-Europeans to apply for asylum in the European Union. I also wrote a blogpost on Versvak.nl, an online platform making academic research available to a wider public. Here, I argued that migration is a process, and that policy designs should therefore not be based on snapshots throughout this process.

\section{Public performances}

I participated twice in a panel debate organised by Studium Generale in Maastricht, an organisation promoting debate between scientists and the general public and societal actors. In both cases, the border policy of the European Union was central, one focusing on the role of Frontex, the other on the situation in Greece. My contribution focussed on the first-hand experience in Turkey and Greece and the ability to share the perspective of migrants I have spoken to.

I also provided a workshop for Amnesty International in Maastricht, pointing out the changeability of intentions and migration strategies en route to students.

Recently I have received an invitation to provide a presentation to a Rotary Club in the Netherlands. The person who invited me told me I had punched some of his stereotypes on migration, and he asked me to do the same for his fellow Rotary Club members.

\footnotetext{
${ }^{18}$ https://www.volkskrant.nl/columns-opinie/uitsluiten-asielzoekers-belet-hun-komst-niet p99cc04b/

${ }^{19}$ http://www.versvak.nl/migratie/mariekewissink/
} 


\section{Legal activities:}

During my fieldwork I encountered three Eritrean migrants who were falsely accused of having set up an internet scam for which they risked imprisonment of 25 years. I believed in their innocence and mobilised support from a German NGO in order to hire a lawyer. I was then invited to give an expert view during the court case. Yet, while present in the court, the case was postponed to a later date, and I could not be present. The three were nevertheless acquitted. While I did not provide the actual expert view in the end, this is an example of a potential activity resulting from the research.

\section{Knowledge dissemination to public actors}

In addition to scientific conferences, I presented at two conferences organised for policymakers and public actors. In 2015, I spoke at a conference by the Ministry of Justice and Safety in the Netherlands. I participated in a session aiming to find solutions for "illegal migrants". In my presentation, I questioned the notion of "illegal", both the word itself as well the fact it was framed as if it were a given attribute policy-makers had to deal with. A conceptual discussion was not in the interest of the public servants in need of policy solutions, and people responded critically to my views. Such conferences, however remain excellent venues to express and give attention to other views, which are more easily dismissed when the agenda is already decided upon at policy tables.

Furthermore, I have been invited by the WODC - the scientific research and documentation centre that is affiliated with the Ministry of Justice and Safety, to provide input on a research on the effect of the EU-Turkey deal on migration flows. During this expert meeting I had the opportunity to reflect on my research experiences and provide a perspective from "the field".

I further presented at an academic seminar organised by UNHCR Turkey, inviting scholars to share their research with UNCHR staff and governmental representatives in 2012. There and in other instances I noticed strong opinions on the distinctions between refugees and other types of migrants prevail. While there is a different legal ground for distinctions, there is also a risk that blinds us for the protection needs of people who do not meet the refugee definition. This thesis can contribute to further debates and policydevelopments in this field.

\section{Practice}

The value of the knowledge provided through this study has become evident in various practices I was part of. First, I shared and applied the knowledge by taking part in Kayiki-a network of lawyers, academics, NGOs workers and activists dealing with migration in the Aegean region in various ways, including border monitoring; legal aid; lobby and advocacy. Notably my field observations were of particular interest in this network.

I also integrated and shared the knowledge during my work for the Dutch Council of Refugees. For example, by giving a workshop about Eritrean refugees to colleagues and 
employees of partner organisations and the municipality. I further built on the study by being aware of the history and the knowledge that migration trajectories are constantly evolving, and that transnational ties need to be taken into account when social workers asses migrants' social network.

At the time of writing this addendum, I work for a mental health organisation where a large part of the clients has a migratory background. My next opportunity for valorisation will be to engage in a discussion with the current municipality I cooperate with, after having read a letter of a public servant addressed to a homeless Somalian family in which was written that while the family would be provided shelter, they should regard this as highly exceptional since the municipality did not want to provide incentives to other homeless families to travel from Somalia to the Netherlands. 

Curriculum Vitae 

Marieke Wissink was born on 23 September 1983 in Doetinchem. She studied Social and Cultural Development at the Utrecht University of Applied Sciences after which she completed her Bachelor's degree in Cultural Anthropology and Development Studies at Radboud University Nijmegen. At the same university, she was admitted to the selective 2-year Research Master program in Social and Cultural Sciences, which she completed (bene meritum) in 2009. Throughout all her studies she focused on the topic of migration. Her particular interest in Turkey and Greece was sparked during her fieldwork for her Master thesis, which addressed the dynamics in migratory intentions. While this planted the seed for her later PhD thesis, she first moved to Turkey where she worked, amongst others, for the Association for Solidarity with Refugees (Mülteci-Der) in Izmir. In 2011, she was awarded a grant by the Faculty of Arts and Social Sciences of Maastricht University to develop a PhD proposal, which ultimately led to the present thesis. After leaving Maastricht University in 2015, she has worked as a senior team leader and project manager at the Dutch Council for Refugees. In spring 2019, she started as a team manager at Perspektief, a care organisation empowering and caring for people with mental vulnerabilities and/or in situations of domestic violence and homelessness. 

Senait from Eritrea travelled to Turkey and tried reaching Greece by boat. Following an accident at sea, she was rescued by the Turkish coastal guards and taken into detention. Upon her release, she resided undocumented and worked as a baby-sitter, after which she applied for asylum. She was recognised as a refugee by the UNHCR in Turkey and waited to become resettled in the USA or Canada. Before resettlement was in sight, she travelled to Greece. In Greece she lived undocumented, before continuing her journey elsewhere years later.

Senait's 'migration trajectory' reveals that migration is not always a linear and straightforward journey from one country to another. The non-linearity of irregular migration trajectories is often attributed to restrictive migration policies or migrants' difficulties with providing financial support to their social networks in their countries of origin, stopping them from moving back or forward. This reasoning gives evidence of certain underlying assumptions about the anticipated course of the migration trajectory and the role of migrants' social networks. This thesis questions such assumptions and investigates by what mechanisms migration trajectories of irregular sub-Saharan African migrants in Turkey and Greece evolve. It shows that this evolution is associated with changes that take place in migrants' social networks over time, as well as with a continuous experience of critical events. The findings stress the importance of viewing migration as part of people's life trajectories, which can take unexpected and uncalculated turns. 